\author{
Universidade de SÃo Paulo \\ Escola de Engenharia de SÃo Carlos \\ DEPARTAMENTo DE ENGENHARIA ElÉtrica \\ Programa de Pós-GraduaÇão em Engenharia Elétrica
}

\title{
Marcelo Suetake
}

\author{
Sistemas Inteligentes para \\ Monitoramento e Diagnósticos de \\ Falhas em Motores de Indução \\ Trifásicos
}

São Carlos 



\section{Marcelo Suetake}

\section{Sistemas Inteligentes para \\ Monitoramento e Diagnósticos de Falhas em Motores de Indução Trifásicos}

Tese de doutorado apresentada ao Programa de Engenharia Elétrica da Escola de Engenharia de São Carlos como parte dos requisitos para a obtenção do título de Doutor em Ciências.

Área de concentração: Sistemas Dinâmicos

ORIENTADOR: Prof. Dr. Ivan Nunes da Silva

São Carlos

2012

Trata-se de uma versão corrigida da tese. A versão original se encontra disponível na EESC/USP que aloja o Programa de Pós-Graduação de Engenharia Elétrica. 
AUTORIZO A REPRODUÇÃO E DIVULGAÇ̃̃O TOTAL OU PARCIAL DESTE TRABALHO, POR QUALQUER MEIO CONVENCIONAL OU ELETRÔNICO, PARA FINS DE ESTUDO E PESQUISA, DESDE QUE CITADA A FONTE.

Ficha catalográfica preparada pela Seção de Tratamento da Informação do Serviço de Biblioteca - EESC/USP

Suetake, Marcelo

Sistemas inteligentes para monitoramento e diagnósticos de falhas em motores de indução trifásicos / Marcelo Suetake; orientador Ivan Nunes da Silva. -- São Carlos, 2012.

Tese (Doutorado - Programa de Pós-Graduação em Engenharia Elétrica e Área de Concentração em Sistemas Dinâmicos) -- Escola de Engenharia de São Carlos da Universidade de São Paulo, 2012.

1. Motor de indução trifásico. 2. Sistemas inteligentes. 3. Identificação e diagnóstico de falhas. 4. Sistemas de monitoramento. 5. Redes Neurais artificiais. I. Título. 
FOLHA DE JULGAMENTO

Candidato: Engenheiro MARCELO SUETAKE.

Título da tese: "Sistemas inteligentes para monitoramento e diagnósticos de falhas em motores de indução trifásicos".

Data da defesa: 11/04/2012

\section{Comissão Julgadora:}

Prof. Associado Ivan Nunes da Silva (Orientador)

(Escola de Engenharia de São Carlos/EESC)

Prof. Associado Diógenes Pereira Gonzaga

(Escola de Engenharia de São Carlos/EESC)

Prof. Dr. Manoel Luís de Aguiar

(Escola de Engenharia de São Carlos/EESC)

Prof. Dr. Walmir Matos Caminhas

(Universidade Federal de Minas Gerais/UFMG)

Prof. Dr. Renato Crivellari Creppe

(Universidade Estadual Paulista "Júlio de Mesquita Filho"/UNESP-campus de Bauru)

Coordenador do Programa de Pós-Graduação em Engenharia Elétrica:

Prof. Titular Denis Vinicius Coury

Presidente da Comissão de Pós-Graduação:

Prof. Associado Paulo Cesar Lima Segantine
Resultado:
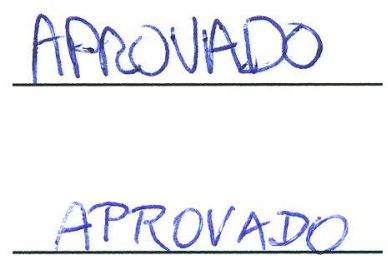

APRONADU

APROVADO

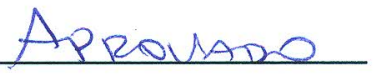



Porque dele e por meio dele, e para ele, são todas as coisas. Glória, pois a ele eternamente. Amém

Romanos, 11, 36 



\section{Agradecimentos}

A conclusão desta tese de doutorado é fruto da dedicação e principalmente da colaboração de diversas pessoas que se envolveram de forma direta e/ou indireta.

Gostaria de agradecer, em primeira instância, a toda minha família pelo especial apoio e incentivo aos estudos que sempre me concederam, em especial, à minha mãe, Massae Susaki Suetake, ao meu pai, Toshiyuki Suetake, e aos meus irmãos Carlos Suetake e Eduardo Suetake.

Ao Prof. Dr. Ivan Nunes da Silva que, mediante sua expressiva tutoria desde o período de Iniciação Científica, contribuiu de forma efetiva, não somente pela conclusão do trabalho, como também para formação ética e profissional. Agradeço pela orientação técnica e acadêmica, pelos ensinamentos na elaboração de projetos, pelo incentivo e motivação à pesquisa e pela revisão dos artigos publicados em fóruns científicos.

Ao Prof. Dr. Alessandro Goedtel, por possibilitar a produção de diversos trabalhos vinculados à bancada de ensaios experimentais desenvolvido durante a sua tese, pelas sugestões e correções de artigos científicos, pelo auxílio nos conceitos relativos às Máquinas Elétricas e pela orientação sobre os inúmeros problemas encontrados durante a confecção desta tese.

Ao Prof. Dr. Rogério Andrade Flauzino que, juntamente ao Prof. Dr. Ivan Nunes da Silva, tem me apoiado de forma significativa desde o período de Iniciação Científica. Além de sua valiosa contribuição técnica, o Prof. Dr. Rogério forneceu também sugestões, conselhos, e orientações significantes para uma formação profissional e acadêmica.

Ao Prof. Dr. Manoel L. de Aguiar que, durante o período de doutorado, contribuiu mediante inúmeras dicas e sugestões para as adaptações da bancada de ensaios experimentais e conceitos relacionados às Máquinas Elétricas.

Aos demais professores da Universidade de São Paulo (USP/EESC/SEL), em especial, ao Prof. Dr. Diógenes P. Gonzaga, ao Prof. Dr. José Roberto B. de A. Monteiro e ao Prof. Dr. Evandro L. L. Rodrigues.

Aos colegas do Laboratório de Automação Inteligente de Processos e Sistemas (LAIPS), Msc. Fernanda Maria Cunha, Msc. Rodrigo Antonio Facciolli, Prof. Dr. Danilo Hernane 
Spatti, Prof. Dr. Ricardo A. S. Fernandes, Eng. Sérgio Date Fujita e Fabbio Borges pelas inúmeras contribuições ao trabalho.

Aos amigos da Universidade de São Paulo (USP/São Carlos), colegas de república e demais amigos, Amilcar Querubini, Renato Machado Monaro, Giovani Pozzebon, Guido Peña, Alexandre Coelho, Eduardo Sylvestre, Moussa R. Mansour, Sara R. Mansour, Eva R. Mansour, Olívia Oiko, Débora Correia, Fernanda Cristina, Marcel Césare, Márley Tavares, Marcelo Marques Melo, Gustavo T. Laureano, Ronny K. M. Portal, Rennê T. M. Portal e Wesley Usida.

Aos professores e companheiros de graduação da UNESP/Bauru, Curso de Engenharia Elétrica-2001, instituição na qual tive o privilégio em adquirir toda base de conhecimento acadêmico.

Aos funcionários da Universidade de São Paulo (USP/EESC/SEL), em especial, aos técnicos de laboratórios, Rui Bertho e Odair da Silva; à secretária de Pós-Graduação, Jussara Ramos Zoia e Marisa H. R. V. Fortulan e ao suporte técnico de informática, Roseli Ribeiro.

À FAPESP (Fundação de Amparo à Pesquisa do Estado de São Paulo), pelo auxílio financeiro concedido no período da realização deste trabalho na forma de bolsa de estudos (2008/0000-4) sem a qual o mesmo não seria possível.

À CAPES (Coordenação de Aperfeiçoamento de Pessoal de Nível Superior), por possibilitar o acesso a inúmeras revistas e periódicos renomados gratuitamente, permitindo o desenvolvimento de um projeto de pesquisa de qualidade diferenciada.

À Escola de Engenharia de São Carlos (EESC/USP) que acolheu esta tese de doutorado, por meio da destinação de espaço físico e apoio administrativo, traduzindo assim a grandiosidade da instituição e visão de futuro. 


\section{Resumo}

SUETAKE, M. (2012). "Sistemas Inteligentes para Monitoramento e Diagnósticos de Falhas em Motores de Indução Trifásicos". Tese de Doutorado - Escola de Engenharia de São Carlos, Universidade de São Paulo, 2012.

O objetivo desta tese consiste na implementação de sistemas inteligentes para monitoramento e diagnósticos de falhas ocorrentes em motores de indução trifásicos. Para tanto, desenvolveu-se uma bancada de experimentos que visa ensaios de falhas relacionados a curto-circuito entre as bobinas do enrolamento de estator, quebras nas barras da gaiola de esquilo do rotor e, finalmente, rolamentos defeituosos. Mais especificamente, o enfoque principal consiste na proposição de uma abordagem neural de detecção de quebras nas barras de rotores de motores de indução trifásicos mediante a análise do espectro de frequência e aplicação de técnicas de análise das componentes principais. Considerou-se o acionamento do motor de indução tanto pela tensão de alimentação da rede quanto por inversor trifásico em diferentes frequências, operando sob diversas condições de torque de carga para a avaliação da metodologia.

Palavras-chave: Motor de Indução Trifásico, Sistemas Inteligentes, Identificação e Diagnóstico de Falhas, Sistemas de Monitoramento, Redes Neurais Artificiais. 



\section{Abstract}

SUETAKE, M. (2012). "Intelligent Systems for Faults Monitoring and Diagnosis in ThreePhase Induction Motors". Doctor Thesis - Engineering School of São Carlos, University of São Paulo, 2012.

The objective of this thesis consists of the implementation of Intelligent Systems for Three-Phase Induction Motors fault diagnosis and condition monitoring. Therefore, an experimental test stand for stator winding inter-turn short circuit faults, broken rotor bar in squirrel cage and, finally, defective wheel bearing has been designed. The main focus is to propose a neural network approach, which uses spectral frequency analysis and principal component analysis techniques to detect broken rotor bar in squirrel cage induction motor. Induction motor operating at different load torque conditions and supplied with sinusoidal voltage supply and three-phase inverter at different frequency was considered in the experiment for methodology evaluation.

Keywords: Three-Phase Induction Motor, Intelligent System, Faults Diagnosis and Identification, Monitoring System, Artificial Neural Networks. 



\section{Lista de Ilustrações}

1.1 Categorias de falhas em motores de indução. . . . . . . . . . . . . . . . . 26

1.2 Ilustração do desalinhamento de entreferro. . . . . . . . . . . . . . . . . 27

2.1 Esquema geral do laboratório de ensaios de máquinas elétricas. . . . . . . . . . 34

2.2 Visão geral da estrutura da bancada de ensaios. . . . . . . . . . . . . . . . . . 34

2.3 Excitação do enrolamento de campo do GCC. . . . . . . . . . . . . . . . . . 35

2.4 Sensores Hall de corrente e tensão. . . . . . . . . . . . . . . . . . . . . . . . 35

2.5 Sistema de aquisição de dados. . . . . . . . . . . . . . . . 36

2.6 Procedimento para a inserção de falhas em rotores. . . . . . . . . . . . . 37

2.7 Disposição das bobinas ao longo das ranhuras do estator. . . . . . . . . . . . 38

2.8 Derivações do enrolamento do estator para realização de ensaios de curto-circuito. 39

2.9 Foto ilustrativa dos terminais de derivação. . . . . . . . . . . . . . . . . . . . 39

2.10 Bancada de ensaios experimentais de curto-circuito entre bobinas dos enrolamentos de estator. . . . . . . . . . . . . . . . . . . . . 40

3.1 Tensões e correntes de linha trifásicas do MIT normal sob carga de 1,0 Nm. . . 42

3.2 Análise espectral da tensão e corrente de linha "a" do MIT normal sob carga

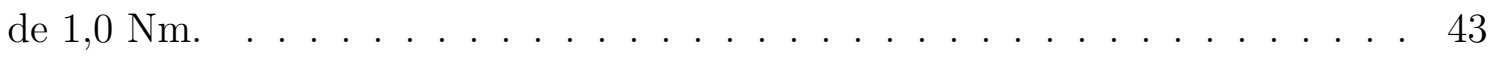

3.3 Tensões e correntes trifásicas do MIT normal sob frequência síncrona de $60 \mathrm{~Hz}$

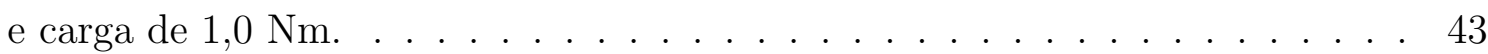

3.4 Análise espectral da tensão e corrente de linha "a" do MIT normal sob frequência síncrona de $60 \mathrm{~Hz}$ e carga de $1,0 \mathrm{Nm}$. . . . . . . . . . . . . . . . . . . . . 44

3.5 Análise espectral da tensão e corrente de linha "a" do MIT normal sob frequência síncrona de $40 \mathrm{~Hz}$ e carga de $1,0 \mathrm{Nm}$. . . . . . . . . . . . . . . 45

3.6 Tensões e correntes trifásicas do MIT com 1 barra quebrada sob carga de 1,0 Nm. 45

3.7 Análise espectral da tensão e corrente de linha "a" do MIT com 1 barra quebrada sob carga de $1,0 \mathrm{Nm}$. . . . . . . . . . . . . . . . . . . . . . 46

3.8 Tensões e correntes trifásicas do MIT com 1 barra quebrada sob frequência síncrona de $60 \mathrm{~Hz}$ e carga de $1,0 \mathrm{Nm}$. . . . . . . . . . . . . . . . . 46 
3.9 Análise espectral da tensão e corrente de linha "a" do MIT com 1 barra quebrada sob frequência síncrona de $60 \mathrm{~Hz}$ e carga de $1,0 \mathrm{Nm}$. . . . . . . . . . 47

3.10 Análise espectral da corrente de linha "a" de um MIT normal e com 4 barras quebradas acionado pela tensão da rede. . . . . . . . . . . . . . . . . . . . . 48

3.11 Análise espectral da corrente de linha "a" de um MIT normal e com 4 barras quebradas acionado pelo inversor. . . . . . . . . . . . . . . . . . . . 48

3.12 Correntes trifásicas do MIT operando sob falha de curto circuito a 1,0 Nm. . . 49

3.13 Análise espectral da corrente de linha "a" de um MIT operando sob curtocircuito a $1,0 \mathrm{Nm}$ de torque de carga. . . . . . . . . . . . . . . . . . 50

3.14 Análise espectral da corrente de linha "a" de um MIT operando sob falha no rolamento a $1,0 \mathrm{Nm}$ de torque de carga. . . . . . . . . . . . . . . . 50

3.15 Imagem termográfica da bancada de experimento durante o ensaio de falha no rolamento. . . . . . . . . . . . . . . . . . . . 51

3.16 Análise espectral da corrente de linha "a" de um MIT de alto rendimento operando sob condições normais a 1,0 Nm de torque de carga. . . . . . . . . . 52

4.1 Neurônio Artificial. . . . . . . . . . . . . . . . . . . . . . 56

4.2 Funções de ativação de um neurônio. . . . . . . . . . . . . . . . . . . 57

4.3 Ilustração da rede Perceptron Multicamadas . . . . . . . . . . . . . . . . . . . 58

4.4 Notação da rede Perceptron Multicamadas. . . . . . . . . . . . . . . . . . . . . 59

4.5 Aplicação da FFT em um determinado sinal $x(t) \ldots$. . . . . . . . . . . . . . 64

4.6 Ilustração do efeito de borda de uma janela de sinal. . . . . . . . . . . . . . 65

4.7 Janelas de Hanning e de Hamming. . . . . . . . . . . . . . . . . . . . . . . . . 66

4.8 Exemplo de aplicação da janela de Hanning no sinal. . . . . . . . . . . . . . . 66

4.9 Efeito de borda no espectro de frequência. . . . . . . . . . . . . . . . . . . . 67

5.1 Sistema inteligente de identificação de quebras em barras de rotores de Motores de Indução Trifásicos (MITs) . . . . . . . . . . . . . . . . . . . . . 71

5.2 Análise espectral da corrente de um MIT acionado por inversor trifásico. . . . 73

5.3 Análise espectral da corrente de um MIT acionado por inversor trifásico após a normalização de frequência. . . . . . . . . . . . . . . . . . 75

5.4 Efeito da variação do torque de carga em MITs sem falhas. . . . . . . . . . . . 76

5.5 Efeito da variação do torque de carga em MITs com 4 barras quebradas. . . . 76

5.6 Efeito da variação do número de barras quebradas. . . . . . . . . . . . . . 77

5.7 Caracterização de motores normais de tipos diferentes. . . . . . . . . . . 78

5.8 Análise de um motor normal e de outro com uma barra quebrada. . . . . . . . 79

5.9 Redução da dimensionalidade do vetor de entrada mediante a PCA. . . . . . . 80

6.1 Desempenho de treinamento da RNA: 2 neurônios na camada oculta. . . . . . 87

6.2 Resultados gerais do sistema neural de detecção de barras quebradas. . . . . . 88

6.3 Desempenho de treinameno da RNA: 20 neurônios na camada oculta. . . . . . 89 
6.4 Deslocamento da janela de análise dos sinais. . . . . . . . . . . . . . . . . . . 90

6.5 Desempenho de treinameno da RNA: 5 neurônios na camada oculta. . . . . . . 91

6.6 Resultados gerais do sistema neural de deteç̧ão de barras quebradas . . . . . 92

6.7 Desempenho de treinamento da RNA: 20 neurônios na camada oculta. . . . . 94

6.8 Resultados gerais do sistema neural de detecção de barras quebradas. . . . . . 95

6.9 Desempenho de treinamento da RNA: 5 neurônios na camada oculta. . . . . . 96

6.10 Resultados gerais do sistema neural de detecção de barras quebradas. . . . . . 97

6.11 Resultados gerais do sistema neural de detecção de barras quebradas. . . . . . 99

6.12 Resultados gerais do sistema neural de detecção de barras quebradas. . . . . . 102

A.1 Rotor de $1,0 \mathrm{cv}$ do tipo gaiola de esquilo. . . . . . . . . . . . . . . . . 116

A.2 Fixação e centralização do rotor no torno mecânico. . . . . . . . . . . . . . . . 116

A.3 Processo de perfuração do eixo utilizando-se uma broca de 9,0 mm. . . . . . . 117

A.4 Acabamento final e resultado da perfuração do eixo. . . . . . . . . . . . . . 117

A.5 Procedimento para fixação da barra no eixo do rotor. . . . . . . . . . . . . . . 118

A.6 Rolamentos utilizados nos rotores. . . . . . . . . . . . . . . . . . . . . . . . 119

A.7 Chavetas usinadas para serem fixadas nos rotores. . . . . . . . . . . . . . 120

A.8 Fixação das chavetas nos eixos dos rotores. . . . . . . . . . . . . . . . . . . 121

A.9 Perfuração da tampa do MIT para a passagem do eixo prolongado. . . . . . . . 121

A.10 Montagem da placa de alimentação com bornes. . . . . . . . . . . . . . . . . . 122

A.11 Procedimento de instalação dos rotores - Parte 1. . . . . . . . . . . . . . . . 123

A.12 Procedimento de instalação dos rotores - Parte 2. . . . . . . . . . . . . . 125

A.13 Instalação do MIT na bancada de experimentos. . . . . . . . . . . . . . . . . . 126

A.14 Procedimento de remoção dos rotores. . . . . . . . . . . . . . . . . . . . 126 



\section{Lista de Tabelas}

1.1 Porcentagem de ocorrência de falhas nos principais componentes do motor. . . 29

6.1 Conjunto de dados disponíveis para análise: Acionamento Direto. . . . . . . . 86

6.2 Taxa de acertos da RNA com 2 neurônios na camada oculta. . . . . . . . . . . 88

6.3 Taxa de acertos da RNA com 20 neurônios na camada oculta. . . . . . . . . . 89

6.4 Conjunto de dados disponíveis para análise: Acionamento Direto. . . . . . . . 90

6.5 Taxa de acertos da RNA . . . . . . . . . . . . . . . . . . . . . . . 91

6.6 Tabela de erros em função do carregamento. . . . . . . . . . . . . . . . . . . 92

6.7 Conjunto de dados disponíveis para análise: Inversor Trifásico. . . . . . . . . . 93

6.8 Taxa de acertos da RNA com 20 neurônios na camada oculta. . . . . . . . . . 94

6.9 Conjunto de dados de disponíveis para análise: Inversor Trifásico. . . . . . . . 96

6.10 Taxa de acertos da RNA com 2 neurônios em sua camada oculta. . . . . . . . 96

6.11 Tabela de erros em função do carregamento. . . . . . . . . . . . . . . . . 97

6.12 Conjunto de dados de disponíveis para análise: Inversor Trifásico. . . . . . . . . 98

6.13 Resultados do desempenho de detecção de falhas da RNA. . . . . . . . . . . . . 99

6.14 Tabela de erros em função do carregamento do MIT. . . . . . . . . . . . . . . 99

6.15 Conjunto de dados de disponíveis para análise: Inversor Trifásico. . . . . . . . 100

6.16 Resultados do desempenho de detecção de falhas da RNA. . . . . . . . . . . . 101

6.17 Tabela de erros em função do carregamento do MIT. . . . . . . . . . . . . . . 101 



\section{Lista de Siglas}

\begin{tabular}{|c|c|}
\hline AG & Algoritmo Genético \\
\hline $\mathrm{CC}$ & Corrente Contínua \\
\hline DFT & Discrete Fourier Transform \\
\hline DSP & Digital Signal Processor \\
\hline EPE & Empresa de Pesquisa Energética \\
\hline EPRI & Electric Power Research Institute \\
\hline FFT & Fast Fourier Transform \\
\hline GCC & Gerador de Corrente Contínua \\
\hline IEEE-IAS & IEEE-Industry Application Society \\
\hline MCC & Máquina de Corrente Contínua \\
\hline MIRGE & Motor de Indução com Rotor em Gaiola de Esquilo \\
\hline MIT & Motor de Indução Trifásico \\
\hline PCA & Principal Component Analysis \\
\hline PWM & Pulse Width Modulation \\
\hline RNA & Rede Neural Artificial \\
\hline SIF & Sistema de Inferência Fuzzy \\
\hline WPD & Wavelet Packet Decomposition \\
\hline
\end{tabular}





\section{Lista de Símbolos}

\begin{tabular}{|c|c|}
\hline$C_{R}$ & Centro do Rotor \\
\hline$C_{E}$ & Centro do Estator \\
\hline$D$ & Desalinhamento Relativo ao Entreferro \\
\hline$d$ & Largura do Desalinhamento \\
\hline$e^{(.)}$ & Função exponencial \\
\hline$f()$. & Função de Ativação \\
\hline$f_{a}$ & Frequência de amostragem em $\mathrm{Hz}$ \\
\hline$f_{a}$ & Frequência de amostragem \\
\hline$f b$ & Frequêncida da banda lateral \\
\hline$f_{\text {fund }}$ & Frequência da componente fundamental \\
\hline$f_{\text {linear }}()$. & Função de ativação linear \\
\hline$f_{\text {logsig }}()$. & Função de ativação sigmóide: logística sigmóide \\
\hline$f_{s}$ & Frequência máxima do sinal em Hz \\
\hline$f_{\text {sindeg }}()$. & Função de ativação sinal ou degrau \\
\hline$f_{\tanh }()$. & Função de ativação sigmóide: tangente hiperbólica \\
\hline$g$ & Largura do Entreferro \\
\hline $\mathbf{I}$ & Vetor de corrente no domínio da frequência \\
\hline$I_{\text {fund }}, I\left(m_{\text {fund }}\right)$ & Componente fundamental do vetor de corrente no domínio da frequência \\
\hline$I_{j}^{(\ell)}$ & Potencial de ativação do $j$-ésimo neurônio da camada neural $\ell$ \\
\hline
\end{tabular}


$\mathbf{I}_{\mathbf{n}} \quad$ Vetor de corrente no domínio da frequência normalizado em amplitude

$\mathbf{I}_{\text {win }}, \mathbf{I}_{\text {FFT }} \quad$ Janela da FFT de corrente analisada em torno de sua fundamental.

$k \quad$ Número inteiro

$\ell \quad$-ésima camada neural

$m \quad$ Índice do vetor de sinal no domínio da frequência $X(m)$

$\max ($.$) \quad Função para encontrar o valor máximo de um vetor$

$m_{\text {fund }} \quad$ Índice da componente fundamental

$m_{p} \quad$ Número de pontos em torno da componente fundamental

$\mathbf{m}_{\text {win }} \quad$ Vetor que contém os índices da janela da FFT de corrente em torno de sua fundamenta.

$N \quad$ Número total de entradas da RNA

$n \quad$ Índice do vetor de sinal no domínio do tempo $x(n)$

$N_{a} \quad$ Número total de amostras

$N \ell \quad$ Número de neurônios da camada $\ell$

$R \quad$ Resolução da FFT em Hz

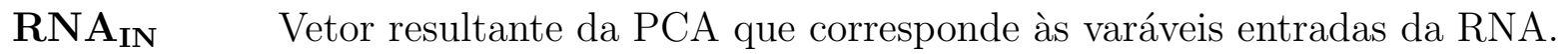

roundup(.) Função arrendondamento para cima

$s \quad$ Escorregamento do MIT

$\sum \quad$ Combinador linear

$\theta \quad$ Limiar de ativação

$t \quad$ Tempo

$t_{a} \quad$ Tempo de amostragem

$t_{a q} \quad$ Tempo de aquisição do sinal

$\theta_{j}^{(\ell)} \quad$ Limiar de ativação do $j$-ésimo neurônio da camada neural $\ell$

$u \quad$ Potencial de ativação

$v \quad$ Número inteiro da potência de 2 
$V / f \quad$ Controle escalar frequência $\times$ tensão constante

$\omega \quad$ Frequência em $\mathrm{rad} / \mathrm{s}$

$W_{j i}^{(\ell)} \quad$ Peso sináptico do $j$-ésino neurônio da camada $\ell$ conectado ao $i$-ésimo neurônio da camada $(\ell-1)$

$w_{n} \quad$ n-ésimo peso sináptico do perceptron simples

$x_{n} \quad$ n-ésima entrada do perceptron simples

$x(t) \quad$ Sinal arbitrário no domínio do tempo

$X(\omega) \quad$ Sinal $x(t)$ no domínio da frequência

$Y_{j}^{(\ell)} \quad$ Saída do $j$-ésimo neurônio da camada $\ell$

$y_{p}\left(y_{r n a}\right) \quad$ Saída da RNA pós-processada

$y_{\text {rna }} \quad$ Saída da RNA 



\section{Sumário}

1 Introdução $\quad 25$

1.1 Motivação e Relevância do Trabalho . . . . . . . . . . . . . . . . . 25

1.2 Objetivos e Justificativas da Tese . . . . . . . . . . . . . . . . . . 31

1.3 Organização da Tese . . . . . . . . . . . . . . . . . . . . . 32

2 Aspectos de Bancada Experimental para Ensaios de Falhas em MIT 33

2.1 Disposição Geral da Bancada de Experimentos . . . . . . . . . . . . . . . . 33

2.2 Inserção de Defeitos nas Barras de Rotores . . . . . . . . . . . . . . . 36

2.3 Inserção de Falhas de Curto-Circuito entre as Bobinas de Estator . . . . . 38

2.4 Inserção de Falhas no Rolamento . . . . . . . . . . . . . . . . . . . 40

3 Aspectos de Levantamento e Análise de Dados Experimentais 41

3.1 Introdução . . . . . . . . . . . . . . . . . . . . . . . . . . 41

3.2 Rotor Normal - Acionamento Direto da Rede . . . . . . . . . . . . . . . . . 42

3.3 Rotor Normal - Acionamento por Inversor de Frequência . . . . . . . . . . 43

3.4 Rotor com 1 Barra Quebrada - Acionamento Direto . . . . . . . . . . . . . 45

3.5 Rotor com 1 Barra Quebrada - Acionamento por Inversor de Frequência . . 46

3.6 Rotor com 4 Barras Quebradas - Acionamento Direto . . . . . . . . . . . 47

3.7 Rotor com 4 Barras Quebradas - Acionamento por Inversor . . . . . . . . . 48

3.8 Curto-Circuito no Estator ． . . . . . . . . . . . . . . . . . . . . . . 49

3.9 Rolamento Defeituoso . . . . . . . . . . . . . . . . . . . . 49

3.10 Motor de Alto Rendimento . . . . . . . . . . . . . . . . . . . 52

4 Fundamentos de Redes Neurais Artificiais e Processamento de Sinais 53

4.1 Redes Neurais Artificiais . . . . . . . . . . . . . . . . . . 53

4.2 Aspectos Fundamentais da Transformada de Fourier . . . . . . . . . . . . . 62

5 Sistema de Identificação Neural de Barras Quebradas em MITs $\quad 69$

5.1 Introdução . . . . . . . . . . . . . . . . . . . . . . 69

5.2 Estrutura do Sistema Neural de Identificação de Barras Quebradas . . . . 71 
5.3 Pré-Processamento dos Sinais . . . . . . . . . . . . . . . . . . . . 72

5.4 Estruturação da RNA . . . . . . . . . . . . . . . . . . . . 81

5.5 Projeto do Sistema Neural de Monitoramento . . . . . . . . . . . . . . . . 82

6 Resultados Experimentais $\quad 85$

6.1 Introdução . . . . . . . . . . . . . . . . . . . . . . . 85

6.2 Acionamento Direto da Rede . . . . . . . . . . . . . . . . 86

6.3 Acionamento pelo Inversor Trifásico . . . . . . . . . . . . . . . . . . 93

6.4 Acionamento Direto da Rede+Inversor Trifásico . . . . . . . . . . . . . . . 98

6.5 Acionamento Direto $\Rightarrow$ Inversor . . . . . . . . . . . . . . . . . . 100

7 Conclusões Gerais e Diretivas Futuras 103

7.1 Conclusões Gerais . . . . . . . . . . . . . . . . . . . . . . . . 103

7.2 Principais Contribuições da Tese . . . . . . . . . . . . . . . . . . . 104

7.3 Diretivas Futuras do Projeto de Pesquisa . . . . . . . . . . . . . . 105

$\begin{array}{ll}\text { Referências } & 107\end{array}$

$\begin{array}{ll}\text { Apêndices } & 113\end{array}$

A Adaptação, Montagem e Desmontagem do MIT 115

A.1 Prolongamento do Eixo dos Rotores para a Aferição de Velocidade . . . . . 115

A.2 Montagem da Placa de Conexão da Alimentação da Máquina . . . . . . . . 120

A.3 Processo de Instalação/Remoção dos Rotores nas Máquinas . . . . . . . . 123 


\section{Capítulo 1}

\section{Introdução}

\subsection{Motivação e Relevância do Trabalho}

A necessidade crescente de busca por processos mais racionais e econômicos no que tange à utilização eficiente da energia elétrica tem implicado na realização de estudos detalhados para a otimização das técnicas de manufatura, os quais visam também à adequada conservação da energia elétrica. Dentro deste contexto, os motores elétricos tornaram-se equipamentos indispensáveis na maioria dos processos que envolvem os setores produtivos, pois estes se destacam como principais elementos de conversão de energia elétrica em mecânica. Como consequência, essas máquinas elétricas passaram, e tendem a continuar passando, por melhorias que atendam as necessidades emergentes dos processos produtivos frente à sua importância energética.

Conforme estudos realizados em 2005 pela Empresa de Pesquisa Energética (EPE), vinculada ao Ministério de Minas e Energia, estima-se que 47,0\% da energia produzida no Brasil são destinadas à classe industrial, o que equivale a aproximadamente 346 bilhões de MWh anuais. Deste montante, estima-se também que 50,0\% da energia consumida são atribuídas aos motores elétricos.

Nesse contexto, especial atenção deve ser dada aos motores de indução, os quais são destacados pela sua simplicidade construtiva e principalmente pelo menor custo. Entre os motores de indução, o Motor de Indução com Rotor em Gaiola de Esquilo (MIRGE) merece um maior destaque, cujas características marcantes são atribuídas à sua robustez, longa vida útil e quase ausência de manutenção, característica esta que o torna mais atraente, especialmente no preço (GOEDTEL, 2007; DIAS; LOBOSCO, 1998; FITZGERALD; KINGSLEY; UMANS, 2006; TRZYNADLOWSKI, 2001; KRAUSE; WASYNCZUK; SUDHOFF, 1995).

A partir de documentação técnica disponibilizada pela Siemens (SIEMENS, 2006) revela-se que estudos de mercados indicam que o custo gerado pelo consumo de energia elétrica é correspondente à cerca de $97 \%$ dos custos totais durante o ciclo de vida de um motor elétrico, na qual o restante (de apenas 3\%) estão relacionados ao custo de aquisi- 
ção, instalação e manutenção. Além disso, em TRZYNADLOWSKI (2001) é descrito que, dentre os diversos tipos de motores elétricos empregados em setores industriais, cerca de 90\% constituem de Motores de Indução Trifásicos (MITs). Consequentemente, deduz-se que os MITs, em especial o MIRGE, contribuem significativamente para os resultados contidos na documentação técnica da Siemens (SIEMENS, 2006). Por outro lado, pesquisas relativas à eficiência energética se tornam também relevantes e motivadoras.

Desta forma, devido às suas aplicações cada vez mais crescentes nas indústrias e à sua relevância no panorama energético, os estudos relativos aos motores elétricos têm se mantido um papel de suma importância no que diz respeito à melhoria de eficiência energética, dimensionamento adequado, técnicas de controle preciso, manutenção preventiva, identificação de falhas e qualidade de energia elétrica.

Os motores elétricos estão expostos a uma variedade de condições ambientais, operando sob diversos tipos de cargas, os quais em conjunto com o envelhecimento natural podem ocasionar falhas inerentes às próprias máquinas ou associadas às condições severas (BONNETT; ALBERS, 2001). Neste contexto, o monitoramento a fim de detectar as falhas em seus estágios iniciais é de suma importância para tratá-las adequadamente, evitando-se danos e, consequentemente, reduzindo-se o custo de manutenção, o custo de estoque de peças e o desligamento do setor industrial no qual as máquinas estão inseridas (DRIF; CARDOSO, 2007). Desta forma, conforme se tem testemunhado em diversos artigos da literatura correlata recente, há então uma necessidade crescente de desenvolver técnicas confiáveis para detectarem falhas em tempo real.

As falhas ocorrentes em motores de indução, em geral, podem ser classificadas conforme o esquema (YEH et al., 2007) ilustrado na Figura 1.1.

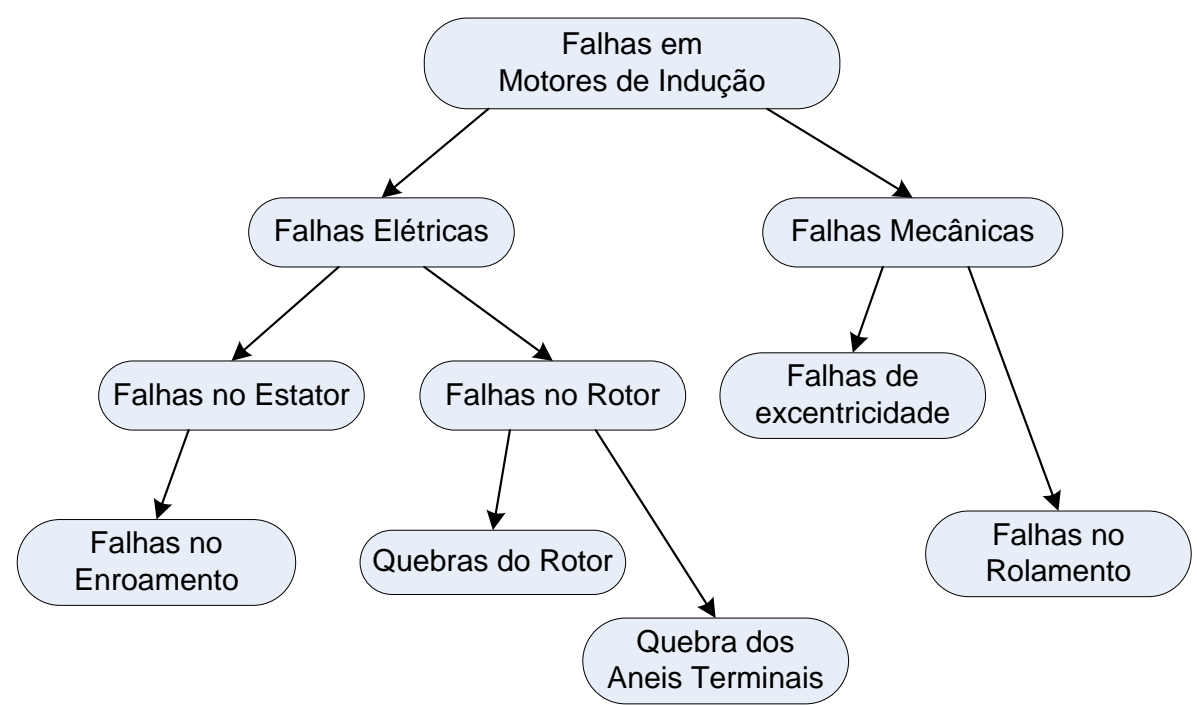

Figura 1.1: Categorias de falhas em motores de indução.

Dentre as falhas mecânicas, as principais estão relacionadas às falhas por excentricidade do entreferro e às falhas no rolamento. A primeira está relacionada ao desali- 
nhamento do eixo de rotação do rotor com o centro do estator e pode ser causada pela ovalização do núcleo estatórico ou pelo posicionamento incorreto do rotor ou estator durante o processo de montagem. A Figura 1.2 ilustra o desalinhamento do entreferro entre o rotor e o estator, em que $C_{E}$ é o centro do estator, $C_{R}$ é o centro do rotor, $g$ é a largura do entreferro e $d$ é largura do desalinhamento.

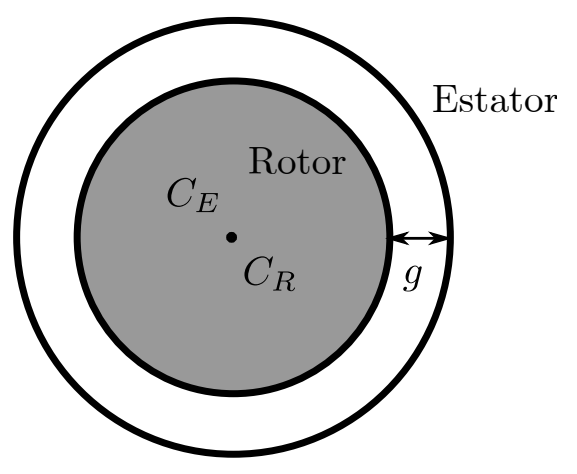

(a) Centro do rotor $C_{R}$ perfeitamente alinhado com a do estator $C_{E}$.

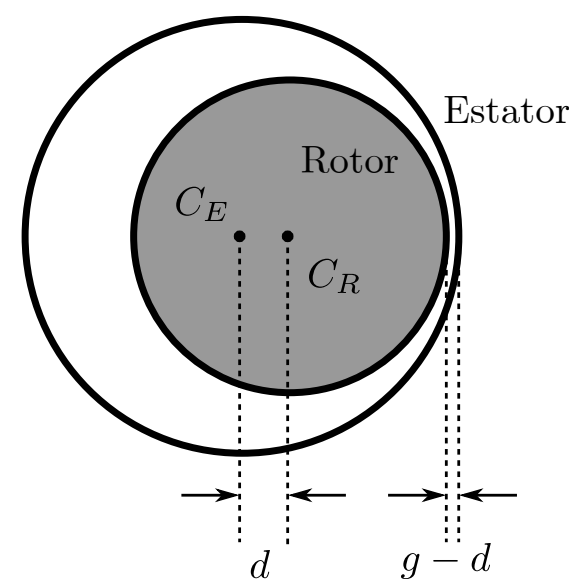

(b) Centro do rotor $C_{R}$ desalinhado com a do estator $C_{E}$.

Figura 1.2: Ilustração do desalinhamento de entreferro.

A Figura 1.2(a) ilustra um MIT cujo centro do rotor $\left(C_{R}\right)$ está perfeitamente alinhado com o centro do estator $\left(C_{E}\right)$. Nesta ilustração, a largura do entreferro $(g)$ é constante ao longo do perímetro do estator. Já a Figura 1.2(b) representa um MIT cujo centro do rotor está deslocado em uma distância $d$ do centro do estator. Nota-se que a largura do entreferro é variável ao longo do perímetro do estator, cuja distância mínima é determinada por $g-d$. Os fabricantes usualmente representam o desalinhamento do entreferro em termos de porcentagem, conforme segue:

$$
D(\%)=\frac{d}{g} \times 100 \%
$$

O desalinhamento do entreferro pode ser do tipo estático ou dinâmico. O primeiro ocorre quando o eixo de rotação mecânica do rotor coincide com o centro do rotor $\left(C_{R}\right)$. Neste caso, a largura do entreferro ao longo da operação do MIT será constante, embora apresente um determinado desalinhamento. Por outro lado, o segundo ocorre quando o eixo de rotação mecânica do rotor não coincide com o centro do rotor, apresentando-se maiores vibrações na estrutura do MIT.

O desalinhamento pode causar empenamento de eixo, desgastes de rolamentos e danos mecânicos à máquina, além de contribuir para agravar ainda mais a própria falha por excentricidade. Os fabricantes sugerem que os desvios de excentricidade acima de $20 \%$ são considerados inaceitáveis, sendo que para níveis acima de $50 \%$ o motor deverá ser removido do serviço (BARBOUR; THOMSON, 1997). Alguns trabalhos relacionados à identificação de falhas por excentricidades podem ser encontrados em BARBOUR; THOMSON 
(1997); FAIZ et al. (2007); GRIEGER et al. (2007); ARDEKANI; FAIZ (2007); HUANG; HABETLER; HARLEY (2007).

As falhas nos rolamentos estão associadas principalmente às assimetrias rotóricas e representam cerca de $40 \%$ de todas as falhas ocorridas em motores. São causadas pelo estresse devido às vibrações inerentes à excentricidade, contaminação por partículas sólidas, corrosão por ações de água/ácido e lubrificação inadequada (YEH et al., 2007; NANDI; TOLIYAT; LI, 2005). As correntes induzidas circulantes nos rolamentos através dos mancais causados pelo chaveamento dos inversores também contribuem para este tipo de falhas (MUETZE; BINDER, 2007). O monitoramento desta falha é de suma importância, visto que a qualidade dos rolamentos influi diretamente no desempenho de operação da máquina dimensionada para uma aplicação específica. Alguns trabalhos relevantes em detecção de falhas nos rolamentos de rotor com resultados já promissores são encontrados em ÖNEL; DALCI; SENOL (2006); BALLAL et al. (2007); ONEL; BENBOUZID (2007); BALLAL et al. (2006).

Considerando-se as falhas elétricas, as mais comumente ocorrentes na prática estão relacionadas ao estator e ao rotor. As falhas no enrolamento estatórico (YEH et al., 2007; TONI; SLOBODAN; ALEKSANDAR, 2007; PEREIRA; GAZZANA; PEREIRA, 2005) geralmente estão associadas às deficiências apresentadas pelos materiais isolantes e contribuem em torno de 30\% a 40\% de todas as falhas no motor de indução (YEH et al., 2007; NANDI; TOLIYAT; LI, 2005). A isolação estatórica pode ser afetada pela elevada taxa de variação da tensão de alimentação $(d V / d t)$, alta temperatura da bobina ou do núcleo estatórico, folga na laminação do núcleo magnético estatórico, perda da proteção das conexões de bobinas, contaminação provocada por óleo, umidade ou sujeira e descargas elétricas (NANDI; TOLIYAT; LI, 2005). Falhas de isolamento entre as bobinas de fase e terra podem causar uma alta corrente, podendo então resultar em danos irreversíveis ao núcleo da máquina. O monitoramento desses tipos de falhas é relevante, pois, uma vez que tais faltas sejam detectadas em seus estágios iniciais de desencadeamento, a máquina poderá então ser ainda reutilizada após o rebobinamento do estator.

A grande parcela dos motores de indução empregado nas indústrias vem acompanhada por módulos de acionamentos. Desta forma, as falhas inerentes vêm de precedências externas, tais como desbalanceamento de tensão, subtensão, sobretensão (YANG; HAN; YIN, 2006; KOLLA; ALTMANA, 2007), sendo que falhas no próprio dispositivo de acionamento influenciam diretamente no desempenho do motor de indução (GUAN; SUN; HE, 2007; KHANNICHE; MAMAT, 2000). Neste contexto, a relevância desta pesquisa de doutorado não se resume apenas ao trabalho de monitoramento e detecção de falhas e faltas que visam a manutenção preventiva, mas proporciona também o desdobramento de diversas pesquisas correlatas, tais como a identificação de falhas no módulo de acionamento e o desenvolvimento de métodos de controle projetados de forma que sejam tolerantes às falhas, estando-se assim em conformidade com outros trabalhos relevantes 
já relatados na literatura (DONGMO et al., 2007; TAHAMI; SHOJAEI; KHATIR, 2006; YEH; DEMERDASH, 2007).

As quebras das barras do rotor ou rachaduras de anéis da gaiola de esquilo contribuem cerca de $5 \%$ a $10 \%$ das falhas em motores de indução. As principais consequências residem no aumento na oscilação de conjugado, vibração excessiva, ruído, centelhamento, pobre dinâmica de partida e redução do desempenho mecânico (YEH et al., 2007; NANDI; TOLIYAT; LI, 2005; KILIC; OZGONENEL; OZDEMIR, 2007). Desta forma, torna-se relevante o desenvolvimento de técnicas que permitem identificar tais falhas com antecedência, evitando-se assim danos de grande magnitude. Trabalhos recentes que tratam a detecção de quebras de barras ou rachaduras de anéis do rotor em gaiola já têm também apresentados alguns resultados promissores (CRUZ; CARDOSO, 2006, 2007; SUPANGAT et al., 2007; AYDIN; KARAKOSE; AKIN, 2007).

Por outro lado, os motores acionados por inversores de frequência estão submetidos a elevado estresse de tensão devido às altas taxas de chaveamentos dos dispositivos semicondutores. Além disso, os motores de indução também são exigidos em aplicações em ambientes altamente empoeirados e corrosivos (DRIF; CARDOSO, 2007). Em consequência, o projeto e a manufatura dos enrolamentos de estator têm passado por melhorias no desenvolvimento e no processo de tratamento de materiais isolantes (BONNETT; ALBERS, 2001; BONNETT; SOUKUP, 1988; BENBOUZID; KLIMAN, 2003).

No entanto, conforme pode ser observado pela Tabela 1.1, as falhas relacionadas aos enrolamentos de estator e às barras do rotor, juntamente com as falhas nos rolamentos de rotor, contribuem para a maior parcela de ocorrências em motores de indução trifásicos (YEH et al., 2007). Portanto, consideram-se tais falhas os principais alvos de estudos neste projeto de pesquisa de doutorado.

Tabela 1.1: Porcentagem de ocorrência de falhas nos principais componentes do motor.

\begin{tabular}{|c|c|c|}
\hline Falhas & $\begin{array}{c}\text { IEEE-IAS } \\
\text { \% de Falhas }\end{array}$ & $\begin{array}{c}\text { EPRI }^{2} \\
\text { de Falhas }\end{array}$ \\
\hline Rolamentos & 44 & 41 \\
\hline Estator & 26 & 36 \\
\hline Rotor & 8 & 9 \\
\hline Outros & 22 & 14 \\
\hline
\end{tabular}

${ }^{1}$ IEEE-Industry Application Society, ${ }^{2}$ Electric Power Research Institute

Paralelamente, a inteligência computacional, por intermédio de técnicas baseadas em Redes Neurais Artificiais (RNAs), Sistemas de Inferência Fuzzy (SIFs) e Algoritmos Genéticos (AGs), tem mostrado resultados bem promissores na detecção e identificação de falhas em motores de indução trifásicos (YANG; HAN; YIN, 2006; KOLLA; ALTMANA, 2007; KILIC; OZGONENEL; OZDEMIR, 2007; AYDIN; KARAKOSE; AKIN, 2007; XUHONG; YI-GANG, 2006, 2007; ZIDANI et al., 2007), fatos estes em virtude da sua ha- 
bilidade de lidar com sistemas não-lineares e variantes no tempo e de não necessitar de modelos matemáticos precisos que representem o sistema, além de apresentar uma grande facilidade de integração computacional com as técnicas convencionais.

As RNAs consistem de um conjunto de unidades de processamento denominadas de neurônios, os quais são interconectados por meio de pesos sinápticos que representam o conhecimento armazenado em forma distribuída. Suas principais características atrativas residem na capacidade de mapear sistemas não-lineares mediante ao processo de aprendizado, à adaptação de seus parâmetros livres aos sistemas variantes no tempo, à capacidade de generalização das soluções, à habilidade de classificar e de agrupar padrões semelhantes (HAYKIN, 1999). Tais virtudes tornam as RNAs uma ferramenta alternativa bem promissora para solução de processos envolvidos na identificação de falhas em máquinas elétricas.

Enquanto as RNAs trabalham com um conjunto de dados a fim de ajustar os seus pesos sinápticos por meio de algoritmos de aprendizagem, os sistemas de inferência fuzzy são capazes de lidar com as incertezas e imprecisões das variáveis envolvidas no processo, mediante a sua base de conhecimento, expressada na forma de regras do tipo "Se-Então" aplicadas em variáveis lingüísticas. Desta forma, os sistemas de inferência fuzzy possuem a habilidade de explorar os aspectos qualitativos do processo visando mapear a solução do problema (TSOUKALAS; UHRIG, 1997). Neste sentido, tais sistemas apresentam uma ampla aplicabilidade em processos envolvidos com máquinas elétricas a fim de contornar as não-linearidades e incertezas paramétricas.

Já os AGs consistem de técnicas de otimização e de busca inspiradas nos mecanismos de seleção natural e genética. Essas técnicas não garantem uma solução ótima para o problema, porém, geralmente encontram soluções quase ou suficientemente ótimas em um tempo considerado aceitável. Os AGs aplicam uma técnica estocástica de busca, que embora aleatória, não definem caminhos desordenados em direção a uma solução ótima, uma vez que se utilizam informações históricas para definir os novos pontos de busca. Estes são realizados, durante cada geração, por meio de operadores, baseados em princípios de seleção, reprodução e mutação, aplicados a uma população de candidatos (BRAGA; LUDERMIR; CARVALHO, 2000). Em virtude da grande capacidade de otimização e busca eficiente, as suas aplicações na identificação de falhas em máquinas elétricas mostram-se promissoras em determinados problemas (YANG; HAN; YIN, 2006).

Os sistemas inteligentes podem ainda ser combinados entre si com o intuito de explorar suas potencialidades e desenvolver sistemas com melhores desempenhos. Técnicas como estas, denominadas de sistemas inteligentes híbridos (TSOUKALAS; UHRIG, 1997), vêm também apresentando ótimos resultados em diversas áreas de atuação. Dentre as combinações, têm-se os sistemas neuro-fuzzy, neuro-genético, fuzzy-genético e neuro-fuzzygenético.

Como exemplo, em YANG; HAN; YIN (2006), os autores propõem um método de di- 
agnóstico de falhas em motor de indução, o qual integra as técnicas de Análises de Componentes Principais, do inglês: Principal Component Analysis (PCA), AGs e RNAs. O sinal de vibração e a corrente de estator são aplicados como entrada do sistema para identificar as falhas, tais como massa de rotor desbalanceado, quebra no rotor, rotor empenado, falhas nos rolamentos, excentricidade e fases desbalanceadas. A PCA é empregada para reduzir a dimensionalidade do vetor de entrada, na qual a seleção de atributos relevantes é realizada pelo algoritmo genético. Este também é utilizado para otimizar a estrutura da RNA usada para a classificação das falhas em motores de indução. Os resultados dos métodos foram promissores e alcançaram taxas de acertos acima de $80 \%$.

Já no trabalho proposto em XU-HONG; YI-GANG (2006) foi desenvolvido um método para detecção on-line de faltas entre as espiras de estator de um motor de indução trifásico, na qual dois sistemas fuzzy do tipo Takagi-Sugeno foram empregados. Um deles foi utilizado para estimar a gravidade da falta, sendo que o outro foi usado para determinar o número de espiras com faltas. Durante a modelagem, um algoritmo de clusterização fuzzy, baseado na avaliação de similaridade, foi proposto para determinar a estrutura ótima do modelo, sendo que um código de AG foi também adotado para otimizar os parâmetros de forma on-line. Tais técnicas tornam o modelo compacto e preciso. Experimentos foram executados em laboratório utilizando motor de indução com bobinas especiais com o intuito de apresentar os promissores resultados do sistema fuzzy na detecção do número de espiras em curto-circuito.

Por outro lado, em YE; SADEGHIAN; WU (2006) foi proposto um algoritmo de identificação on-line de falhas mecânicas em motor de indução alimentado por dispositivos de controle de velocidade. Mediante a aplicação da Técnica de Wavelet Packet Decomposition (WPD), um conjunto de coeficientes característicos, representados com diferentes resoluções de frequência relacionados às falhas mecânicas, é então extraído a partir da corrente de estator do motor de indução operando em uma ampla faixa de velocidade. Os valores pré-processados são atribuídos ao sistema de detecção proposto que se baseia em uma abordagem neuro-fuzzy. Em tal trabalho, o algoritmo de identificação se mostrou eficiente, sendo capaz de detectar as quebras nas barras do rotor e as falhas por excentricidade com alta precisão.

\subsection{Objetivos e Justificativas da Tese}

Os objetivos gerais desta pesquisa consistem na investigação, desenvolvimento, projeto, implementação e validação de arquiteturas de sistemas inteligentes em Digital Signal Processor (DSP), os quais podem ser utilizados nos processos envolvidos com a identificação de falhas em motores de indução trifásicos. Dentro desse contexto, os objetivos da pesquisa de doutorado são pautados em cinco itens principais apresentados a seguir:

$\square$ Constituir uma bancada de ensaios de falhas para simular, de maneira experimental, 
diversos tipos de falhas envolvidos em motores de indução trifásicos.

$\square$ Projetar as estratégias baseadas em sistemas inteligentes para identificação de falhas em motores de indução, as quais serão primeiramente implementadas em software (MATLAB) e, posteriormente, em hardware (DSP), com o intuito de constituir um sistema de detecção de falhas on-line e de tempo real.

$\square$ Permitir que novas técnicas, desenvolvidas por meio da aplicação de sistemas inteligentes e de métodos convencionais, possam ser testadas e validadas experimentalmente.

$\square$ Disponibilizar um banco de informações com dados experimentais que poderão ser utilizados em diversas outras pesquisas afins realizadas pela comunidade científica.

\subsection{Organização da Tese}

No Capítulo 1 foi apresentada a introdução e pesquisas bibliográficas relacionadas às principais falhas ocorrentes em motores de indução trifásicos. Adicionalmente, a motivação, a relevância e os objetivos da tese também foram discutidos.

No Capítulo 2, descrevem-se os principais componentes da bancada de experimentos e discute suas adaptações para realizar ensaios de quebras nas barras da gaiola de esquilo do rotor, curto circuito entre as bobinas do estator e defeitos nos rolamentos do motor.

No Capítulo 3 são apresentados os principais ensaios de diversas falhas em motores de indução que visam à constituição de uma base de dados experimentos. Ilustram-se também as análises gerais e preliminares dos sinais de tensão e corrente.

No Capítulo 4 são discutidos os aspectos fundamentais relacionados às redes neurais artificiais e a transformada rápida de Fourier.

No Capítulo 5, o projeto de um sistema neural de identificação de quebras em barras de rotores de gaiola de esquilo, bem como suas principais análises serão delineadas.

No Capítulo 6, ilustram-se os principais resultados experimentais dos sistemas de identificação de quebras em barras de rotores de gaiola de esquilo.

No Capítulo 7, fornecem-se as conclusões gerais, as principais contribuições da tese e as respectivas diretivas de investigação em trabalhos futuros.

Por fim, no Apêndice A, mostram-se os detalhes sobre a adaptação da bancada de experimentos para prolongar o eixo do rotor visando aferição de velocidade. 


\section{Aspectos de Bancada Experimental para Ensaios de Falhas em Motores de Indução Trifásicos}

\subsection{Disposição Geral da Bancada de Experimentos}

Nesta seção será apresentada a descrição dos principais componentes da estrutura do hardware envolvidos no processo de aquisição de dados experimentais que serão aplicados para o estudo e o desenvolvimento do sistema de identificação de falhas em motores de indução trifásicos.

A Figura 2.1 ilustra de maneira genérica a forma em que as estruturas de ensaios de máquinas elétricas estão organizadas, sendo compostas de uma bancada de ensaios, na qual se situa a máquina de indução trifásica; a Máquina de Corrente Contínua (MCC), o encoder e o torquímetro; um quadro de comando no qual podem ser realizados o ajuste da tensão aplicada no motor de indução, escolher o tipo de acionamento (estrela ou triângulo), selecionar o tipo de alimentação (tensão direta da rede ou inversor trifásico), entre outros; um circuito de alimentação da bobina de campo do Gerador de Corrente Contínua (GCC), cuja carga é conectada à bobina de armadura; os circuitos aplicados para o condicionamento dos sinais dos sensores para a placa de aquisição de dados localizada em um computador.

O MIT utilizado nesta pesquisa consiste basicamente de um motor da linha standard, 1,0 cv, 220V/380V, 3,02A/1,75A, 4 pólos, $60 \mathrm{~Hz}, 4,1 \mathrm{Nm}$ e velocidade nominal de $1715 \mathrm{rpm}$. A MCC consiste de uma máquina de $2 \mathrm{~kW}$ de potência, $190 \mathrm{~V}$ de tensão nominal de campo e $250 \mathrm{~V}$ de tensão nominal de armadura. O encoder óptico incremental apresenta uma resolução de 2000 pulsos por rotação, cuja finalidade consiste na medição da velocidade angular do MIT. Embora esta variável não seja diretamente empregada nessa pesquisa para a identificação de falhas, a sua aferição é de suma importância para 


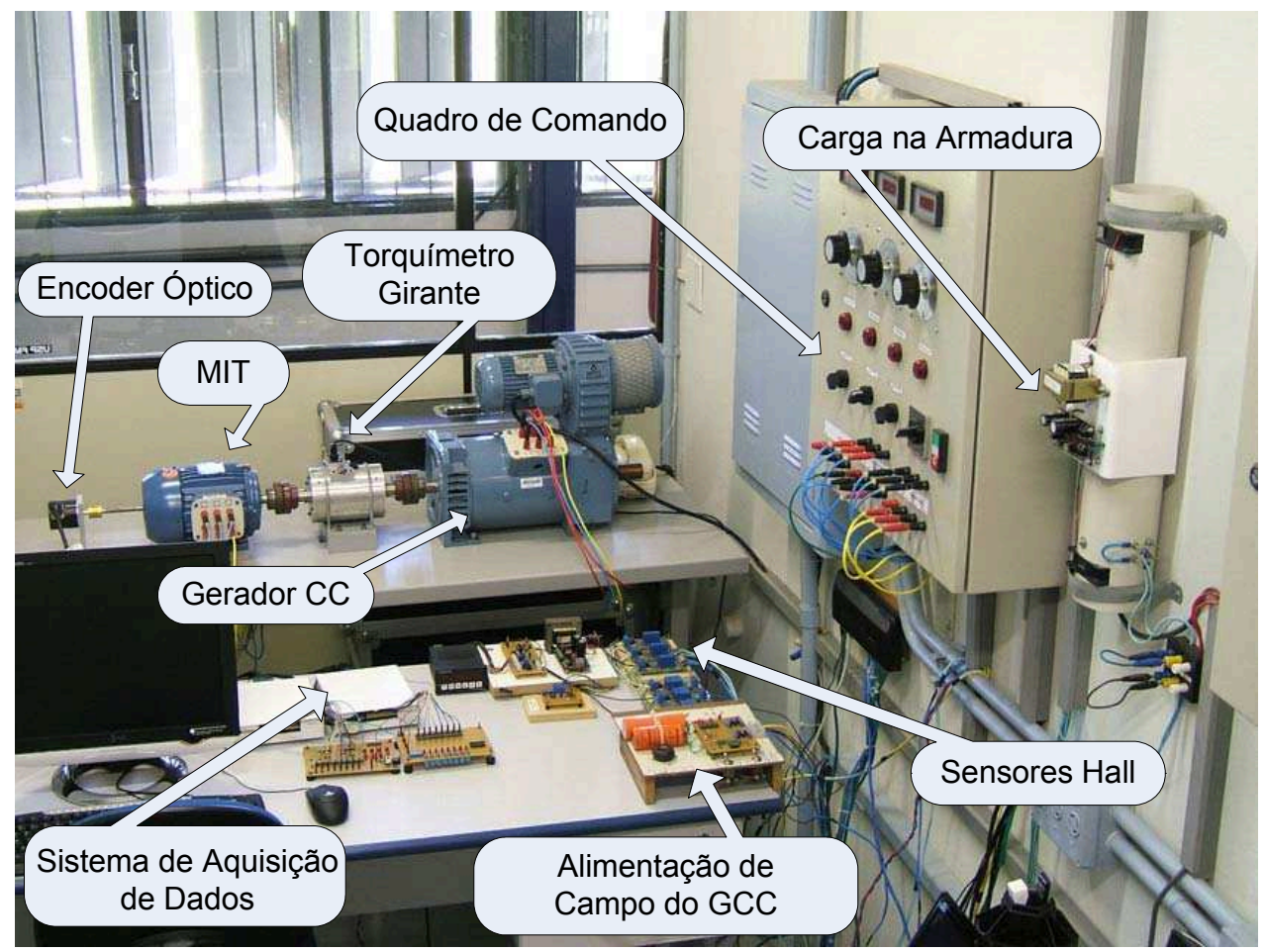

Figura 2.1: Esquema geral do laboratório de ensaios de máquinas elétricas.

o monitoramento do estado de funcionamento do MIT.

O eixo da MCC, a qual atua como gerador, é acoplado ao MIT por intermédio de um torquímetro rotativo. O GCC é responsável pela simulação experimental de uma determinada carga acoplada ao eixo do MIT, uma vez que o torque resistente imposto pelo gerador pode ser alterado, conforme a variação da tensão do enrolamento de campo. Alternativamente, tal ajuste pode ser realizado mediante a variação da sua carga acoplada no enrolamento de armadura. A configuração da bancada de experimentos pode ser visualizada com maiores detalhes na Figura 2.2.

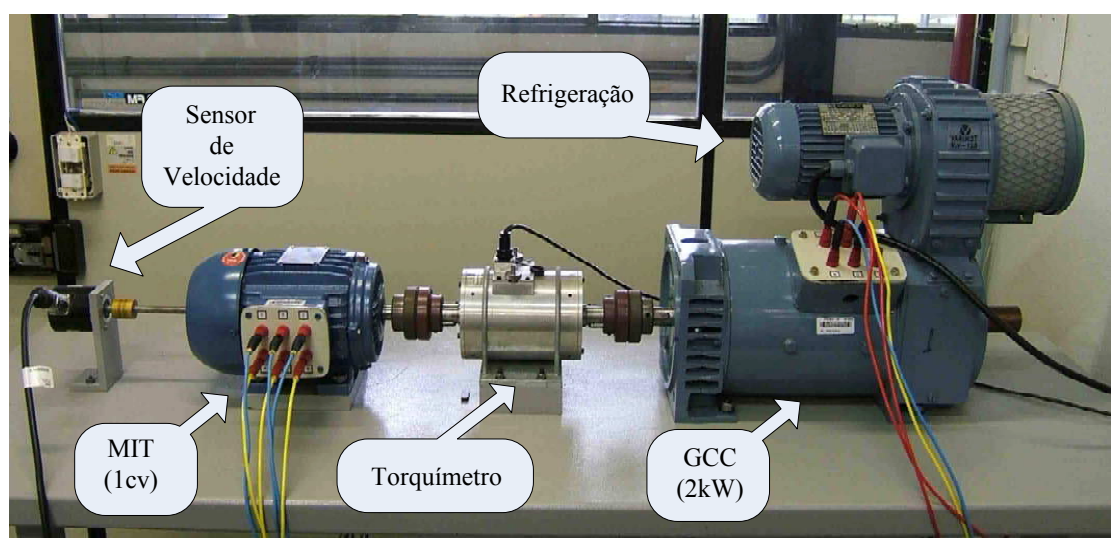

Figura 2.2: Visão geral da estrutura da bancada de ensaios.

O ajuste manual do torque de carga é realizado por meio da variação da tensão dos terminais do variador de tensão (variac), o qual é conectado a uma ponte retificadora 
monofásica com filtro. Este, por sua vez, é responsável pela alimentação do enrolamento de campo do GCC. A Figura 2.3(a) ilustra o variac de 1800 W, enquanto que a Figura 2.3(b) mostra o circuito da fonte de tensão de alimentação do enrolamento de campo. Esta também pode ser visualizada na Figura 2.1.

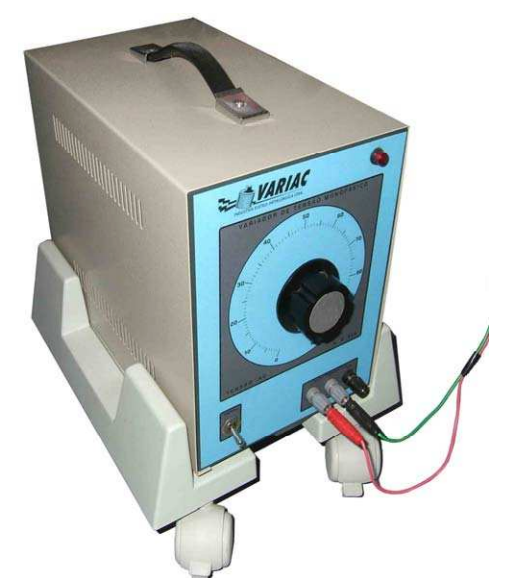

(a) Variador de tensão monofásico.

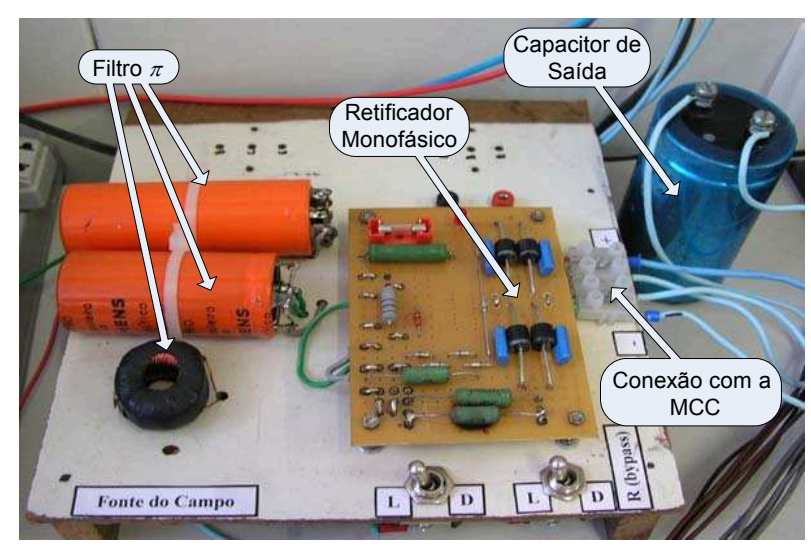

(b) Fonte de alimentação de campo.

Figura 2.3: Excitação do enrolamento de campo do GCC.

O sensor Hall de corrente utilizado na bancada de experimentos é o LAH-25 NP do fabricante LEM. A corrente nominal deste dispositivo é de 25 A. O condicionamento de sinal é realizado utilizando-se o amplificador operacional TL081 com ajuste de offset. O sensor Hall de corrente é ilustrado na Figura 2.4(a).

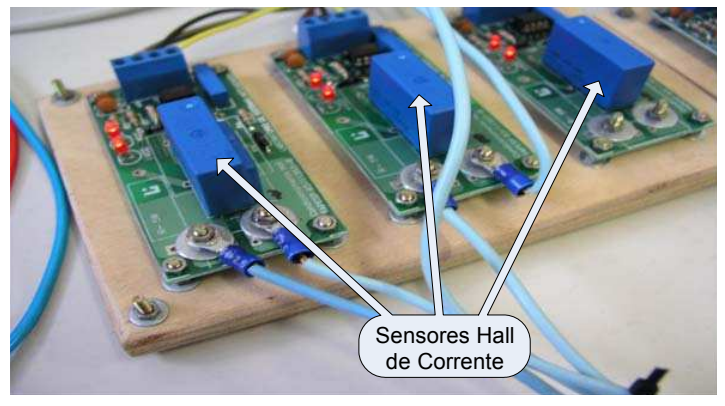

(a) Sensor Hall de corrente.

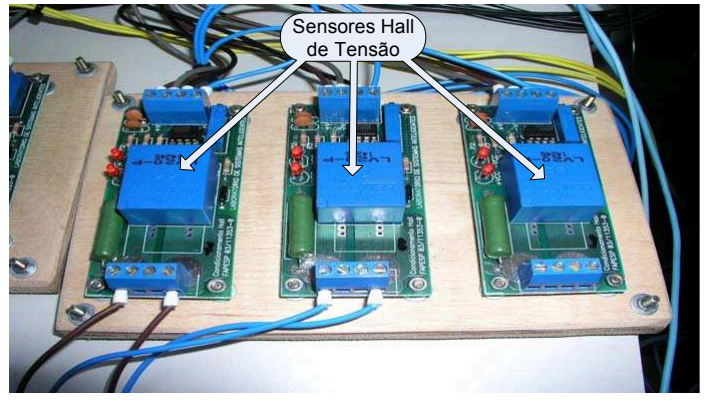

(b) Sensor Hall de tensão.

Figura 2.4: Sensores Hall de corrente e tensão.

Em contrapartida, o sensor Hall de tensão utilizado neste trabalho é o LV-20P do fabricante LEM. Assim como descrito no sensor Hall de corrente, utilizou-se uma placa responsável pelo condicionamento de sinal dos sensores Hall. A mesma placa é adaptada para receber os sinais dos sensores Hall tanto de corrente como de tensão, já que, desta forma, o custo de fabricação dos sensores seria reduzido. Esta metodologia é aplicada na indústria eletro-eletrônica com bastante frequência. O sensor Hall de tensão é ilustrado na Figura 2.4(b). 
Na Figura 2.1 ilustram-se os sensores Hall utilizados para mensurar as tensões e correntes dos enrolamentos de campo e armadura do GCC. As variáveis do MIT são mensuradas mediantes sensores Hall inseridos internamente ao quadro de comando.

O sistema de aquisição de dados é de suma importância para efetuar análises e validação dos ensaios experimentais. O laboratório de pesquisa é equipado por uma placa de aquisição de dados que dispõe de uma quantidade de canais analógicos suficientes para aferição de diversos sinais envolvidos nos ensaios realizados. A Figura 2.5(a) ilustra a placa de aquisição de dados da National Instruments (modelo NIDAQmx PCIe-6259).

As principais características do NIDAQmx PCIe-6269 consistem na presença de 32 canais analógicos de entrada de 16 bits, com taxa de aquisição de 1,25 mega-amostras por segundo; 4 canais analógicos de saída de 16 bits, com taxa de 2,8 mega-amostras por segundo, e 48 canais de I/O digitais com capacidade de operar na frequência de clock de até $10 \mathrm{MHz}$.

A placa NIDAQmx PCIe-6259 é conectada no barramento PCI-Express do computador. As interconexões com os dispositivos externos são realizadas por um bloco conector SCB-68 ilustrado na Figura 2.5(b). Em tal bloco, além da interface de conexões relativas a todas as portas analógicas e digitais, permite-se também a implementação de filtros de sinais em hardware.

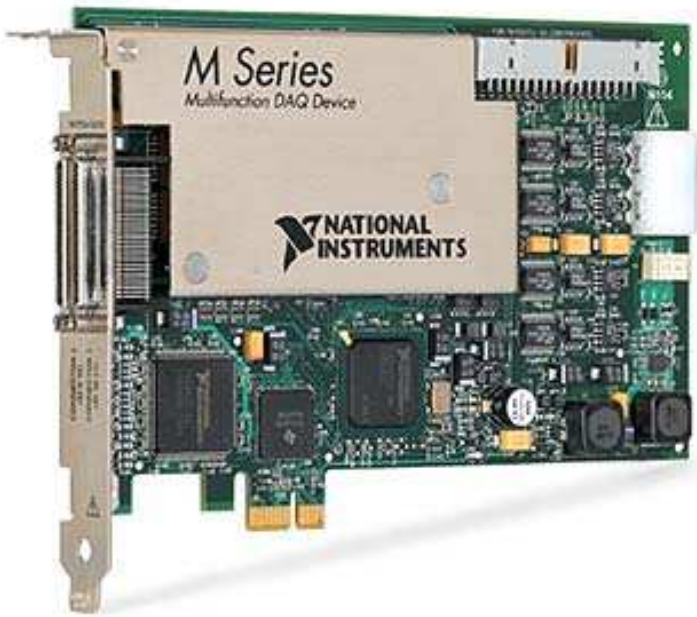

(a) Placa de aquisição de dados da National Instruments (NIDAQmx PCIe-6259).

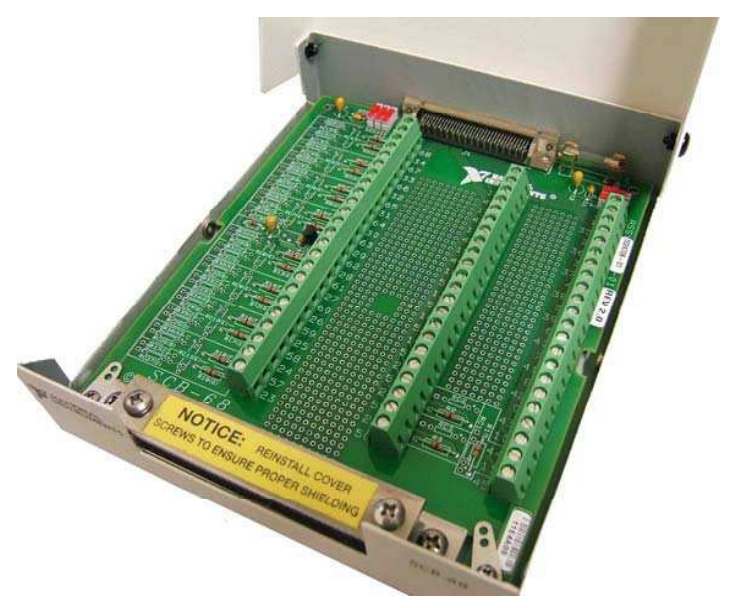

(b) Bloco de conexões SCB-68.

Figura 2.5: Sistema de aquisição de dados.

\subsection{Inserção de Defeitos nas Barras de Rotores}

A inserção de defeitos nos rotores de MITs consiste basicamente de seccionar algumas barras da gaiola de esquilo. Este procedimento pode ser realizado mediante a perfuração do rotor por meio de uma broca de 6,0 mm de dimensão, que é suficientemente maior que a largura da barra. 
Antes de se iniciar a perfuração, é necessário localizar o centro do rotor para que o orifício gerado apresente um caminho radial. A Figura 2.6(a) ilustra a metodologia adotada para se encontrar o centro. Inicialmente, efetua-se uma pequena marcação no raio externo de uma das extremidades do eixo com uma broca. Em seguida, mensura-se o diâmetro deste eixo e o da broca. Desta forma, a posição do centro é exatamente o raio do eixo somado ao raio da broca. Este deslocamento é efetuado de forma precisa, uma vez que esta furadeira apresenta sensores de posição vertical e horizontal.

A Figura 2.6(b) ilustra a imagem do momento em que o rotor estava sendo perfurado, efetuando-se, desta forma, o seccionamento de uma das barras do rotor. Nota-se que a coloração dos resíduos da perfuração é da cor prateada, evidenciando-se aqui que as barras são de alumínio.

A Figura 2.6(c) ilustra com mais nitidez o orifício de seccionamento de uma das barras da gaiola de esquilo. A Figura 2.6(d) ilustra a imagem de um rotor com duas barras seccionadas.

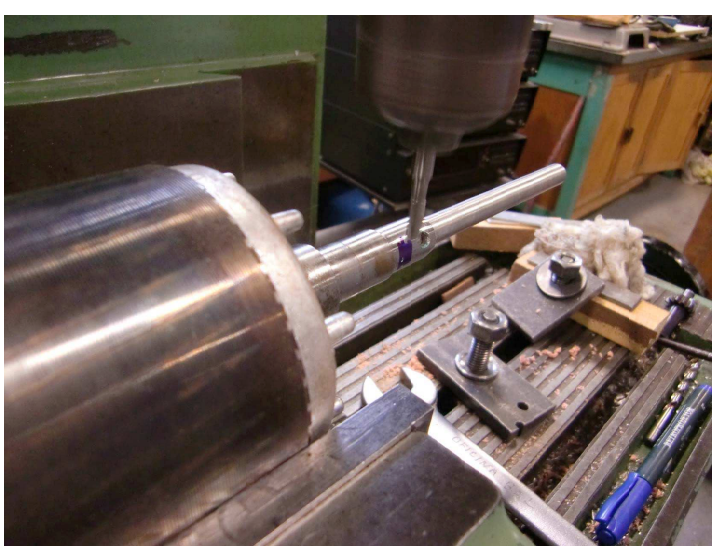

(a) Marcação para encontrar o centro do rotor.

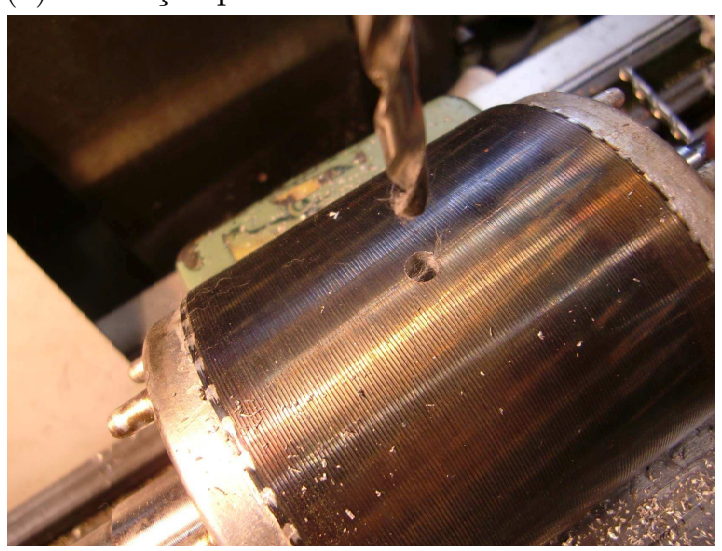

(c) Imagem da barra seccionada.

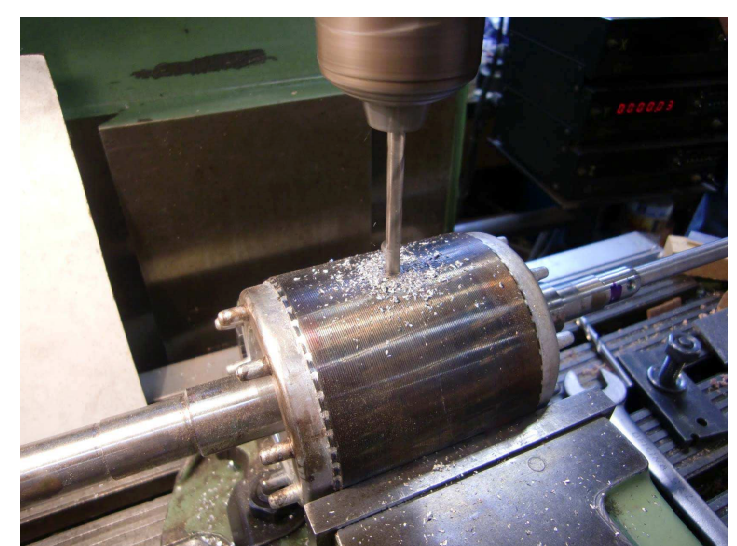

(b) Processo de seccionamento da barra da gaiola.

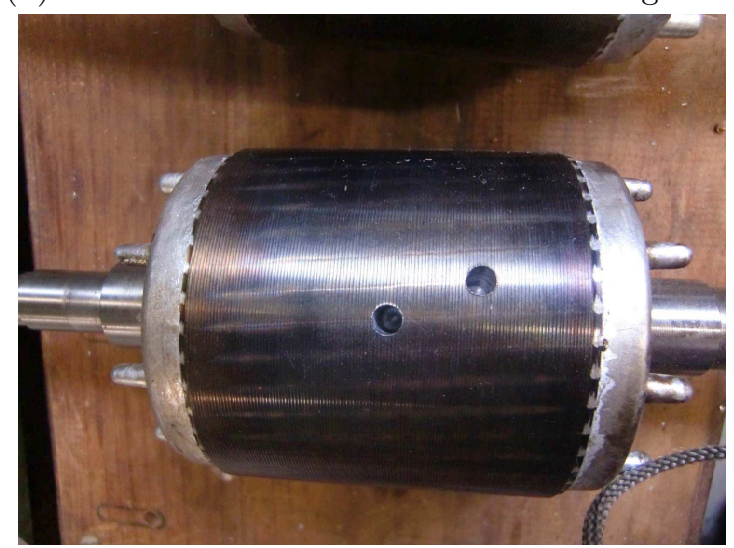

(d) Imagem de duas barras seccionadas.

Figura 2.6: Procedimento para a inserção de falhas em rotores.

Os ensaios experimentais que visam à constituição da base de dados de falhas em rotores foram conduzidos mediante sucessivas substituições de rotores defeituosos. Este procedimento deve ser cuidadosamente realizado por meio da montagem\desmontagem do MIT, a fim de não danificar e \ou desalinhar a sua estrutura física. 


\subsection{Inserção de Falhas de Curto-Circuito entre as Bobinas de Estator}

O MIT de 4 pólos utilizado nesta tese se constitui de um arranjo de bobinas concêntricas alocadas ao longo de 36 ranhuras do estator, conforme pode ser observado na Figura 2.7. As bobinas em vermelho, representadas pelas letras $A$ e $A^{\prime}$, são os enrolamentos da fase a. De forma análoga, as bobinas em azul e verde, indicadas pelas letras $B, B^{\prime}, C$ e $C^{\prime}$, são os enrolamentos da fase $b$ e $c$, respectivamente. Ressalta-se que o enrolamento da fase $a$ é subdividido em dois conjuntos de bobinas $A$ e $A^{\prime}$ em virtude deste MIT apresentar 4 pólos. A mesma observação é válida para os enrolamentos das fases $b$ e $c$.

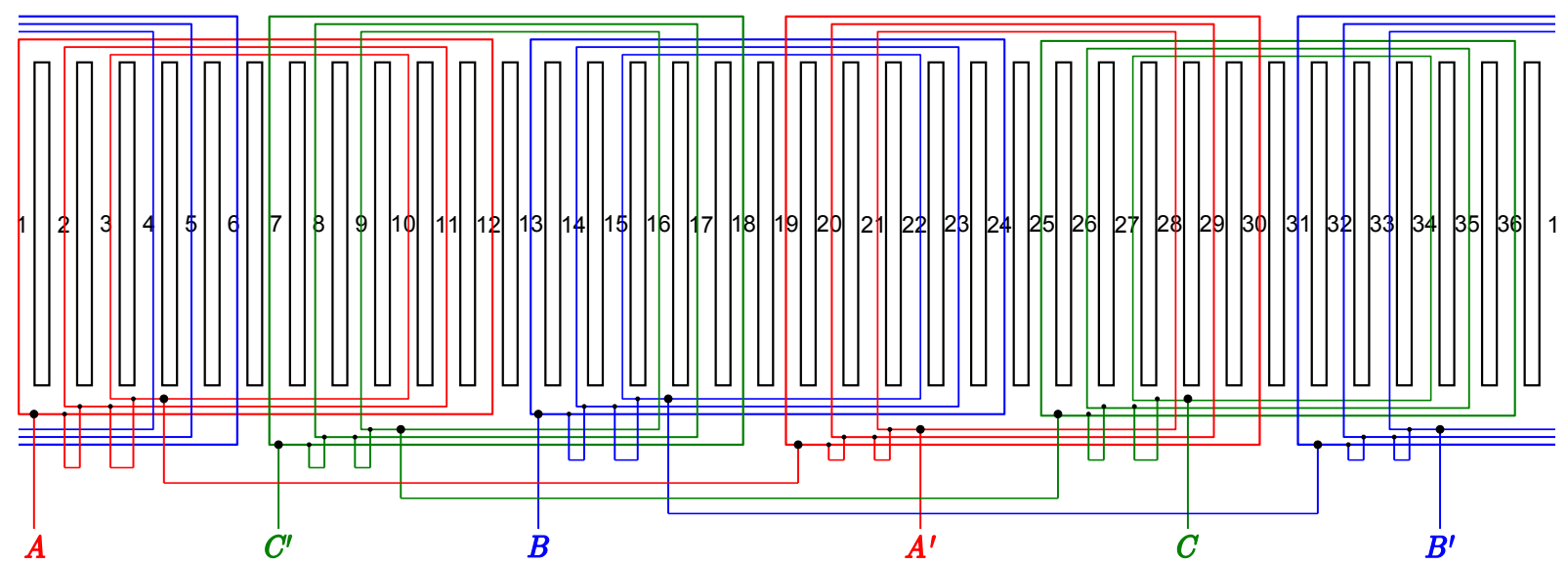

Figura 2.7: Disposição das bobinas ao longo das ranhuras do estator.

A partir do diagrama de enrolamento planificado da Figura 2.7, nota-se que há possibilidades de ocorrência de três tipos de falhas: curto-circuito entre bobinas da mesma fase; curto-circuito entre bobinas de duas fases diferentes; e curto-circuito entre as bobinas das três fases, simultaneamente.

A probabilidade de ocorrência de falhas entre bobinas da mesma fase é aquela maior entre as três, visto que as bobinas são alocadas em ranhuras. Em virtude de ter a menor capacidade de refrigeração, o aumento de temperatura decorrente da condição de funcionamento do MIT pode ocasionar a degradação da isolação e provocar o curto-circuito. Há também a possibilidade de ocorrência de curto-circuito na parte externa, no caminho entre uma ranhura e outra, porém, com menor probabilidade.

Em virtude das bobinas de fases diferentes não compartilharem a mesma ranhura, a sua taxa de ocorrência de falhas é menor, já que o curto-circuito só é possível na parte externa, no caminho entre uma ranhura e outra.

Finalmente, a probabilidade de ocorrência de falhas entre as três fases simultaneamente é mínima. Conforme pode ser observado na Figura 2.7, nota-se que praticamente não há pontos comuns entre as três fases. Esta falha eventualmente pode ocorrer nos pontos em que os terminais de acesso aos enrolamentos são levados para a caixa de alimentação. 
Em conformidade com essas observações, projetaram-se então as derivações do enrolamento do estator para efetuar os ensaios de curto-circuito entre as bobinas, conforme ilustrado na Figura 2.8. Cada fase é representada por seis bobinas que estão alocadas em seis ranhuras, obedecendo-se o diagrama planificado ilustrado na Figura 2.7. As derivações são realizadas nos pontos intermediários e das extremidades das bobinas situadas em cada ranhura.

A partir destas derivações é possível realizar uma diversidade de combinação de falhas entre bobinas da mesma fase; bobinas entre fases diferentes; e bobinas entre as três fases, simultaneamente.

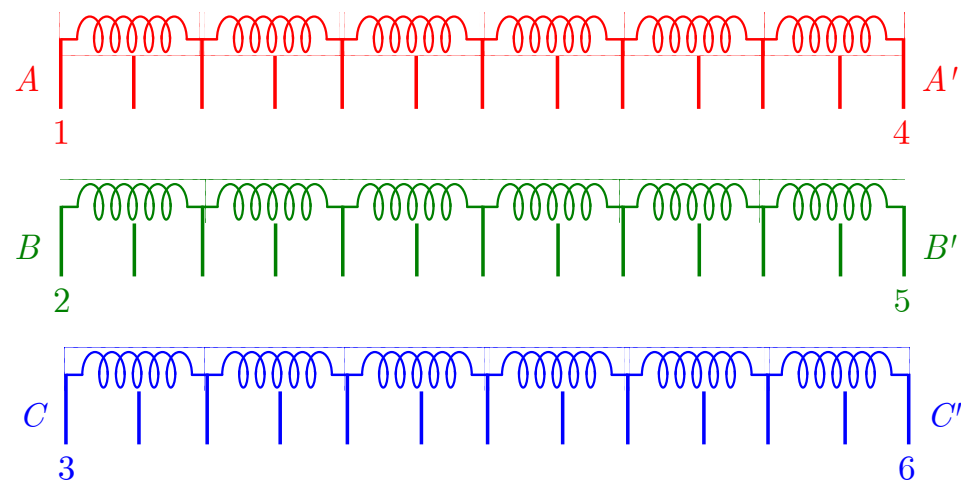

Figura 2.8: Derivações do enrolamento do estator para realização de ensaios de curtocircuito.

A adaptação dos enrolamentos do estator foi realizada por uma empresa de manutenção de motores de indução situada na cidade de São Carlos - SP. A Figura 2.9 ilustra as fotos das derivações dos pontos de curto-circuito realizadas no MIT.

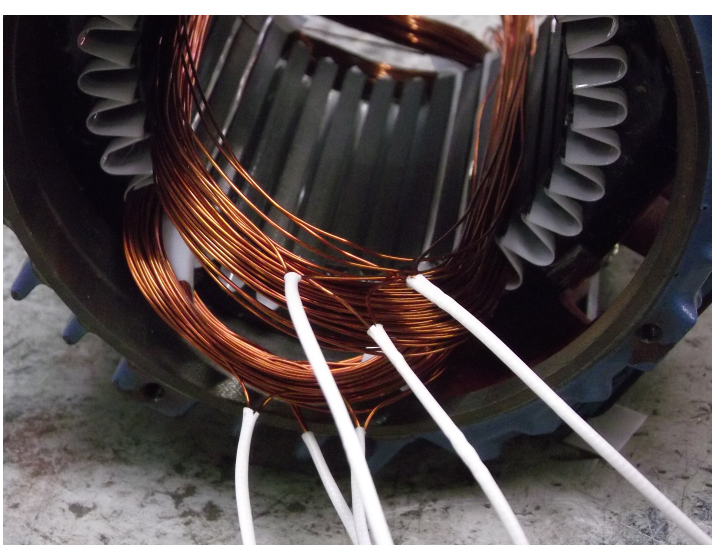

(a)

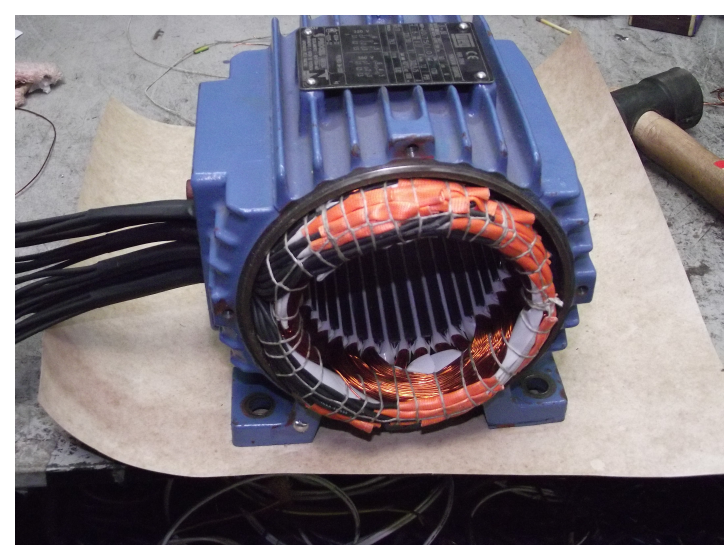

(b)

Figura 2.9: Foto ilustrativa dos terminais de derivação.

Após este procedimento, adaptações mecânicas foram realizadas no motor para efetuar os ensaios de curto-circuito na bancada experimental, conforme ilustrado na Figura 2.10. A Figura 2.10(a) mostra a placa de bornes de conexão com os terminais de derivação 


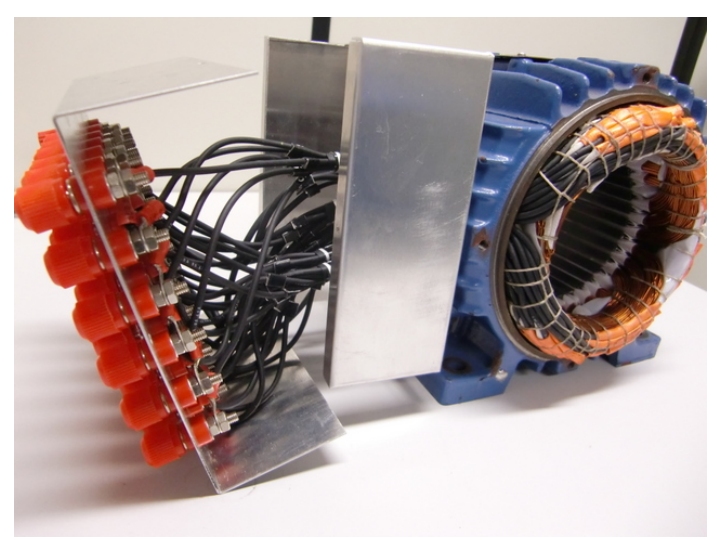

(a) MIT com os pontos de acesso às derivações.

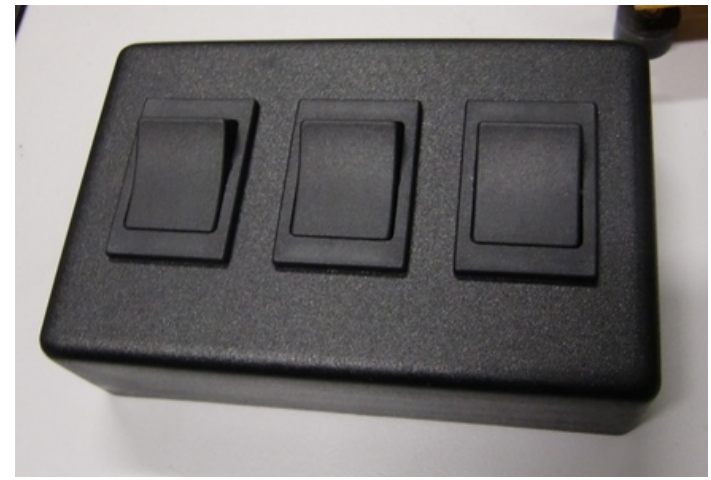

(b) Chave para realização de curto-circuitos.

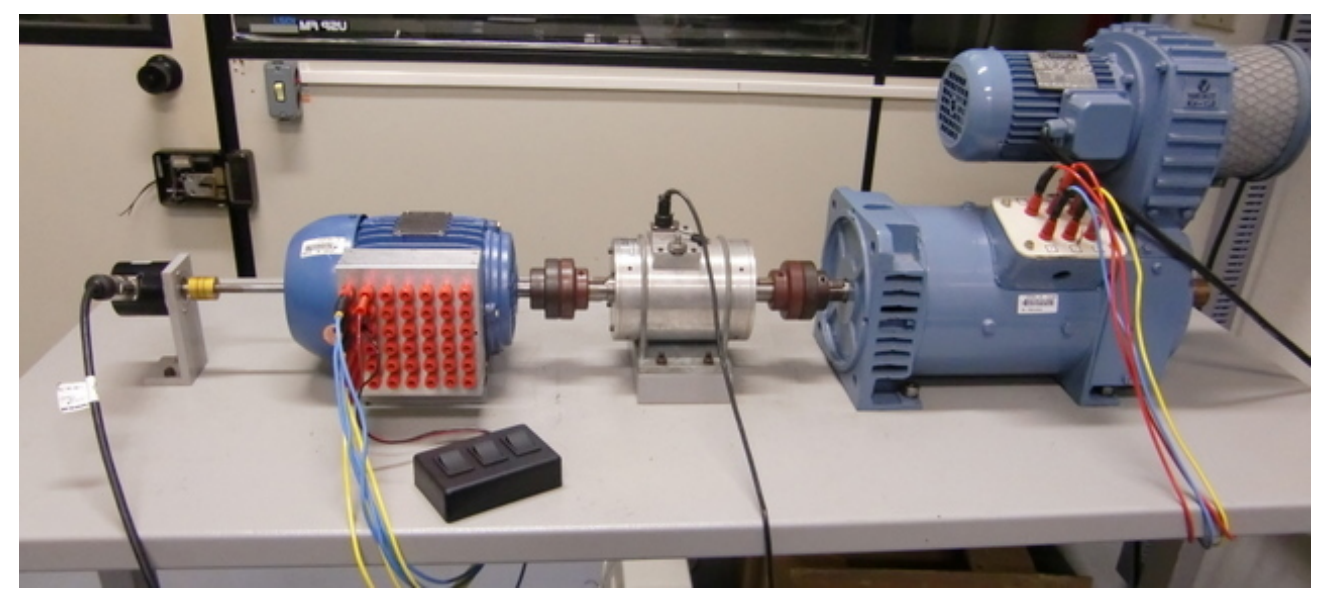

(c) Visão geral da bancada de ensaios experimentais.

Figura 2.10: Bancada de ensaios experimentais de curto-circuito entre bobinas dos enrolamentos de estator.

dos enrolamentos de estator. A Figura 2.10(b) ilustra a chave utilizada para realizar uma das combinações (até 3 simultâneas) de curto-circuito durante a operação do MIT. Finalmente, a Figura 2.10(c) apresenta a visão geral da bancada de ensaios experimentais de curto-circuito entre bobinas do estator.

\subsection{Inserção de Falhas no Rolamento}

Para o processo de inserção de falhas no rolamento do MIT, não houve aqui a necessidade de desenvolver nenhum tipo de adaptação na bancada experimental. A empresa Eletro Cavalaro, a qual realizou o rebobinamento dos enrolamentos para os ensaios de curto-circuito, também trabalha com a manutenção de motores elétricos. Neste sentido, a empresa gentilmente forneceu rolamentos defeituosos de MITs que se situavam em ambientes industriais. Desta forma, mediante uma simples troca de rolamento é possível conduzir ensaios experimentais para a constituição da base de dados de sinais com este tipo de falha. 


\section{Aspectos de Levantamento e Análise de Dados Experimentais}

\subsection{Introdução}

Nesta seção serão apresentados os aspectos metodológicos para a realização do levantamento da base de dados experimentais de MITs com falhas em seus rotores, rolamentos e enrolamentos de estator. Os ensaios consideram um MIT operando em regime permanente sob circunstâncias de cargas constantes. São admitidos tanto o acionamento direto da rede elétrica quanto o acionamento pelo inversor trifásico.

Neste contexto, a base de dados experimentais é constituída pelos seguintes ensaios: a) acionamento direto da rede elétrica com torque de carga aplicado de 0,5 Nm, 1,0 Nm, 2,0 Nm, 3,0 Nm e 4,0 Nm. A conexão do motor foi configurada em $\Delta$ com tensão de alimentação de linha de $220 \mathrm{~V}$ equilibrada. b) acionamento com o inversor trifásico com frequência síncrona de $60 \mathrm{~Hz}, 55 \mathrm{~Hz}, 50 \mathrm{~Hz}, 45 \mathrm{~Hz}$ e $40 \mathrm{~Hz}$. Para cada valor de frequência, aplicou-se torque de carga de $0,5 \mathrm{Nm}, 1,0 \mathrm{Nm}, 1,5 \mathrm{Nm}, 2,0 \mathrm{Nm}, 2,5 \mathrm{Nm}, 3,0 \mathrm{Nm}, 3,5 \mathrm{Nm}$ e 4,0 Nm. A tensão no barramento CC fora ajustada para a tensão plena da rede $(311 \mathrm{~V})$ e o algoritmo empregado foi o acionamento escalar $V / f$ constante em malha aberta com frequência de chaveamento de $5 \mathrm{kHz}$.

Ambos os ensaios foram realizados para atender tanto os motores cujos rotores são normais quanto motores que apresentavam quebras nas barras dos rotores, curtos-circuitos nos enrolamentos de estator e falhas no rolamento.

Entre os ensaios de barras quebradas, serão apresentados os resultados de 1 barra quebrada e de 4 barras quebradas consecutivamente. Com relação ao ensaio com as bobinas em curto-circuito, serão mostrados os resultados de 1 caso de curto entre bobinas da mesma fase, equivalente à meia bobina de uma ranhura. Ensaios com um motor de alto rendimento serão também apresentados para aumentar a base de dados que se constitui de motores normais. Por fim, 1 caso de rolamento defeituoso também será mostrado. 


\subsection{Rotor Normal - Acionamento Direto da Rede}

Neste ensaio, partiu-se o MIT com tensão nominal de linha de $220 \mathrm{~V}$ até atingir o seu regime permanente. Em seguida, aplicaram-se torque de cargas entre 0,5 Nm e 4,0 Nm para constituir a base de dados experimentais. A Figura 3.1 ilustra os primeiros ciclos dos sinais de correntes e de tensões de linha trifásicas de um MIT sob carga de 1,0 Nm.

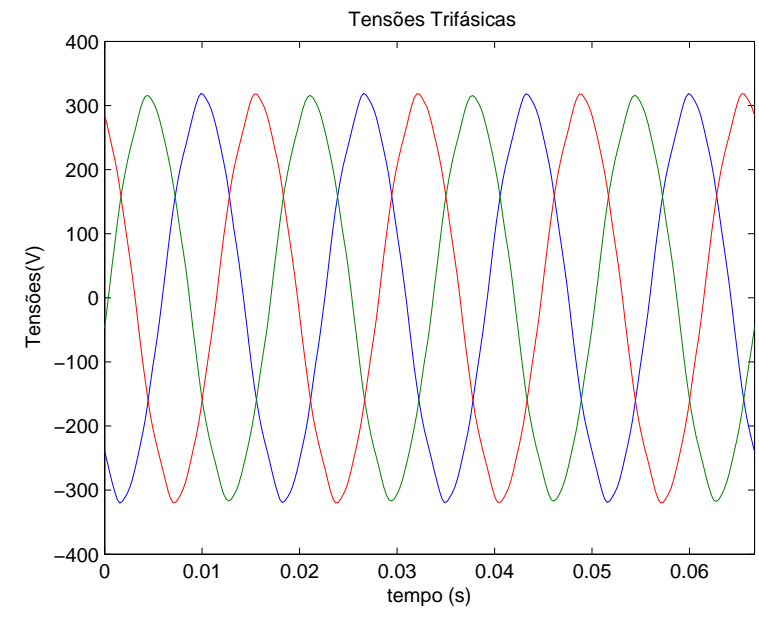

(a) Tensões de linha trifásicas do MIT.

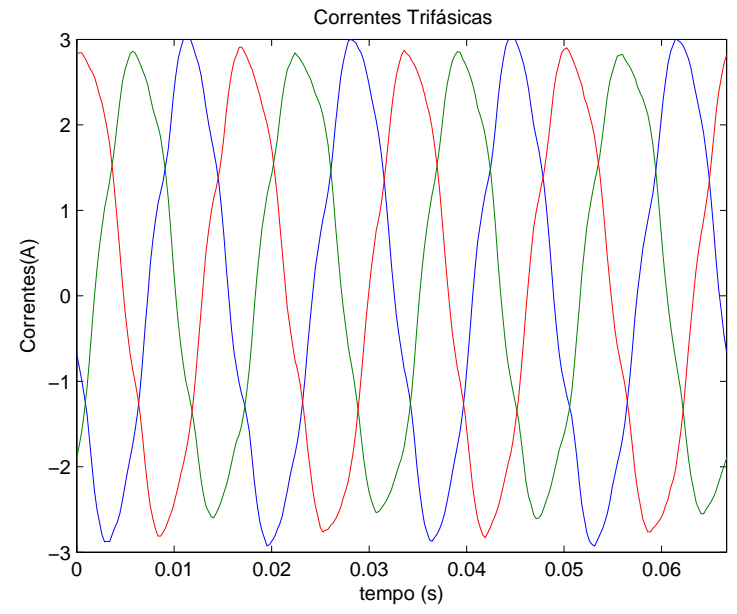

(b) Correntes trifásicas de linha do MIT.

Figura 3.1: Tensões e correntes de linha trifásicas do MIT normal sob carga de 1,0 Nm.

A Figura 3.1(a) ilustra as tensões de linha trifásicas aplicadas ao MIT. Nota-se que as tensões estão equilibradas e sem sinal visual de distorções.

Por outro lado, a Figura 3.1(b) ilustra as correntes de linha trifásicas para o mesmo ensaio do MIT. Observa-se uma pequena distorção quando comparado com os sinais de tensões. Considerando-se que a assinatura deste motor é de um motor com funcionamento normal, tais características podem ser resultantes de diversos fatores. Em se tratando de um motor ideal, a corrente no estator deveria apresentar características senoidais perfeitas. Entretanto, na prática, a distribuição do fluxo eletromagnético ao longo das ranhuras não são senóides perfeitas; além disso, os enrolamentos trifásicos também não são exatamente iguais.

Em busca de uma análise com mais detalhes, aplicou-se de início, a Transformada Rápida de Fourier (FFT) tanto no sinal de uma das fases da tensão quanto no sinal de corrente, conforme pode ser observado na Figura 3.2. Conforme esperado, a frequência de $60 \mathrm{~Hz}$ é aquela predominante, apresentando o maior módulo tanto no sinal de tensão (Figura 3.2(a)) como no de corrente (Figura 3.2(b)). Mediante uma observação detalhada da corrente na Figura 3.2(b), nota-se também que há uma pequena representação de sinal nas frequências de $30 \mathrm{~Hz}$ e $90 \mathrm{~Hz}$.

De acordo com os resultados encontrados em CHOI et al. (2011), tais componentes de frequências estão relacionadas ao efeito de vibração do motor, que por mais que se tenha cautela em alinhá-lo, tal procedimento é realizado de forma manual. 


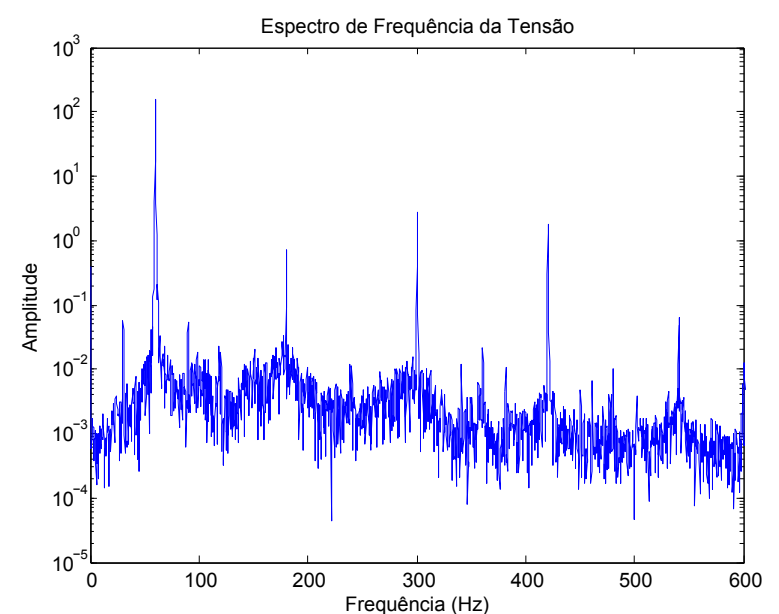

(a) Análise espectral da tensão de linha "a".

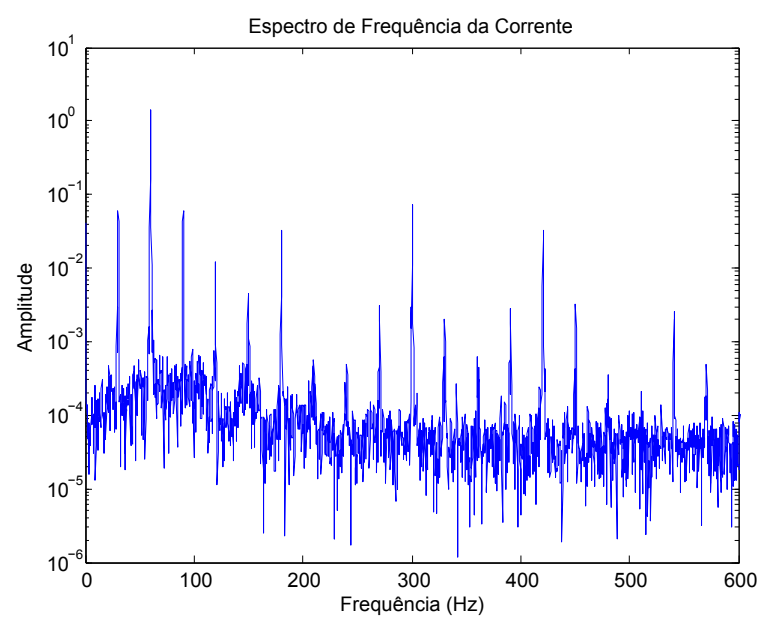

(b) Análise espectral da corrente de linha "a".

Figura 3.2: Análise espectral da tensão e corrente de linha "a" do MIT normal sob carga de $1,0 \mathrm{Nm}$.

\subsection{Rotor Normal - Acionamento por Inversor de Frequência}

Neste ensaio, partiu-se o MIT até o seu regime permanente utilizando-se de um inversor de frequência trifásico. Por meio de comandos de configuração do inversor, ajustou-se a frequência síncrona de alimentação entre $40 \mathrm{~Hz}$ e $60 \mathrm{~Hz}$. Para cada caso, o torque de carga aplicado ao eixo do MIT foi ajustado entre 0,5 $\mathrm{Nm}$ e 4,0 $\mathrm{Nm}$.

A Figura 3.3 ilustra os gráficos de tensão de uma das linhas e as correntes de linha trifásicas para o caso em que a frequência fora ajustada para $60 \mathrm{~Hz}$, sendo que o torque de carga aplicado foi de 1,0 $\mathrm{Nm}$.

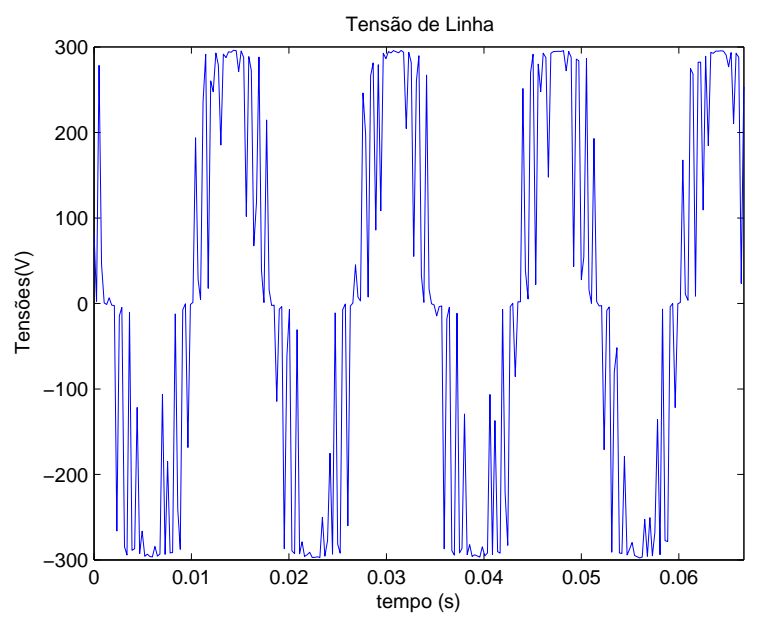

(a) Tensão de linha aplicada ao MIT.

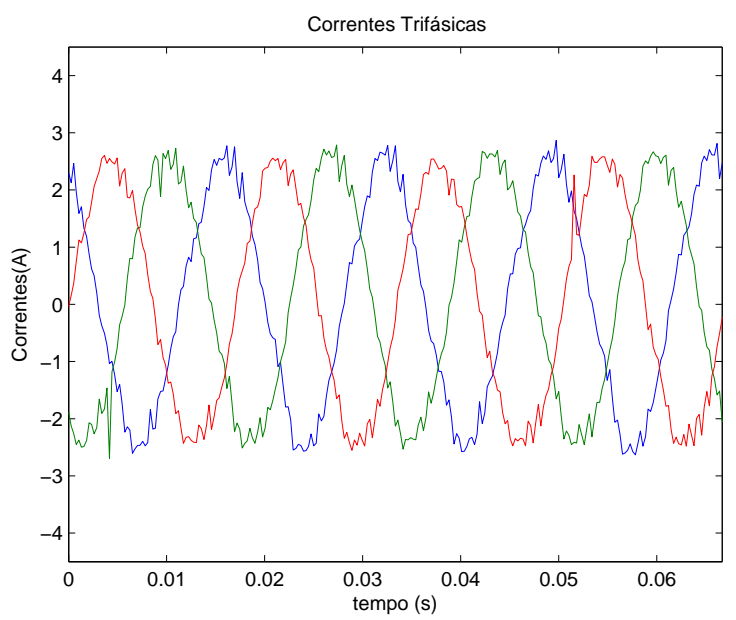

(b) Correntes de linha trifásicas do MIT.

Figura 3.3: Tensões e correntes trifásicas do MIT normal sob frequência síncrona de $60 \mathrm{~Hz}$ e carga de $1,0 \mathrm{Nm}$. 
Conforme pode ser observado na Figura 3.3(a), a tensão de linha apresenta formato distinto de uma onda senoidal, uma vez que o acionamento é realizado por meio da tensão PWM. Em virtude da frequência de amostragem ser de $3,84 \mathrm{kHz}$, o formato da onda quadrada com ciclo de trabalho variável não foi perfeitamente capturado. Além disso, há a distorção da própria resposta em frequência do sensor de tensão.

Por outro lado, a Figura 3.3(b) ilustra as correntes de linha trifásicas do estator. A indutância da máquina por si só consiste de um filtro passa baixa, preservando a frequência fundamental da tensão de acionamento. Nota-se que o sinal de corrente é mais ruidoso que a corrente de acionamento direto da rede elétrica, conforme a Figura 3.1(b).

A Figura 3.4 ilustra a análise espectral de uma das tensões e correntes de linha, aplicando-se a FFT. Conforme o esperado, a frequência dominante do sinal é de $60 \mathrm{~Hz}$.

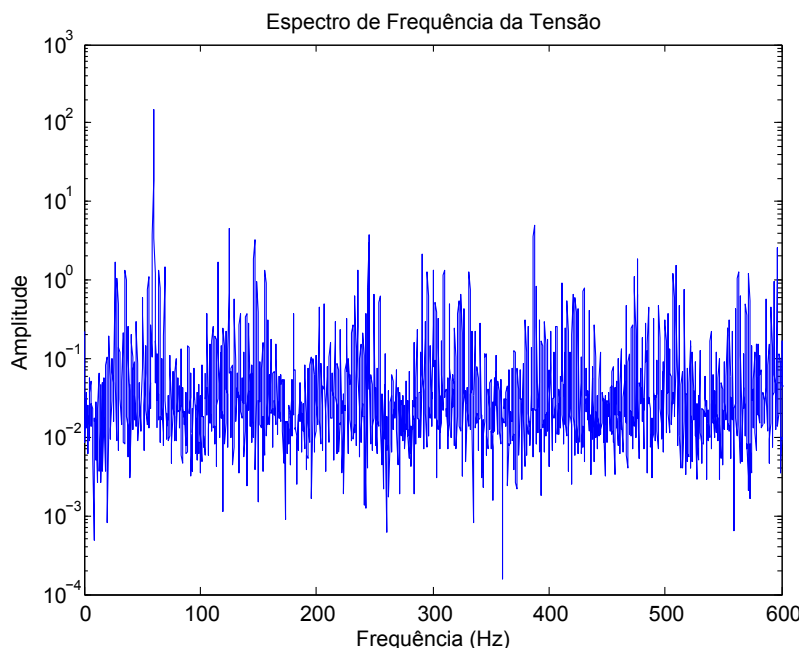

(a) Análise espectral da tensão de linha "a".

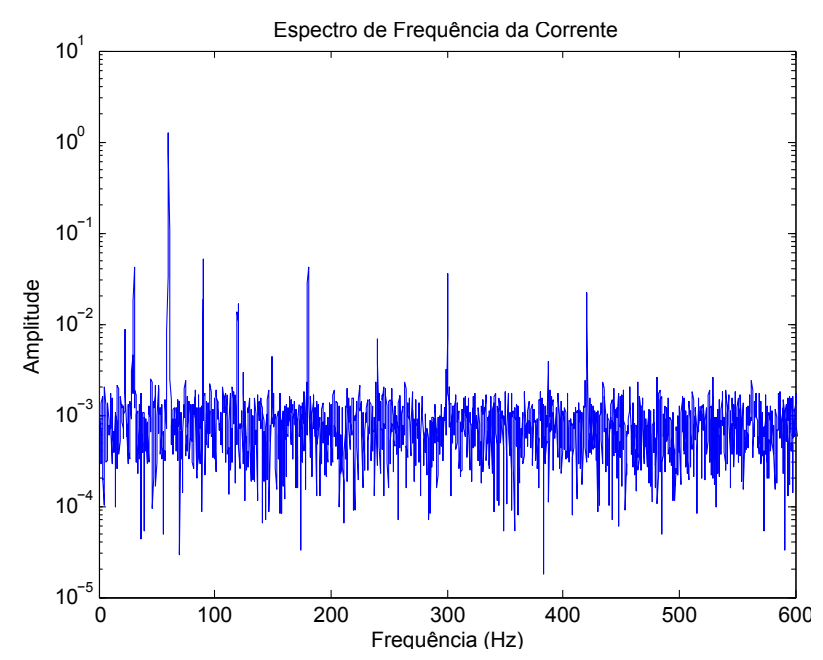

(b) Análise espectral da corrente de linha "a".

Figura 3.4: Análise espectral da tensão e corrente de linha "a" do MIT normal sob frequência síncrona de $60 \mathrm{~Hz}$ e carga de 1,0 Nm.

A distorção no espectro observado na Figura 3.4(a) é devido ao efeito de aliasing das componentes de altas frequências da tensão PWM que refletem nas baixas frequências, visto que a taxa de aquisição é de apenas $3,84 \mathrm{kHz}$.

Mediante a observação da Figura 3.4(b), nota-se aqui que há mais componentes de frequência que se evidencia em virtude do chaveamento do inversor. Ainda assim, ficam evidentes as componentes de frequência de $30 \mathrm{~Hz}$ e $90 \mathrm{~Hz}$.

A Figura 3.5 ilustra a análise espectral de tensão e corrente de linha do motor acionado com frequência síncrona de $40 \mathrm{~Hz}$. Mediante a análise da Figura 3.5(b), observa-se que além da frequência da componente fundamental de $40 \mathrm{~Hz}$, notam-se duas componentes que se sobressaem, isto é, $20 \mathrm{~Hz}$ e $60 \mathrm{~Hz}$. De maneira similar aos casos anteriores, observa-se que ambas são $50 \%$ para mais e para menos da componente fundamental. 


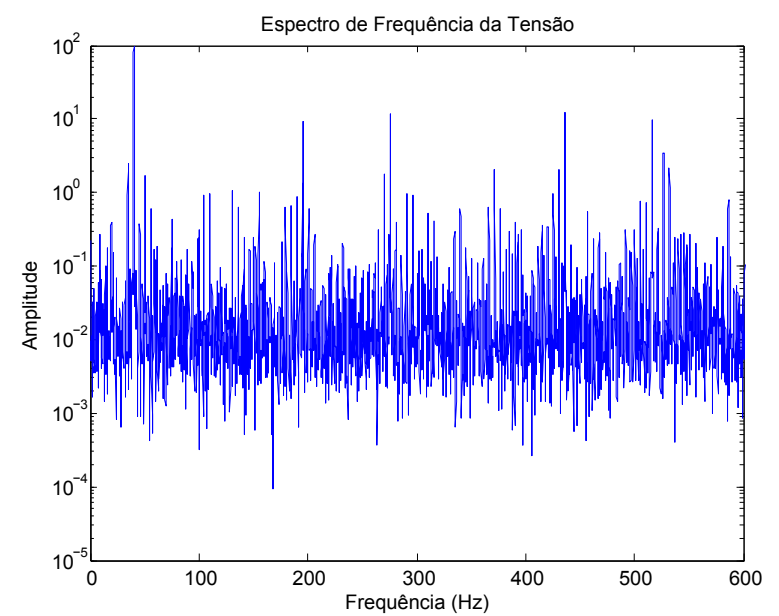

(a) Análise espectral da tensão de linha "a".

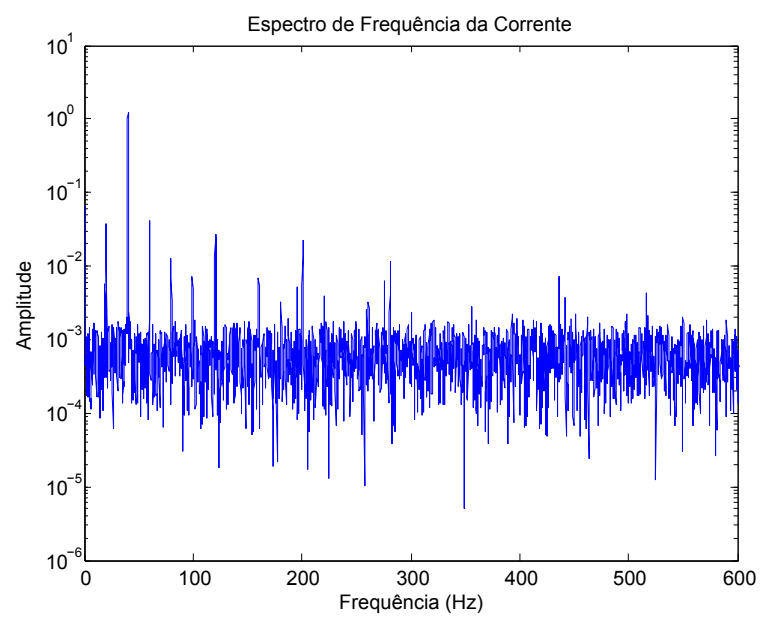

(b) Análise espectral da corrente de linha "a".

Figura 3.5: Análise espectral da tensão e corrente de linha "a" do MIT normal sob frequência síncrona de $40 \mathrm{~Hz}$ e carga de 1,0 Nm.

\subsection{Rotor com 1 Barra Quebrada - Acionamento Direto}

De maneira similar à Subseção 3.2, partiu-se o MIT até o seu regime permanente com tensão nominal de linha de $220 \mathrm{~V}$. Em seguida, aplicaram-se torque de cargas entre 0,5 Nm e 4,0 Nm em seu eixo. A Figura 3.6 ilustra os primeiros ciclos dos sinais de tensões e correntes trifásicas de um MIT sob torque de carga de 1,0 Nm.

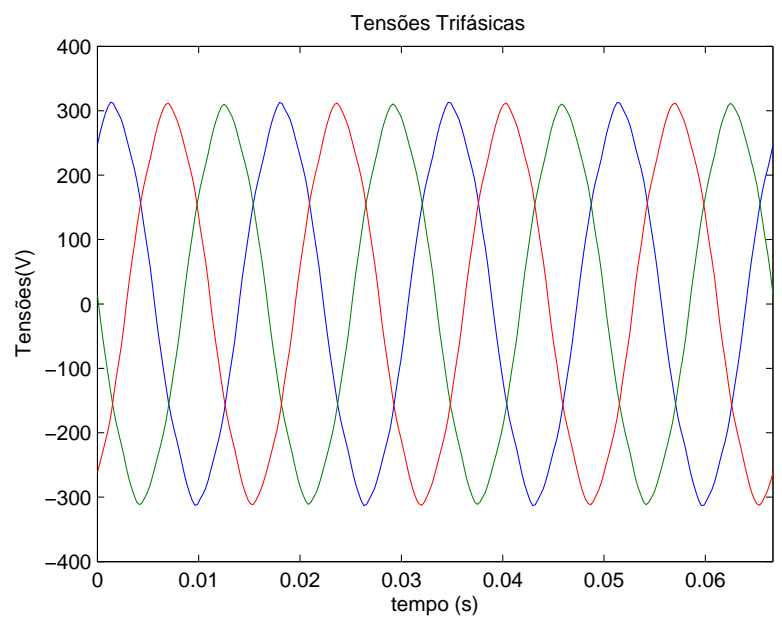

(a) Tensões trifásicas do MIT.

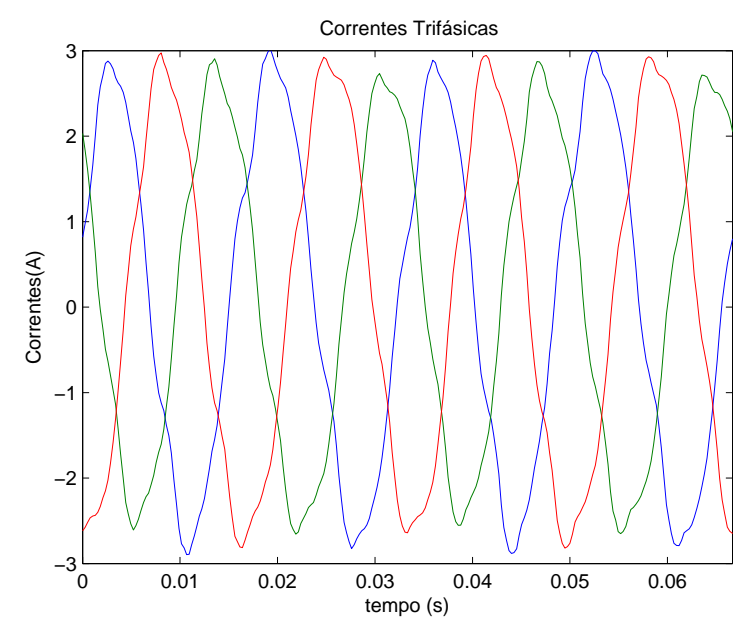

(b) Correntes trifásicas do MIT.

Figura 3.6: Tensões e correntes trifásicas do MIT com 1 barra quebrada sob carga de $1,0 \mathrm{Nm}$.

Nota-se que a corrente do estator de um motor com 1 barra de rotor quebrada é imperceptivelmente distinta de um rotor normal, quando se compara à Figura 3.1(b) 
e à Figura 3.6(b). A partir da observação da análise espectral do sinal de tensão e corrente, sobressaem-se, além da componente fundamental, as frequências de $30 \mathrm{~Hz}$ e $90 \mathrm{~Hz}$, conforme à Figura 3.7.

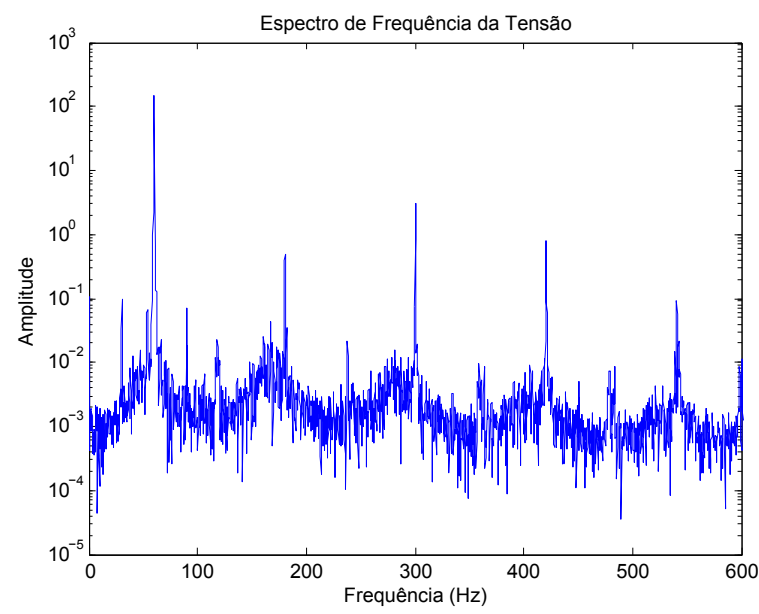

(a) Análise espectral da tensão de linha "a".

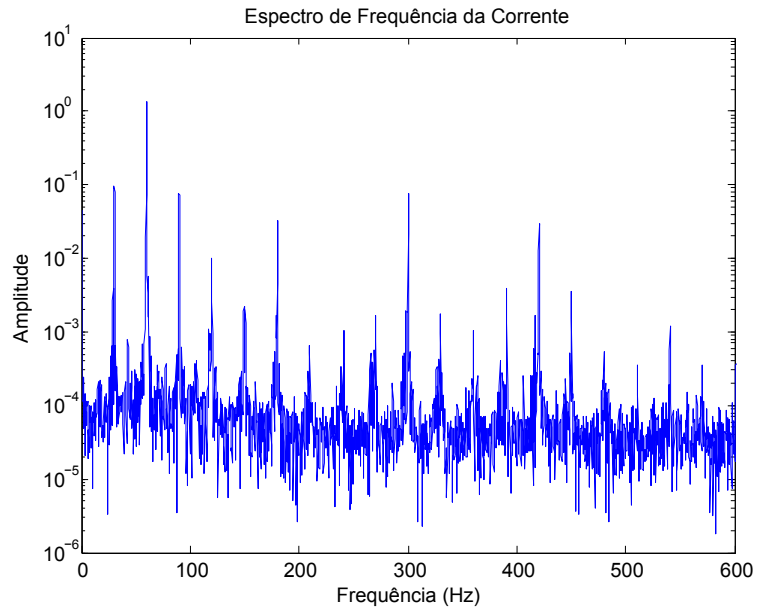

(b) Análise espectral da corrente de linha "a".

Figura 3.7: Análise espectral da tensão e corrente de linha "a" do MIT com 1 barra quebrada sob carga de 1,0 Nm.

\subsection{Rotor com 1 Barra Quebrada - Acionamento por Inversor de Frequência}

De forma idêntica aos ensaios realizados na Subseção 3.3, acionou-se o MIT até o seu regime permanente empregando-se o inversor trifásico. Ajustou-se a frequência síncrona

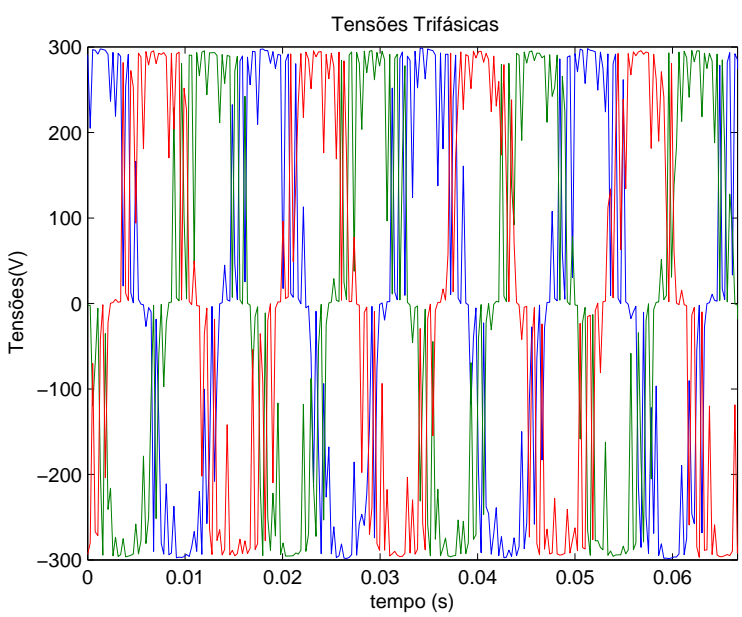

(a) Tensões trifásicas do MIT.

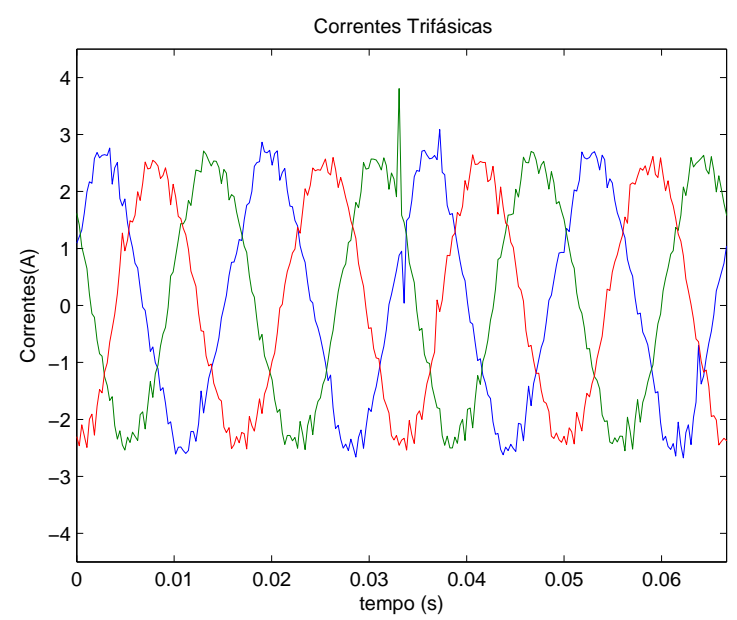

(b) Correntes trifásicas do MIT.

Figura 3.8: Tensões e correntes trifásicas do MIT com 1 barra quebrada sob frequência síncrona de $60 \mathrm{~Hz}$ e carga de 1,0 Nm. 
da tensão de alimentação entre $40 \mathrm{~Hz}$ e $60 \mathrm{~Hz}$. Para cada situação, o torque de carga aplicado ao eixo do MIT foi ajustado entre 0,5 Nm e 4,0 Nm.

A Figura 3.8 ilustra os gráficos das tensões e correntes trifásicas do MIT acionado por uma frequência síncrona de $60 \mathrm{~Hz}$.

Conforme pode ser observado na Figura 3.8(b), nota-se que, visualmente, é extremamente difícil de verificar as diferenças de sinais entre um rotor normal e um rotor com barra quebrada.

A Figura 3.9 ilustra a análise espectral de tensão e corrente de linha do motor acionado com frequência síncrona de $60 \mathrm{~Hz}$.

Mediante a análise espectral da assinatura de corrente de linha do estator, ilustrado na Figura 3.9(b), observa-se que o seu comportamento apresentou característica semelhante ao ensaio do rotor normal.

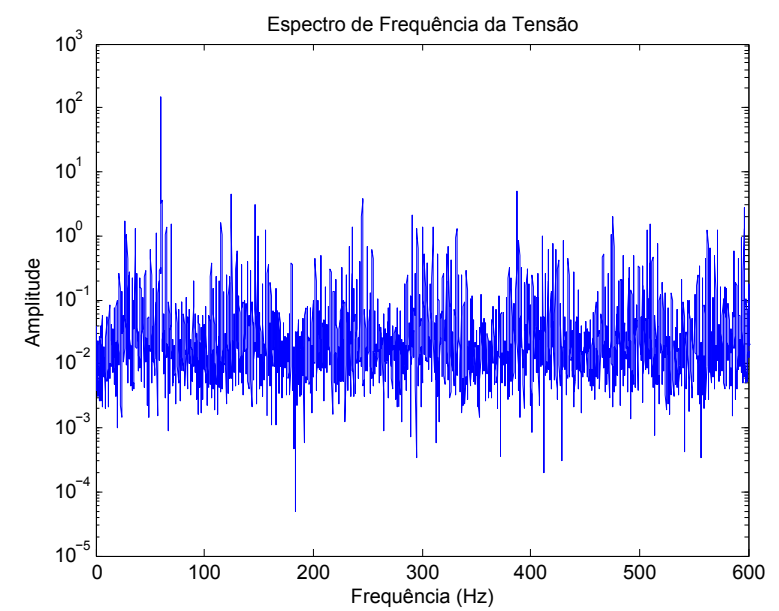

(a) Análise espectral da tensão de linha "a".

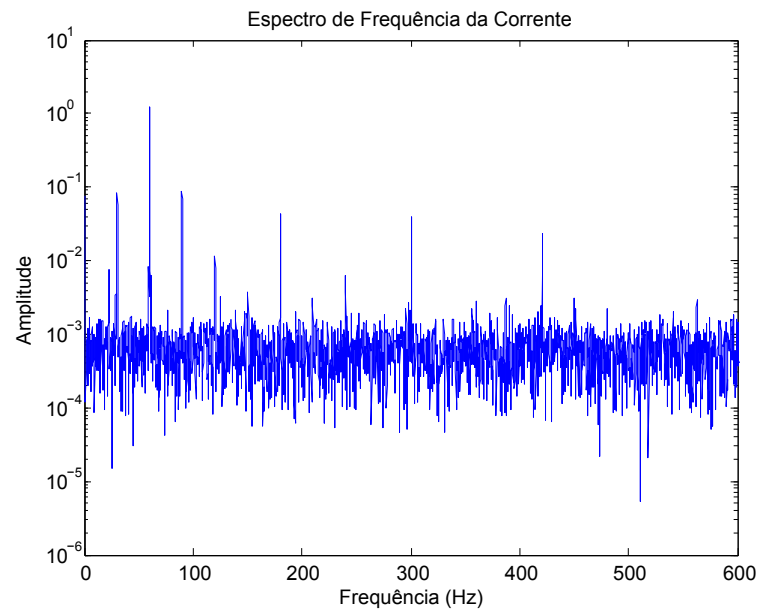

(b) Análise espectral da corrente de linha "a".

Figura 3.9: Análise espectral da tensão e corrente de linha "a" do MIT com 1 barra quebrada sob frequência síncrona de $60 \mathrm{~Hz}$ e carga de 1,0 Nm.

\subsection{Rotor com 4 Barras Quebradas - Acionamento Direto}

De maneira similar aos experimentos anteriores, partiu-se o MIT até o seu regime permanente com tensão nominal de linha de 220 V. Em seguida, aplicaram-se torque de cargas entre $0,5 \mathrm{Nm}$ e $4,0 \mathrm{Nm}$ em seu eixo.

A Figura 3.10(a) ilustra a análise espectral da corrente de linha "a" de um MIT normal, com alimentação da rede de $220 \mathrm{~V}$ e 1,0 Nm de torque de carga. Por outro lado, a Figura 3.10(b) representa a curva espectral da corrente de linha "a" referente à operação de um MIT com 4 barras de rotores consecutivamente seccionadas. 


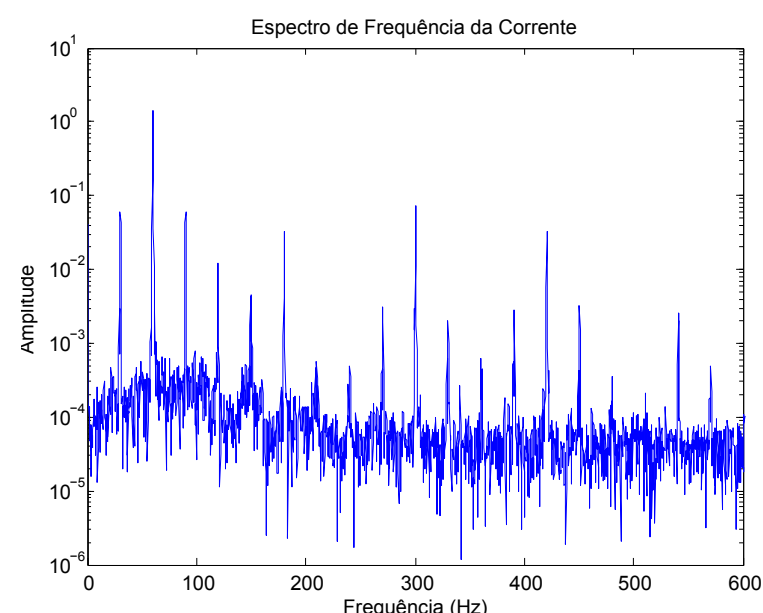

(a) Análise espectral da corrente de linha "a" de um MIT normal.

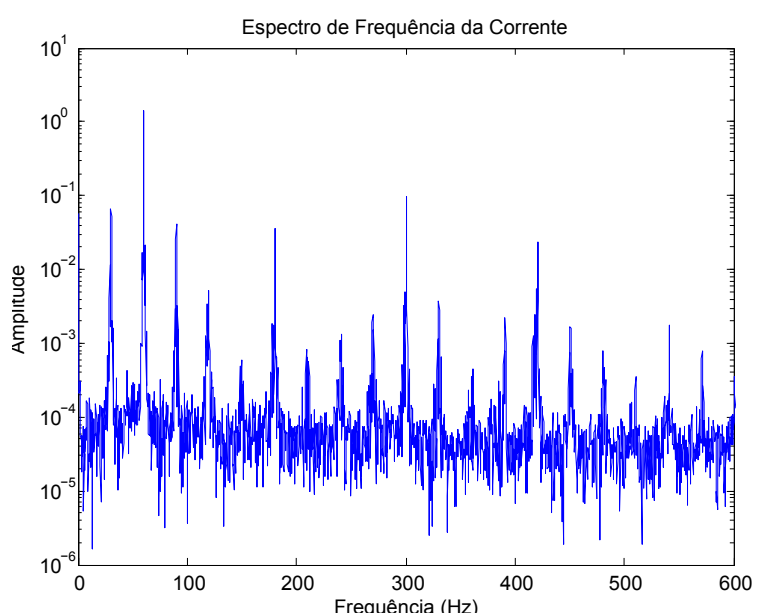

(b) Análise espectral da corrente de linha "a" de um MIT com 4 barras quebradas.

Figura 3.10: Análise espectral da corrente de linha "a" de um MIT normal e com 4 barras quebradas acionado pela tensão da rede.

\subsection{Rotor com 4 Barras Quebradas - Acionamento por Inversor}

De forma idêntica aos ensaios realizados nas seções anteriores, acionou-se o MIT até o seu regime permanente empregando-se o inversor trifásico da WEG. Ajustou-se a frequência síncrona da tensão de alimentação entre $40 \mathrm{~Hz}$ e $60 \mathrm{~Hz}$. Para cada situação, o torque de carga aplicado ao eixo do MIT foi ajustado entre 0,5 Nm e 4,0 Nm. A Figura 3.11 ilustra os gráficos das análises espectrais da corrente de linha "a" do MIT acionado por uma frequência síncrona de $60 \mathrm{~Hz}$ e 1,0 Nm de torque de carga.

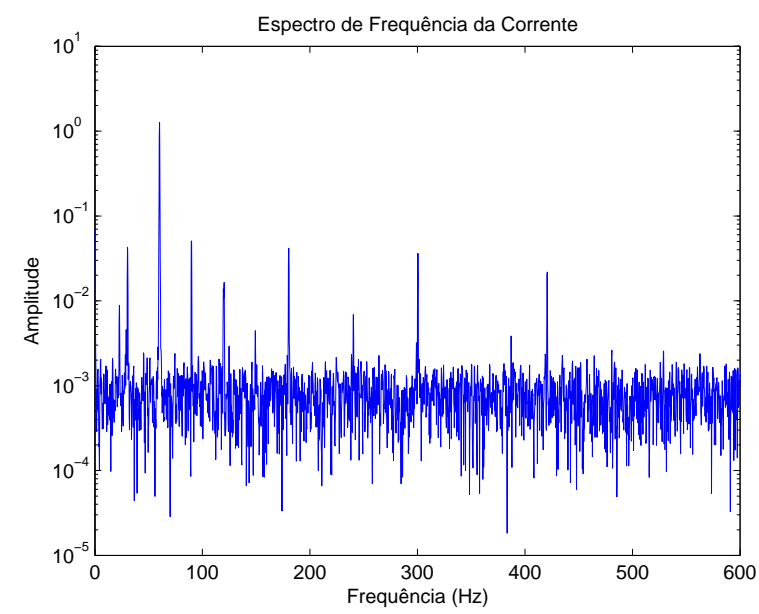

(a) Análise espectral da corrente de linha "a" de um MIT normal.

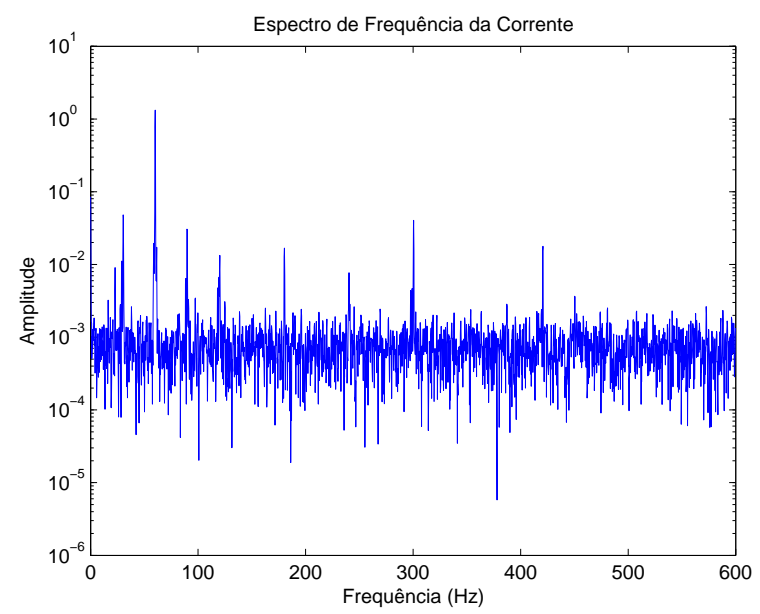

(b) Análise espectral da corrente de linha "a" de um MIT com 4 barras quebradas.

Figura 3.11: Análise espectral da corrente de linha "a" de um MIT normal e com 4 barras quebradas acionado pelo inversor. 


\subsection{Curto-Circuito no Estator}

O ensaio experimental para aquisição de dados experimentais de curto-circuito foi aqui realizado, partindo-se o MIT até o seu regime permanente e aplicando-se tanto a tensão da rede equilibrada de $220 \mathrm{~V}$ quanto a tensão proveniente do inversor trifásico da WEG. Em ambos os tipos de acionamento, variou-se o torque de carga de 0,5 $\mathrm{Nm}$ até $4 \mathrm{Nm}$ no degrau de 0,5 Nm. O inversor trifásico foi acionado variando-se a frequência síncrona de $40 \mathrm{~Hz}$ até $60 \mathrm{~Hz}$. No instante em que o MIT atinge a operação de regime permanente, aciona-se então a chave para efetuar a combinação de curto-circuito entre as bobinas do enrolamento do estator.

A Figura 3.12 ilustra os resultados das correntes trifásicas da operação do MIT em curto-circuito.

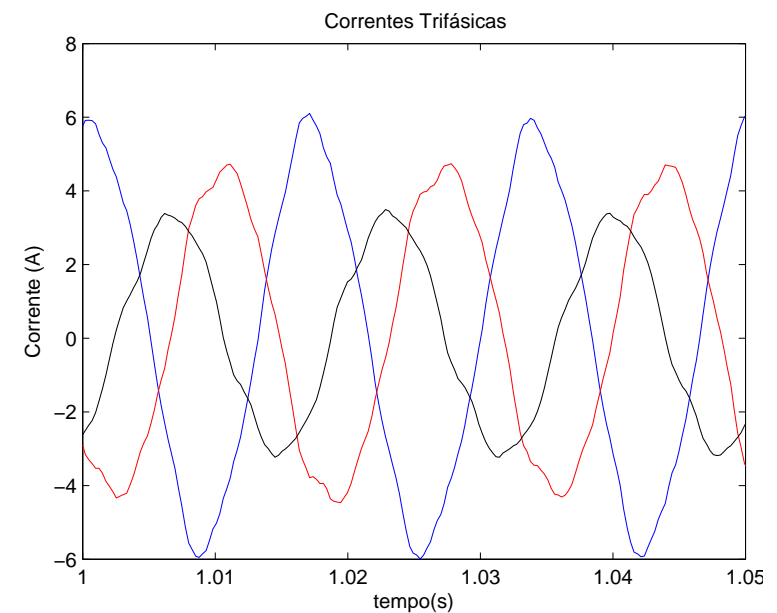

(a) Correntes trifásicas do MIT acionado pela rede $220 \mathrm{~V}$.

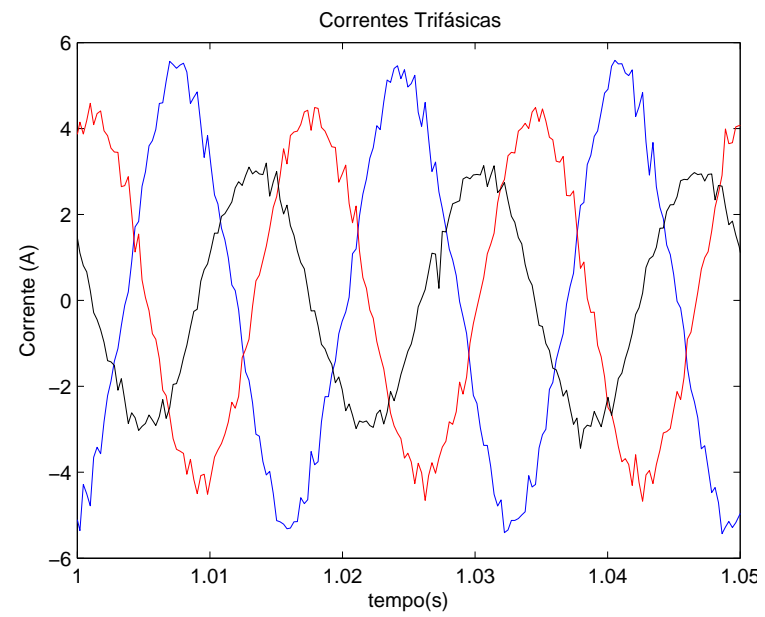

(b) Correntes trifásicas do MIT acionado pelo inversor em $60 \mathrm{~Hz}$.

Figura 3.12: Correntes trifásicas do MIT operando sob falha de curto circuito a 1,0 Nm.

Por meio das observações da Figura 3.12, nota-se que as correntes de linha circulantes no motor se tornam desequilibradas. Comparando-se com os valores de operações normais, o módulo de duas das correntes são superiores, atingindo-se valores de pico de aproximadamente $4.2 \mathrm{~A}$ (vermelho) e $5.7 \mathrm{~A}$ (azul). Ao contrário dos resultados encontrados na avaliação de dados de quebra nas barras de rotores, a falha de curto-circuito pode ser verificada facilmente no gráfico.

A análise espectral dos sinais da corrente de linha "a" para o acionamento direto da rede, assim como para o inversor trifásico, pode ser observado na Figura 3.13

\subsection{Rolamento Defeituoso}

De maneira similar, os ensaios experimentais para a aquisição da base de dados de falhas em rolamentos foram então realizados, partindo-se o MIT até o seu regime permanente de 


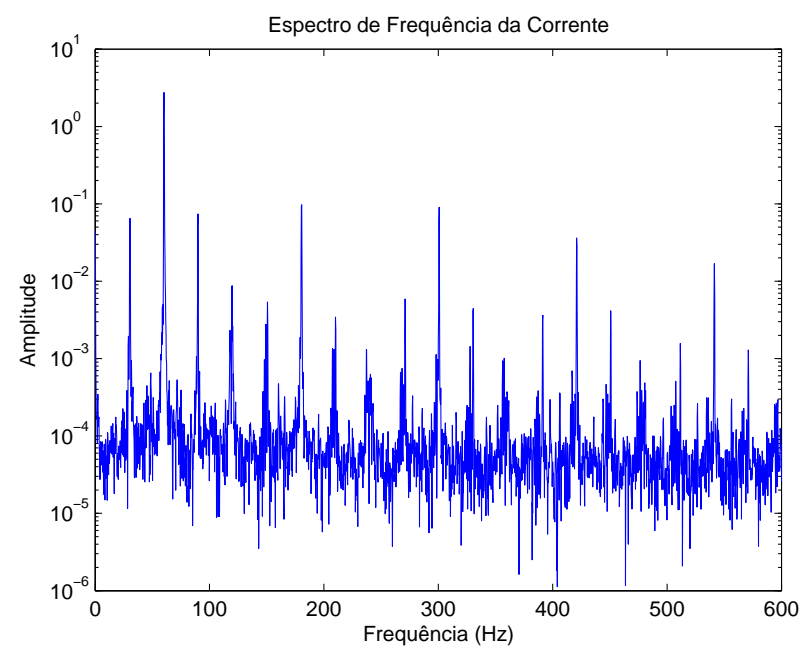

(a) Acionamento da rede $220 \mathrm{~V}$.

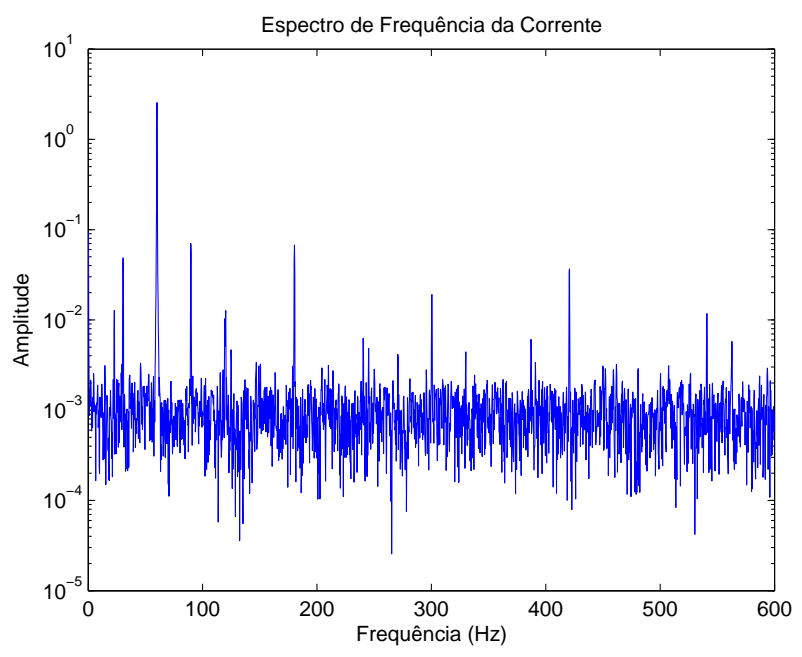

(b) Acionamento pelo inversor trifásico em $60 \mathrm{~Hz}$.

Figura 3.13: Análise espectral da corrente de linha "a" de um MIT operando sob curtocircuito a 1,0 $\mathrm{Nm}$ de torque de carga.

operação. Variou-se o torque de carga de 0,5 Nm até $4 \mathrm{Nm}$, sendo acionado pela tensão da rede em $220 \mathrm{~V}$ e pelo inversor trifásico da WEG, entre as frequências de $30 \mathrm{~Hz}$ a $60 \mathrm{~Hz}$. Ressalta-se que para realizar este ensaio, o motor foi desmontado trocando-se o rolamento original por um rolamento defeituoso advindo de desgaste natural em ambientes industriais.

A Figura 3.14 ilustra a análise espectral da corrente de linha "a" de um MIT operando sob falha no rolamento a 1,0 Nm. Outro aspecto relevante a ser mencionado consiste no fato de que durante este ensaio, o ruído gerado pelo motor foi muito superior em relação aos outros experimentos realizados, evidenciando-se então o defeito no rolamento.

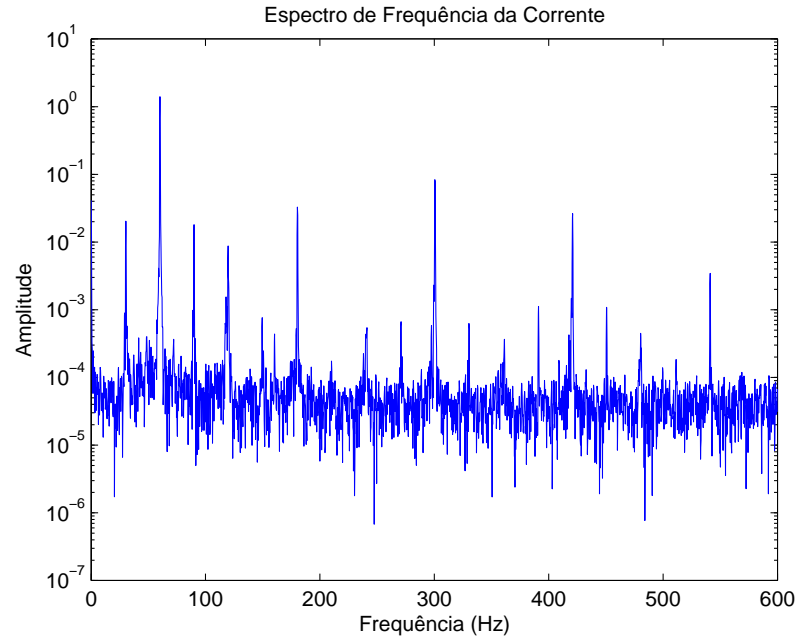

(a) Acionamento da rede de $220 \mathrm{~V}$.

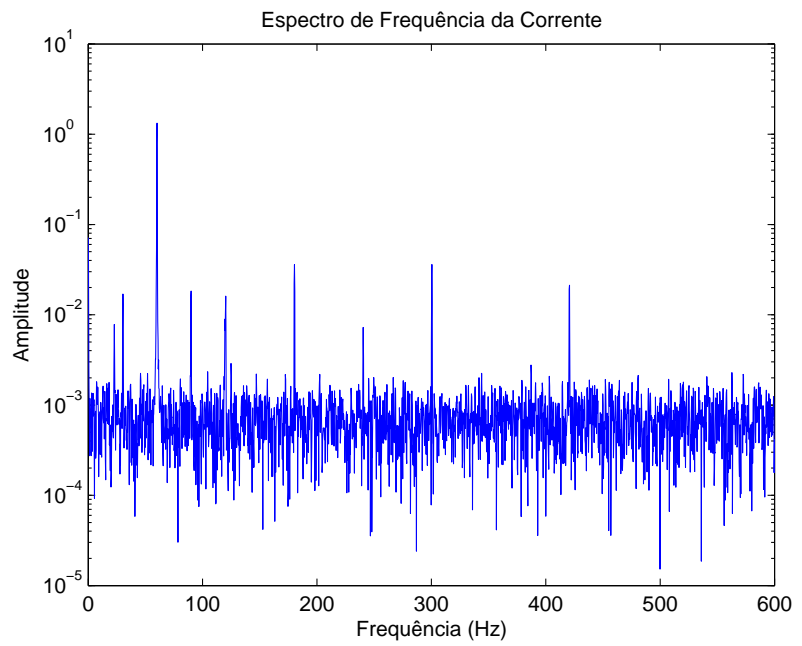

(b) Acionamento pelo inversor trifásico em $60 \mathrm{~Hz}$.

Figura 3.14: Análise espectral da corrente de linha "a" de um MIT operando sob falha no rolamento a 1,0 $\mathrm{Nm}$ de torque de carga. 
A Figura 3.15 ilustra a imagem termográfica da bancada de experimento adquirida durante e ao final dos ensaios experimentais de falhas no rolamento do MIT. O rolamento defeituoso se situa na parte direita do MIT no qual se acopla a carga. Mediante as observações das Figuras 3.15(a) e 3.15(b), nota-se se que o corpo do MIT é mais aquecido em relação às demais regiões. A lateral esquerda do motor é fria em virtude da ventilação forçada que está acoplada ao seu eixo. Observa-se também que a parte em que se localiza o rolamento também provoca aquecimento, o que pode ser evidenciado na Figura 3.15(c), observando-se o acoplamento do GCC.

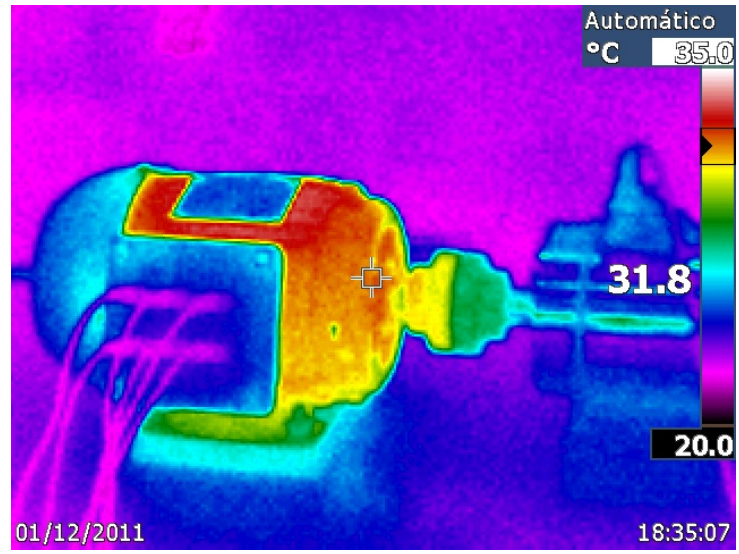

(a) Vista da termografia do MIT.

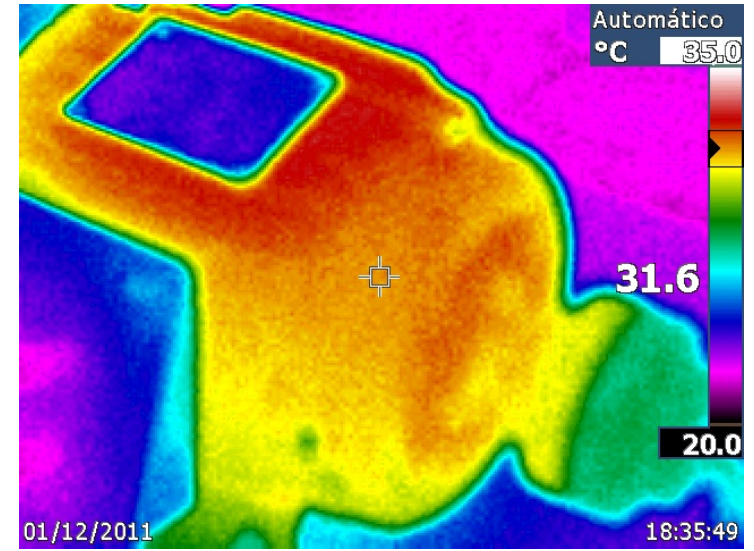

(b) Visão em detalhes do MIT.

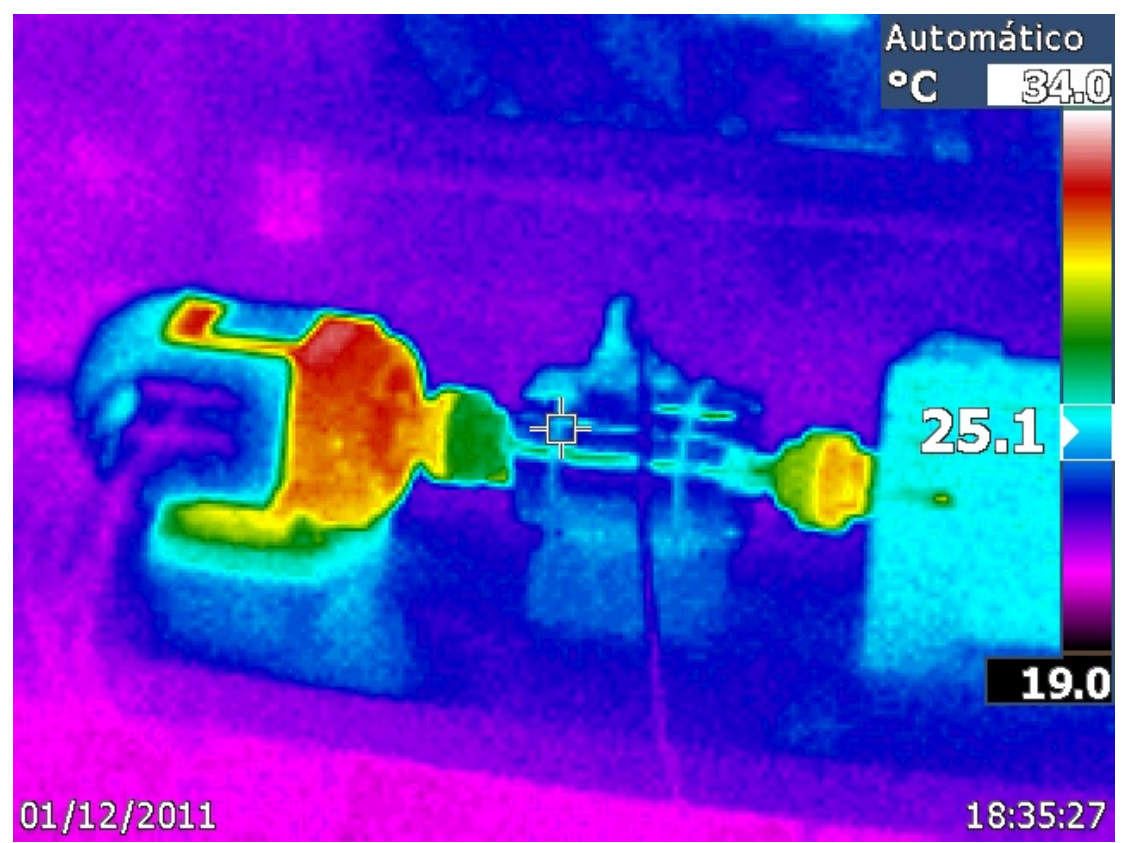

(c) Vista geral da bancada de experimento.

Figura 3.15: Imagem termográfica da bancada de experimento durante o ensaio de falha no rolamento. 


\subsection{Motor de Alto Rendimento}

Finalmente, com o intuito de aumentar a base de dados de motores saudáveis e que tenha construção distinta, efetuou-se também ensaios experimentais com motores de alto rendimento. As características de placa são basicamente as mesmas do motor comum utilizado nesta tese. Os ensaios executados neste MIT são similares àqueles realizados nos outros experimentos, em que se parte o motor até o seu regime variando-se a carga de 0,5 Nm até 4,0 Nm. Consideraram-se também tanto o acionamento pela rede com tensão $220 \mathrm{~V}$ equilibrada quanto acionamento pelo inversor trifásico operando sob frequências entre $40 \mathrm{~Hz}$ e $60 \mathrm{~Hz}$.

A Figura 3.16 ilustra a análise espectral da corrente de linha "a" do MIT de alto rendimento operando a 1,0 $\mathrm{Nm}$ de torque de carga.

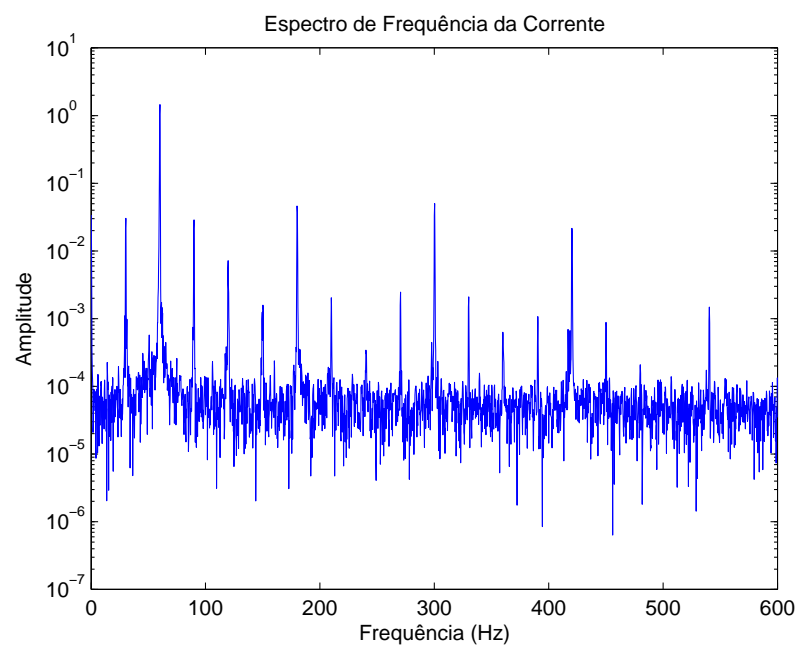

(a) Acionamento pela rede de $220 \mathrm{~V}$.

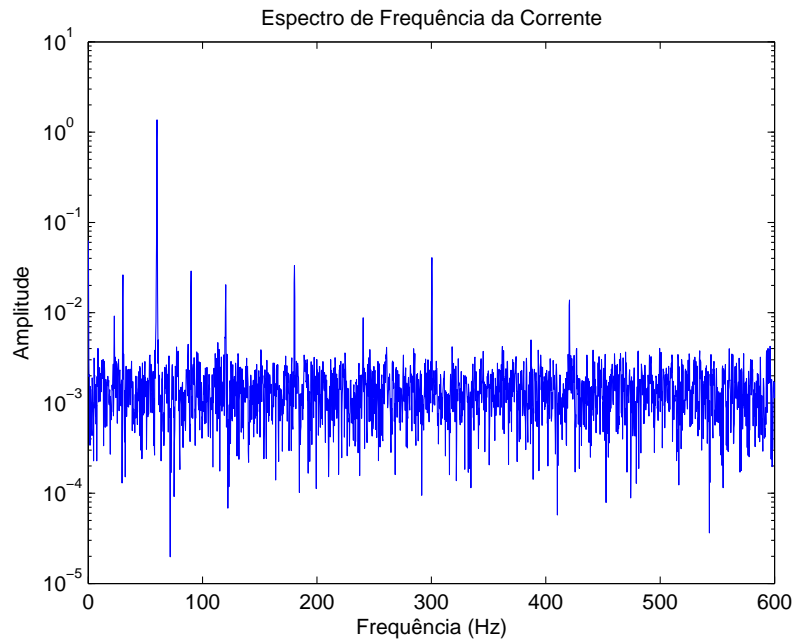

(b) Acionamento pelo inversor em $60 \mathrm{~Hz}$.

Figura 3.16: Análise espectral da corrente de linha "a" de um MIT de alto rendimento operando sob condições normais a 1,0 Nm de torque de carga. 


\section{Capítulo 4}

\section{Fundamentos de Redes Neurais}

\section{Artificiais e Processamento de Sinais}

\subsection{Redes Neurais Artificiais}

As RNAs, em linhas gerais, são modelos computacionais inspirados no funcionamento do sistemas nervosos biológicos. São compostas por unidades de processamento associadas a alguns pesos, representando, respectivamente, os neurônios e as conexões sinápticas nas redes neurais biológicas. Todo conhecimento adquirido é propagado por todos os neurônios de maneira a alterar-lhes os pesos sinápticos. O treinamento ou aprendizagem é realizado a fim de reajustar os pesos sinápticos ao longo da rede de neurônios até que esta forneça respostas em suas saídas que sejam compatíveis a um conjunto de estímulos (entradas) predeterminado. Dessa forma, os pesos sinápticos da RNA são balanceados até que se obtenham padrões de respostas aos estímulos, os quais sejam coerentes com aqueles valores que se desejam (HAYKIN, 1999; SILVA; SPATTI; FLAUZINO, 2010).

\subsubsection{Principais Características}

As RNAs são capazes de lidar com problemas que contém grandes volumes de variáveis e conjunto de dados. Apresentam também a habilidade de mapear sistemas não lineares e variantes no tempo, requerendo aqui pouca informação sobre eventuais modelos analíticos que regem o processo. A RNA é capaz de criar o seu próprio critério e sofrer transformações internas mediante o algoritmo de treinamento a qual é submetida. Esta característica é fundamental no que se diz respeito à modelagem de sistemas complexos, pois é dispendioso ou até mesmo impossível de se chegar a uma expressão analítica a fim de se poder definir as regras para confeccionar o algoritmo convencional. As principais características das RNAs são listadas brevemente em tópicos a seguir (SILVA; SPATTI; FLAUZINO, 2010):

$\square$ Capacidade de aprendizagem: mediante a apresentação de um conjunto de amostras de treinamento, a RNA ajusta os seus parâmetros internos, tipicamente 
os pesos sinápticos, adaptando-se ao comportamento do processo.

$\square$ Capacidade de se adaptar: em sistemas variantes no tempo, a RNA apresenta a capacidade de se adaptar às mudanças no comportamento do fenômeno, sem a necessidade de se realizar quaisquer ajustes estruturais internos, já que a rede é capaz de se reorganizar mediante apresentação de novos padrões de treinamento.

$\square$ Capacidade de generalização: a RNA é capaz de efetuar o mapeamento do relacionamento existente entre os conjuntos de amostras e generalizar o conhecimento para casos desconhecidos, isto é, aqueles que não participaram do processo de treinamento. Em outras palavras, a rede tipicamente desenvolve regras internas generalizadas que representam o comportamento do processo.

$\square$ Agrupar ou organizar dados e informações: a RNA apresenta a capacidade de extrair características intrínsecas de um determinado conjunto de informações, a fim de reorganizar sua estrutura interna, visando o agrupamento de padrões que apresentam similaridades.

\ Tolerância às falhas: em virtude do conhecimento condizente a um determinado processo ser distribuído por inúmeros neurônios artificiais e conexões sinápticas, mesmo que parte de sua estrutura seja corrompida, a RNA não se torna inoperante, fato este que incrementa sua robustez.

$\square$ Facilidade de prototipagem: tipicamente, a implementação de uma RNA pode ser desenvolvida facilmente em software e ser embarcado em um hardware dedicado. Após a realização do treinamento, seus resultados podem ser obtidos mediante operações matemáticas elementares.

\subsubsection{Aplicações Gerais das RNAs}

Existem, atualmente, diversas aplicações utilizando RNAs em áreas de variadas disciplinas. Algumas áreas dessas aplicações serão apresentadas a seguir (SILVA; SPATTI; FLAUZINO, 2010):

$\square$ Reconhecimento de padrões: tem como objetivo associar à cada amostra de entrada uma classe predefinida. Os principais campos de aplicação são os reconhecimentos de caracteres, voz, imagem, entre outros.

$\square$ Clustering/Categorização: consiste em explorar as semelhanças entre o conjunto de amostras de entrada e agrupar os padrões com características similares. A identificação automática de classes e compactação e garimpagem de dados são focos de aplicação. 
\ Aproximação de funções: basicamente consiste em efetuar o mapeamento funcional do relacionamento entre variáveis de entrada e saída mediante um conjunto de dados que constitui a representação de um determinado processo. Engloba os principais problemas de modelagem científica e de engenharia, realizando o mapeamento de processos cujo modelo analítico é desconhecido, muito complexo, ou de difícil obtenção.

- Previsão/estimação: a rede pode estimar e prever situações futuras por intermédio de um conjunto de exemplos referentes a intervalos de tempo decorridos anteriormente. Redes modeladas desta maneira são úteis em sistemas dinâmicos, na previsão do tempo e de mercados financeiros.

$\square$ Otimização: minimizar ou maximizar uma função sujeita a um conjunto de restrições. São aplicáveis em problemas de otimização restrita, problemas de programação dinâmica, etc.

$\square$ Memórias associativas: a rede é capaz de recuperar padrões corretos mesmo que a entrada seja parcial, incerta ou imprecisa. As áreas de aplicação são: processamento de imagens, transmissão de sinais, identificação de caracteres, etc.

Controle de processos: gerar entradas de controle para que o sistema siga trajetórias especificadas por modelos de referência. Geralmente, são aplicadas em sistemas de controle envolvidos com robótica, indústria de processos, manufatura, eletrodomésticos, etc.

\subsubsection{O Neurônio Artificial}

O primeiro modelo artificial para um neurônio biológico foi proposto pelo trabalho de Warren McCulloch, psiquiatra e neuroanatomista, e Walter Pitts, matemático, em 1943 (MCCULLOCH; PITTS, 1943). Em tal trabalho foram apresentados os conceitos de um neurônio como sendo uma unidade básica de processamento que receberia vários estímulos de entrada e, mediante uma soma ponderada destes, resultaria em uma reposta na saída (HAYKIN, 1999). A Figura 4.1 apresenta o diagrama ilustrativo de um neurônio artificial proposto por Mculloch e Pitts.

Os sinais $\left\{x_{1}, x_{2}, x_{3}, \ldots, x_{N}\right\}$ consistem de estímulos de entrada do neurônio e são provenientes do meio externo, tais como sinais de medidas de sensores. As variáveis $\left\{w_{1}\right.$, $\left.w_{2}, w_{3}, \ldots, w_{N}\right\}$ são valores que representam as conexões sinápticas e são empregados para ponderar cada uma das variáveis da rede, permitindo-se quantificar as relevâncias dos estímulos de entrada. O símbolo $\left(\sum\right)$ efetua a agregação dos sinais ponderados de entrada, ou seja, desenvolve a combinação linear entre os vetores de entrada e os vetores de pesos sinápticos. O limiar de ativação $(\theta)$ especifica o patamar de ativação para que o resultado do combinador linear possa produzir um valor de disparo para outro neurônio 


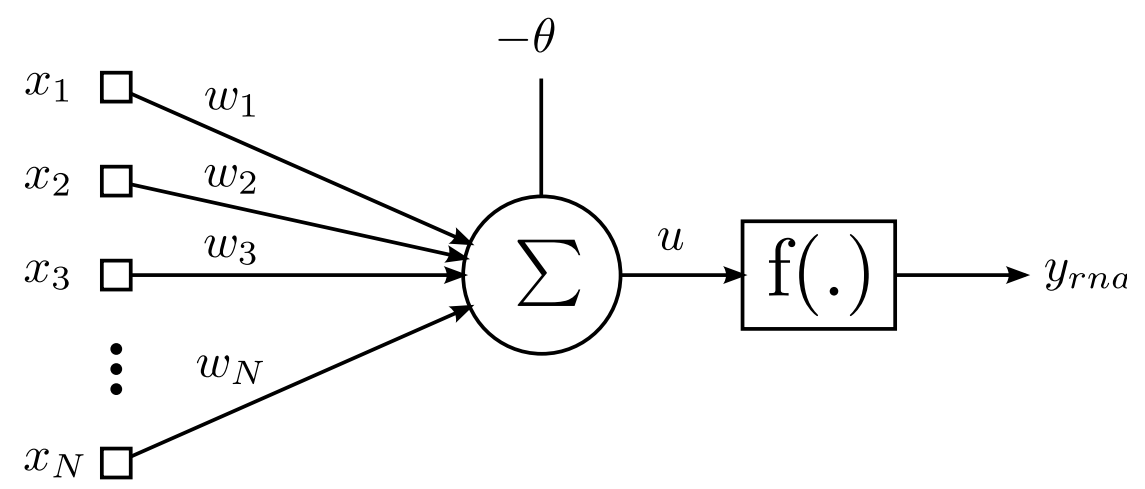

Figura 4.1: Neurônio Artificial.

na saída. O símbolo $u$ representa o potencial de ativação e é o resultado da diferença entre o limiar de ativação $(\theta)$ e a agregação dos sinais de entradas ponderados produzido pelo combinador linear $\left(\sum\right)$. A função $f($.$) refere-se à função de ativação que desenvolve o$ valor de saída do neurônio, cujo objetivo é limitar a saída em um intervalo determinado ou efetuar o mapeamento não linear (HAYKIN, 1999; SILVA; SPATTI; FLAUZINO, 2010).

O potencial de ativação $(u)$ é determinado matematicamente pela seguinte expressão:

$$
u=\sum_{i=1}^{N} w \cdot x_{i}-\theta
$$

A saída do neurônio é calculada mediante a função de ativação $f($.$) , conforme segue:$

$$
y_{r n a}=f(u)
$$

em que $y_{r n a}$ é a saída do neurônio.

\subsubsection{Funções de Ativação}

As principais funções de ativação das RNAs são aquelas do tipo linear, degraus ou sinais, e sigmoidal (HAYKIN, 1999; SILVA; SPATTI; FLAUZINO, 2010). As funções degraus ou sinais são funções descontínuas que retornam valores iguais a $y_{r n a}=0$ (degrau) ou $y_{r n a}=-1$ (sinal) para potenciais de ativação negativos $(u<0)$ e $y_{r n a}=1$ para $u \geq 0$, conforme segue:

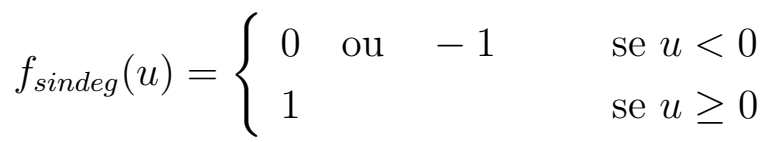

Tais funções de ativação são caracterizadas por não serem diferenciávéis em todo seu domínio e, normalmente, são empregadas para aplicações de classificação de padrões e pós-processamento de uma RNA.

As funções sigmóides são funções contínuas e diferenciáveis ao longo de todo seu domínio, as quais retornam valores no intervalo entre -1 e 1 para funções tangentes hiperbólicas 
e entre 0 e 1 para funções logísticas, conforme segue:

$$
\begin{aligned}
f_{\text {tanh }}(u) & =\frac{1-e^{-\beta \cdot u}}{1+e^{-\beta \cdot u}} \\
f_{\text {logsig }}(u) & =\frac{1}{1+e^{-\beta \cdot u}}
\end{aligned}
$$

em que $\beta$ é o parâmetro de inclinação. Essas funções são caracterizadas por possibilitar o mapeamento não linear e são muito empregadas em redes de múltiplas camadas neurais.

A função linear ou identidade produz resultados de saída equivalentes aos valores do pontencial de ativação $u$, sendo definida por:

$$
f_{\text {linear }}(u)=u
$$

A Figura 4.2 ilustra os formatos das funções de ativação do tipo sinal, tangente hiperbólica, logística e função linear.

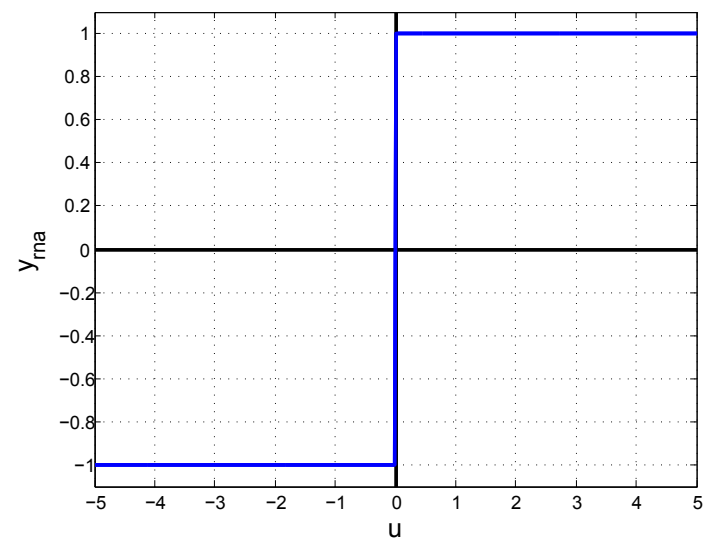

(a) Função sinal.

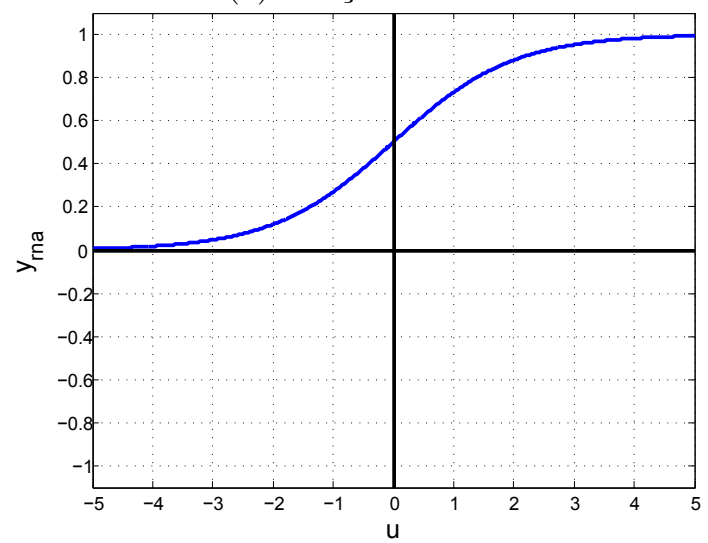

(c) Função logística.

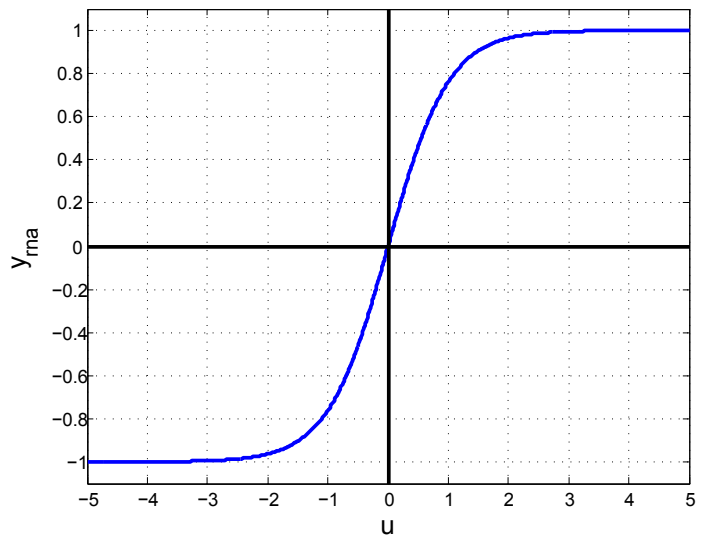

(b) Função tangente hiperbólica.

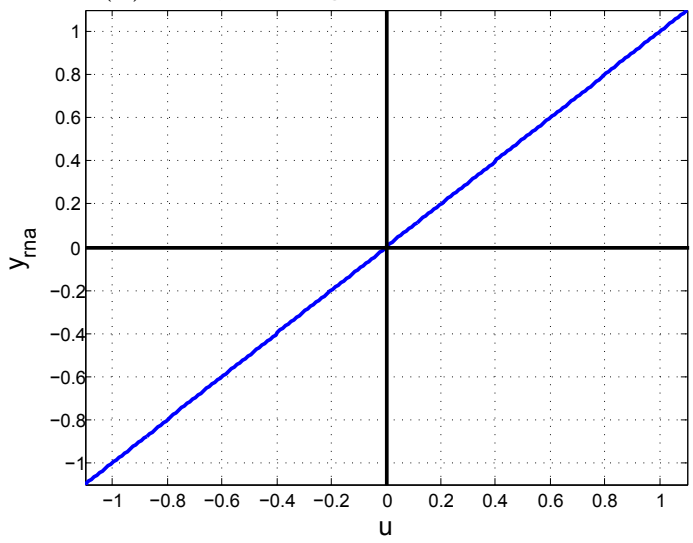

(d) Função linear.

Figura 4.2: Funções de ativação de um neurônio.

\subsubsection{Redes Perceptron Multicamadas}

A topologia de rede Perceptron Multicamadas é constituída de um sistema de neurônios interconectados por conexões sinápticas. Conforme ilustrado na Figura 4.3, os neurônios 
deste tipo de rede são organizados em camadas neurais (HAYKIN, 1999; SILVA; SPATTI; FLAUZINO, 2010).

Basicamente, podem-se identificar três tipos de camadas neurais: a camada de entrada, a camada oculta ou escondida (dividida em duas camadas na ilustração) e a camada de saída. A camada de entrada é responsável por receber os estímulos ou padrões do sistema ao qual a rede está conectada. A camada de entrada também é responsável por fornecer estes estímulos aos neurônios da primeira camada escondida. Desta maneira, os neurônios da camada de entrada não realizam operações com os estímulos de entrada da rede.

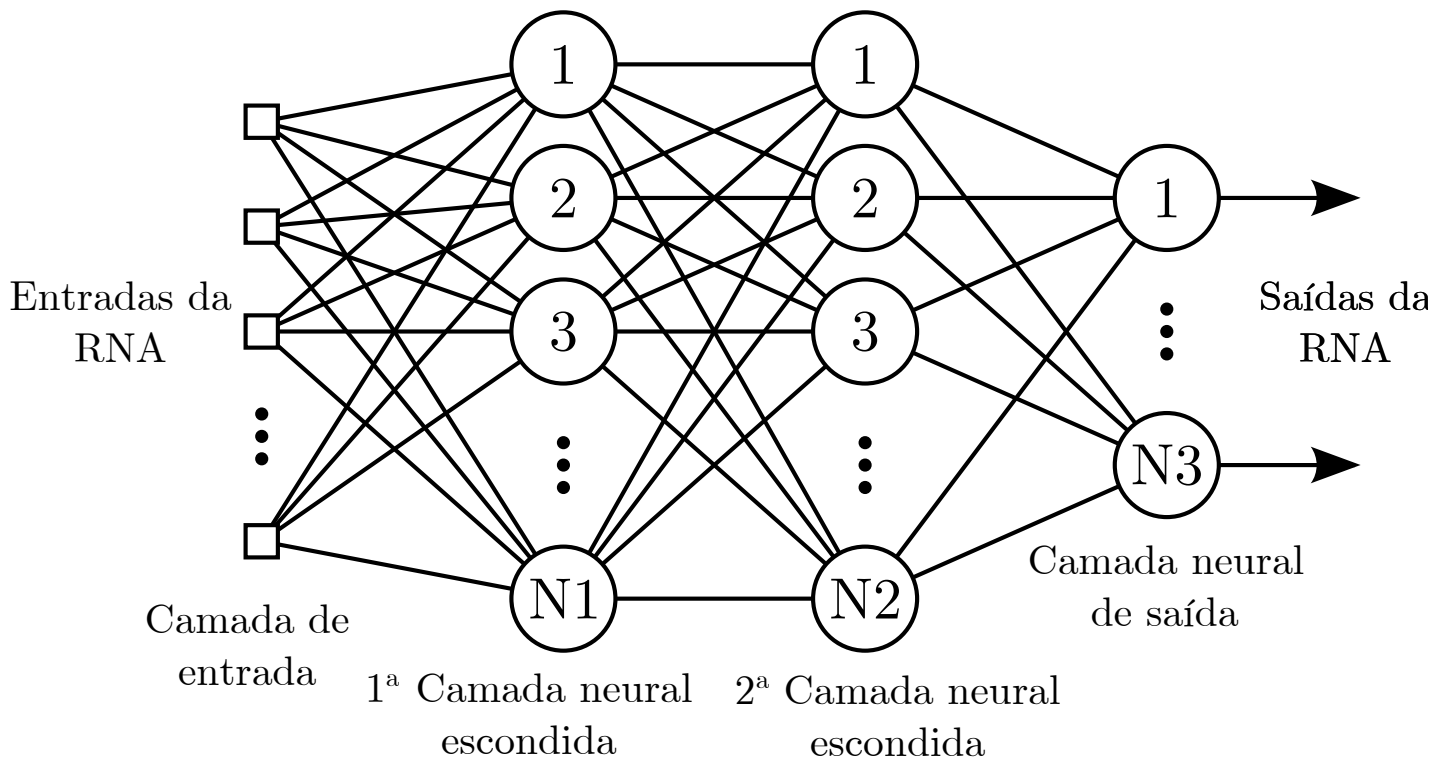

Figura 4.3: Ilustração da rede Perceptron Multicamadas

As RNAs do tipo Perceptron Multicamadas são capazes de realizar mapeamentos entre um espaço de entrada com dimensão $N$ e um espaço de saída com dimensão $N 3$. O número de sinais na camada de entrada é igual à dimensão do espaço de entrada, ou seja, ao número de variáveis de entrada do sistema. Da mesma forma, o número de neurônios na camada de saída é igual ao número de variáveis de saídas do sistema.

Nas camadas escondidas, algumas técnicas podem indicar uma estimação para a quantidade ideal de neurônios em cada camada, assim como o número dessas camadas. As técnicas usuais para estas estimações são baseadas em heurísticas, não permitindo assim a garantia de que a arquitetura escolhida será aquela com melhor desempenho global.

\subsubsection{Processamento da PMC}

Os estímulos $\left\{x_{1}, x_{2}, x_{3}, \ldots, x_{N}\right\}$ captados pelos neurônios da primeira camada oculta são processados levando-se em consideração os pesos sinápticos associados a cada conexão entre estes neurônios e os neurônios da camada de entrada $\left(W_{j i}^{(\ell)}\right)$, bem como em função do tipo de função de ativação associada à primeira camada oculta da rede. Os estímulos processados pelas camadas ocultas se propagam camada a camada até atingirem a camada 
de saída da rede. A camada de saída da rede processa as informações recebidas da última camada oculta e fornece a resposta referente ao estímulo apresentado na camada de entrada. A Figura 4.4 ilustra a notação simbólica e esquemática da rede Perceptron Multicamadas para fins de equacionamento.

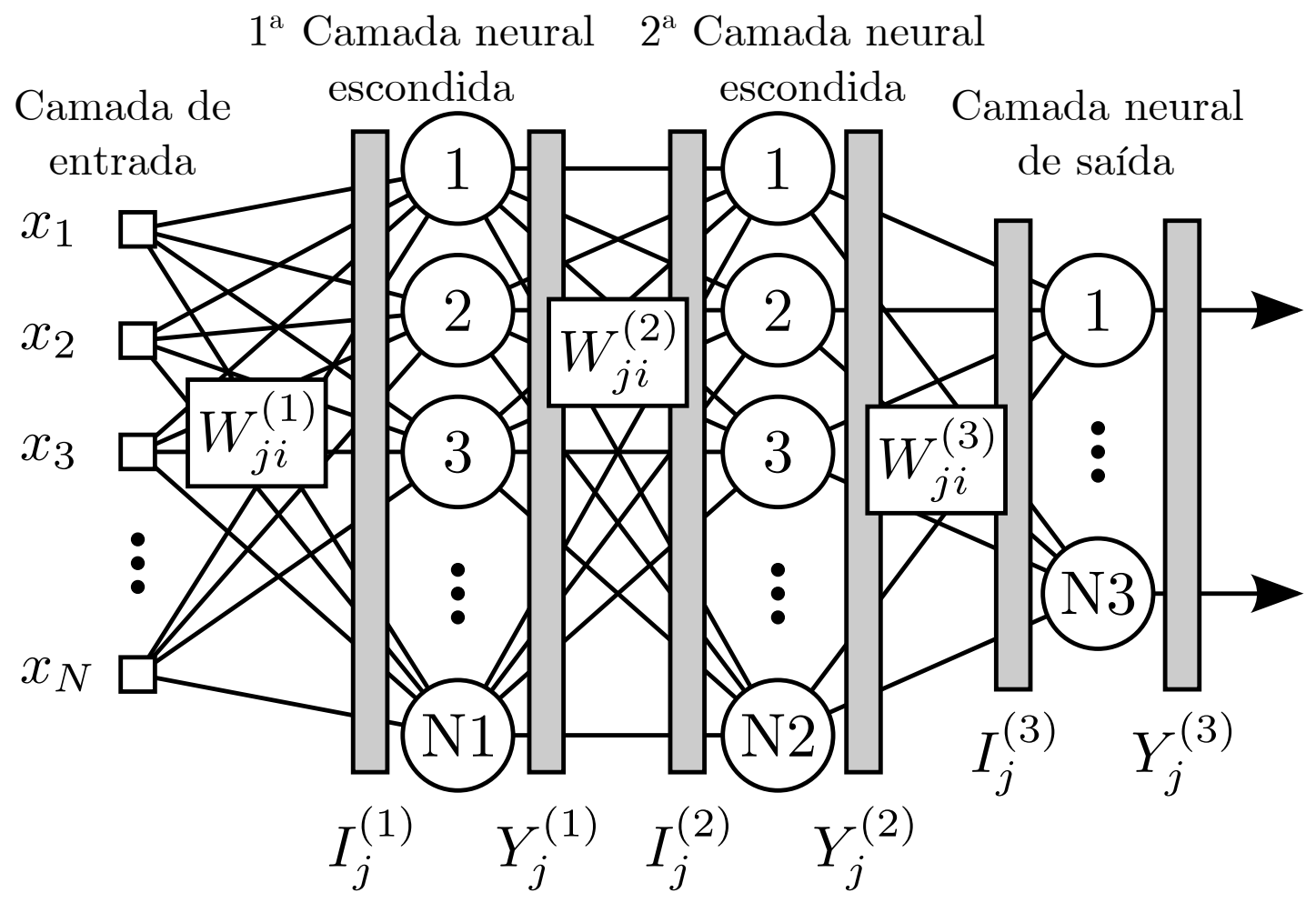

Figura 4.4: Notação da rede Perceptron Multicamadas.

em que:

$\square W_{j i}^{(\ell)}$ é o peso sináptico do $j$-ésino neurônio da camada $\ell$ conectado ao $i$-ésimo neurônio da camada $(\ell-1)$.

$\square I_{j}^{(\ell)}$ é o potencial de ativação do $j$-ésimo neurônio da camada $\ell$ e $\theta_{j}^{(\ell)}$ é o limiar de ativação do $j$-ésimo neurônio da camada $\ell$ que, embora não ilustrado na Figura 4.4, também está presente no equacionamento, ou seja:

$$
\begin{aligned}
I_{j}^{(1)} & =\sum_{i=1}^{N} W_{j i}^{(1)} \cdot x_{i}-\theta_{j}^{(1)} \\
I_{j}^{(2)} & =\sum_{i=1}^{N} W_{j i}^{(2)} \cdot Y_{j}^{(1)}-\theta_{j}^{(2)} \\
I_{j}^{(3)} & =\sum_{i=1}^{N} W_{j i}^{(3)} \cdot Y_{j}^{(2)}-\theta_{j}^{(3)}
\end{aligned}
$$


$\square Y_{j}^{(\ell)}$ é a saída do $j$-ésimo neurônio da camada $\ell$, ou seja:

$$
\begin{aligned}
& Y_{j}^{(1)}=f\left(I_{j}^{(1)}\right) \\
& Y_{j}^{(2)}=f\left(I_{j}^{(2)}\right) \\
& Y_{j}^{(3)}=f\left(I_{j}^{(3)}\right)
\end{aligned}
$$

em que $f($.$) é uma função de ativação diferenciável (sigmóide ou linear).$

\subsubsection{Processo de Treinamento das Redes PMC}

$\mathrm{Na}$ aprendizagem por retropropagação, existem duas fazes de treinamento: O passo forward e o passo backward. A primeira fase consiste no processo de propagação dos sinais no sentido da camada de entrada para a camada de saída. O segundo refere-se ao processo oposto, ou seja, da camada de saída para a camada de entrada.

No passo forward, a rede recolhe os dados de entrada, em seguida, essas informações serão processadas fluindo camada por camada resultando em uma resposta na saída. Este valor será então comparado com a resposta desejada para este mesmo estímulo. Em seguida, o erro é calculado e caso este valor não seja satisfatório de acordo com critérios predeterminados, o algoritmo entrará no passo backward, retropropagando-se o erro, camada por camada, a fim de atualizar todos os pesos sinápticos necessários desde a saída até a entrada.

O algoritmo de retropropagação basicamente trabalha de modo a ajustar os valores das matrizes $W_{i j}^{\ell}$ caminhando na direção oposta do gradiente da função erro quadrático. Os detalhes matemáticos para a implementação do algoritmo backpropagation podem ser consultados em (HAYKIN, 1999) ou na Seção 5.3 de (SILVA; SPATTI; FLAUZINO, 2010).

\subsubsection{Aspectos de Projeto de Redes Perceptron Multicamadas}

No projeto de redes multicamadas há um grande número de variáveis a ser definida em uma modelagem de um sistema específico. A seguir são apresentadas algumas técnicas que auxiliam na resolução destes problemas (BEALE; HAGAN; DEMUTH, 2011).

\section{Parâmetros de Configurações das RNAs}

Para se determinar a topologia de rede ideal para um determinado problema é necessário definir os seus parâmetros e configurações físicas adequadamente. Alguns de seus parâmetros a serem determinados são os seguintes:

\ Número de Camadas Escondidas: este parâmetro está relacionado com a complexidade do sistema. Em problemas de classificação de padrões, uma camada escondida resolve problemas de conjuntos convexos. Já, com duas camadas, é possível 
solucionar problemas de conjuntos não convexos e desconexos. Entretanto, na prática, a disposição geométrica dos dados é desconhecida em virtude da dimensão do problema ser em geral maior que duas. Desta forma, este parâmetro é normalmente determinado por métodos empíricos.

$\square$ Número de Neurônios por Camada: O número de neurônios está relacionado com a capacidade de aprendizagem. Quanto maior o número de neurônios, mais a rede terá condições de mapear o conjunto de entrada/saída. Entretanto, se este número for excessivo, esta pode apresentar problemas de generalização da aprendizagem.

$\square$ Funções de Ativação: Geralmente, aplicam-se funções sigmóides nas camadas ocultas para efetuar o mapeamento não linear no relacionamento entre as variáveis de entradas e saídas, sendo funções lineares usadas na camada de saída a fim de reduzir o esforço computacional.

\section{Problemas de Generalização e Overfitting}

No caso em que a RNA consegue alcançar um erro extremamente reduzido durante o processo de treinamento, mas quando um novo dado é apresentado ela retorna um erro elevado, diz-se que a RNA está em overfitting, ou seja, sobre-ajustada. Desta forma, a RNA memoriza os dados de treinamento, porém, não é capaz de generalizar suas soluções para novas situações.

Visando avaliar o desempenho da generalização da RNA, em geral, particiona-se o conjunto de dados disponíveis em dois subconjuntos: conjunto de treinamento e conjunto de testes. O primeiro conjunto deve ser formado por dados que representem o conjunto total e é empregado para realizar efetivamente o treinamento da RNA. De acordo com a quantidade disponível de dados, sua composição pode variar entre $80 \%$ e $90 \%$ do conjunto total. O segundo conjunto também deve representar o conjunto total de dados, mas não deve participar em nenhum momento do processo de treinamento, sendo utilizado apenas para avaliar o desempenho de generalização da RNA. Sua composição pode variar entre $20 \%$ a \%10 do conjunto total de dados. Esses procedimentos são denominados de validação cruzada na literatura.

Uma das formas de contornar este problema de generalização consiste em reduzir a complexidade da rede, diminuindo-se, por exemplo, o número de neurônios da camada oculta. No entanto, se esse número for excessivamente reduzido, a rede pode se tornar menos eficiente.

Outra técnica comumente empregada consiste no particionamento do conjunto de dados disponíveis em três subconjuntos: conjunto de treinamento, conjunto de validação e conjunto de testes. Semelhantemente ao processo de validação cruzada, o conjunto de treinamento representa os dados que serão efetivamente utilizados para o processo de 
treinamento da RNA. O conjunto de validação também é aplicado durante o processo de treinamento, entretanto, sua função se restringe apenas a avaliação do desempenho de generalização da RNA ao longo do treinamento. Portanto, ela não é utilizada para atualizar os pesos sinápticos. No início do treinamento, tanto o erro do conjunto de treinamento quanto o conjunto de validação é elevado, sendo decrementado ao longo das épocas. Quando a RNA entra na fase de overfitting, o erro de treinamento continua a decair e o erro de validação começa a aumentar. No caso em que o erro de validação aumenta consecutivamente por um número predeterminado, o processo de treinamento é interrompido. Este procedimento é denominado de early stopping na literatura. Na sequência, o conjunto de teste é aplicado para definitivamente avaliar o desempenho da generalização da RNA uma vez que, embora o conjunto de validação não participe do ajuste dos pesos sinápticos, sua avaliação de generalização pode ser tendenciosa.

\subsection{Aspectos Fundamentais da Transformada de Fourier}

A transformada de Fourier de uma função $x=x(t)$ é definida como segue:

$$
X(\omega)=\int_{-\infty}^{\infty} x(t) e^{-j \omega t} d t
$$

em que $X(\omega)$ é o sinal $x(t)$ representado no domínio da frequência $(\omega)$; e o símbolo "e" é a função exponencial.

\subsubsection{Transformada Discreta de Fourier}

No domínio de tempo discreto, a expressão (4.13) recebe a denominação de Transformada Discreta de Fourier, do inglês: Discrete Fourier Transform (DFT), pode ser expressa da seguinte forma (OPPENHEIM; SCHAFER; BUCK, 1998):

$$
X(m)=\sum_{n=0}^{N_{a}-1} x(n) e^{-j\left(2 \pi / N_{a}\right) m n}
$$

em que: $n$ é um número inteiro, entre $\left[0 \cdots N_{a}\right]$, que representa o índice do vetor discreto do sinal $x(n)$ no domínio do tempo; $m$ é um número inteiro, entre $\left[0 \cdots N_{a}\right]$, relativo ao índice do vetor discreto do sinal $X(m)$ no domínio da frequência; $N_{a}$ é a quantidade total de amostra; e $j$ é a representação do número imaginário.

De acordo com a Equação (4.14), o cálculo de uma DFT é equivalente ao cálculo da transformada de Fourier em $N_{a}$ amostragens de frequência, $\omega_{m}=2 \pi m / N_{a}$, uniformemente espaçadas. 


\subsubsection{Transformada Rápida de Fourier}

A Transformada Rápida de Fourier, do inglês: Fast Fourier Transform (FFT), consiste de um conjunto de passos ordenados que utiliza-se das propriedades do cálculo da DFT para reduzir o número de somas e multiplicações aritméticas, desenvolvendo-se, desta forma, um algoritmo com menos complexidade computacional. Seus detalhes de implementação podem ser consultados na Seção 3 de OPPENHEIM; SCHAFER; BUCK (1998).

Um dos requisitos da FFT consiste no fato de que a quantidade de amostras $N_{a}$ da janela de dados deve ser em função da potência de 2, conforme segue:

$$
N_{a}=2^{v}
$$

em que $v$ é um número inteiro positivo.

Em situações que a quantidade de amostras da janela de dados não respeita a Equação (4.15), complementa-se com elementos de valor nulo até a potência de 2 subsequente mais próxima. Por exemplo, considerando um determinado sinal $x$ com 1000 amostras na janela, a potência de 2 subsequente mais próxima é de $v=10$, sendo $N_{a}=1024$. Os 24 elementos entre $x(1001)$ e $x(1024)$ são preenchidos com zeros. Esse procedimento é conhecido como zero - padding na literatura (OPPENHEIM; SCHAFER; BUCK, 1998).

\subsubsection{Frequência de Amostragem}

Em conformidade com o teorema de amostragem de Nyquist, a taxa de amostragem de um sinal deve ser pelo menos o dobro da frequência máxima do sinal (OPPENHEIM; SCHAFER; BUCK, 1998), conforme segue:

$$
f_{a}=2 \cdot f_{s}
$$

em que $f_{a}$ é a frequência de amostragem e $f_{s}$ é a frequência máxima do sinal.

A Figura 4.5 ilustra o resultado da aplicação da FFT em um determinado sinal $x(t)$. Analisando-se o sinal transformado na região entre 0 e $f_{a}$, nota-se que há uma simetria ao redor de $f_{a} / 2$, a qual é a frequência de Nyquist, conforme a Equação (4.16). O sinal espelhado em relação a tal frequência adiciona informações redundantes, reforçando o teorema de amostragem. Neste contexto, na prática, apenas o intervalo entre 0 e $f_{a} / 2$ são geralmente empregados para fins de análises.

\subsubsection{Resolução em Frequência}

A resolução da frequência pode ser determinada pela razão entre a frequência de Nyquist e o número total de pontos até esta frequência, ou seja:

$$
R=\frac{f_{a}}{2} \cdot \frac{1}{\frac{N_{a}}{2}}=\frac{f_{a}}{N_{a}}
$$




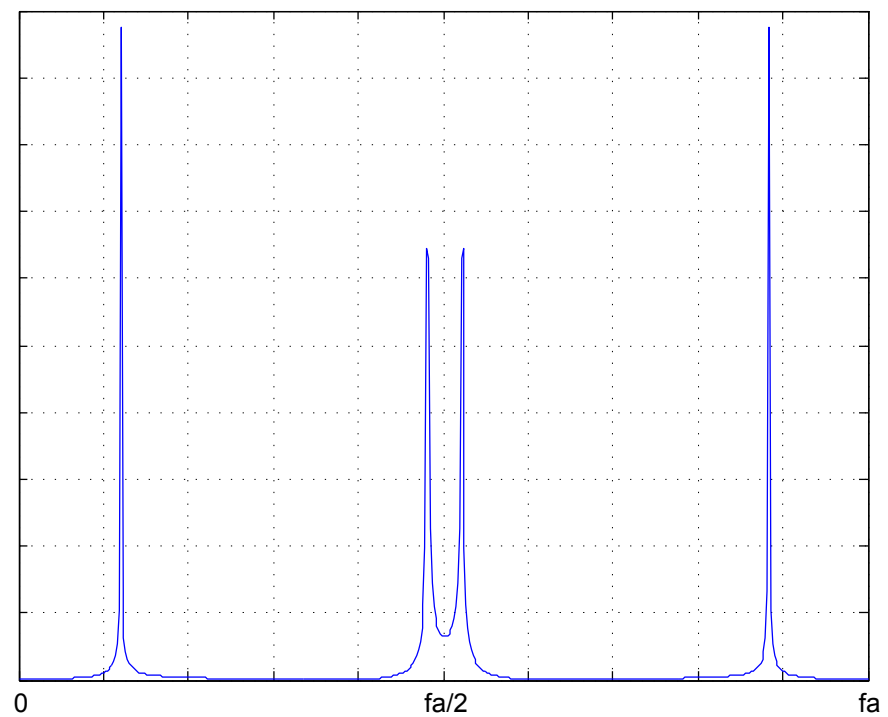

Figura 4.5: Aplicação da FFT em um determinado sinal $x(t)$.

O tempo de aquisição de dados pode ser expresso em termos de $f_{a}$ e $N_{a}$ da seguinte forma:

$$
t_{a q}=t_{a} \cdot N_{a}=\frac{1}{f_{a}} \cdot N_{a}
$$

Substituindo-se a Equação (4.18) em (4.17), tem-se:

$$
R=\frac{1}{t_{a q}}
$$

Logo, a resolução de frequência de uma DFT depende apenas do tempo de aquisição de dados. Entretanto, cabe ressaltar que o algoritmo da FFT requer que o número de pontos da janela, $N_{a}$, seja uma potência de 2 subsequente mais próxima, conforme fora mencionado anteriormente. No caso da utilização do zero-padding, a resolução de frequência pode ser determinada substituindo a Equação (4.15) na Equação (4.17):

$$
R=\frac{f_{a}}{2^{v}}=\frac{f_{a}}{\operatorname{roundup}\left(\log _{2}^{N_{a}}\right)}
$$

em que roundup(.) é uma função para efetuar o arreondamento para cima de um valor decimal.

O aumento excessivo do zero-padding pode provocar uma distorção no espectro de frequência e comprometer a sua análise. Para reduzir este efeito, o tempo de aquisição de dados pode ser ajustado para a potência de 2 , conforme segue:

$$
t_{a q}=2^{v} \cdot t_{a}=\frac{2^{v}}{f_{a}}
$$




\subsubsection{Efeito de Borda e Janelamento}

A transformada de Fourier é calculada mediante um intervalo de tempo entre $[-\infty,+\infty]$, conforme a definição representada na Equação (4.13). Na prática, porém, um determinado sinal somente pode ser mensurado por um período limitado de tempo e, portanto, o comportamento fora do intervalo é desconhecido. A Figura 4.6(a) ilustra um exemplo de um sinal $x(t)=0,5 \sin (2 \pi 60 \cdot t)+0,5 \sin (2 \pi 120 \cdot t+\pi / 3)$ amostrado em um determinado intervalo de tempo. A transformada de Fourier assume implicitamente que o sinal é periódico, em que o sinal medido é replicado ao longo do tempo, conforme pode ser ilustrado na Figura 4.6(b). Nota-se que o efeito da replicação do sinal ao longo do tempo proporciona uma descontinuidade na curva periódica, apresentando sinais com componentes de alta frequência na borda do sinal original.

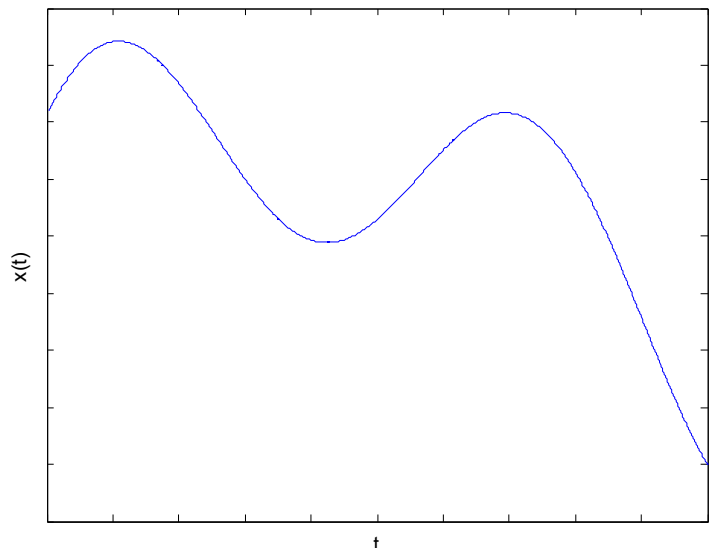

(a) Janela de aquisição de dados de um determinado sinal $x(t)$.

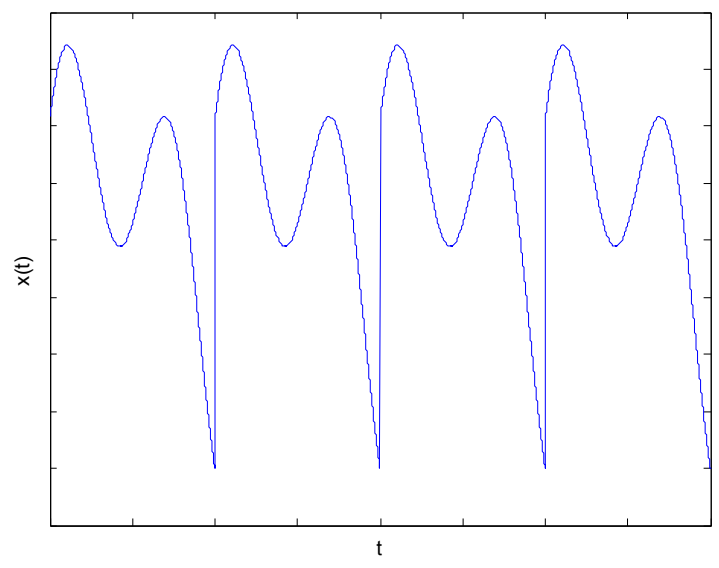

(b) Réplica do intervalo de amostragem ao longo do tempo.

Figura 4.6: Ilustração do efeito de borda de uma janela de sinal.

A maioria dos sinais reais apresentam descontinuidades nas bordas do intervalo de medição e, em virtude da FFT assumir que os sinais são periódicos, ela considerará as descontinuidades do sinal que, de fato, não existem. Com o intuito de reduzir este efeito empregam-se as técnicas de janelamento de sinais que visam eliminar a descontinuidade nas bordas do sinais; dentre elas, podem-se citar: Janela de Hanning, Hamming, Kaiser, Tukey, Gaussiana, Triangular, Blackman, entre outros que podem ser consultadas em OPPENHEIM; SCHAFER; BUCK (1998).

As Figuras 4.7(a) e (b) ilustram as janelas de Hanning e Hamming, respectivamente. As equações que regem o seu comportamento são descritas como seguem (OPPENHEIM; SCHAFER; BUCK, 1998):

$$
\begin{gathered}
W_{\text {hann }}(n)=0,5\left[1-\cos \left(\frac{2 \pi n}{N_{a}-1}\right)\right], \quad 0 \leq n \leq N_{a}-1 \\
W_{\text {hamm }}(n)=0,54-0,46 \cos \left(\frac{2 \pi}{N_{a}-1}\right), \quad 0 \leq n \leq N_{a}-1
\end{gathered}
$$


em que $W_{\text {hann }}$ é a janela de Hanning; $W_{\text {hamm }}$ é a janela de Hamming; $N_{a}$ é o número total de amostras e $n$ é o índice da amostra.

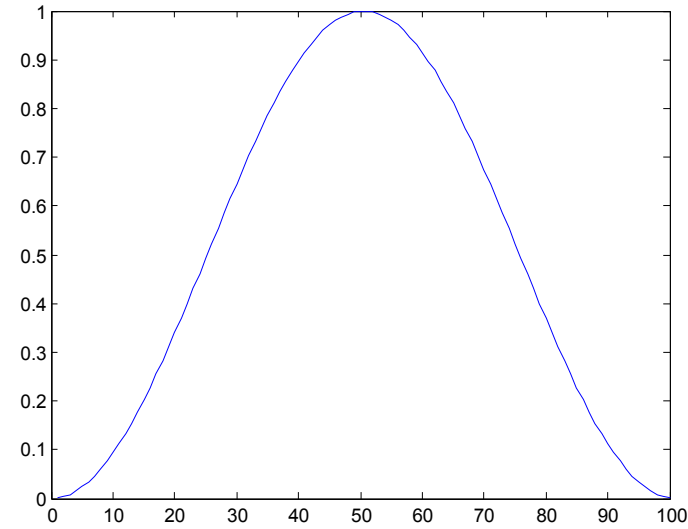

(a) Janela de Hanning.

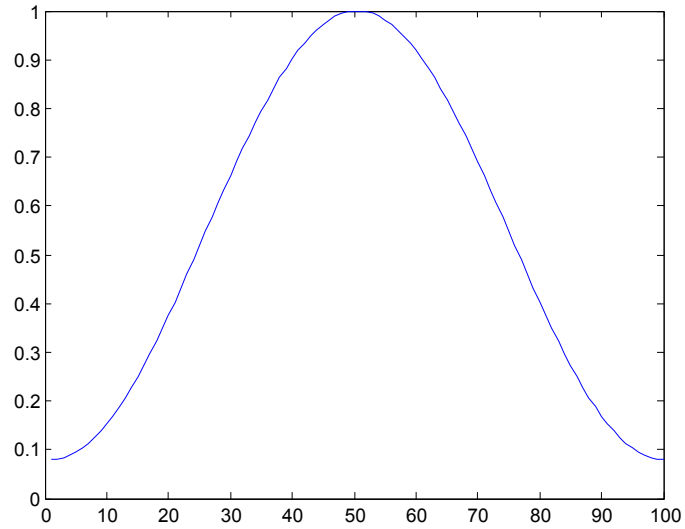

(b) Janela de Hamming.

Figura 4.7: Janelas de Hanning e de Hamming.

Para ilustrar o efeito do janelamento, considera-se o sinal $x(t)$ do exemplo anterior amostrado em uma maior janela de tempo, conforme apresentado na Figura 4.8(a). A Figura 4.8(b) representa o sinal $x(t)$ após a aplicação do janelamento de Hanning. Embora haja a distorção no formato de onda de $x(t)$, o efeito de borda do sinal é eliminado, visto que tanto o limite da esquerda quanto o limite da direita apresentam valores bem próximos a zero. Em virtude da FFT consistir de uma representação de um sinal no espaço de frequência, o janelamento deve ser determinado de forma que influencie o mínimo possível em seu espectro. Tal escolha é dependente do tipo e característica do sinal que está sendo analisado (OPPENHEIM; SCHAFER; BUCK, 1998). Entretanto, como este é geralmente desconhecido na prática, a janela é determinada de forma empírica.

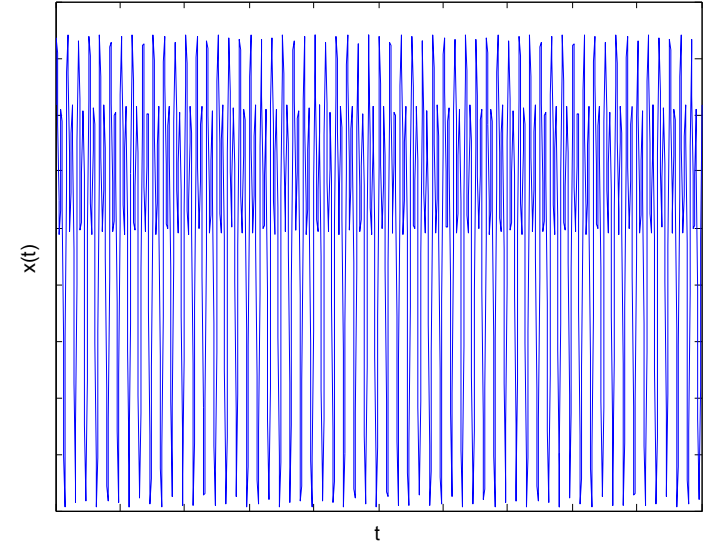

(a) Janela do sinal $x(t)$ amostrado no tempo.

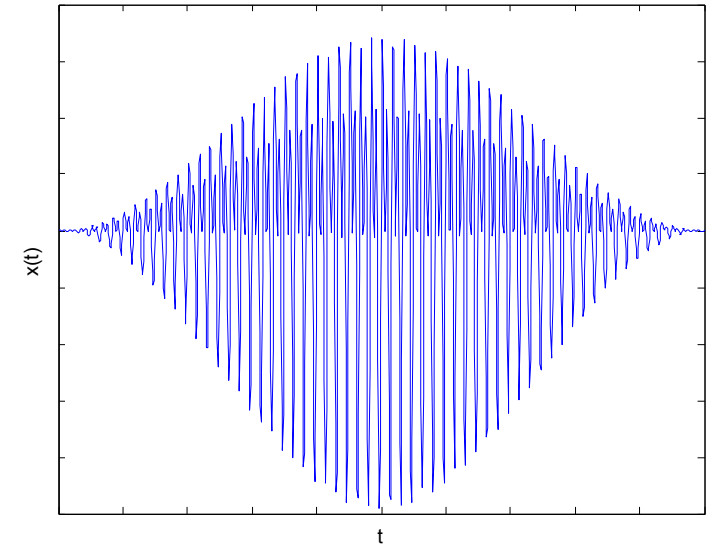

(b) Aplicação da janela de Hanning no sinal $x(t)$.

Figura 4.8: Exemplo de aplicação da janela de Hanning no sinal.

A Figura 4.9(a) ilustra o espectro de frequência do sinal $x(t)=0,5 \sin (2 \pi 60 \cdot t)+$ $0,5 \sin (2 \pi 120 \cdot t+\pi / 3)$ que possui componentes de frequência de $60 \mathrm{~Hz}$ e $120 \mathrm{~Hz}$ sem 
janelamento (também conhecido como janela retangular). Observa-se que há um espalhamento de espectro aos redores das componentes de frequências dominantes $(60 \mathrm{~Hz}$ e $120 \mathrm{~Hz}$ ). Este comportamento se deve ao fato de que as componentes de altas frequências advindas do efeito de borda são refletidas nos sinais de baixa frequência, visto que a frequência de amostragem é menor que o dobro da frequência máxima do sinal, conforme o teorema de amostragem de Nyquist, expresso na Equação (4.16) localizada na Página 63.

A Figura 4.9(b) ilustra o espectro de frequência do sinal $x(t)$ após a aplicação do janelamento de Hanning. Observa-se que o espalhamento do espectro é menos evidente e a amplitude dos sinais de $60 \mathrm{~Hz}$ e $120 \mathrm{~Hz}$ são mais próximos do sinal $x(t)$, ou seja, 0,5.

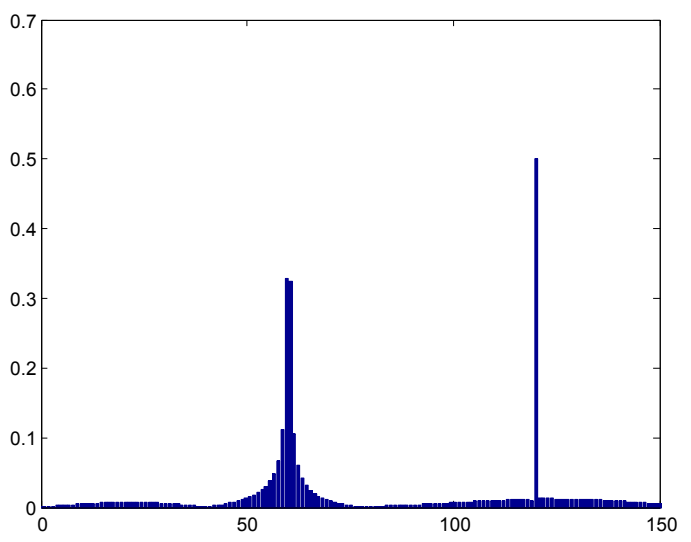

(a) Aplicação da FFT no sinal $x(t)$ sem janelamento.

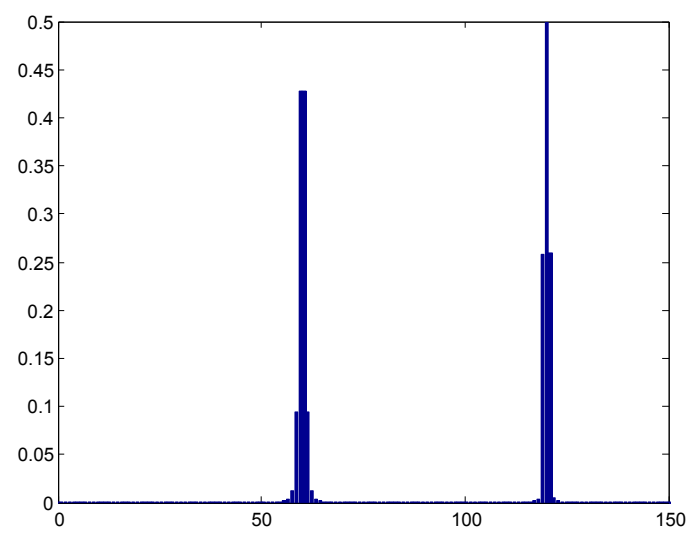

(b) Aplicação da FFT no sinal $x(t)$ com janelamento de Hanning.

Figura 4.9: Efeito de borda no espectro de frequência. 



\section{Sistema de Identificação Neural de Barras Quebradas em Motores de Indução Trifásicos}

\subsection{Introdução}

Neste capítulo serão abordados os principais aspectos metodológicos para desenvolver um sistema baseado em RNAs para efetuar a identificação online de quebras em barras de rotores de gaiola de esquilo de motores de indução trifásicos.

Para tanto, a metodologia considera tanto a alimentação do MIT a partir da rede elétrica quanto por inversor trifásico operando sob diversas condições de carregamento.

Conforme mencionado no Capítulo 2, a bancada de experimento é controlada por um quadro de comando constituído por três variadores de tensão monofásicos, configurados em Y, que são conectados aos enrolamentos do MIT ou ao barramento CC do inversor trifásico da WEG. Em virtude de o variador monofásico ser de $127 \mathrm{~V}$ e a tensão nominal do MIT ser de 220/380 V, seus enrolamentos foram conectados em $\Delta$ de tal forma que a tensão de $220 \mathrm{~V}$ seja aplicada em cada bobina de fase do motor. Os ensaios realizados neste tipo de acionamento consideraram tensões trifásicas equilibradas e frequência da rede de $60 \mathrm{~Hz}$. Com o intuito de analisar a robustez do sistema neural de identificação, os carregamentos de $0,5 \mathrm{Nm}, 1,0 \mathrm{Nm}, 1,5 \mathrm{Nm}, 2,0 \mathrm{Nm}, 3,5 \mathrm{Nm}$ e 4,0 $\mathrm{Nm}$ foram aplicados ao eixo do MIT.

Considerando-se o acionamento pelo inversor trifásico comercial da WEG, deve-se notar que a tensão aplicada ao MIT se constitui de tensões com formato de onda retangulares e moduladas por largura de pulso (PWM). Além disso, a amplitude e frequência da tensão fundamental varia de acordo com a operação do MIT, tornando um desafio ainda maior para o desenvolvimento de um sistema de identificação de falhas. Os ensaios realizados neste tipo de acionamento consideraram frequências de acionamento de $40 \mathrm{~Hz}, 45 \mathrm{~Hz}$, 
$50 \mathrm{~Hz}, 55 \mathrm{~Hz}$ e $60 \mathrm{~Hz}$. Para cada frequência, aplicaram-se torques de cargas de 0,5 Nm, $1,0 \mathrm{Nm}, 1,5 \mathrm{Nm}, 2,0 \mathrm{Nm}, 3,5 \mathrm{Nm}$ e 4,0 Nm.

O principal objetivo de tais ensaios é permitir o desenvolvimento e a avaliação de uma metodologia de diagnóstico de quebras de barras de rotores que seja independente da frequência fundamental atuante na tensão de alimentação do MIT e do carregamento em seu eixo rotativo.

Adicionalmente, uma base de dados de ensaios experimentais de falhas de quebra em barras de rotores, conforme descrito no Capítulo 3, foi constituída com o intuito de se estudar e desenvolver um sistema de identificação de falhas e generalizado para diferentes particularidades.

As falhas que serão empregadas para tal estudo serão: 1) uma barra quebrada; 2) duas barras quebradas consecutivas; 3 ) duas barras quebradas consecutivamente em lados diametralmente opostos; 4) barras quebradas consecutivamente. Ressalta-se que para cada tipo de falha, utilizaram-se dados de ensaios experimentais referentes ao acionamento do MIT tanto pela tensão direta da rede elétrica quanto pelo inversor trifásico operando sob diversas condições de cargas.

Visando a uma maior diversidade de dados para a caracterização de um motor operando sob condições normais, foram realizados os ensaios experimentais com os seguintes motores:

$\square$ Motor Normal: Este é um motor com rotor normal que também foi empregado para realizar os ensaios de falhas de rotores com barras quebradas. A cada experimento, efetuou-se a substituição dos rotores conforme os procedimentos de remoção e montagem descritos no Apêndice A.

$\square$ Motor de Fábrica: Este refere-se a um motor novo de fábrica sem que o mesmo tenha sido submetido a algum tipo de acesso interno ou adaptação. O processo de montagem e desmontagem manual da máquina pode eventualmente provocar um desalinhamento de eixo e consequentemente do entreferro. Inseriu-se este motor no estudo para verificar se o método proposto é influenciado ou não pelo fato de um motor ter sido acessado.

$\square$ Motor de Alto Rendimento: Este motor apresenta uma característica de construção e de material diferente de um motor normal, em que se aqui a eficiência total de operação. A inclusão deste tipo de MIT se torna interessante para se analisar a influência e robustez da metodologia de identificação proposta nesta tese.

$\square$ Motor Adaptado: Este é o MIT que fora adaptado para realizar os ensaios experimentais de curto-circuito no estator. Em virtude dos enrolamentos serem totalmente substituídos por outros que contém acesso aos terminais de curto, este motor, na configuração normal (sem curto-circuito), também fora incluído no estudo para verificar se não haveria nenhum resultado inesperado. Esta análise é relevante para 
investigar se um motor que sofreu manutenção de troca de enrolamento, por algum motivo, possa influenciar ou não no método de identificação de falhas.

\subsection{Estrutura do Sistema Neural de Identificação de Barras Quebradas}

A estrutura genérica do sistema inteligente de identificação de barras quebradas em rotores de MITs pode ser representada pela Figura 5.1.

Corrente de Linha Pré-Processamento

RNA
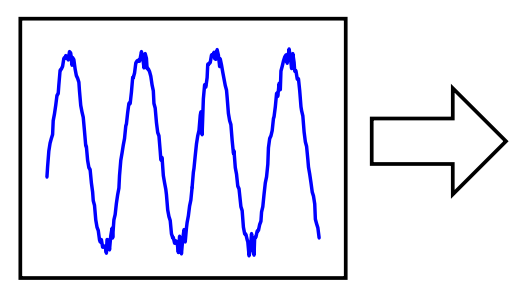
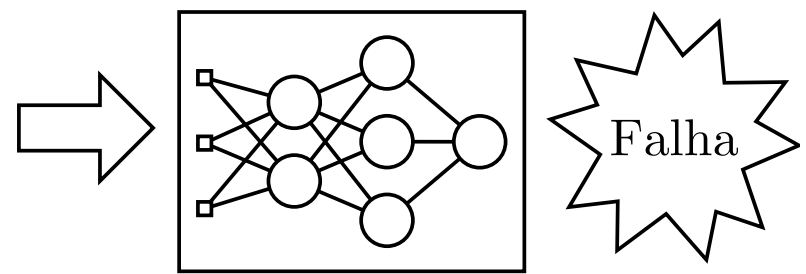

Figura 5.1: Sistema inteligente de identificação de quebras em barras de rotores de MITs.

O sistema proposto baseia-se em RNAs, cujas etapas de processamento são descritas conforme os seguintes tópicos:

$\square$ Aquisição da corrente de linha: A corrente de linha de uma das fases de alimentação é coletada por um sistema de aquisição de dados. A base de ensaios experimentais utilizada se constitui de sinais adquiridos a uma frequência de amostragem $\left(f_{a}\right)$ de $3,84 \mathrm{kHz}$ durante um intervalo de tempo $\left(t_{a q}\right)$ de aproximadamente $4 \mathrm{~s}$. A escolha dos valores de tais parâmetros foi realizada de forma que haja componentes de frequência e resolução suficientes para análises e estudos preliminares. Neste contexto, mediante a avaliação dos resultados finais, tais valores seriam reajustados para que a metodologia seja embarcada em hardware dedicado.

Pré-processamento: Na sequência, a corrente é processada para o domínio da frequência mediante o algoritmo da FFT. O resultado desta operação é normalizado em termos de amplitude e frequência para que o sistema de identificação seja menos influente às variações de carga e de frequência de acionamento do inversor. Com a finalidade de reduzir a dimensionalidade do vetor de entrada da RNA, procede-se à segunda etapa de pré-processamento baseada em análise de componentes principais (PCA). Dessa forma, a RNA se torna mais simples e compacta, exigindo menos recursos computacionais e de hardware.

\ Sistema neural de identificação: Por intermédio da base de ensaios experimentais, a RNA do tipo Perceptron Multicamadas é treinada e dimensionada em termos de número de camadas neurais e de quantidade de neurônios por camada, de modo 
a efetuar a detecção de quebras nas barras de rotores. A proposta neste estudo consiste então em desenvolver uma RNA especializada para processar as informações de entrada visando determinar se o motor opera sob condições normais ou de falhas.

\subsection{Pré-Processamento dos Sinais}

A base de ensaios de falhas experimentais, conforme mencionado anteriormente, é composta por por dados cuja frequência de aquisição fora de $3,84 \mathrm{kHz}$ durante o intervalo de aproximadamente $4 \mathrm{~s}$.

Entretanto, utilizou-se o tempo de amostragem de apenas $3 \mathrm{~s}$ para a janela de tempo da FFT, constituindo-se assim de 11520 amostras (vide Equação (4.18) da Página 64).

Dessa forma, o tamanho do vetor do sinal de corrente processado na frequência será de $N_{a}=16384$ amostras, visto que a potência de 2 subsequente a 11520 amostras é de $v=14$, em conformidade com a Equação (4.15).

Neste contexto, a resolução de frequência da FFT é de $R=0.2344 \mathrm{~Hz}$ (vide Equação (4.17)), a qual se verificou suficientemente adequada para a realização da identificação de quebra nas barras de rotores.

Cabe ressaltar que empregou-se o janelamento de Hamming, ilustrado na Figura 4.7(b), durante o processamento da FFT para reduzir as frequências de espraiamento ocasionado pelo efeito de borda do sinal original.

\subsubsection{Normalização de Amplitude}

A normalização de amplitude empregada no sistema de identificação proposto processa todas as frequências de forma que tornem proporcionais à amplitude da frequência fundamental. Basicamente, o vetor de corrente no domínio da frequência é dividido pelo módulo da fundamental, conforme segue:

$$
\mathbf{I}_{\mathbf{n}}=\mathbf{I} / I\left(m_{\text {fund }}\right)
$$

em que $\mathbf{I}_{\mathbf{n}}$ é o vetor de corrente no domínio da frequência $\left[I_{n}(1), I_{n}(2), \cdots, I_{n}(m)\right]$ normalizado em amplitude; I é o vetor de corrente no domínio da frequência $[I(1), I(2), \cdots, I(m)]$ e $I\left(m_{f u n d}\right)$ é a sua componente fundamental.

Para determinar a amplitude da frequência fundamental, basta então realizar a seguinte operação no vetor de corrente:

$$
I_{\text {fund }}=\max (\mathbf{I})
$$

em que a função $\max ($.$) é a operação para encontrar o maior valor em um vetor.$

Nota-se que a componente fundamental da corrente sempre terá valores equivalentes a 1 (um). O restante das frequências serão valores fracionários e proporcionais a essa 
componente. Este simples pré-processamento pode auxiliar no sistema de detecção de falhas em condições de operação do MIT que proporcione a variação de módulo da corrente, tais como variação de cargas ou tensão de alimentação, embora sua relação não seja exatamente linear.

\subsubsection{Seleção das Frequências em torno da Fundamental}

Considerando-se o acionamento do MIT pelo inversor trifásico operando sob algoritmo de controle $V / f$, a frequência da tensão de alimentação e, consequentemente, da corrente podem ser variáveis. Neste contexto, o espectro da componente fundamental e os demais correlacionados serão também variantes ao longo do eixo de frequência, conforme ilustrado na Figura 5.2.

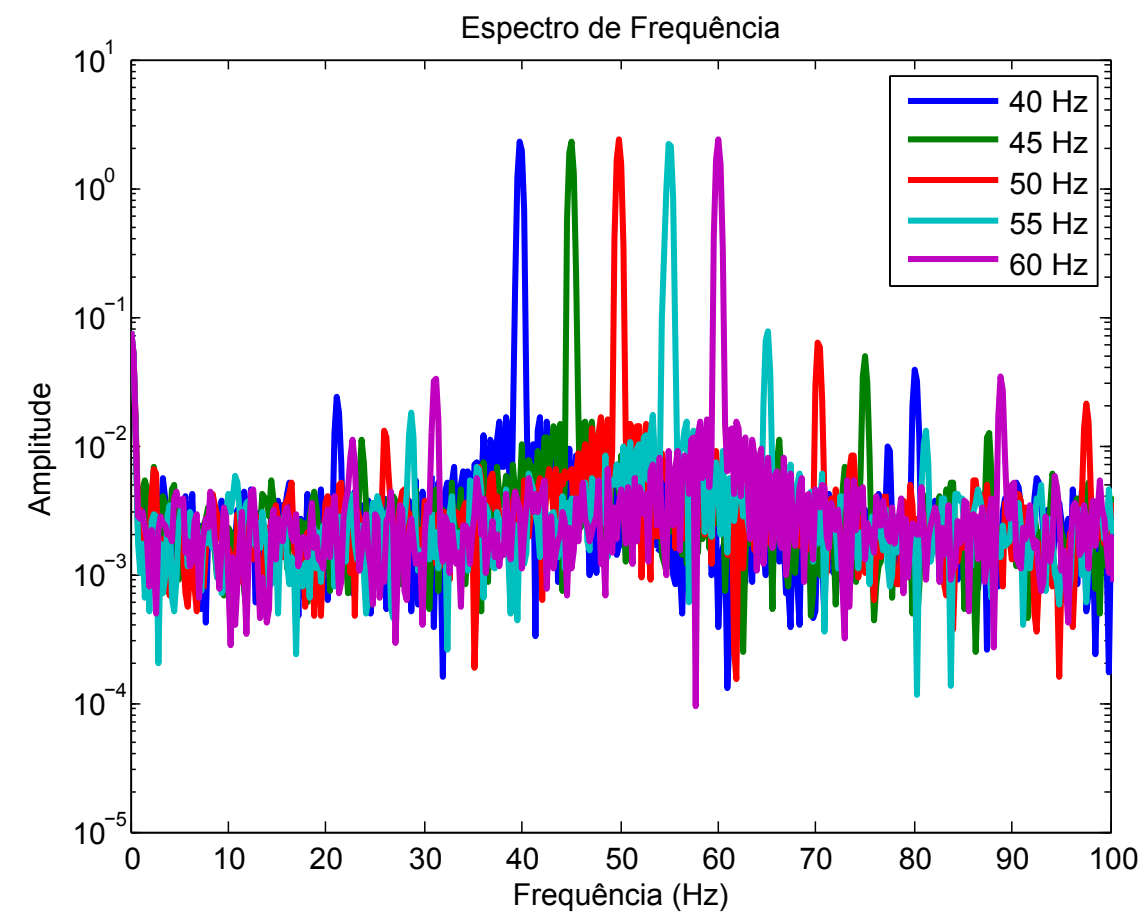

Figura 5.2: Análise espectral da corrente de um MIT acionado por inversor trifásico.

O MIT utilizado neste ensaio consiste de um motor normal operando em regime permanente sob carregamento nominal de 4,0 Nm. De acordo com a Figura 5.2, nota-se que a componente fundamental se desloca para a direita ao longo do eixo das abscissas conforme se aumenta a frequência da tensão de acionamento de $40 \mathrm{~Hz}$ à $60 \mathrm{~Hz}$.

Esta variação pode comprometer o projeto do sistema de identificação de falhas, visto que se torna mais difícil de caracterizar o motor. Além disso, o algoritmo de identificação deve prever que o MIT pode operar em frequências intermediárias às mostradas no gráfico.

Uma das técnicas comumente empregada para se normalizar a frequência para fins de análise consiste em dividir o vetor de frequência que compõe o eixo das abscissas pelo valor da frequência fundamental. Entretanto, em termos computacionais, o vetor discretizado 
que contém as amplitudes das componentes é o que de fato será empregado para o sistema de identificação neural. Neste contexto, torna-se mais interessante identificar o índice do vetor que contém a frequência fundamental, $m_{f u n d}$, a partir da Equação (5.2) e utilizálo como índice de referência. A partir desse índice, a FFT pode ser caracterizada por $m_{p}$ pontos de discretização de frequência em torno da fundamental, em que cada ponto corresponde à resolução de frequência, $R$.

Desta forma, a janela de dados da FFT empregada para análise pode ser representada como segue:

$$
\mathbf{I}_{\text {win }}=\mathbf{I}_{\mathbf{n}}\left(\mathbf{m}_{\text {win }}\right)
$$

em que

$$
\mathbf{m}_{\text {win }}=\left[-m_{p}+m_{f u n d}, \cdots, m_{\text {fund }}-1, m_{\text {fund }}, m_{\text {fund }}+1, \cdots, m_{\text {fund }}+m_{p}\right]
$$

logo, o tamanho da janela pode ser determinado por:

$$
N_{\text {win }}=2 \cdot m_{p}+1
$$

Para uma análise gráfica, o eixo das abscissas pode ser representado em termos de frequência, conforme segue:

$$
\mathbf{f}_{\text {win }}=R \cdot \mathbf{m}_{\text {win }}-f_{\text {fund }}
$$

em que a operação de subtrair $f_{\text {fund }}$ é realizado para condicionar todas as frequências fundamentais ao marco de referência zero.

A Figura 5.3 representa a análise espectral de corrente processada em torno da componente fundamental. Os ensaios consideraram o acionamento do MIT por meio do inversor trifásico operando sob frequências de $40 \mathrm{~Hz}$ a $60 \mathrm{~Hz}$ a uma carga nominal de 4,0 Nm.

A Figura 5.3(a) representa as análises espectrais dos mesmos ensaios realizados na Figura 5.2. Entretanto, neste caso, os sinais foram recondicionados à referência da frequência fundamental e o gráfico foi gerado em torno dessa frequência. Utilizou-se o valor de $m_{p}=40$, ou seja, 40 pontos para direita e para esquerda da fundamental para representar a janela, desta forma, $N_{w i n}=41$. Complementarmente, de acordo com a Equação (5.6), a janela de análise compreende frequências entre -9,376 Hz e 9,376 Hz em torno da fundamental, já que $R=0,2344 \mathrm{~Hz}$.

Observa-se que este pré-processamento foi capaz de caracterizar o motor normal independentemente da frequência de acionamento, uma vez que todas as curvas se sobrepõem. Aplicando-se o mesmo procedimento em um motor com quatro barras quebradas, operando também à carga nominal de 4,0 Nm, nota-se que o espectro de frequência também se torna bem caracterizado, conforme pode ser observado na Figura 5.3(b). 


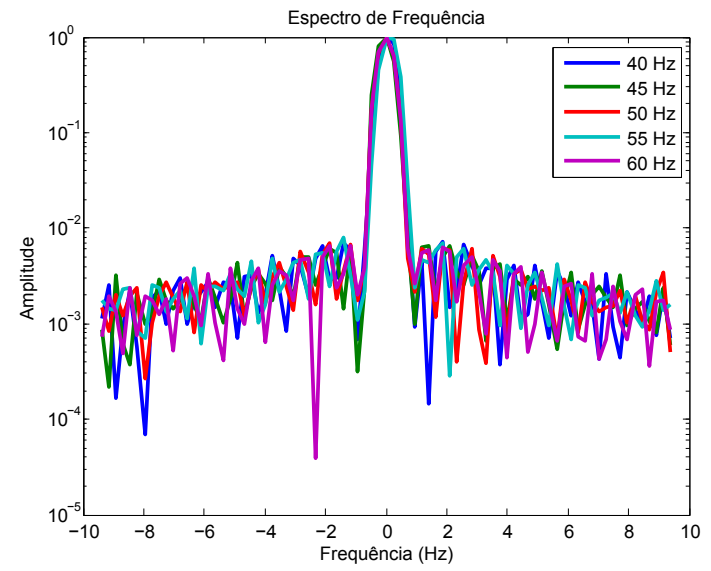

(a) Motor de indução normal.

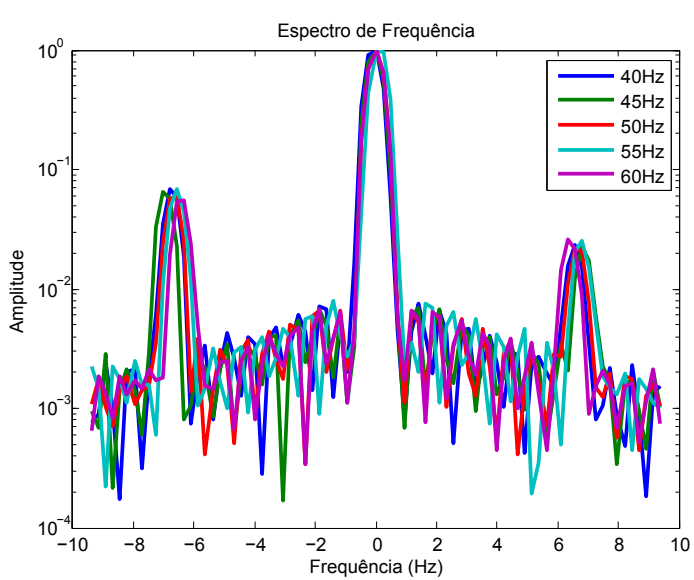

(b) Motor de indução com 4 barras quebras consecutivamente.

Figura 5.3: Análise espectral da corrente de um MIT acionado por inversor trifásico após a normalização de frequência.

\subsubsection{Análise Espectral em torno da Frequência Fundamental}

A análise espectral em torno da frequência fundamental proporciona alguns resultados ilustrativos que auxiliam no desenvolvimento do sistema de identificação de quebra em barras de rotores de MITs. Neste contexto, algumas análises foram realizadas para caracterizar os MITs normais ou com quebra nas barras dos rotores sob diversas condições de operação.

Portanto, realizaram-se os estudos do comportamento espectral: 1) de um MIT normal sob variação de carga; 2) de um MIT com quebra na barra sob variação de carga; 3) de um conjunto de MITs normais sob condições de frequência de acionamento e torque de carga constante; 4) de um conjunto de MITs com quebra na barra sob condições de frequência e torque de carga constante.

\section{MIT Normal sob Variação de Carga}

A normalização em amplitude e frequência busca reduzir os efeitos da variação da amplitude da corrente devido às mudanças no comportamento da carga e da variação da frequência de alimentação quando o MIT é acionado por um inversor. A caracterização de um motor normal em termos da variação da frequência de acionamento fora ilustrado na Figura 5.3(a).

Em contrapartida, a Figura 5.4 apresenta o comportamento dos espectros de frequências em torno da fundamental de um motor operando em regime permanente sob carregamento entre $0,5 \mathrm{Nm}$ e 4,0 Nm. Os quatros ensaios realizados consistiram de um MIT acionado por inversor trifásico a uma frequência de $60 \mathrm{~Hz}$. Nota-se que os sinais de espectros são bem caracterizados e não apresenta variações significativas com a carga aplicada em seu eixo. 


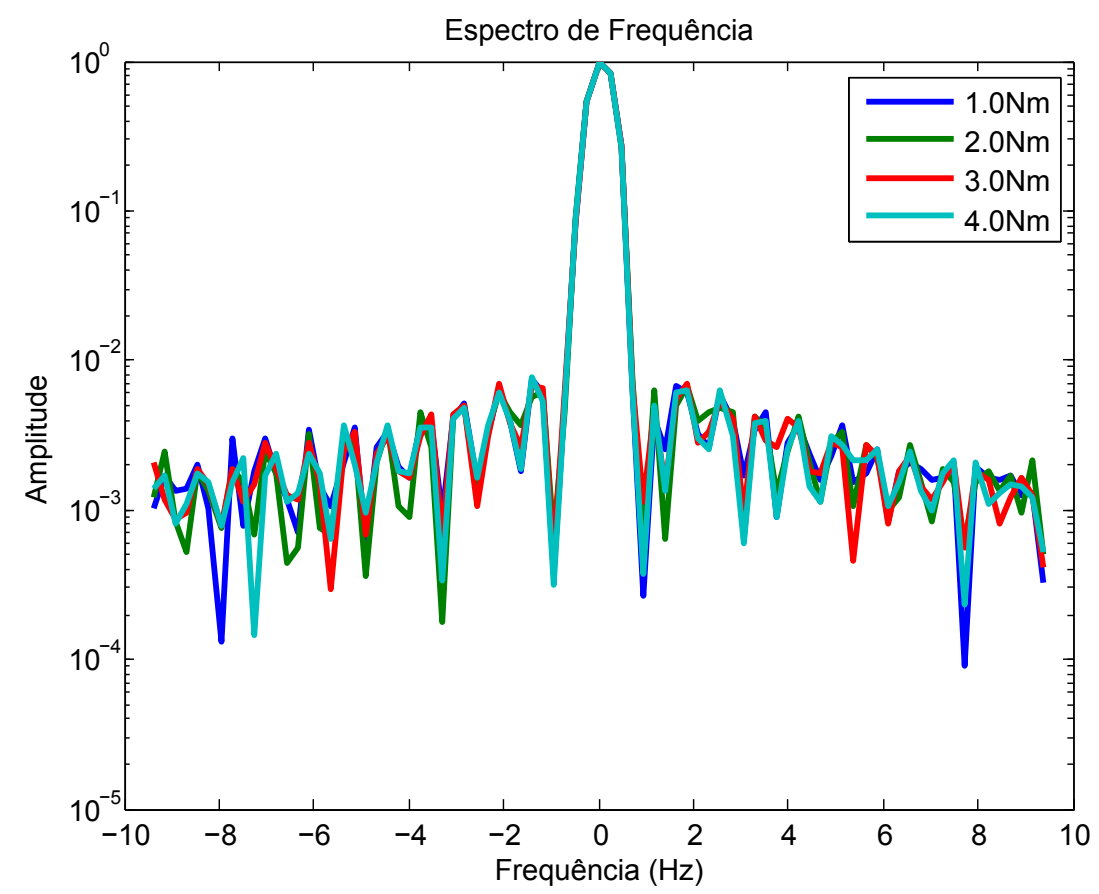

Figura 5.4: Efeito da variação do torque de carga em MITs sem falhas.

\section{MIT com 4 Barras Quebradas sob Variação de Carga}

Esta análise consiste de um MIT com 4 barras quebradas acionado pelo inversor a uma frequência de $60 \mathrm{~Hz}$ e operando em regime permanente sob carregamentos entre 1,0 Nm e 4,0 Nm. A Figura 5.5 ilustra o estudo do comportamento do espectro de frequência em relação à variação de carga no eixo do MIT operando sob falhas.

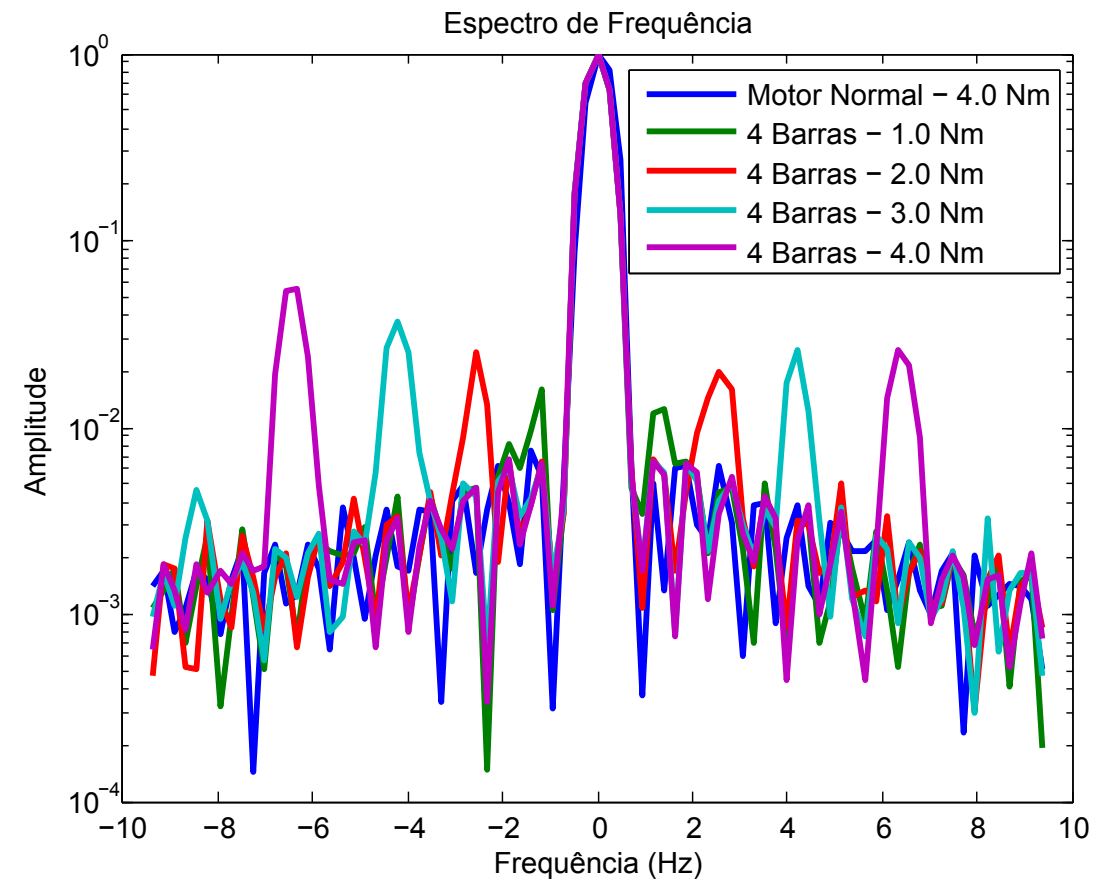

Figura 5.5: Efeito da variação do torque de carga em MITs com 4 barras quebradas. 
Analisando seus espectros de frequências, nota-se que algumas componentes em torno da frequência fundamental se sobressaem em relação aos motores normais. Conforme se aumenta o carregamento, duas componentes em torno da fundamental se tornam mais evidentes, incrementando-se o seu módulo e o seu deslocamento em frequência. De acordo com pesquisas correlatas (BOSSIO et al., 2009; RAZIK; CORREA; SILVA, 2009), as frequências de tais bandas laterais podem ser determinadas por:

$$
f_{b}=f_{\text {fund }} \cdot(1 \pm 2 k s)
$$

em que $f_{b}$ é a frequência da banda lateral, $k$ é um número inteiro e $s$ é o escorregamento do MIT.

\section{Conjunto de MITs com Barras Quebradas}

Enquanto as análises anteriores realizadas na Figura 5.5 procuravam estudar os efeitos da variação da carga em torno de uma única falha, esta análise busca investigar os efeitos no espectro de frequência em torno da fundamental quanto ao número de barras quebradas ou suas combinações de quebra.

Para tanto, realizaram-se os ensaios com o MIT acionado pelo inversor trifásico a $60 \mathrm{~Hz}$ de frequência fundamental e com carregamento nominal de 4,0 Nm para cada tipo de falha, ou seja, motor com: uma, duas, quatro barras quebradas consecutivamente e duas barras quebradas em lados opostos. A Figura 5.6 ilustra o efeito da variação do número de barras quebradas no espectro de frequência em torno da fundamental e o compara com um motor sem falhas.

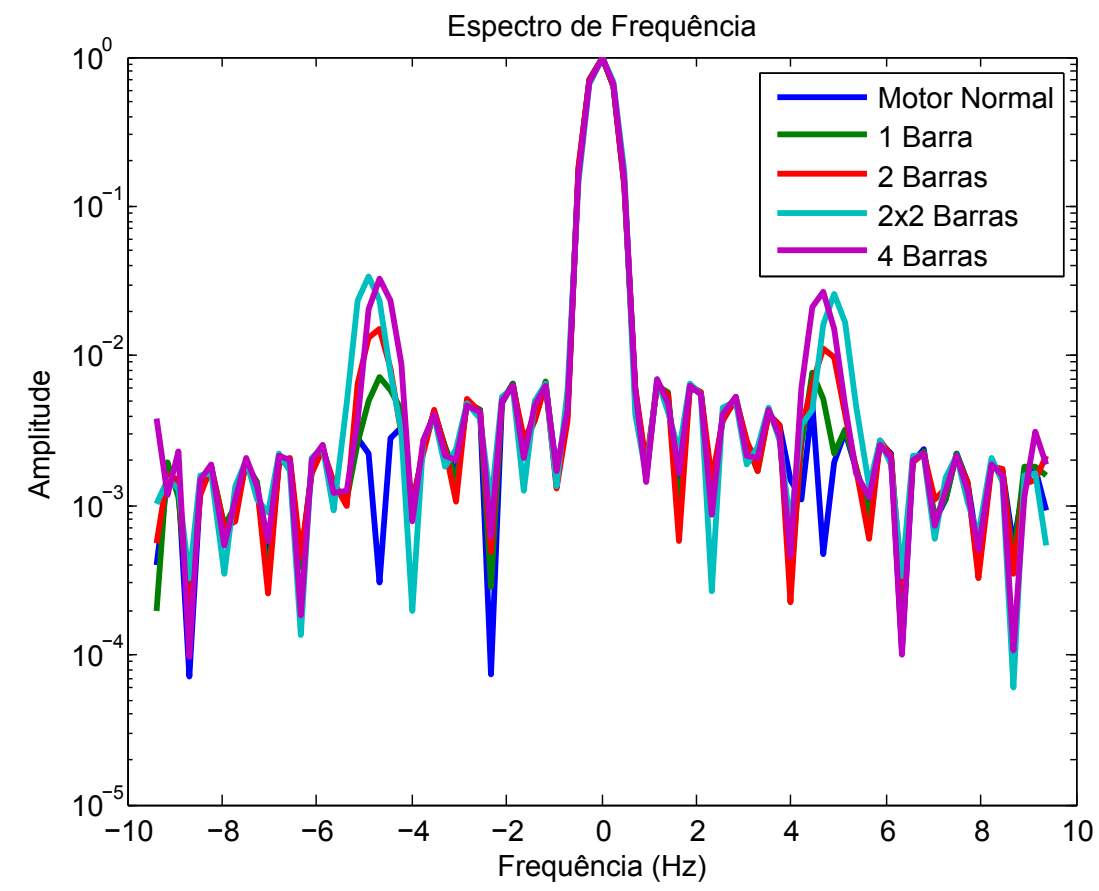

Figura 5.6: Efeito da variação do número de barras quebradas. 
Mediante a análise da Figura 5.6, observa-se que conforme se aumenta a quantidade de barras quebradas, as frequências sobressalentes em torno da fundamental se torna mais evidente. Adicionalmente, verifica-se que o módulo da amplitude de tais componentes de frequências de um motor com 4 barras quebradas são equivalentes a um motor com 2 barras consecutivamente quebradas em lados diametralmente opostos. Desta forma, a posição geométrica das barras quebradas não influenciou nas frequências da corrente. Entretanto, ensaios contendo outras combinações de barras quebradas devem ser realizados com o intuito de se ter uma base mais fundamentada para averiguar se os módulos dessas componentes estão relacionados à posição da quebra ou à quantidade de barras quebradas.

\section{Conjunto de MITs Normais}

Finalmente, esta análise consiste em investigar possíveis divergências nos espectros em torno da frequência fundamental entre os tipos de motores sem falhas disponibilizados no laboratório. Neste contexto, consideraram-se os motores: 1) motores normais, 2) motor de fábrica; 3) motor de alto rendimento; 4) motor adaptado para os ensaios de curto-circuito na configuração normal. Assim como nos estudos anteriores, o MIT foi acionado pelo inversor a $60 \mathrm{~Hz}$ com torque nominal de 4,0 Nm, sendo que sua análise espectral pode ser verificada mediante a Figura 5.7.

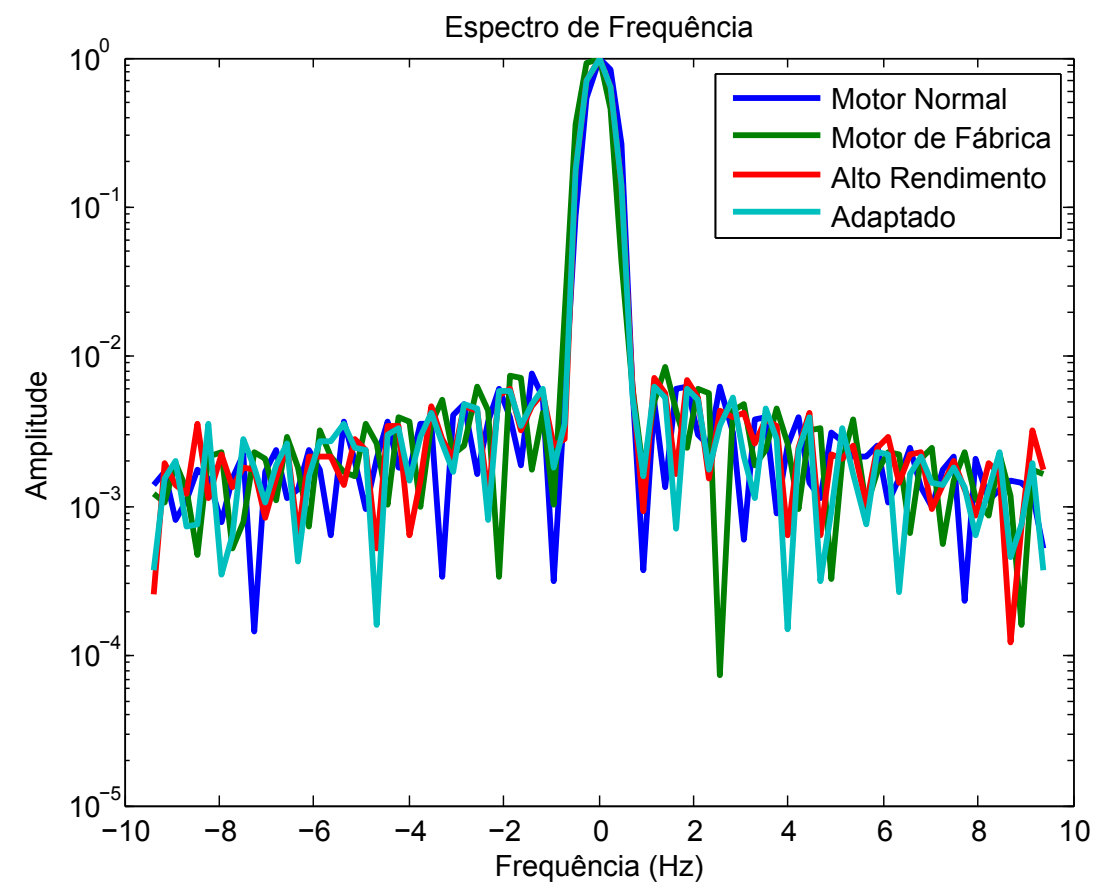

Figura 5.7: Caracterização de motores normais de tipos diferentes.

De acordo com a Figura 5.7, nota-se que as componentes de frequência de todos os motores estudados apresentam resultados idênticos. Desta forma, a invariância da análise espectral com relação ao tipo de motor o caracteriza adequadamente como um motor sem 
falhas, o qual se torna de suma importância para se desenvolver um sistema de detecção de falhas.

\section{Caso de Difícil Distinção}

A partir das análises realizadas até o momento, nota-se que com a diminuição do número de barras seccionadas, a amplitude dos sinais sobressalentes de frequências em torno da fundamental também é decrementado, conforme os resultados da Figura 5.6. Tais sinais também ficam menos evidentes e o seu deslocamento em torno da fundamental diminui quando o nível de carregamento no eixo do MIT é reduzido, conforme a Figura 5.5.

Desta forma, com o intuito de representar o caso mais difícil de distinção, considerou-se a comparação entre o acionamento de um MIT normal e outro com uma barra quebrada, estando o rotor sob o carregamento de apenas $0,5 \mathrm{Nm}$. Em tal análise o MIT foi acionado por um inversor trifásico a $60 \mathrm{~Hz}$ e seus resultados são ilustrados na Figura 5.8.

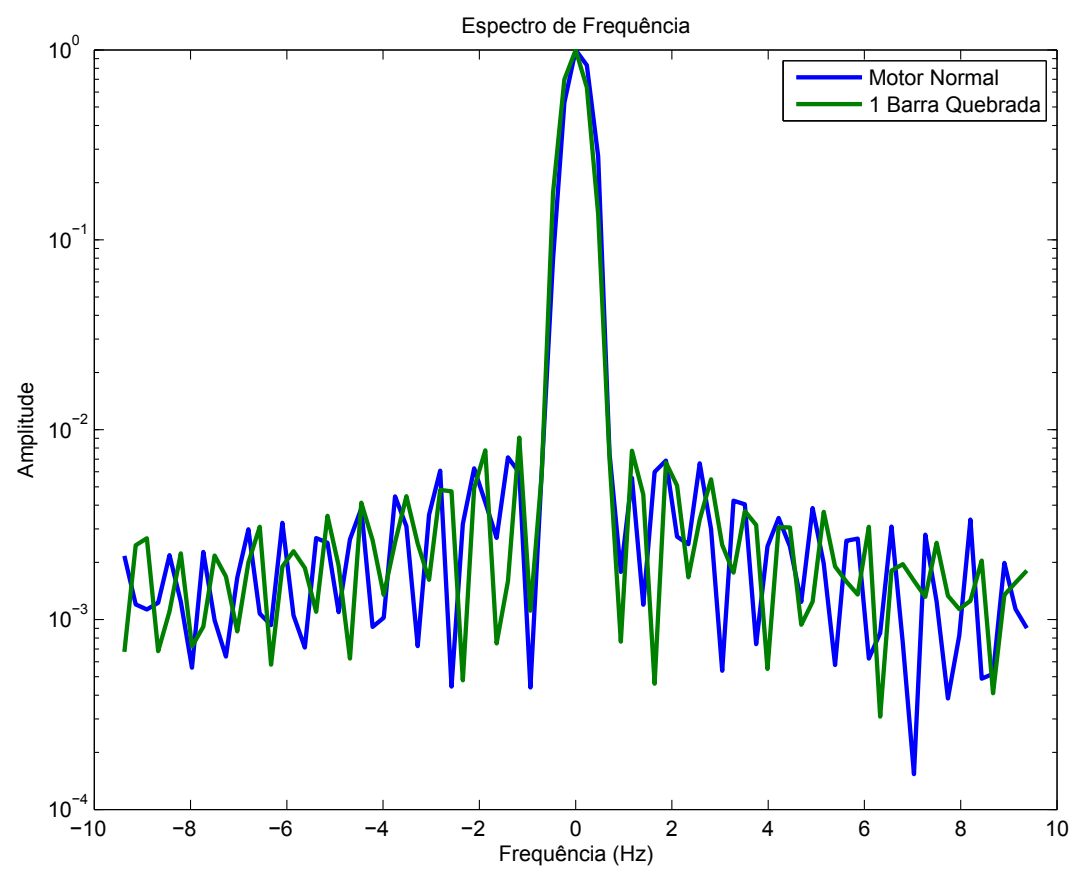

Figura 5.8: Análise de um motor normal e de outro com uma barra quebrada.

A partir dos resultados contidos na Figura 5.8, nota-se que a distinção entre um motor sem falhas e outro com uma barra quebrada é comprometida. Entretanto, em ambientes industriais, os MITs são geralmente dimensionados para operar próximo ao carregamento nominal, sendo raros os casos que trabalham a vazio.

\subsubsection{Análise de Componentes Principais}

Em algumas situações em que o número de variáveis de entrada para a RNA é muito grande, mas que os seus componentes estejam altamente correlacionados, ou seja, são linearmente dependentes, é recomendado reduzir a dimensão do vetor. A técnica utilizada 
pelo processo da análise de componentes principais resulta em três efeitos: 1) ortogonaliza os componentes do vetor de entrada para que os mesmos tornem linearmente independentes entre si; 2) ordena os resultados dos componentes ortogonais em ordem decrescente dos componentes de maior variação; 3) elimina os componentes que menos contribuem para a variância do conjunto de dados (BEALE; HAGAN; DEMUTH, 2011).

Considerando-se o pré-processamento de dados realizados até este instante, a RNA para o diagnóstico de quebras em barras de rotores do MIT seria composta por $2 m_{p}+1$ entradas, conforme representado na Equação 5.5. Entretanto, a complexidade e o esforço computacional quanto ao tempo de treinamento é relativamente elevado nesta situação. A implementação embarcada em hardware também requisitará maiores quantidades de memórias e/ou recursos de processamento, tornando o custo de desenvolvimento mais dispendioso.

O sistema neural de identificação de quebras em barras de rotores apresenta a estrutura ilustrada em diagrama de blocos na Figura 5.9. O sinal de corrente é processado pela FFT e normalizado em termos de amplitude e frequência. O vetor resultante $\mathbf{I}_{\mathbf{F F T}}$, o qual apresenta uma dimensão de $2 m_{p}+1$, é atribuído à técnica de PCA com o intuito de efetuar a transformação linear do espaço de $2 m_{p}+1$ dimensões para o eixo de coordenadas que apontam para o máximo e mínimo da variância do sinal. Em seguida, elimina-se as componentes que contribui menos que um patamar da variância total (JOLLIFFE, 2002). Nos testes realizados nesta tese, tal patamar foi determinado como sendo 1\% por métodos empíricos. O vetor resultante da PCA, $\mathbf{R N A}_{\mathbf{I N}}$, terá então uma dimensão reduzida em relação ao vetor $\mathbf{I}_{\mathbf{F F T}}$ e será empregado como variáveis de entradas da RNA.

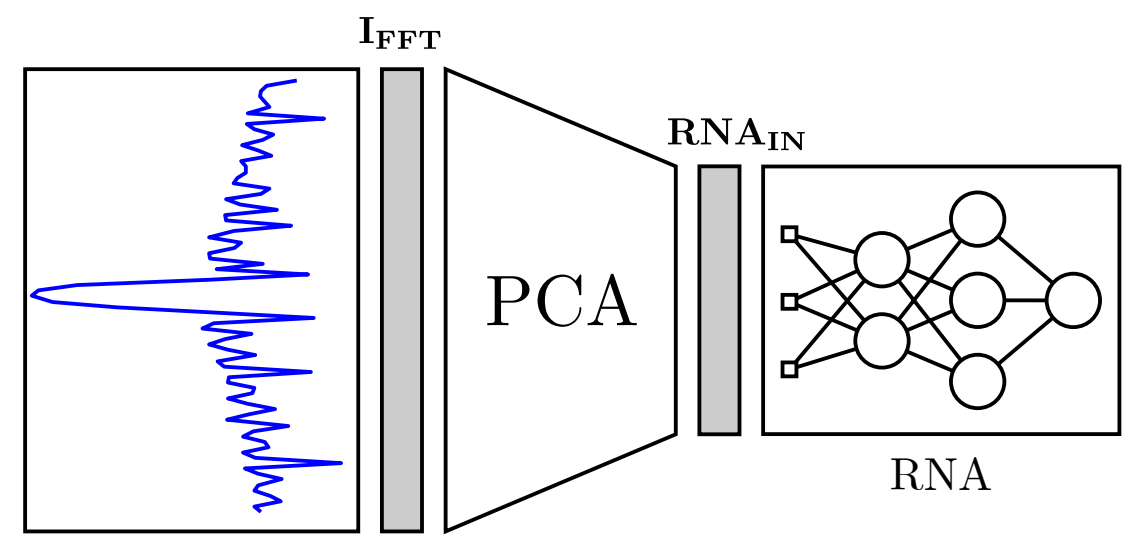

Sinal FFT

Figura 5.9: Redução da dimensionalidade do vetor de entrada mediante a PCA.

Os detalhes matemáticos do PCA e sua abordagem algorítmica de implementação podem ser consultados em JOLLIFFE (2002). Basicamente, o vetor RNA IN pode ser determinado para qualquer vetor $\mathbf{I}_{\mathbf{F F T}}$, conforme segue:

$$
\mathbf{R N A}_{\mathbf{I N}[\mathrm{N} \times 1]}=\mathbf{C}_{\left[\mathrm{N} \times \mathrm{N}_{\mathrm{win}}\right]} \cdot \mathbf{I}_{\mathbf{F F T}\left[\mathrm{N}_{\mathrm{win}} \times 1\right]}
$$

em que $\mathbf{C}_{\left[\mathrm{N} \times \mathrm{N}_{\text {win }}\right]}$ é a matriz de coeficientes de transformação obtidos no PCA. 


\subsection{Estruturação da RNA}

A topologia de RNA empregada no sistema proposto de identificação de barras quebradas consiste de uma Perceptron Multicamadas.

\subsubsection{Configuração da RNA}

Em virtude de a presente tese realizar diversos estudos de casos para avaliar a metodologia proposta, diferentes configurações de RNA foram projetadas. Desta forma, a estruturação da RNA em termos de número de camadas, número de neurônios, conjuntos de treinamento e sua divisão será especificada em cada seção do Capítulo 6.

As funções de ativação das camadas ocultas em todos os estudos de casos foram definidas como tangente hiperbólica, em virtude de ser considerada apropriada para efetuar o mapeamento não linear do relacionamento entre entrada e saída. A função de ativação da camada de saída se constitui de uma função linear, em virtude do seu baixo custo computacional e simplicidade de implementação. Como o neurônio de saída, de acordo com estas configurações, efetua a combinação linear de funções não-lineares, o mapeamento não linear se torna intrínseco.

\subsubsection{Variáveis de Entrada}

A quantidade de entradas da RNA, conforme visto na seção anterior, é determinada de acordo com o processamento do PCA. Como o conjunto de treinamento varia de acordo com cada estudo, este número pode ser diferente para cada caso.

\subsubsection{Variáveis de Saída}

O principal objetivo nesta etapa do trabalho consiste em determinar se o MIT está operando sob condições normais ou em condições de falhas. Neste contexto, não há interesse em determinar a quantidade de barras quebradas ou a disposição de suas quebras. Portanto, a variável é caracterizada por duas classes distintas, definidas conforme segue:

$$
\left\{\begin{array}{lll}
\text { Motor sem Falhas } & \Rightarrow & -1 \\
\text { Quebras em Barras } & \Rightarrow & +1
\end{array}\right.
$$

\subsubsection{Pós-Processamento}

Em virtude da função de ativação do neurônio de saída ser linear, seus resultados podem teoricamente assumir valores entre $[-\infty,+\infty]$. Como a saída é classificada aos valores +1 e -1, o seguinte pós-processamento é realizado:

$$
y_{p}\left(y_{r n a}\right)= \begin{cases}-1 & \text { se } \quad y_{r n a}<0 \\ 1 & \text { se } \quad y_{r n a} \geq 0\end{cases}
$$




\subsection{Projeto do Sistema Neural de Monitoramento}

A metodologia proposta para o projeto do sistema neural de monitoramento de quebra de barras de rotores requer o dimensionamento de inúmeros parâmetros que serão descritos nesta seção.

\subsubsection{Especificação dos Parâmetros da FFT}

Em relação a etapa da FFT, deve-se proceder os seguintes passos:

1. Determinar a resolução em frequência $(R)$ adequada para efetuar a análise requerida;

2. Selecionar a frequência de amostragem $\left(f_{a}\right)$ compatível com a frequência máxima do sinal $\left(f_{s}\right)$ de interesse; se for caso, desenvolver um filtro anti-aliasing para essa frequência.

3. A partir de $R$ e $f_{a}$ e, considerando-se que $N_{a}$ deve ser equivalente a uma potência de 2 , determinar o tempo de necessário para a aquisição $\left(t_{a q}\right)$.

4. Finalmente, selecionar quantas amostras em torno da fundamental deverá ser empregada para análise $\left(m_{p}\right)$

\subsubsection{Especificação dos Parâmetros do PCA}

O processamento do PCA determinará a dimensão do vetor de entrada da RNA. Sua especificação é realizada conforme os seguintes passos:

1. Especificar o patamar para rejeição de componentes que apresentam percentualmente baixa variância do conjunto em seu eixo.

2. Aplicar a técnica de PCA no conjunto de treinamento da RNA e adquirir a matriz de coeficientes de transformação $\mathbf{C}$.

3. Aplicar a Equação (5.8) nos conjuntos de validação e de teste antes de atribuir às entradas da RNA. Este procedimento também deverá ser realizado em campo.

\subsubsection{Especificação dos Parâmetros da RNA para operação offline}

O dimensionamento da RNA para o sistema neural de identificação de barras quebradas em MIT é basicamente realizado de acordo com os procedimentos mencionados na Seção 4.1.8 localizada na Página 60. Os principais parâmetros da RNA que deverão ser identificados após seu treinamento para embarcá-la em hardware estão listados a seguir: 
1. Número de camadas neurais;

2. Número de neurônios em cada camada;

3. Funções de ativação de cada neurônio;

4. Matriz de pesos sinápticos após o treinamento. 



\section{Capítulo 6}

\section{Resultados Experimentais}

\subsection{Introdução}

Neste capítulo serão apresentados os resultados obtidos a partir da implementação de um sistema de detecção de quebras em barras de rotores de gaiola de esquilo de MITs.

A base de dados experimentais se constitui de uma ampla variedade de condições de operação e acionamento, sendo eles: 1) acionamento direto da rede (AD); 2) acionamento pelo inversor trifásico (INV) da WEG; 3) frequência de acionamento de $40 \mathrm{~Hz}, 45 \mathrm{~Hz}$, $50 \mathrm{~Hz}, 55 \mathrm{~Hz}$ e $60 \mathrm{~Hz}$; 4) torque de carga de 0,5 Nm, 1,0 Nm, 1,5 Nm, 2,0 Nm, 2,5 Nm, 3,0 Nm, 3,5 Nm e 4,0 Nm; 5) tipos de motores entre Motor Normal (MN), Alto Rendimento (AR), Motor de Fábrica (MF) e Motor Adaptado (MA); 6) rotores com 1 barra quebrada (R1BQ), duas barras consecutivamente quebradas (R2BQ), duas barras consecutivamente quebradas em posições diametralmente opostas (R2x2BQ) e quatro barras consecutivamente quebradas (R4BQ).

Com o intuito de investigar o desempenho e a robustez da metodologia de projeto do sistema proposto, efetuaram-se os seguintes estudos:

$\square$ Acionamento Direto: Utiliza-se apenas de dados relacionados ao acionamento direto do MIT, sendo o sistema de identificação de falhas especializado para este tipo de acionamento.

$\square$ Acionamento pelo Inversor Trifásico: Foca-se em aplicações para identificar falhas em motores acionados por inversores trifásicos. Desta forma, trabalha-se apenas com este tipo de dados experimentais.

\ Acionamento Direto + Inversor Trifásico: Trabalha-se simultaneamente com dados de acionamento direto e de inversor trifásicos a fim de se constituir uma única ferramenta.

$\square$ Acionamento Direto $\Rightarrow$ Inversor Trifásico: Objetiva-se implementar um sistema especializado no acionamento direto com o intuito de generalizar suas soluções 
para o inversor trifásico.

\subsection{Acionamento Direto da Rede}

Esta análise visa implementar um sistema neural de identificação de barras quebradas em MITs que são acionados diretamente pela rede elétrica. Neste contexto, considera-se que as tensões trifásicas de alimentação são nominais e equilibradas, com frequência de $60 \mathrm{~Hz}$.

A base de dados empregada para a modelagem do sistema de identificação é composta por: 1) motores normais; 2) motores de alto rendimento; 3) motores de fábrica; 4) motores adaptados. Consideram-se também toda a faixa de torque, ou seja: 0,5 Nm, 1,0 Nm, 1,5 Nm, 2,0 Nm, 2,5 Nm, 3,0 Nm, 3,5 Nm e 4,0 Nm.

Embora se tenha uma quantidade razoável de ensaios experimentais, poucos padrões por combinação estão presentes nas bases de dados. Para aumentar a quantidade de padrões, adotou-se a estratégia de utilizar as correntes trifásicas, ou seja, $i_{a}, i_{b}$ e $i_{c}$. Entretanto, ressalta-se que o sistema de identificação utilizará apenas uma variável de corrente.

O conjunto de dados totais foi dividido em dois subconjuntos, são eles: 1) conjunto de treinamento; 2) conjunto de teste. A Tabela 6.1 ilustra como os ensaios foram divididos entre conjunto de treinamento e de teste para a rede neural. Ao total são 183 amostras no conjunto de dados, sendo 122 empregadas para o treinamento da RNA e 61 dados para checar sua generalização. Observa-se que as correntes $i_{a}$ e $i_{b}$ foram utilizadas para o treinamento e a corrente $i_{c}$ para o teste de generalização.

Tabela 6.1: Conjunto de dados disponíveis para análise: Acionamento Direto.

\begin{tabular}{|c|c|c|}
\hline Descrição & Treinamento & Testes \\
\hline \hline Acionamento & $\mathrm{AD}$ & $\mathrm{AD}$ \\
\hline Tipos & $\mathrm{MN}, \mathrm{MF}, \mathrm{MA}, \mathrm{AR}$ & $\mathrm{MN}, \mathrm{MF}, \mathrm{MA}, \mathrm{AR}$ \\
\hline Falhas & $\mathrm{R} 1 \mathrm{BQ}, \mathrm{R} 2 \mathrm{BQ}, \mathrm{R} 2 \mathrm{x} 2 \mathrm{BQ}, \mathrm{R} 4 \mathrm{BQ}$ & $\mathrm{R} 1 \mathrm{BQ}, \mathrm{R} 2 \mathrm{BQ}, \mathrm{R} 2 \times 2 \mathrm{BQ}, \mathrm{R} 4 \mathrm{BQ}$ \\
\hline Sinais & $i_{a}, i_{b}$ & $i_{c}$ \\
\hline Padrões & 122 & 61 \\
\hline
\end{tabular}

A estrutura RNA escolhida consiste de uma rede de apenas uma camada oculta contendo dois neurônios, cujas funções de ativação foram as tangentes sigmóides. A camada de saída é composta por um neurônio com função de ativação linear.

O processo de treinamento da RNA foi realizado mediante o ambiente MATLAB ao longo de 1000 épocas, conforme ilustrado na Figura 6.1. Observa-se que o desempenho da RNA em relação ao conjunto de treinamento se aprimora a cada época. Em contrapartida, o desempenho dos dados de teste melhora até aproximadamente 100 épocas e, em seguida, o seu erro começa a aumentar. Este fenômeno é um indicativo de que a RNA inicia 
o processo de sobre-ajustagem de seus parâmetros livres, cujo efeito é de deteriorar o desempenho de generalização.

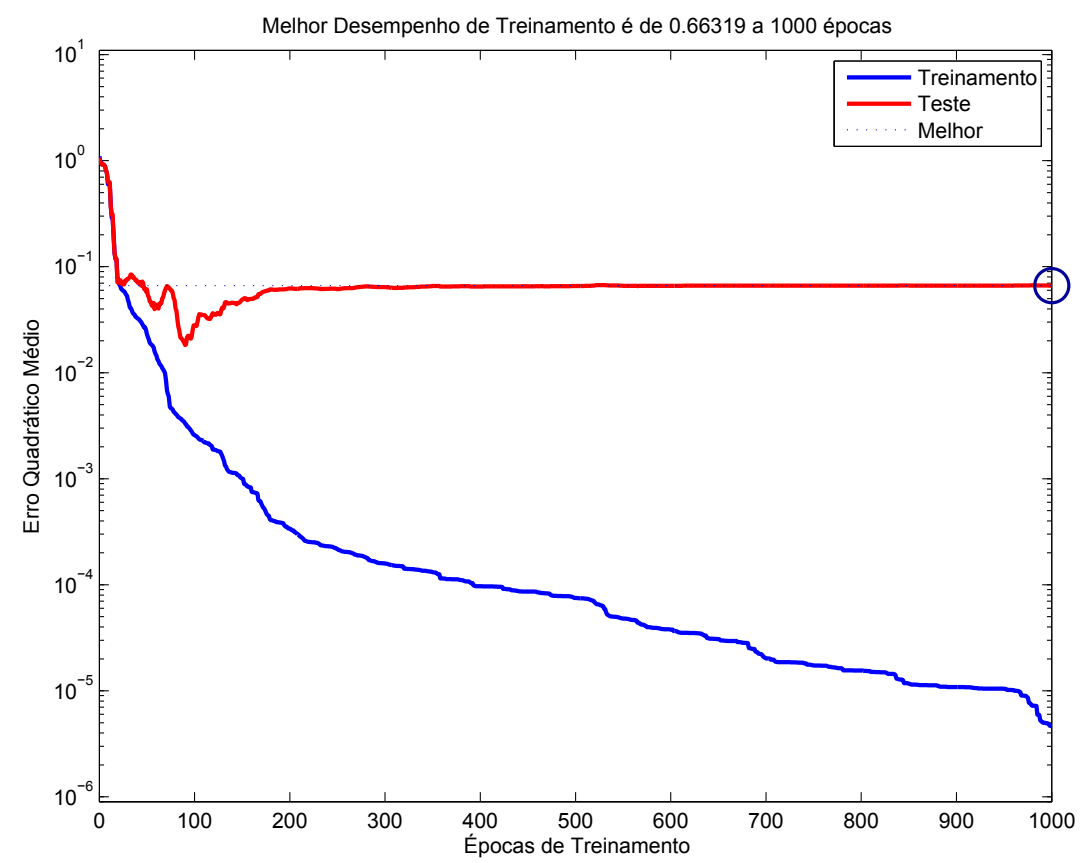

Figura 6.1: Desempenho de treinamento da RNA: 2 neurônios na camada oculta.

Ressalta-se que embora o desempenho dos dados de teste tenha sido traçado ao longo das épocas, o mesmo não participou em nenhuma instância do algoritmo backpropagation. Desta forma, a RNA teria melhor desempenho de generalização se o processo de treinamento tivesse sido interrompido em aproximadamente 100 épocas de treinamento. Para tanto, o conjunto de dados deveria ser dividido em três conjuntos, são eles: conjunto de treinamento, validação e teste, efetuando-se aqui o procedimento de parada antecipada (early stopping). Em virtude de pouca disponibilidade de dados, evitou-se tal separação de dados.

A janela de dados da FFT foi dimensionada para um tempo de aquisição de 3 segundos, obtendo-se a resolução de 0,2344 Hz. A janela da FFT normalizada foi avaliada a $m_{p}=30$ pontos para esquerda e para a direita, ou seja, $\pm 7,032 \mathrm{~Hz}$ em torno da frequência fundamental.

O PCA foi configurado para eliminar as componentes em que os dados representam menos de $1 \%$ da variância total. Após o processamento, a janela da FFT normalizada em torno da fundamental que apresentava 61 elementos foi reduzida para apenas 15 elementos, os quais são utilizados como variáveis de entrada da RNA.

Os resultados de desempenho da RNA são descritos em termos de taxas de acertos na Tabela 6.2. Observa-se que a RNA foi capaz de diagnosticar motores com barras quebradas adequadamente tanto com os dados de treinamento quanto com os dados de testes, apresentando desempenho de $100 \%$ e 98,36\%, respectivamente. 
Tabela 6.2: Taxa de acertos da RNA com 2 neurônios na camada oculta.

\begin{tabular}{|c|c|c|}
\cline { 2 - 3 } \multicolumn{1}{c|}{} & Treinamento & Teste \\
\hline Taxa de Acerto & $100 \%$ & $98,36 \%$ \\
\hline
\end{tabular}

Dentre os dados de testes atribuídos ao sistema de detecção de falhas, a RNA forneceu diagnóstico de alarme falso negativo em apenas um ensaio, o qual consistiu de um MIT com 4 barras quebradas no rotor operando ao torque de carga de 0,5 $\mathrm{Nm}$.

O gráfico ilustrado na Figura 6.2 mostra os resultados de classificação do sistema neural de detecção de quebra nas barras nos rotores de MITs. O eixo das abscissas é o limiar de classificação, ou seja, valores da saída da RNA acima de zero são classificados como barras quebradas e abaixo de zero como motores saudáveis. Os dados do intervalo de amostras entre 1 e 122 são os os dados de treinamento, enquanto que o restante são os dados de testes. A curva em azul são as classes dos dados de treinamento, já os marcadores vermelhos são os resultados produzido pela RNA antes do pós-processamento denotado pela Equação (5.9).

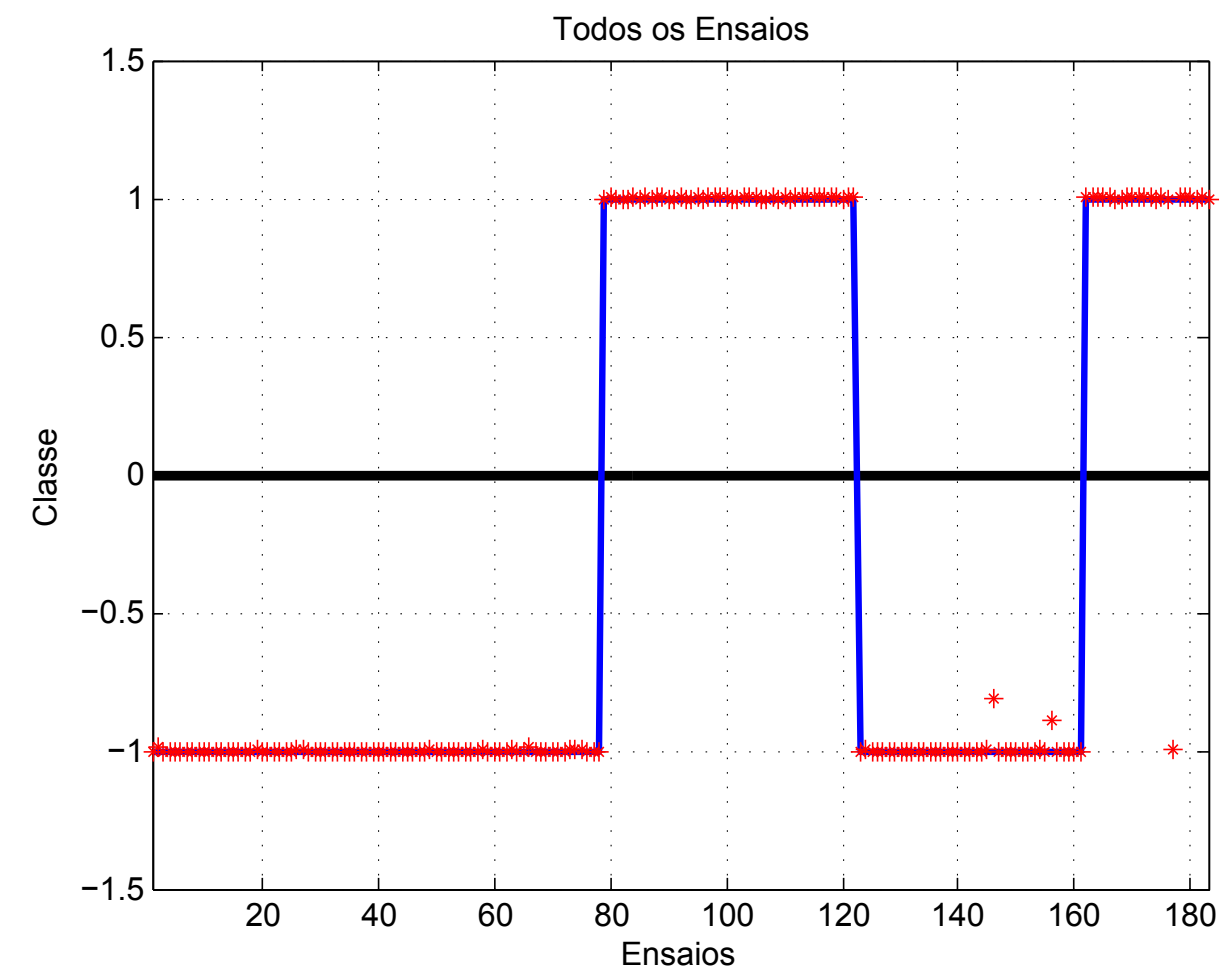

Figura 6.2: Resultados gerais do sistema neural de detecção de barras quebradas.

Na sequência, propôs-se analisar o desempenho da RNA ao aumentar o número de neurônios da camada oculta para 20 unidades. O gráfico que ilustra o desempenho de treinamento desta arquitetura de RNA é ilustrado na Figura 6.3. Embora o aumento da complexidade da RNA tenda a resultar em "overfitting", esta arquitetura foi capaz de melhorar os resultados de generalização, conforme pode ser observado na Tabela 6.3. 


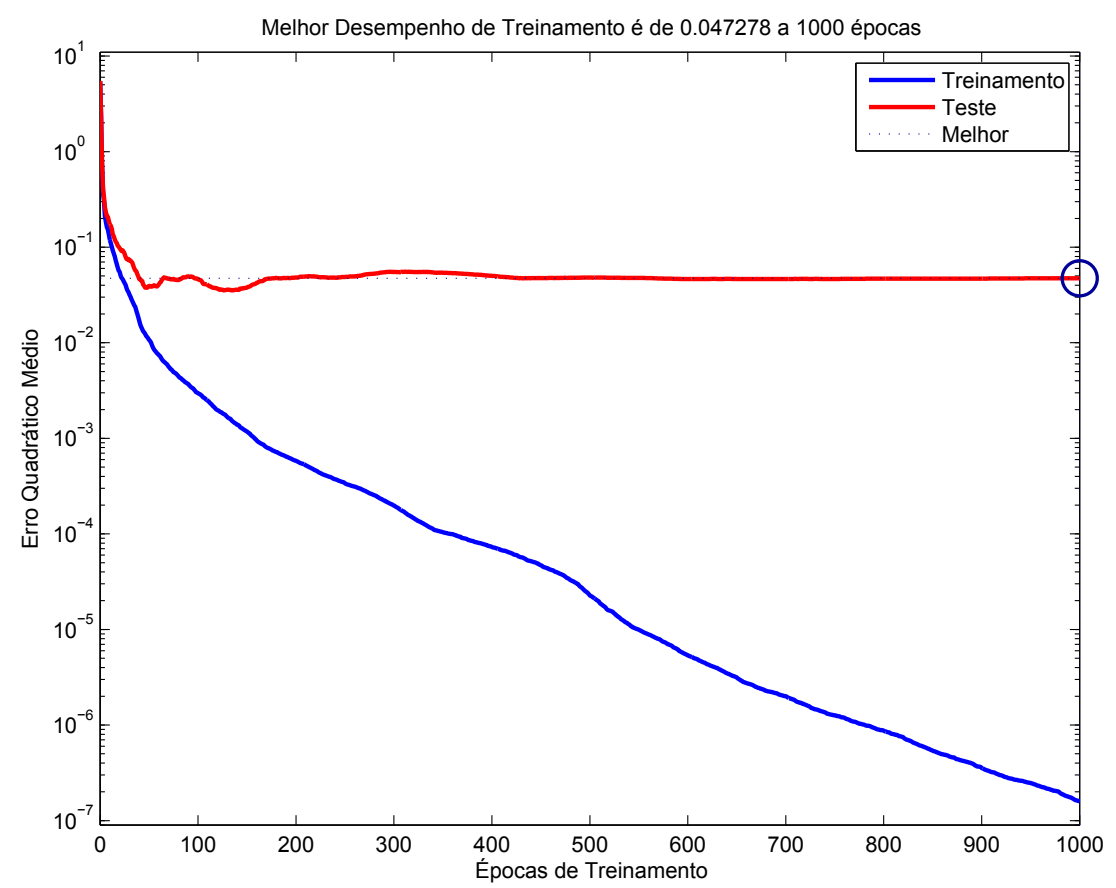

Figura 6.3: Desempenho de treinameno da RNA: 20 neurônios na camada oculta.

Neste caso, o sistema de detecção de quebras nas barras atingiu taxas de acertos de $100 \%$ tanto para o conjunto de treinamento quanto para o conjunto de teste, obtendo $100 \%$ de aproveitamento geral.

Tabela 6.3: Taxa de acertos da RNA com 20 neurônios na camada oculta.

\begin{tabular}{|l|c|c|}
\cline { 2 - 3 } \multicolumn{1}{c|}{} & Treinamento & Teste \\
\hline Taxa de Acerto & $100 \%$ & $100 \%$ \\
\hline
\end{tabular}

Embora esta configuração desta rede obtenha melhores resultados, a sua complexidade computacional é maior, requisitando-se aqui mais recursos de hardware e de memória. A partir desta análise, tal acréscimo do número de neurônios não se justificaria, visto que o incremento de desempenho é mínimo.

Conforme se observa na Tabela 6.1, a quantidade de dados reservada para a análise de teste é de $33 \%$ do total de dados disponíveis, cujo valor pode ser considerado alto já que a disponibilidade de dados é baixa. Neste contexto, com o intuito de explorar ainda mais a potencialidade da metodologia neural de detecção de quebra nas barras no rotores e contornar o problema da baixa disponibilidade de dados, adotou-se a seguinte estratégia: como a metodologia requer 3 segundos de aquisição para efetuar a análise e a base de dados contém em média 4 segundos de sinal, efetuou-se o deslocamento da janela de aquisição em 0,3 segundos até se atingir o final da base de dados, conforme ilustrado na Figura 6.4. Embora parte dos dados seja redundante em comparação à primeira janela, outra parte dos dados conterá informações que serão distintas das de treinamento. 


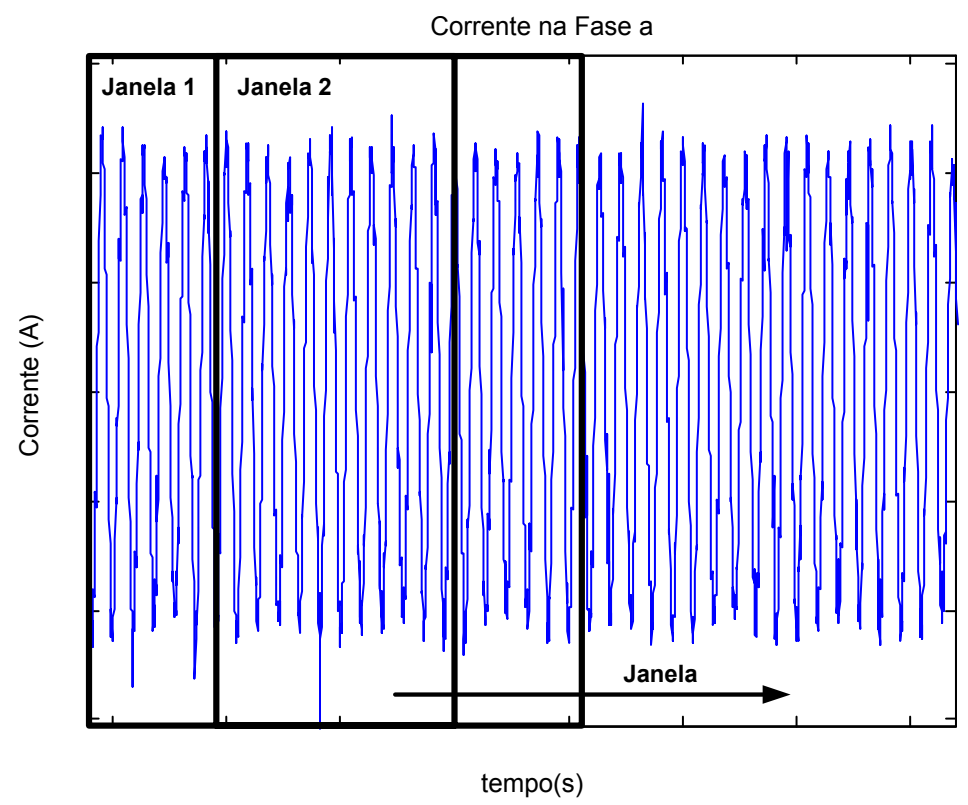

Figura 6.4: Deslocamento da janela de análise dos sinais.

A Tabela 6.4 ilustra a composição dos ensaios realizados e a divisão de dados para o processo de treinamento do sistema neural de detecção. Em virtude da maior disposição de dados, optou-se por dividir o conjunto de dados total em três subconjuntos: 1) conjunto de treinamento, 2) conjunto de validação, 3) conjunto de testes. Basicamente, a composição dos dados da Tabela 6.1 foi utilizada para desempenhar o papel do treinamento e de sua validação a fim de melhorar os resultados de generalização mediante a técnica de parada antecipada. Os restantes dos dados advindos do deslocamento da janela de aquisição foram empregados para efetuar o teste da RNA.

Tabela 6.4: Conjunto de dados disponíveis para análise: Acionamento Direto.

\begin{tabular}{|c|c|c|c|}
\hline Descrição & Treinamento & Validação & Testes \\
\hline \hline Acionamento & $\mathrm{AD}$ & $\mathrm{AD}$ & $\mathrm{AD}$ \\
\hline Tipos & $\mathrm{MN}, \mathrm{MF}, \mathrm{MA}, \mathrm{AR}$ & idem & idem \\
\hline Falhas & $\mathrm{R} 1 \mathrm{BQ}, \mathrm{R} 2 \mathrm{BQ}, \mathrm{R} 2 \mathrm{x} 2 \mathrm{BQ}, \mathrm{R} 4 \mathrm{BQ}$ & idem & idem \\
\hline Sinais & {$[$ janela 1$] i_{a}, i_{b}$} & {$\left[\right.$ janela 1] $i_{c}$} & {$[$ restante $] i_{a}, i_{b}, i_{c}$} \\
\hline Padrões & 122 & 61 & 399 \\
\hline
\end{tabular}

A base de dados é composta por 122 dados de correntes $i_{a}$ e $i_{b}$ da primeira janela para o conjunto de treinamento, 61 dados de correntes $i_{c}$ da primeira janela para o conjunto de validação e 399 dados de correntes $i_{a}, i_{b}$ e $i_{c}$ das restantes das janelas de dados para o conjunto de testes. Nota-se que o desempenho da rede é avaliado por um conjunto que representa $68,5 \%$ da quantidade total de dados. Isto ilustra que a RNA foi treinada por um universo de dados reduzidos e suas regras de mapeamento foram generalizadas por um conjunto maior de dados.

Diante da nova composição de dados, a RNA foi reestruturada de forma a obter 
resultados com altas taxas de acertos. Sua estrutura é caracterizada por uma rede com uma camada escondida com 5 neurônios.

A Figura 6.5 ilustra o desempenho durante o treinamento da RNA. O gráfico apresenta os erros quadráticos médios dos conjuntos de treinamento, validação e teste. Conforme mencionado anteriormente, os dados de testes não são utilizados em nenhuma das etapas do algoritmo de treinamento, embora os seus erros quadráticos médios sejam ilustrados no gráfico. Por outro lado, o conjunto de validação é empregado para monitorar o nível de generalização da RNA ao longo do processo de treinamento. Nota-se que o erro de validação decai juntamente com o erro de treinamento até 42 épocas, aumentando-se a partir deste ponto. Desta forma, a RNA adota o critério de parada antecipada e utiliza as configurações dos parâmetros livres da RNA (pesos sinápticos e limiares) de 42 épocas, assumindo-se que a rede não estará sobre-ajustada e apresentará uma melhor capacidade de generalização.

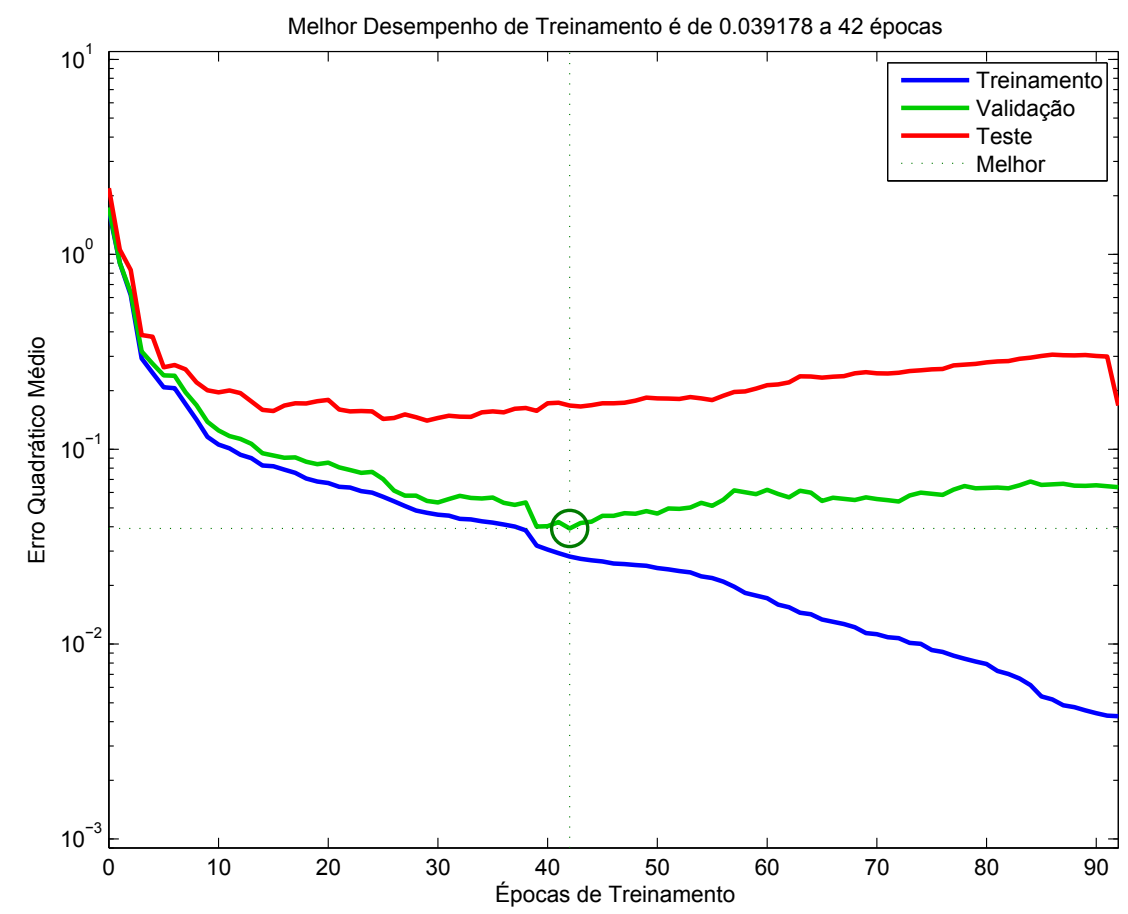

Figura 6.5: Desempenho de treinameno da RNA: 5 neurônios na camada oculta.

A Tabela 6.5 ilustra o desempenho da RNA para identificar quebras em barras de rotor de MITs, obtendo taxas de acertos de $100 \%$ para o conjunto de treinamento e $98,4 \%$ para o conjunto de validação e $94,7 \%$ para o conjunto de testes. O desempenho geral atingiu taxa de acerto de $96,2 \%$.

Tabela 6.5: Taxa de acertos da RNA.

\begin{tabular}{|c|c|c|c|}
\cline { 2 - 4 } \multicolumn{1}{c|}{} & Treinamento & Validação & Teste \\
\hline Taxa de Acerto & $100 \%$ & $98,4 \%$ & $94,7 \%$ \\
\hline
\end{tabular}


Tais resultados ilustram que a o sistema neural de identificação de quebras nas barras de rotores foi capaz de mapear o limiar de classificação das falhas e generalizar a regra para dados não participantes do treinamento.

A Tabela 6.6 representa uma compilação de erros em função do carregamento do eixo do MIT. Observa-se que no conjunto de dados de teste, 12 amostras obtiveram erro de identificação ao carregamento de $0,5 \mathrm{Nm}$. Por outro lado, em geral, nota-se que a RNA alcançou $100 \%$ de acertos em todos os conjuntos considerando o carregamento acima de 2,5 Nm. Este resultado torna-se vantajoso, visto que, na prática, os MITs são dimensionados para operar próximo ao carregamento nominal.

Tabela 6.6: Tabela de erros em função do carregamento.

\begin{tabular}{|c|c|c|c|c|c|c|c|c|c|}
\hline Carregamento $(\mathrm{Nm})$ & 0,5 & 1,0 & 1,5 & 2,0 & 2,5 & 3,0 & 3,5 & 4,0 & Total \\
\hline \hline Treinamento & 0 & 0 & 0 & 0 & 0 & 0 & 0 & 0 & 0 \\
\hline Validação & 0 & 1 & 0 & 0 & 0 & 0 & 0 & 0 & 1 \\
\hline Testes & 12 & 2 & 0 & 7 & 0 & 0 & 0 & 0 & 20 \\
\hline
\end{tabular}

A Figura 6.6 ilustra o desempenho do classificador neural (sem ser pós-processado pela Equação (5.8))ao longo do conjunto total de dados experimentais. As amostras entre 1 e 122 representam o conjunto de treinamento, enquanto que as amostras entre 123 e 183 consistem nos dados de validação. O restante das amostras refere-se ao conjunto de teste utilizado para avaliar o nível de generalização da solução encontrada pela RNA.

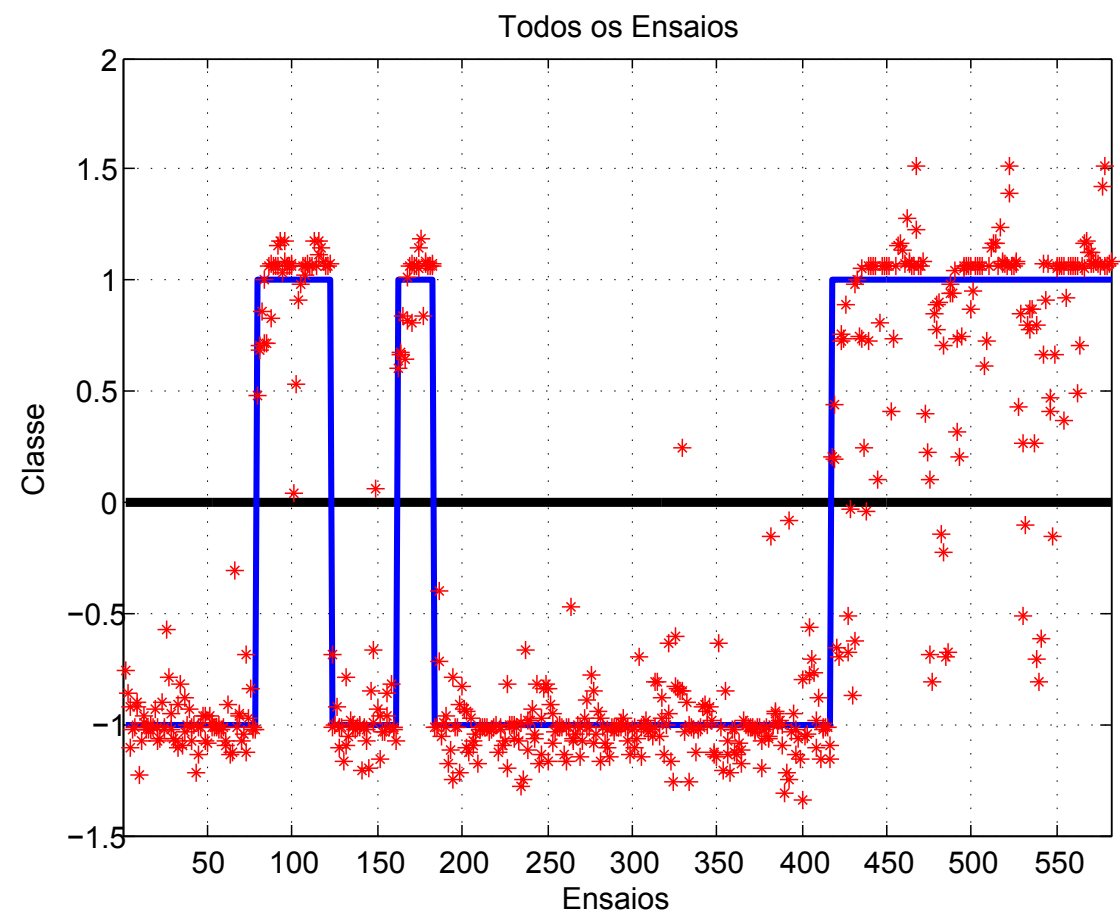

Figura 6.6: Resultados gerais do sistema neural de detecção de barras quebradas 


\subsection{Acionamento pelo Inversor Trifásico}

O principal objetivo desta análise consiste em desenvolver um sistema neural de detecção de barras quebradas de rotores de gaiola de esquilo de um MIT acionado por um inversor PWM trifásico. Desta forma, consideram-se tensões senoidais moduladas por largura de pulsos com frequências de acionamento de $40 \mathrm{~Hz}, 45 \mathrm{~Hz}, 50 \mathrm{~Hz}, 55 \mathrm{~Hz}$ e $60 \mathrm{~Hz}$.

A base de dados empregada para a modelagem do sistema de identificação é dada por: 1) motores normais; 2) motores de alto rendimento; 3) motores de fábrica; 4) motores adaptados. Consideram-se também toda faixa de torque, ou seja: 0,5 Nm, 1,0 Nm, 1,5 Nm, 2,0 Nm, 2,5 Nm, 3,0 Nm, 3,5 Nm e 4,0 Nm.

As falhas consideradas neste estudo são rotores com: 1) uma barra quebrada; 2) duas barras quebradas; 3) duas barras quebradas em lados radialmente opostos e 4) quatro barras quebradas.

A Tabela 6.7 ilustra como os ensaios foram divididos entre conjuntos de treinamento e de teste para a rede neural. Ao total são 3423 amostras no conjunto de dados, sendo 618 empregados para o treinamento da RNA e 309 dados para checar sua generalização. As correntes $i_{a}$ e $i_{b}$ foram utilizados para o treinamento e a corrente $i_{c}$ para o teste de generalização.

Tabela 6.7: Conjunto de dados disponíveis para análise: Inversor Trifásico.

\begin{tabular}{|c|c|c|}
\hline Descrição & Treinamento & Testes \\
\hline \hline Acionamento & $\mathrm{INV}$ & INV \\
\hline Frequência & $40 \mathrm{~Hz}, 45 \mathrm{~Hz}, 50 \mathrm{~Hz}, 55 \mathrm{~Hz}, 60 \mathrm{~Hz}$ & idem \\
\hline Tipos & $\mathrm{MN}, \mathrm{MF}, \mathrm{MA}, \mathrm{AR}$ & $\mathrm{MN}, \mathrm{MF}, \mathrm{MA}, \mathrm{AR}$ \\
\hline Falhas & $\mathrm{R} 1 \mathrm{BQ}, \mathrm{R} 2 \mathrm{BQ}, \mathrm{R} 2 \mathrm{x} 2 \mathrm{BQ}, \mathrm{R} 4 \mathrm{BQ}$ & $\mathrm{R} 1 \mathrm{BQ}, \mathrm{R} 2 \mathrm{BQ}, \mathrm{R} 2 \mathrm{x} 2 \mathrm{BQ}, \mathrm{R} 4 \mathrm{BQ}$ \\
\hline Sinais & $i_{a}, i_{b}$ & $i_{c}$ \\
\hline Padrões & 618 & 309 \\
\hline
\end{tabular}

Esta seleção de dados é bem semelhante à primeira análise do sistema de detecção de barras quebradas de MITs acionados diretamente pela rede, conforme a Tabela 6.1. Entretanto, em virtude do inversor trifásico acionar o MIT sob diversas condições de frequência, a quantidade disponível de dados é maior.

A RNA parametrizada mediante este dois conjuntos de dados apresentou a estrutura de 1 camada oculta com 20 neurônios. As funções de ativação da camada oculta são do tipo tangente sigmóide enquanto que da saída é do tipo linear.

O desempenho da RNA ao longo do treinamento é ilustrado pela Figura 6.7. Durante o início do processo, tanto o erro do conjunto de treinamento quanto o erro do conjunto de teste diminuem até atingir aproximadamente 150 épocas. A partir deste ponto, a rede inicia o processo de sobre-ajuste de parâmetros internos, deteriorando-se a sua habilidade de generalização ao longo das épocas. 


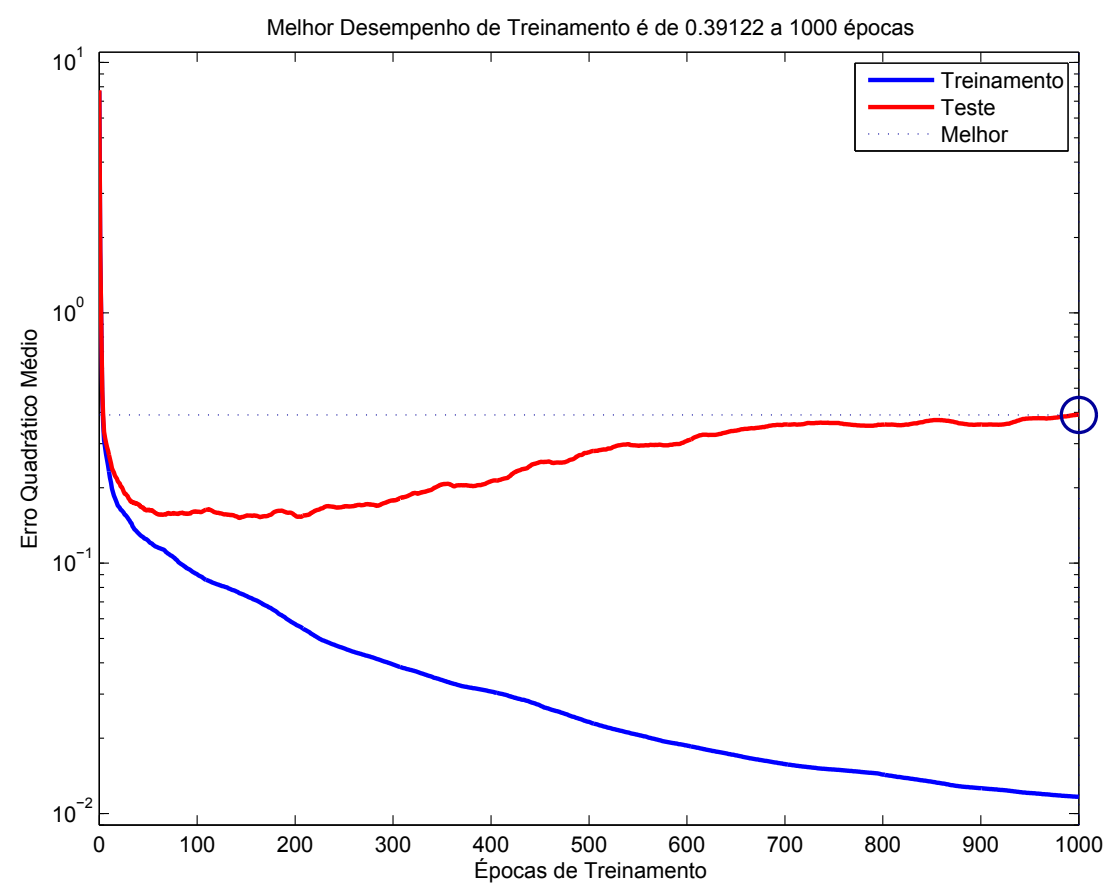

Figura 6.7: Desempenho de treinamento da RNA: 20 neurônios na camada oculta.

Em virtude de não se dispor de um conjunto de validação para a RNA controlar o nível de generalização, o treinamento continua até se atingir um dos critérios de parada, neste caso, 1000 épocas de treinamento.

O desempenho de detecção de MITs operando sob condições de barras quebradas em seu rotor são expressas na Tabela 6.8. Nota-se que a taxa de acerto dos ensaios do conjunto de treinamento foi de $100 \%$, enquanto que a precisão dos dados de teste de validação atingiu os 92,56\%, o que representa a capacidade rede de generalizar suas regras internas. O taxa de acertos global do sistema de identificação alcançou resultados de $97,52 \%$.

Tabela 6.8: Taxa de acertos da RNA com 20 neurônios na camada oculta.

\begin{tabular}{|c|c|c|}
\cline { 2 - 3 } \multicolumn{1}{c|}{} & Treinamento & Teste \\
\hline Taxa de Acerto & $100 \%$ & $92,56 \%$ \\
\hline
\end{tabular}

A Figura 6.8 ilustra o resultado global da saída da RNA antes da etapa de pósprocessamento do sinal. As amostras entre 1 e 618 referem-se ao conjunto de treinamento, enquanto que os dados entre 619 e 927 correspondem aos ensaios utilizados no conjunto de teste de generalização do sistema de identificação. Nota-se que a saída da RNA referente ao conjunto de treinamento fornece resultados cujos valores são bem próximos à classe de referência, enquanto que aqueles do conjunto de teste são mais dispersos. Observa-se ainda que alguns ensaios apresentam valores bem próximos à fronteira de decisão, estado bastante propício ao erro de classificação. 


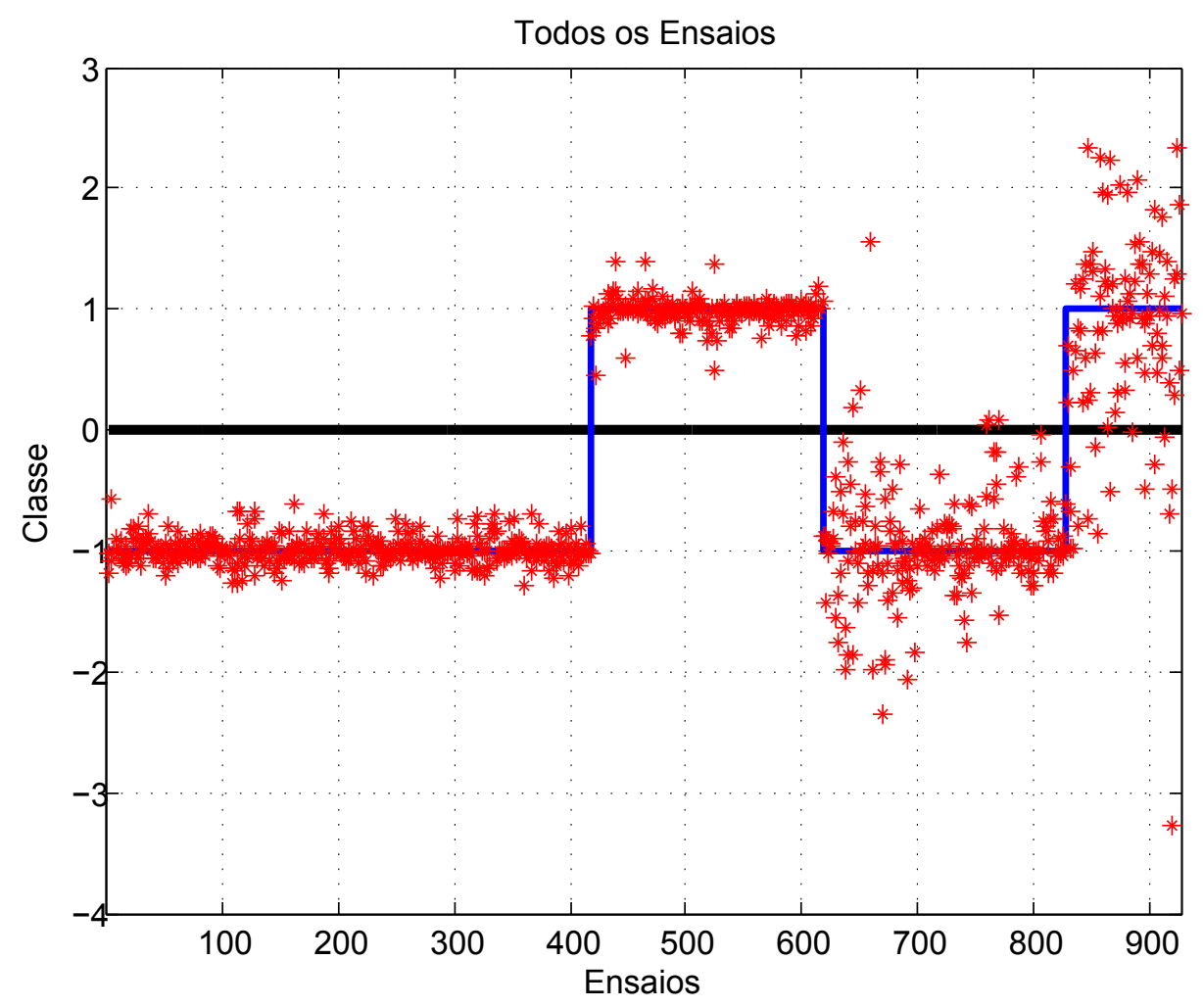

Figura 6.8: Resultados gerais do sistema neural de detecção de barras quebradas.

Com o intuito de analisar o desempenho da metodologia proposta ao longo de uma maior base de dados de amostras experimentais, incrementou-se a o tamanho do conjunto de dados mediante o deslocamento de janela. Desta forma, empregaram-se os dados de treinamento e de teste da análise anterior e os utilizaram como conjuntos de treinamento e de validação do sistema ao longo do treinamento, cujo procedimento visa à parada antecipada a fim de aprimorar os resultados de generalização. O conjunto de teste é constituído pelo conjunto de dados advindos do deslocamento da janela.

A Tabela 6.9 ilustra a descrição do conjunto de ensaios que foram utilizados para efetuar o treinamento do sistema neural de detecção de falhas. O conjunto de treinamento e de validação se constituem, respectivamente, de 618 e 309 amostras. Já o conjunto de teste de generalização da RNA é composto por 2949 ensaios, os quais representam 75,9\% do conjunto total disponível.

A estrutura da RNA utilizada para o sistema de monitoramento constitui de 1 camada neural com apenas 5 neurônios em sua saída. O procedimento de dividir o conjunto disponível de dados em três subconjuntos visando a antecipação da parada para aprimorar a generalização, conforme pode ser notado, auxilia na simplificação da RNA. A Figura 6.9 ilustra o desempenho ao longo do treinamento da RNA. Com o intuito de evitar a deterioração da generalização da rede mediante o sobre-ajuste dos parâmetros internos da RNA, a parada antecipada do treinamento foi alcançada em 58 épocas.

A Tabela 6.10 ilustra o desempenho global da taxa de acertos do sistema neural de 
Tabela 6.9: Conjunto de dados de disponíveis para análise: Inversor Trifásico.

\begin{tabular}{|c|c|c|c|}
\hline Descrição & Treinamento & Validação & Testes \\
\hline \hline Acionamento & INV & INV & INV \\
\hline Frequência & $40 \mathrm{~Hz}, 45 \mathrm{~Hz}, 50 \mathrm{~Hz}, 55 \mathrm{~Hz}, 60 \mathrm{~Hz}$ & idem & idem \\
\hline Tipos & $\mathrm{MN}, \mathrm{MF}, \mathrm{MA}, \mathrm{AR}$ & idem & idem \\
\hline Falhas & $\mathrm{R} 1 \mathrm{BQ}, \mathrm{R} 2 \mathrm{BQ}, \mathrm{R} 2 \times 2 \mathrm{BQ}, \mathrm{R} 4 \mathrm{BQ}$ & idem & idem \\
\hline Sinais & {$[$ janela 1$] i_{a}, i_{b}$} & {$\left[\right.$ janela1] $i_{c}$} & {$\left[\right.$ restante] $i_{a}, i_{b}, i_{c}$} \\
\hline Padrões & 618 & 309 & 2949 \\
\hline
\end{tabular}

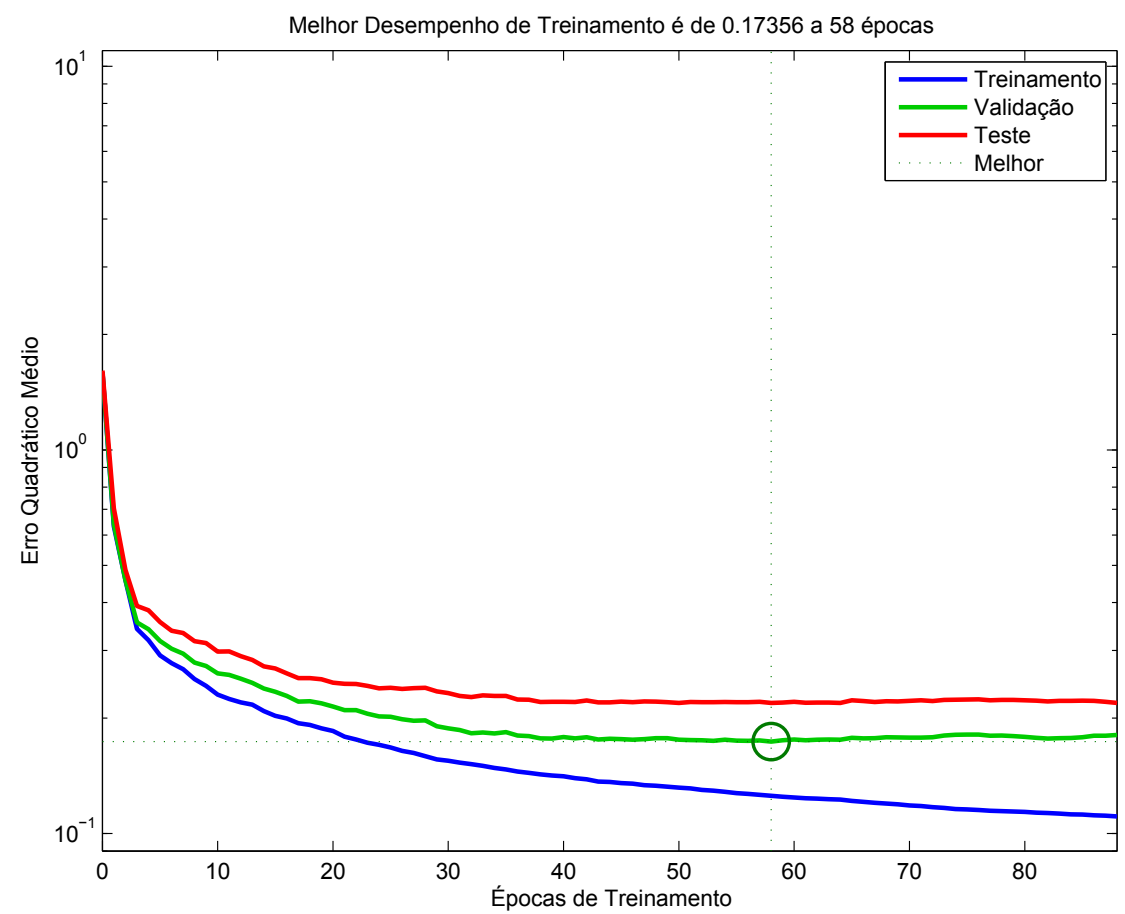

Figura 6.9: Desempenho de treinamento da RNA: 5 neurônios na camada oculta.

detecção de quebra em barras de rotores de MIT. A taxa de acertos do conjunto de dados de treinamento e validação atingiram, respectivamente, resultados de 94,32\% e 95,15\%. Já a precisão da generalização da RNA alcançou 93,86\%.

Tabela 6.10: Taxa de acertos da RNA com 2 neurônios em sua camada oculta.

\begin{tabular}{|c|c|c|c|}
\cline { 2 - 4 } \multicolumn{1}{c|}{} & Treinamento & Validação & Teste \\
\hline Taxa de Acerto & $94,32 \%$ & $95,15 \%$ & $93,86 \%$ \\
\hline
\end{tabular}

A Tabela 6.11 ilustra os resultados da precisão do classificador neural em função do nível de carregamento do MIT. Nota-se que o sistema de detecção de falhas obteve um total de 220 erros, sendo que 103 deles foram relativos ao carregamento de $0.5 \mathrm{Nm}$. A quantidade total de ensaios relativo a essa carga correspondem a 570 amostras, atingindose então uma taxa de erro de $18,1 \%$, o que é considerado relativamente alto.

Outro aspecto importante a ser mencionado consiste no fato de que a taxa de erros 
Tabela 6.11: Tabela de erros em função do carregamento.

\begin{tabular}{|c|c|c|c|c|c|c|c|c|c|}
\hline Carregamento $(\mathrm{Nm})$ & 0,5 & 1,0 & 1,5 & 2,0 & 2,5 & 3,0 & 3,5 & 4,0 & Total \\
\hline \hline Treinamento & 17 & 2 & 5 & 0 & 0 & 0 & 0 & 0 & 24 \\
\hline Validação & 9 & 3 & 3 & 0 & 0 & 0 & 0 & 0 & 15 \\
\hline Testes & 77 & 59 & 42 & 3 & 0 & 0 & 0 & 0 & 181 \\
\hline \hline Total de Erros & 103 & 64 & 50 & 3 & 0 & 0 & 0 & 0 & 220 \\
\hline Total de Amostras & 570 & 591 & 579 & 456 & 420 & 420 & 420 & 420 & 3876 \\
\hline \% de Erros & 18,1 & 10,8 & 8,63 & 0,65 & 0 & 0 & 0 & 0 & 5,67 \\
\hline
\end{tabular}

para cargas maiores que 2,5 Nm são de 0\%, ou seja, o sistema de detecção de quebra nas barras da gaiola atingiu $100 \%$ de precisão. Considera-se este resultado muito atraente no sentido de que, reforçando, os MITs são dimensionados na prática para trabalhar próximo à carga nominal.

A Figura 6.10 ilustra o desempenho global da saída da RNA no instante antes do pós-processamento. As amostras entre: 1 e 618 representam o conjunto de treinamento, 619 e 928 correspondem ao conjunto de validação e 929 e 3876 equivalem ao conjunto de teste.

Comparando-se à RNA de 20 neurônios treinada com quantidade reduzida de dados, observa-se que o resultado de saída apresenta uma maior variância em torno da classe de referência, apesar de estar dentro da fronteira de classificação.

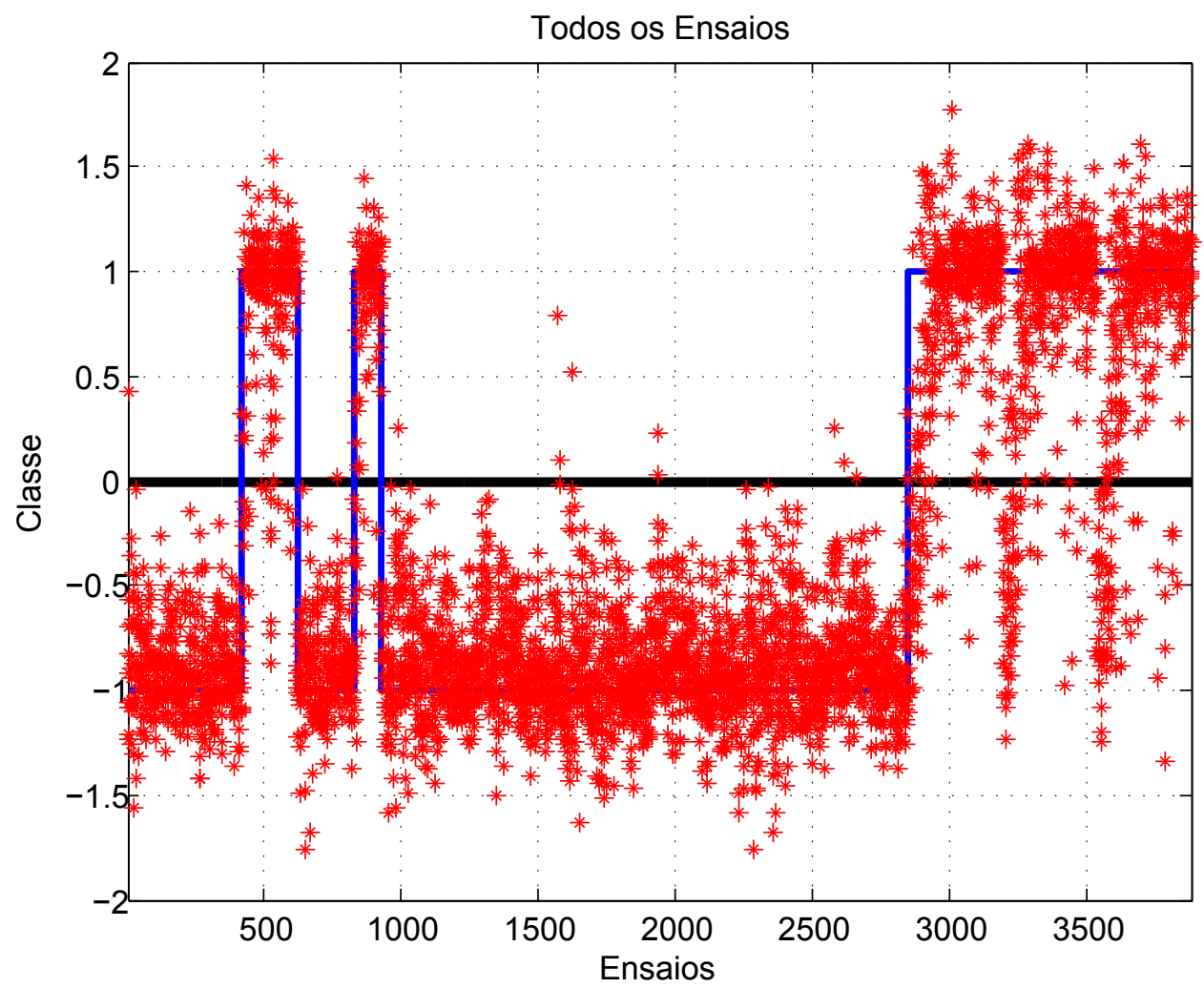

Figura 6.10: Resultados gerais do sistema neural de detecção de barras quebradas. 


\subsection{Acionamento Direto da Rede+Inversor Trifásico}

Enquanto o estudo relativo ao acionamento direto da rede e ao inversor trifásico são sistemas neurais de identificação de quebra em barras de rotores específicos ao seu tipo de acionamento, este estudo visa investigar um único sistema que englobe ambos os acionamentos.

De forma semelhante aos estudos anteriores, a base de dados empregada para a modelagem do sistema de identificação foi a seguinte: 1) motores normais; 2) motores de alto rendimento; 3 ) motores de fábrica; 4) motores adaptados. Consideram-se também toda a faixa de torque, ou seja: $0,5 \mathrm{Nm}, 1,0 \mathrm{Nm}, 1,5 \mathrm{Nm}, 2,0 \mathrm{Nm}, 2,5 \mathrm{Nm}, 3,0 \mathrm{Nm}, 3,5 \mathrm{Nm}$ e 4,0 Nm. No caso do acionamento direto da rede, a frequência de alimentação foi de $60 \mathrm{~Hz}$, enquanto que o inversor empregou-se a faixa de frequência entre $40 \mathrm{~Hz}, 45 \mathrm{~Hz}, 50 \mathrm{~Hz}$, $55 \mathrm{~Hz}$ e $60 \mathrm{~Hz}$.

As falhas consideradas neste estudo são rotores com: 1) uma barra quebrada; 2) duas barras quebradas; 3) duas barras quebradas em lados radialmente opostos e 4) quatro barras quebradas.

A Tabela 6.7 ilustra como os ensaios foram divididos entre conjunto de treinamento e de teste para a rede neural. Ao total são 4563 amostras no conjunto de dados, sendo 760 empregadas para o treinamento da RNA, 380 para o teste de validação e 3423 dados para checar a sua generalização, os quais representam $75 \%$ do conjunto total de dados. As correntes $i_{a}$ e $i_{b}$ da primeira janela de dados foram utilizadas para o treinamento e a corrente $i_{c}$ para o teste de generalização. Já o conjunto de teste de generalização foi composto pelo restante das janelas deslocadas no tempo das correntes $i_{a}, i_{b}$ e $i_{c}$.

Tabela 6.12: Conjunto de dados de disponíveis para análise: Inversor Trifásico.

\begin{tabular}{|c|c|c|c|}
\hline Descrição & Treinamento & Validação & Testes \\
\hline \hline Acionamento & $\mathrm{AD}, \mathrm{INV}$ & $\mathrm{AD}, \mathrm{INV}$ & $\mathrm{AD}, \mathrm{INV}$ \\
\hline Frequência & $40 \mathrm{~Hz}, 45 \mathrm{~Hz}, 50 \mathrm{~Hz}, 55 \mathrm{~Hz}, 60 \mathrm{~Hz}$ & idem & idem \\
\hline Tipos & $\mathrm{MN}, \mathrm{MF}, \mathrm{MA}, \mathrm{AR}$ & idem & idem \\
\hline Falhas & $\mathrm{R} 1 \mathrm{BQ}, \mathrm{R} 2 \mathrm{BQ}, \mathrm{R} 2 \times 2 \mathrm{BQ}, \mathrm{R} 4 \mathrm{BQ}$ & idem & idem \\
\hline Sinais & {$[$ janela 1$] i_{a}, i_{b}$} & {$[$ janela 1$] i_{c}$} & {$[$ restante $] i_{a}, i_{b}, i_{c}$} \\
\hline Padrões & 760 & 380 & 3423 \\
\hline
\end{tabular}

A RNA treinada mediante este conjunto de dados apresentou uma estrutura neural de 16 entradas, com uma camada escondida composta de 10 unidades de neurônio. O desempenho do sistema de detecção de MITs operando sob falhas de quebra em barras de rotores é expresso na Tabela 6.13. A taxa de acertos do conjunto de treinamento apresentou resultados de $97,5 \%$, enquanto que o conjunto de validação obteve $95,53 \%$. Adicionalmente, o teste de generalização da RNA obteve respostas de 95,38\% de precisão.

A Tabela 6.14 expressa os resultados de detecção de falhas de barras quebradas no rotor do MIT em função do nível de carregamento. Nota-se que a precisão do sistema 
Tabela 6.13: Resultados do desempenho de detecção de falhas da RNA.

\begin{tabular}{|c|c|c|c|}
\cline { 2 - 4 } \multicolumn{1}{c|}{} & Treinamento & Validação & Teste \\
\hline Taxa de Acerto & $97,5 \%$ & $95,53 \%$ & $94,89 \%$ \\
\hline
\end{tabular}

Tabela 6.14: Tabela de erros em função do carregamento do MIT.

\begin{tabular}{|c|c|c|c|c|c|c|c|c|c|}
\hline Carregamento $(\mathrm{Nm})$ & 0,5 & 1,0 & 1,5 & 2,0 & 2,5 & 3,0 & 3,5 & 4,0 & Total \\
\hline \hline Treinamento & 11 & 1 & 5 & 0 & 0 & 2 & 0 & 0 & 19 \\
\hline Validação & 10 & 2 & 3 & 1 & 0 & 1 & 0 & 0 & 17 \\
\hline Testes & 76 & 47 & 34 & 6 & 3 & 8 & 1 & 0 & 175 \\
\hline \hline Total de Erros & 97 & 50 & 42 & 7 & 3 & 11 & 1 & 0 & 211 \\
\hline Total de Amostras & 660 & 684 & 642 & 561 & 483 & 525 & 483 & 525 & 4563 \\
\hline \% de Erros & 14,70 & 7,31 & 6,54 & 1,28 & 0,62 & 2,10 & 0,21 & 0 & 4,62 \\
\hline
\end{tabular}

neural generalizado, tanto para acionamento direto quanto por inversor trifásico, obteve precisão sutilmente inferior aos sistemas especializados para cada tipo de acionamento, apresentando baixa taxas de erros para cargas superiores a 2,0 Nm. Em um universo de 4563 amostras, o erro acumulado acima dessa carga foi de 21 ensaios, representando uma taxa de erro de $0,48 \%$.

A Figura 6.11 ilustra o resultado global dos conjuntos de treinamento, validação e teste que representam a saída da RNA antes do pós-processamento de classificação.

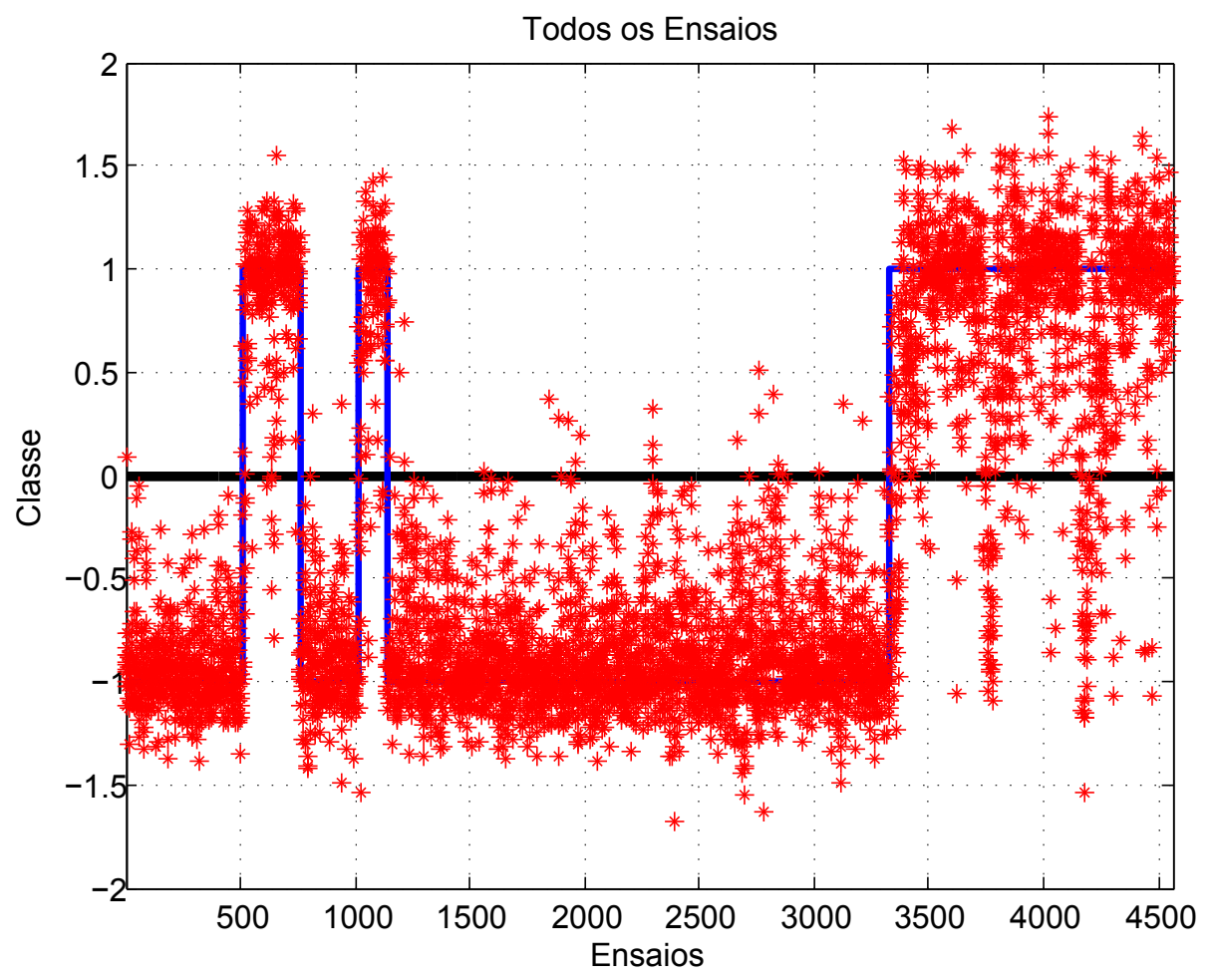

Figura 6.11: Resultados gerais do sistema neural de detecção de barras quebradas.

As amostras entre 1 e 760 correspondem ao conjunto de dados de treinamento, en- 
quanto que os elementos entre 761 e 1140 representam o conjunto de validação de dados. Já os dados contidos no intervalo entre 1141 e 4563 equivalem aos dados empregados para o teste de generalização da RNA.

\subsection{Acionamento Direto $\Rightarrow$ Inversor}

Este estudo consiste em desenvolver um sistema de identificação de quebras em barras de rotores de MITs considerando-se a utilização apenas da base de dados que contém ensaios de motores acionados diretamente da rede, de modo a verificar se este modelo neural é capaz de generalizar suas soluções para motores acionados por inversores de frequência.

De forma semelhante aos estudos anteriores, a base de dados de tipos de motores empregados para a modelagem do sistema de identificação foi a seguinte: 1) motores normais; 2) motores de alto rendimento; 3) motores de fábrica; 4) motores adaptados. Consideram-se também toda faixa de torque, ou seja: $0,5 \mathrm{Nm}, 1,0 \mathrm{Nm}, 1,5 \mathrm{Nm}, 2,0 \mathrm{Nm}$, 2,5 Nm, 3,0 Nm, 3,5 Nm e 4,0 Nm. No caso do acionamento direto da rede, a frequência de alimentação foi de $60 \mathrm{~Hz}$, enquanto que o inversor empregou-se a faixa de frequência entre $40 \mathrm{~Hz}, 45 \mathrm{~Hz}, 50 \mathrm{~Hz}, 55 \mathrm{~Hz}$ e $60 \mathrm{~Hz}$.

As falhas consideradas neste estudo são rotores com: 1) uma barra quebrada; 2) duas barras quebradas; 3) duas barras quebradas em lados radialmente opostos e 4) quatro barras quebradas.

A Tabela 6.15 ilustra a divisão de dados em conjuntos de treinamento, de validação e de testes para a RNA. Ao total foram 1614 amostras no conjunto de dados, sendo 458 empregadas para o treinamento da RNA, 229 para o teste de validação e 927 dados para checar sua generalização, o qual representa 57,6\% do conjunto total de dados. As correntes $i_{a}$ e $i_{b}$ da primeira janela de dados foram utilizadas para o treinamento e a corrente $i_{c}$ para o teste de generalização. Já o conjunto de teste de generalização foi composto pelo restante das janelas deslocadas no tempo das correntes $i_{a}, i_{b}$ e $i_{c}$.

Tabela 6.15: Conjunto de dados de disponíveis para análise: Inversor Trifásico.

\begin{tabular}{|c|c|c|c|}
\hline Descrição & Treinamento & Validação & Testes \\
\hline \hline Acionamento & $\mathrm{AD}$ & $\mathrm{AD}$ & $\mathrm{INV}$ \\
\hline Frequência & $60 \mathrm{~Hz}$ & $60 \mathrm{~Hz}$ & $40-60 \mathrm{~Hz}$ \\
\hline Tipos & $\mathrm{MN}, \mathrm{MF}, \mathrm{MA}, \mathrm{AR}$ & idem & idem \\
\hline Falhas & $\mathrm{R} 1 \mathrm{BQ}, \mathrm{R} 2 \mathrm{BQ}, \mathrm{R} 2 \times 2 \mathrm{BQ}, \mathrm{R} 4 \mathrm{BQ}$ & idem & idem \\
\hline Sinais & {$[$ janela 1$] i_{a}, i_{b}$} & {$[$ janela1 $] i_{c}$} & {$[$ restante $] i_{a}, i_{b}, i_{c}$} \\
\hline Padrões & 458 & 229 & 927 \\
\hline
\end{tabular}

Os parâmetros da estrutura interna da RNA apresentam 17 entradas com camada oculta de 10 unidades de neurônios. Os resultados do desempenho de detecção de quebras em barras de rotores pode ser visualizada na Tabela 6.16. Observa-se que a taxa de acertos 
para o conjunto de treinamento e de validação apresentam resultados próximos de 100\%. Já o conjunto de teste de validação obteve precisão de 80,79\% em sua taxa de acertos.

Este resultado é promissor, visto que embora o acionamento por inversor apresente sinais de correntes com componentes harmônicas superiores ao acionado pela rede elétrica, o sistema de identificação de falhas ainda obteve taxas de acertos relativamente elevadas.

Tabela 6.16: Resultados do desempenho de detecção de falhas da RNA.

\begin{tabular}{|l|c|c|c|}
\cline { 2 - 4 } \multicolumn{1}{c|}{} & Treinamento & Validação & Teste \\
\hline Taxa de Acerto & $99,78 \%$ & $100 \%$ & $80,79 \%$ \\
\hline
\end{tabular}

A Tabela 6.17 ilustra os resultados do sistema neural em termos do nível de carregamento do eixo. Ao total de 1614 amostras, em 179 delas a RNA classificou inadequadamente a operação do MIT. Comparando-se com os resultados de estimação dos estudos anteriores, nota-se que mesmo em carregamentos próximo ao torque nominal, o sistema de identificação obteve taxas de erros relativamente elevadas.

Tabela 6.17: Tabela de erros em função do carregamento do MIT.

\begin{tabular}{|c|c|c|c|c|c|c|c|c|c|}
\hline Carregamento $(\mathrm{Nm})$ & 0,5 & 1,0 & 1,5 & 2,0 & 2,5 & 3,0 & 3,5 & 4,0 & Total \\
\hline \hline Treinamento & 1 & 0 & 0 & 0 & 0 & 0 & 0 & 0 & 1 \\
\hline Validação & 0 & 0 & 0 & 0 & 0 & 0 & 0 & 0 & 0 \\
\hline Testes & 31 & 16 & 38 & 14 & 9 & 12 & 31 & 27 & 178 \\
\hline \hline Total de Erros & 31 & 17 & 38 & 14 & 9 & 12 & 31 & 27 & 179 \\
\hline Total de Amostras & 222 & 225 & 195 & 216 & 168 & 210 & 168 & 210 & 1614 \\
\hline$\%$ de Erros & 13,96 & 7,55 & 19,49 & 6,48 & 5,36 & 5,71 & 18,45 & 12,86 & 11,09 \\
\hline
\end{tabular}

A Figura 6.11 ilustra os resultados globais dos conjuntos de treinamento, validação e teste que representam a saída da RNA antes do pós-processamento de classificação. As amostras entre 1 e 458 correspondem ao conjunto de dados de treinamento, enquanto que os elementos entre 459 e 687 representam o conjunto de validação de dados. Já os dados contidos no intervalo entre 688 e 1614 equivalem aos dados empregados para o teste de generalização da RNA.

Embora os resultados globais ilustrados na Tabela 6.16 sejam promissores, esta investigação ainda deve ser realizada de maneira aprofundada, utilizando-se maiores quantidades de ensaios e de dados para proporcionar uma ferramenta de identificação ainda mais confiável. A Figura 6.12 ilustra que a variância das respostas da RNA em torno do nível de classificação entre motor saudável e com quebra nas barras ([-1 e 1]) apresenta valor elevados, principalmente nos casos de motores operando com falhas que são inadequadamente classificados como normais. 


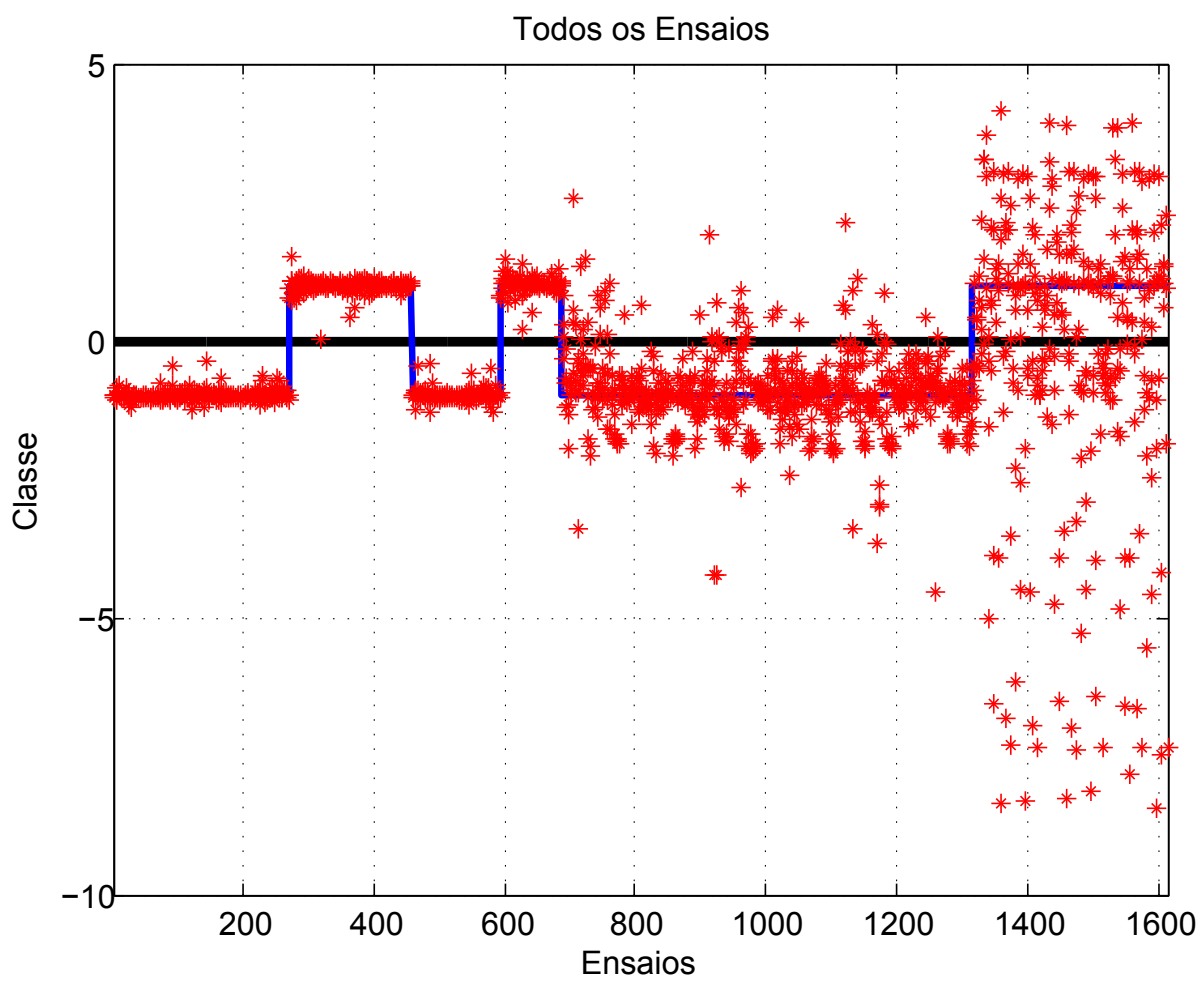

Figura 6.12: Resultados gerais do sistema neural de detecção de barras quebradas. 


\section{Capítulo 7}

\section{Conclusões Gerais e Diretivas Futuras}

\subsection{Conclusões Gerais}

Neste trabalho, investigou-se sobre a identificação e diagnóstico de falhas em motores de indução trifásicos. Um dos principais desafios consistiu na adaptação da bancada de experimentos a fim de realizar os ensaios de diversos tipos de falhas ocorrentes em MIT, tendo-se aqui o intuito de constituir uma base de dados adequada para se implementar o sistema inteligente de detecção e diagnósticos.

Neste contexto, a bancada de experimentos foi reestruturada para permitir simular experimentalmente ensaios de quebra nas barras e anéis de rotores, de curto-circuito entre as espiras do enrolamento do estator e de rolamento defeituoso (coletado em campo industrial).

Mediante a aquisição de diversos rotores do MIT estudado, permitiu-se aqui a realização de diversas combinações de falhas, tais como: uma barra seccionada, duas barras consecutivas seccionadas, quatro barras consecutivas seccionadas, duas barras consecutivas seccionadas em lados radialmente opostos, entre outras.

Com o intuito de diversificar os ensaios experimentais em termos do tipo de motor, consideraram-se também ensaios com motores de fábrica que não tiveram nenhum tipo de acesso, motores normais que passaram por processos de montagem e desmontagem, motores adaptados ou rebobinados por serviços de manutenção e, finalmente, motores de alto rendimento.

As inúmeras derivações advindas do rebobinamento dos enrolamentos de estator permitiram a execução também de diversas combinações de curto-circuito entre as espiras do enrolamento de estator, proporcionando-se a constituição de uma base de dados adequada para se desenvolver o sistema de monitoramento inteligente de falhas.

A partir dessa base de dados de ensaios de falhas, a presente tese de doutorado focou-se principalmente na investigação dos defeitos relacionados às quebras nas barras de rotores de gaiola de esquilo, mediante a análise do espectro de frequência de uma das correntes de linha do MIT conectado em $\Delta$. Tais sinais foram normalizados em termos de frequência 
de amplitude e investigaram-se seus efeitos em função da frequência de acionamento do inversor e da variação de carga. Os resultados da análise são promissores no sentido de que, independentemente da carga ou da frequência da tensão de alimentação, os motores normais e com quebra na barras de seus rotores se tornaram bem caracterizados.

Em função do pré-processamento dos sinais, desenvolveu-se uma metodologia de um sistema de monitoramento de barras quebradas em rotores de gaiola de esquilo baseado em redes neurais artificiais. Para tanto, em função da diversidade de ensaios experimentais, estudos de casos que englobam acionamento direto da rede e pelo inversor trifásico foram investigados obtendo resultados promissores de identificação. A técnica mostrou-se robusta, principalmente em carregamentos das máquinas entre $50 \%$ a $100 \%$ do torque nominal. Em função dos MITs serem, na prática, dimensionados para trabalhar próximo ao carregamento nominal, a aplicabilidade da técnica de identificação proposta é válida.

\subsection{Principais Contribuições da Tese}

As principais contribuições da tese são delineadas nos seguintes tópicos:

$\square$ O desenvolvimento de uma bancada de experimentos que permite a realização de ensaios de diversas falhas incipientes em motores de indução trifásicos industriais. Desta forma, constituiu-se uma base de dados experimentais de sinais relacionados às falhas curto-circuito entre as bobinas do enrolamento do estator, quebras nas barras da gaiola do rotor e falhas nos rolamentos situados nos mancais do MIT.

$\square$ O estudo da normalização de amplitude e frequência nos sinais advindos da transformada rápida de Fourier aplicados em uma das correntes trifásicas do MIT operando sob condições de quebra nas barras de seu rotor. Tais normalizações permitiram a caracterização evidente de motores normais e com quebras no espectro de frequência, sendo o MIT acionado sob diversas condições de cargas e de frequência de acionamento do inversor. Em tais caracterizações foram consideradas a análise do sinal processado em termos da variação do carregamento do eixo, da frequência de acionamento, do número de barras quebradas e de tipos diferentes de motores.

- A proposição de um método baseado em redes neurais artificiais para a detecção de falhas incipientes de barras quebradas nos rotores. Para tanto, empregou-se aqui apenas a corrente de uma das fases (corrente de linha em $\Delta$ ) do MIT, préprocessou-se o sinal no domínio tempo para o domínio da frequência utilizando-se a FFT, normalizou-se em amplitude e frequência em torno da fundamental. Em seguida, aplicou-se a técnica de análise de componentes principais para reduzir a dimensionalidade do vetor de entrada da RNA. 
$\square$ O estudo da metodologia neural de detecção de falhas de quebras em rotores em diversos aspectos de treinamento, validação e testes de generalização. Neste contexto, investigou-se o desempenho da metodologia proposta para a identificação de tais falhas para as seguintes condições: 1) um MIT que seja alimentado pela rede elétrica, cuja tensão trifásica é equilibrada, senoidal e frequência de $60 \mathrm{~Hz}$; 2) um MIT que seja acionado por um inversor trifásico, cuja tensão é modulada por largura de pulso com frequências fundamentais variantes entre $40 \mathrm{~Hz}$ e $60 \mathrm{~Hz}$; 3) desenvolvimento de uma única ferramenta capaz de identificar falhas de MITs acionados tanto pela rede elétrica quanto pelo inversor trifásico; 4) projeto de uma única ferramenta que se baseia em ensaios experimentais de MITs acionados pela rede elétrica que generaliza seus resultados de detecção de falhas para acionamentos por inversores de frequência.

$\square$ A análise de desempenho do método proposto em função a diversos níveis de carregamentos, tornando-se evidente na maioria dos estudos de casos apresentados que sua precisão é melhor para níveis de carregamentos próximos ao nominal.

$\square$ Permitir a constituição de uma extensa base de dados para simular de forma experimental uma gama de possibilidades e combinações de eventos, possibilitando que inúmeras pesquisas sejam originadas no futuro, as quais são apresentadas na próxima seção.

\subsection{Diretivas Futuras do Projeto de Pesquisa}

As diretivas de trabalhos futuros desta pesquisa consistem em explorar a bancada de experimentos e complementar os ensaios relacionados às falhas de motores de indução trifásicos. Neste contexto, os seguintes tópicos são pautados como focos de investigação:

1. Efetuar novas medições de dados experimentais que estejam mais voltados à identificação de barras de rotores. Neste caso, a resolução de frequência é de suma importância para o diagnóstico; entretanto, como a análise espectral se restringe aos arredores da frequência fundamental de acionamento, o sistema não necessita de uma alta taxa de aquisição de dados. Desta forma, projetos de filtros anti-aliasing também devem ser investigados.

2. Investigar métodos para identificar também o número de barras seccionadas a fim de quantificar o nível da falha mecânica.

3. Concentrar a base de dados de treinamento e validação da RNA em apenas um tipo de motor e obter uma generalização para motores de diferentes potências e tipos. Na ocasião, o laboratório de pesquisa já dispõe de motores de 0,75 cv e 1,5 cv e amostras de rotores suficientes para análise. 
4. Analisar do comportamento da técnica de identificação em termos de desequilíbrio da rede de alimentação.

5. Investigar métodos para detecção de curto-circuito entre espiras do estator em função da base de ensaios de experimentos já constituída nesta tese.

6. Desenvolver métodos de detecção de falhas em rolamentos de MIT defeituosos de fábrica.

7. Efetuar combinações de falhas e investigar sistemas de monitoramento para identificar e diagnósticá-las adequadamente. 


\section{Referências}

ARDEKANI, I. T.; FAIZ, J. Influence of Vector Control Algorithms on Stator Current Harmonics in Three-phase Squirrel-cage Induction Motors under Mixed Eccentricity Faults. In: IEEE INTERNATIONAL ELECTRIC MACHINES \& DRIVES CONFERENCE (IEMDC), 2007. Proceedings. . . [S.l.: s.n.], 2007. p.495-502.

AYDIN, I.; KARAKOSE, M.; AKIN, E. A Simple and Efficient Method for Fault Diagnosis Using Time Series Data Mining. In: IEEE INTERNATIONAL ELECTRIC MACHINES \& DRIVES CONFERENCE (IEMDC), 2007. Proceedings. . . [S.l.: s.n.], 2007. v.1, p.596-600.

BALLAL, M. S.; KHAN, Z. J.; SURYAWANSHI, H. M.; SONOLIKAR, R. L. Induction Motor: fuzzy system for the detection of winding insulation condition and bearing wear. Electric Power Components and Systems, [S.1.], v.34, n.2, p.159-171, 2006.

BALLAL, M. S.; KHAN, Z. J.; SURYAWANSHI, H. M.; SONOLIKAR, R. L. Adaptive Neural Fuzzy Inference System for the Detection of Inter-Turn Insulation and Bearing Wear Faults in Induction Motor. IEEE Transactions on Industrial Electronics, [S.l.], v.54, n.1, p.250-258, 2007.

BARBOUR, A.; THOMSON, W. T. Finite element study of rotor slot designs with respect to current monitoring for detecting static airgap eccentricity in squirrel-cage induction motors. In: CONFERENCE RECORD OF THE 1997 IEEE INDUSTRY APPLICATIONS CONFERENCE 32ND IAS ANNUAL MEETING, 1997. Proceedings... [S.l.: s.n.], 1997. v.1, p.112-119 vol.1.

BEALE, M. H.; HAGAN, M. T.; DEMUTH, H. B. Neural Network Toolbox: user's guide. Natick, MA: The MathWorks, Inc., 2011.

BENBOUZID, M. E. H.; KLIMAN, G. B. What stator current processing-based technique to use for induction motor rotor faults diagnosis? IEEE Transactions on Energy Conversion, [S.l.], v.18, n.2, p.238-244, 2003. 
BONNETT, A. H.; ALBERS, T. Squirrel-cage rotor options for ac induction motors. IEEE Transactions on Industrial Application, [S.l.], v.37, p.1197-1209, 2001.

BONNETT, A. H.; SOUKUP, G. C. Analysis of rotor failures in squirrel-cage induction motors. IEEE Transactions on Industry Applications, [S.1.], v.24, n.6, p.11241130, 1988.

BOSSIO, G.; De Angelo, C.; BOSSIO, J.; PEZZANI, C.; GARCIA, G. Separating Broken Rotor Bars and Load Oscillations on IM Fault Diagnosis Through the Instantaneous Active and Reactive Currents. IEEE Transactions on Industrial Electronics, [S.l.], v.56, n.11, p.4571-4580, Nov. 2009.

BRAGA, A. P.; LUDERMIR, T. B.; CARVAlHO, A. C. P. L. F. Redes Neurais Artificiais - Teoria e Aplicações. [S.l.]: LTC, 2000.

CHOI, S.; AKIN, B.; RAHIMIAN, M. M.; TOLIYAT, H. a. Implementation of a Fault-Diagnosis Algorithm for Induction Machines Based on Advanced Digital-SignalProcessing Techniques. IEEE Transactions on Industrial Electronics, [S.l.], v.58, n.3, p.937-948, Mar. 2011.

CRUZ, S. M. A.; CARDOSO, A. J. M. Diagnosis of Rotor Faults in Closed-Loop Induction Motor Drives. In: CONFERENCE RECORD OF THE 2006 IEEE INDUSTRY APPLICATIONS CONFERENCE 41ST IAS ANNUAL MEETING, 2006. Proceedings... [S.l.: s.n.], 2006. v.5, p.2346-2353.

CRUZ, S. M. A.; CARDOSO, A. J. M. Fault Indicators for the Diagnosis of Rotor Faults in FOC Induction Motor Drives. In: IEEE INTERNATIONAL ELECTRIC MACHINES \& DRIVES CONFERENCE (IEMDC), 2007. Proceedings... [S.l.: s.n.], 2007. v.2, p.1136-1141.

DIAS, L.; LOBOSCO, O. S. Electrical Motors: selection and application (in portuguese). [S.l.]: McGraw-Hill, 1998.

DONGMO, J.-E.; KWATNY, H. G.; NWANKPA, C.; BAJPAI, G.; TEOLIS, C. Variable Structure Design of a Fault Tolerant Control System for Induction Motors. In: IEEE ELECTRIC SHIP TECHNOLOGIES SYMPOSIUM (ESTS), 2007. Proceedings... [S.l.: s.n.], 2007. p.531-535.

DRIF, M. H.; CARDOSO, A. J. M. Rotor Cage Fault Diagnostics in Three-Phase Induction Motors by the Instantaneous Phase-Angle Signature Analysis. In: IEEE INTERNATIONAL ELECTRIC MACHINES \& DRIVES CONFERENCE (IEMDC), 2007. Proceedings. . . [S.l.: s.n.], 2007. p.1440-1445. 
FAIZ, J.; EBRAHIMI, B. M.; TOLIYAT, H. A.; AKIN, B. Diagnosis of a Mixed Eccentricity Fault in a Squirrel-cage Three-phase Induction Motor using Time Stepping Finite Element Technique. In: IEEE INTERNATIONAL ELECTRIC MACHINES \& DRIVES CONFERENCE (IEMDC), 2007. Proceedings. . . [S.l.: s.n.], 2007. v.2, p.14461450 .

FITZGERALD, A. E.; KINGSLEY, C.; UMANS, D. Electric Machinery. 6th.ed. [S.l.]: Bookman, 2006.

GOEDTEL, A. Estimador Neural de Velocidade para Motores de Indução Trifásicos. 2007. Tese de Doutorado — Universidade de São Paulo (USP/EESC).

GRIEGER, J.; SUPANGAT, R.; ERTUGRUL, N.; SOONG, W. L. Induction Motor Static Eccentricity Severity Estimation Using Evidence Theory. In: IEEE INTERNATIONAL ELECTRIC MACHINES \& DRIVES CONFERENCE (IEMDC), 2007. Proceedings... [S.l.: s.n.], 2007. v.1, p.190-195.

GUAN, Y.; SUN, D.; HE, Y. Mean Current Vector Based Online Real-Time Fault Diagnosis for Voltage Source Inverter fed Induction Motor Drives. In: IEEE INTERNATIONAL ELECTRIC MACHINES \& DRIVES CONFERENCE (IEMDC), 2007. Proceedings... [S.l.: s.n.], 2007. v.2, p.1114-1118.

HAYKIN, S. Neural Networks - A Comprehensive Foundation. Upper Saddle River, NJ: Prentice Hall, 1999.

HUANG, X.; HABETLER, T. G.; HARLEY, R. G. Detection of Rotor Eccentricity Faults in a Closed-Loop Drive-Connected Induction Motor Using an Artificial Neural Network. IEEE Transactions on Power Electronics, [S.l.], v.22, n.4, p.1552-1559, 2007.

JOLlifFE, I. T. Principal Component Analysis. 2nd.ed. New York: Springer, 2002.

KHANNICHE, M. S.; MAMAT, I. M. R. Condition monitoring of PWM voltage source inverters. In: TENCON, 2000. Proceedings. . [S.l.: s.n.], 2000. v.3, p.295-299 vol.3.

KILIC, E.; OZGONENEL, O.; OZDEMIR, A. E. Fault Identification in Induction Motors with RBF Neural Network Based on Dynamical PCA. In: IEEE INTERNATIONAL ELECTRIC MACHINES \& DRIVES CONFERENCE (IEMDC), 2007. Proceedings... [S.l.: s.n.], 2007. v.1, p.830-835.

KOLLA, S. R.; ALTMANA, S. D. Artificial neural network based fault identification scheme implementation for a three-phase induction motor. ISA Transactions, [S.l.], v.46, p.261-266, 2007.

KRAUSE, P. C.; WASYNCZUK, O.; SUDHOFF, S. D. Analysis of Electric Machinery. [S.l.]: New York, IEEE Press, 1995. 
MCCULLOCH, W. S.; PITTS, W. A logical calculus of the ideas immanent in nervous activity. Bulletin of Mathematical Biophysics, [S.l.], v.5, p.115-133, 1943.

MUETZE, A.; BINDER, A. Practical Rules for Assessment of Inverter-Induced Bearing Currents in Inverter-Fed AC Motors up to $500 \mathrm{~kW}$. IEEE Transactions on Industrial Electronics, [S.l.], v.54, n.3, p.1614-1622, June 2007.

NANDI, S.; TOLIYAT, H. A.; LI, X. Condition monitoring and fault diagnosis of electrical motors-a review. IEEE Transactions on Energy Conversion, [S.l.], v.20, n.4, p.719$729,2005$.

ONEL, I. Y.; BENBOUZID, M. E. H. Induction Motors Bearing Failures Detection and Diagnosis: park and concordia transform approaches comparative study. In: IEEE INTERNATIONAL ELECTRIC MACHINES \& DRIVES CONFERENCE (IEMDC), 2007. Proceedings. . [S.1.: s.n.], 2007. v.2, p.1073-1078.

ÖNEL, I. Y.; DALCI, K. B.; SENOL, . Detection of bearing defects in three-phase induction motors using Park's transform and radial basis function neural networks. Sadhana, [S.l.], v.31, p.235-244, 2006.

OPPENHEIM, A. V.; SCHAFER, R. W.; BUCK, J. R. Discrete-Time Signal Processing. 2nd.ed. Upper Saddle River, New Jersey: Prentice Hall, 1998.

PEREIRA, L. A.; GAZZANA, D. S.; PEREIRA, L. F. A. Motor current signature analysis and fuzzy logic applied to the diagnosis of short-circuit faults in induction motors. In: ANNUAL CONFERENCE OF IEEE INDUSTRIAL ELECTRONICS SOCIETY (IECON), 32., 2005. Proceedings... [S.l.: s.n.], 2005. p.6.

RAZIK, H.; CORREA, M. B. A. D. R.; SILVA, E. R. C. da. A Novel Monitoring of Load Level and Broken Bar Fault Severity Applied to Squirrel-Cage Induction Motors Using a Genetic Algorithm. IEEE Transactions on Industrial Electronics, [S.l.], v.56, n.11, p.4615-4626, Nov. 2009.

SIEMENS. Motores de Indução para Baixa Tensão. [S.l.: s.n.], 2006.

SILVA, I. N. da; SPATTI, D. H.; FLAUZINO, R. A. Redes Neurais Artificiais para Engenharia e Ciências Aplicadas. São Paulo, SP: Artliber, 2010.

SUPANGAT, R.; GRIEGER, J.; ERTUGRUL, N.; SOONG, W. L.; GRAY, D. A.; HANSEN, C. Detection of Broken Rotor Bar Faults and Effects of Loading in Induction Motors during Rundown. In: IEEE INTERNATIONAL ELECTRIC MACHINES \& DRIVES CONFERENCE (IEMDC), 2007. Proceedings... [S.l.: s.n.], 2007. v.1, p.196201. 
TAHAMI, F.; SHOJAEI, A.; KHATIR, D. A. A diversity based reconfigurable method for fault tolerant control of induction motors. In: INTERNATIONAL SYMPOSIUM ON POWER ELECTRONICS, ELECTRICAL DRIVES, AUTOMATION AND MOTION (SPEEDAM), 2006. Proceedings... [S.1.: s.n.], 2006. p.66-71.

TONI, K.; SLOBODAN, M.; ALEKSANDAR, B. Detection of Turn to Turn Faults in Stator Winding with Axial Magnetic Flux in Induction Motors. In: IEEE INTERNATIONAL ELECTRIC MACHINES \& DRIVES CONFERENCE (IEMDC), 2007. Proceedings... [S.l.: s.n.], 2007. v.1, p.826-829.

TRZYNADLOWSKI, M. A. Control of Induction Motors. [S.l.]: Academic Press, 2001.

TSOUKALAS, L. H.; UHRIG, R. E. Fuzzy and Neural Approaches in Engineering. New York, NY: John Wiley \& Sons, 1997.

XU-HONG, W.; YI-GANG, H. Fuzzy Model based On-line Stator Winding Turn Fault Detection for Induction Motors. In: IEEE INTERNATIONAL SYMPOSIUM ON INDUSTRIAL ELECTRONICS, 2006. Proceedings... [S.l.: s.n.], 2006. v.3, p.22722276 .

XU-HONG, W.; YI-GANG, H. Fuzzy Neural Network based On-line Stator Winding Turn Fault Detection for Induction Motors. In: IEEE CONFERENCE ON INDUSTRIAL ELECTRONICS AND APPLICATIONS (ICIEA), 2., 2007. Proceedings... [S.l.: s.n.], 2007. p.2461-2464.

YANG, B.-S.; HAN, T.; YIN, Z.-J. Fault Diagnosis System of Induction Motors Using Feature Extraction, Feature Selection and Classification Algorithm. JSME International Journal Series C,, [S.l.], v.49, p.734-741, 2006.

YE, Z.; SADEGHIAN, A.; WU, B. Mechanical fault diagnostics for induction motor with variable speed drives using Adaptive Neuro-fuzzy Inference System. Electric Power Systems Research, [S.l.], v.76, n.9-10, p.742-752, June 2006.

YEH, C.-C.; DEMERDASH, N. A. O. Induction Motor-Drive Systems with Fault Tolerant Inverter-Motor Capabilities. In: IEEE INTERNATIONAL ELECTRIC MACHINES \& DRIVES CONFERENCE (IEMDC), 2007. Proceedings... [S.l.: s.n.], 2007. v.2, p.1451-1458.

YEH, C.-C.; SIZOV, G. Y.; SAYED-AHMED, A.; DEMERDASH, N. A. O.; POVINELLI, R. J.; YAZ, E. E.; IONEL, D. M. A Reconfigurable Motor for Experimental Emulation of Stator Winding Inter-Turn and Broken Bar Faults in Polyphase Induction Machines. In: IEEE INTERNATIONAL CONFERENCE OF ELECTRIC MACHINES \& DRIVES (IEMDC), 2007. Anais... [S.1.: s.n.], 2007. v.2, p.1413-1419. 
ZIDANI, F.; DIALLO, D.; BENBOUZID, M. E. H.; BERTHELOT, E. Diagnosis of Speed Sensor Failure in Induction Motor Drive. In: IEEE INTERNATIONAL ELECTRIC MACHINES \& DRIVES CONFERENCE (IEMDC), 2007. Proceedings. . . [S.l.: s.n.], 2007. v.2, p.1680-1684. 
Apêndices 



\section{Adaptação, Montagem e Desmontagem do MIT}

\section{A.1 Prolongamento do Eixo dos Rotores para a Aferição de Velocidade}

Uma das principais adaptações realizadas nos rotores consiste no prolongamento de seu eixo para efetuar a aferição da velocidade angular. Conforme pode ser observado na Figura 2.2 da Página 34, nota-se que o encoder incremental é acoplado nas terminações do eixo. Como este tipo de encoder não possibilita a sua inserção entre o torquímetro e motor, houve-se então a necessidade de desenvolver uma adaptação mecânica em todos os rotores adquiridos.

Cabe ressaltar que a velocidade da máquina não será empregada como entrada do algoritmo de identificação de falhas em rotores. Entretanto, o seu monitoramento é fundamental para se analisar as condições de funcionamento do MIT durante os ensaios experimentais, uma vez que diversas condições de operações da máquina serão alvos de estudo.

Nesta seção serão explicitados os procedimentos adotados para se realizar o prolongamento do eixo dos rotores. Todos os integrantes deste laboratório de pesquisa, Laboratório de Automação Inteligente de Processo e Sistemas (LAIPS), agradecem à participação do técnico do laboratório de mecânica da USP de São Carlos, Sr. Ruy Berto, para a concretização desta relevante etapa.

A Figura A.1 ilustra um rotor do tipo gaiola de esquilo de um MIT de 1,0 cv de potência antes de iniciar o processo de adaptação. Na extremidade esquerda se acopla a carga da máquina, neste trabalho, o GCC, através de um torquímetro girante. Já na extremidade oposta, uma ventoinha empregada para fins de ventilação é conectada e fixada por uma haste que se encaixa no orifício ilustrado na figura. O processo de prolongamento do eixo deve ser realizado nesta extremidade. 


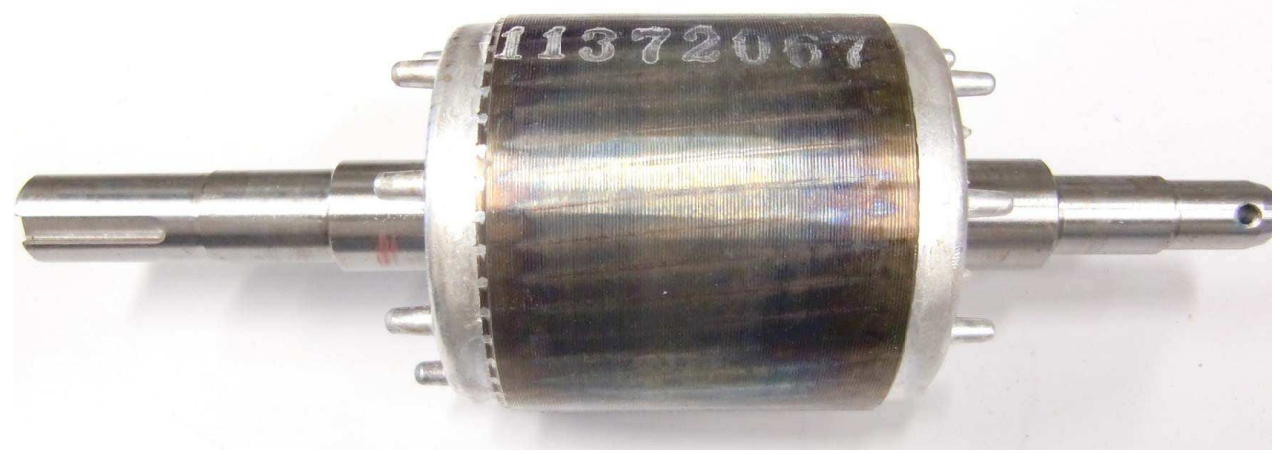

Figura A.1: Rotor de 1,0 cv do tipo gaiola de esquilo.

Conforme às orientações do técnico de laboratório, o prolongamento pode ser efetuado de forma bem simples e rápido por meio do encaixe de um eixo no interior da extremidade da direita. Para tanto, o procedimento adotado consiste em perfurar o eixo do rotor utilizando-se uma broca, encaixar e fixar o prolongamento mediante uma espécie de cola anaeróbica (Trabrasil RA3), específica para fixação de peças mecânicas. Esta metodologia é consistente e válida, visto que a carga conectada nesta extremidade é significativamente baixa, pois apenas o encoder é acoplado.

\section{A.1.1 Furo Centralizado do Eixo do Rotor}

Um dos aspectos importantes a ser mencionado antes de se iniciar o processo de perfuração do eixo consiste de sua centralização. Este procedimento foi realizado utilizando-se um rolamento auxiliar fixado no eixo do rotor e apoiado no torno mecânico, conforme pode ser observado na Figura A.2. A Figura A.2(a) ilustra a visão geral do rotor fixado no torno mecânico, enquanto que a Figura A.2(b) apresenta os detalhes do alinhamento e centralização do eixo. Nota-se também uma peça pontiaguda fixada no mandril que se apóia lateralmente na concavidade da extremidade do eixo, auxiliando também no processo de centralização.

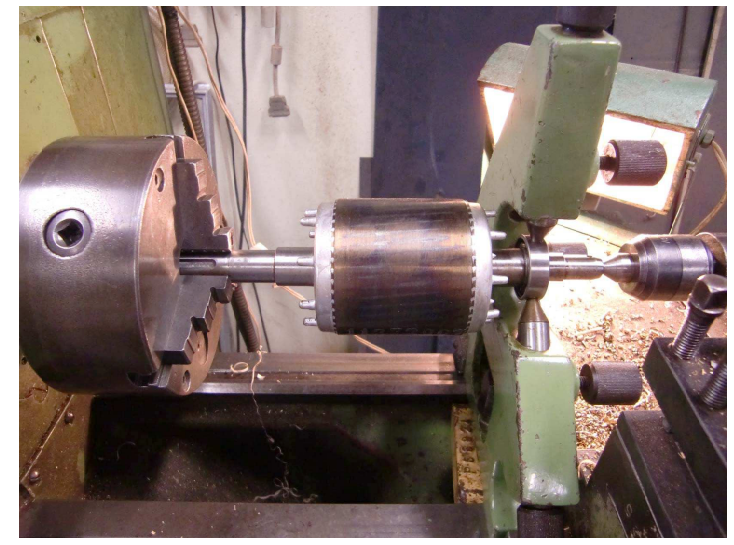

(a) Visão geral do torno mecânico.

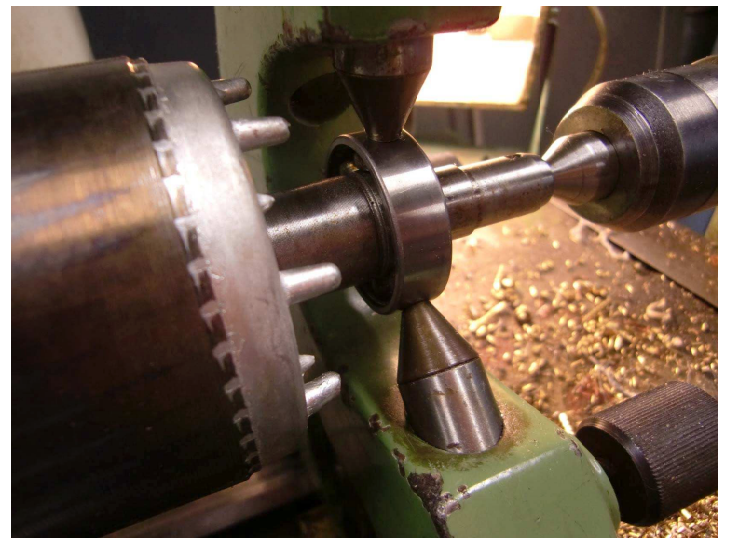

(b) Detalhes da centralização do eixo.

Figura A.2: Fixação e centralização do rotor no torno mecânico. 
Uma vez que o rotor esteja centralizado no torno mecânico, o processo de perfuração pode ser inicializado, conforme pode ser observado na Figura A.3(a), em que se ilustra a visão geral do procedimento. A parte do torno mecânico em que o rotor é fixado é aquela que apresenta movimento rotacional, enquanto que o mandril que prende a broca se mantém firme e possui apenas movimento transversal horizontal.

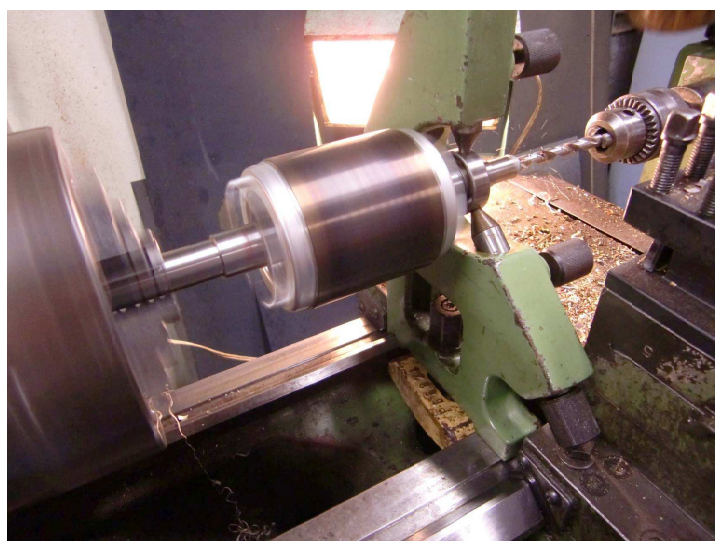

(a) Visão geral do processo de perfuração.

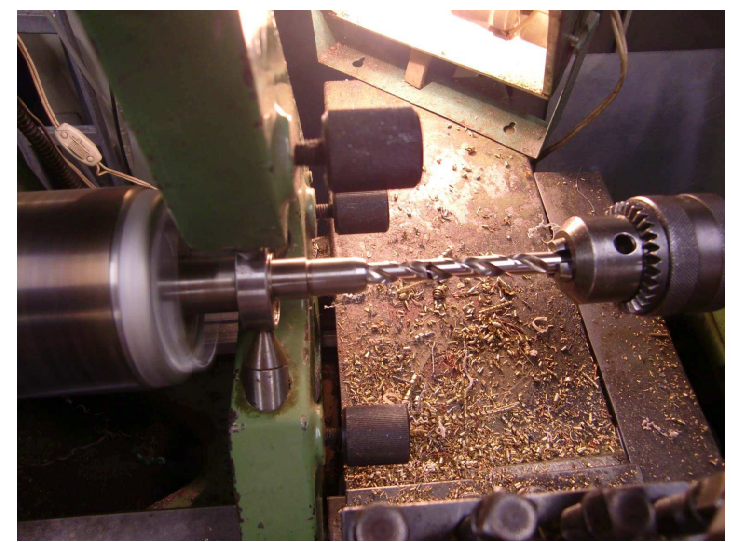

(b) Detalhes da perfuração do eixo.

Figura A.3: Processo de perfuração do eixo utilizando-se uma broca de 9,0 mm.

O prologamento do eixo apresenta um diâmetro de 10,0 $\mathrm{mm}$. Entretanto, a broca empregada na etapa ilustrada na Figura A.3 foi de 9,0 mm, apresentando então uma diferença de 1,0 mm. Este procedimento foi adotado para se realizar um acabamento, conforme mostrado na Figura A.4.

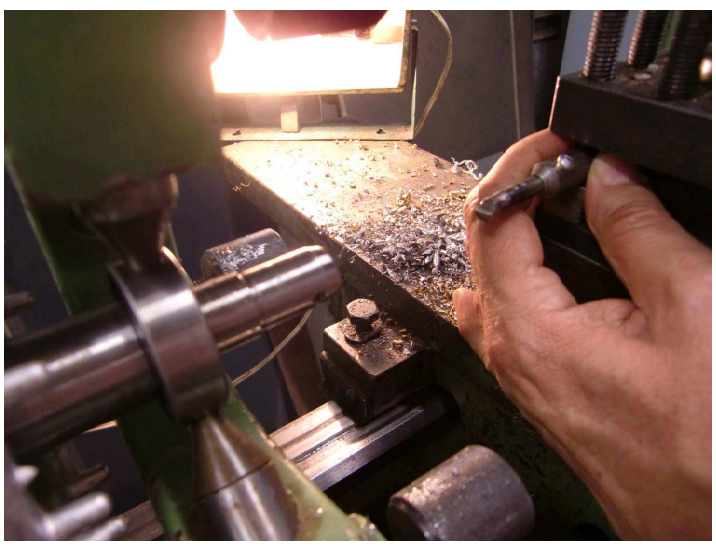

(a) Acabamento final.

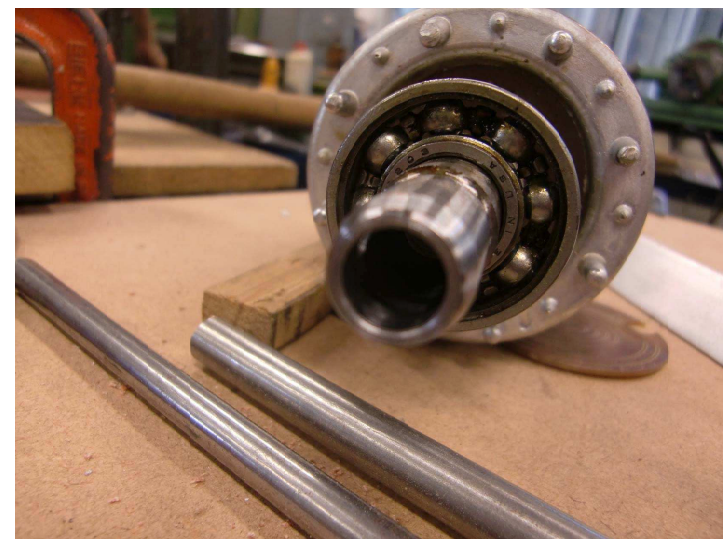

(b) Resultado da perfuração.

Figura A.4: Acabamento final e resultado da perfuração do eixo.

De acordo com a sugestão do técnico, utilizar-se de apenas uma broca para efetuar a perfuração sem o devido acabamento pode, eventualmente, resultar em um pequeno desalinhamento no produto final. De fato, o prolongamento do primeiro rotor realizado neste projeto não estava adequado, pois o mesmo apresentava oscilações quando a máquina foi instalada na bancada e acionada. Neste contexto, utilizou-se de uma ferramenta para 
torno a fim de efetuar o alargamento do diâmetro ao longo do eixo transversal de forma precisa, conforme ilustrado na Figura A.4(a). A Figura A.4(b) ilustra o resultado final da perfuração do eixo do rotor.

\section{A.1.2 Fixação do Prolongamento do Eixo}

O prolongamento do eixo empregado nesta pesquisa se constitui de um material inoxidável com 10,0 mm de diâmetro. O principal motivo de se utilizar este tipo de material reside no fato de que o prolongamento da bancada experimental anterior apresentava fortes sinais de oxidação e ferrugem. Além de apresentar um aspecto de aparência deselegante, uma bancada que está em constante modificações, montagem e desmontagem pode gerar alterações nas dimensões da barra, o que poderia tornar um empecilho no futuro. A Figura A.5 ilustra o procedimento adotado para realizar a fixação do prolongamento no eixo do rotor.

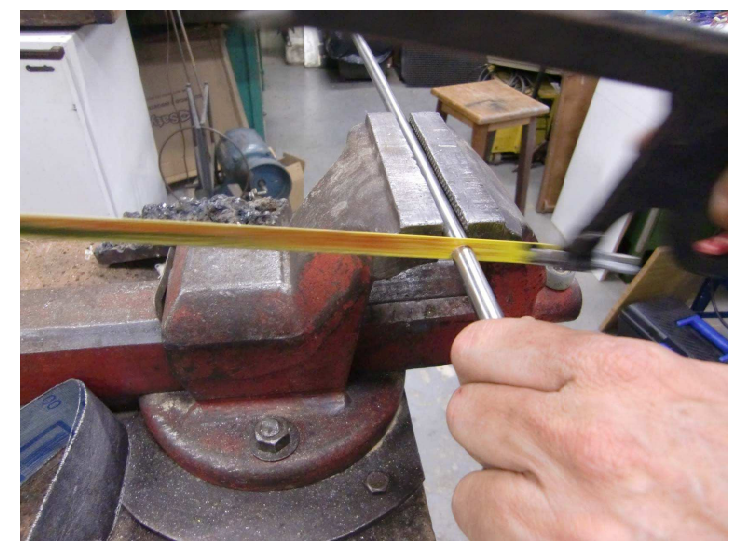

(a) Corte manual da barra de inox.

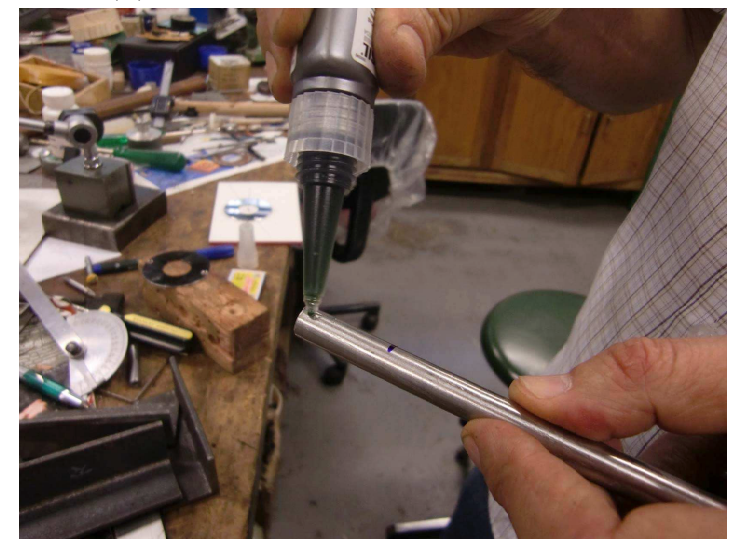

(c) Aplicação da cola anaeróbica.

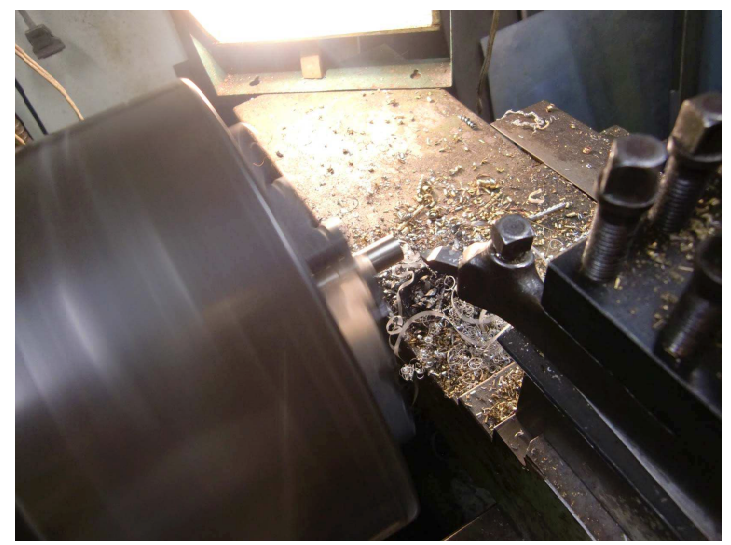

(b) Acabamento da barra no torno mecânico.

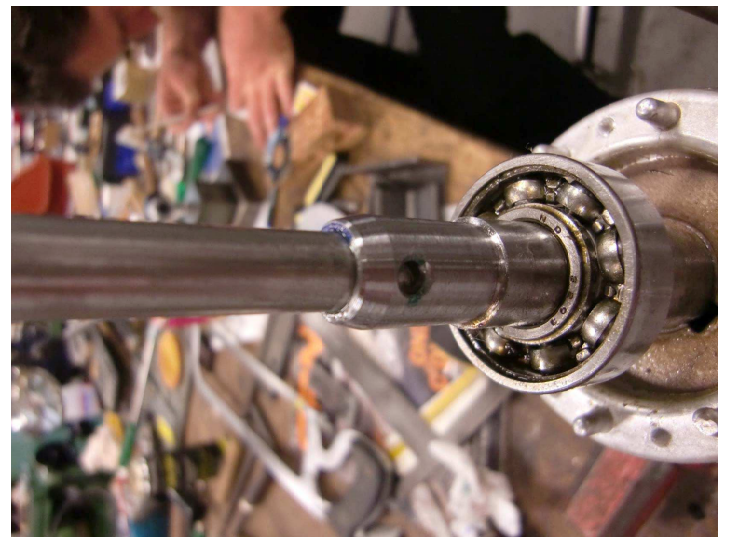

(d) Resultado final da fixação da barra.

Figura A.5: Procedimento para fixação da barra no eixo do rotor.

A barra de inox cilíndrica foi fixada em uma morsa e cortada manualmente mediante uma serra, conforme ilustrado na Figura A.5(a). Como este procedimento resulta em farpas ao redor do corte, na etapa A.5(b) é então realizado um acabamento por meio da utilização do torno mecânico visando à precisão do alinhamento. 
No passo ilustrado na Figura A.5(c), aplica-se aqui uma cola anaeróbica (Trabrasil RA3) específica para trabalhar com peças mecânicas na barra de inox, a fim de fixá-la ao eixo do rotor. Este produto consiste de uma resina líquida que se polimeriza por ausência de oxigênio e efeito catalisador dos metais. Preenchem $100 \%$ do espaço livre, alojandose nas rugosidades e unindo as peças, formando-se então um corpo único que absorve vibrações e choques, evitando-se também fugas e desgastes. Finalmente, a Figura A.5(d) ilustra o resultado final da fixação do prolongamento do eixo do rotor do MIT.

\section{A.1.3 Rolamentos e Chavetas}

A constituição de base de dados experimentais de MITs com falhas em seus rotores exige diversas configurações de quebras. Desta forma, a montagem e desmontagem do MIT para efetuar a troca de rotores tornam-se uma rotina frequente durante a realização desses experimentos. Neste contexto, optou-se por adquirir rolamentos para cada rotor em estudo, a fim de evitar a sua substituição cada vez que haver a necessidade de troca. Os rolamentos geralmente são fixados com força bruta e suas constantes remoções e fixações podem danificá-los com o tempo. A Figura A.6 ilustra os rolamentos adquiridos para serem fixados nos rotores. O rolamento da esquerda é fixado no mancal que se situa o prolongamento do eixo. O rolamento da direita, o qual apresenta uma dimensão maior, é fixado no mancal do eixo da carga.

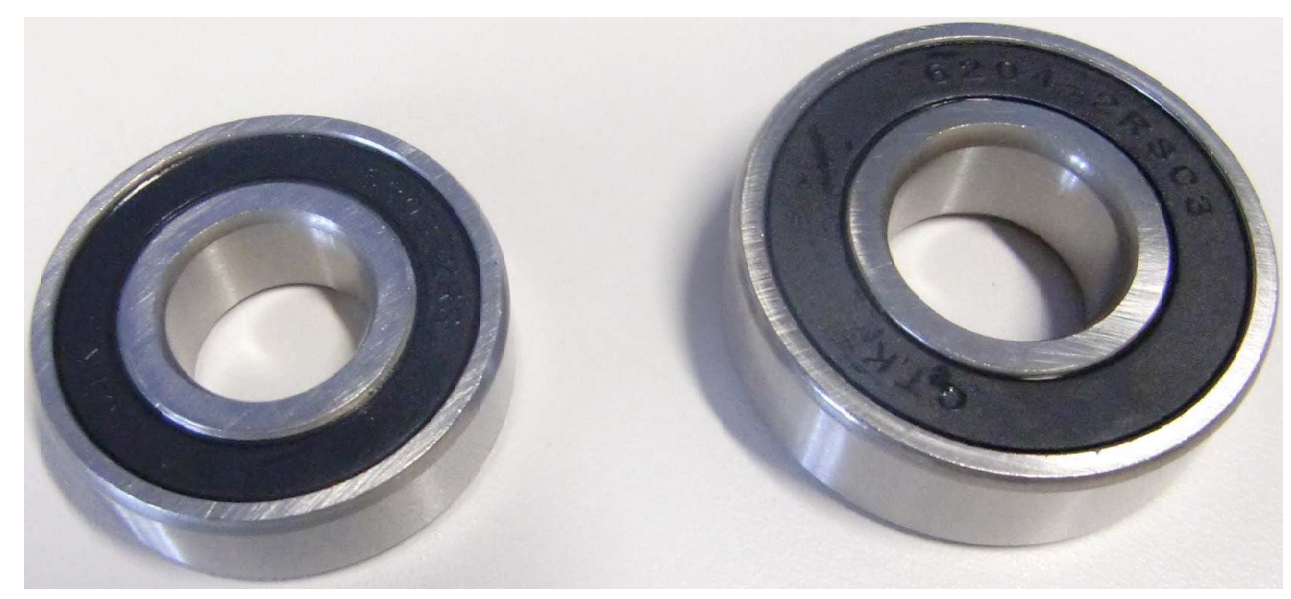

Figura A.6: Rolamentos utilizados nos rotores.

De maneira similar, as chavetas também merecem uma atenção especial no que se refere à sua constante troca. As chavetas são fixadas transversalmente em um chanfro localizado na extremidade do eixo em que se conecta a carga. A sua função consiste em evitar escorregamentos do acoplador, promovendo a transmissão adequada de torque. A sua constante substituição pode proporcionar o alargamento da depressão ou até mesmo desgaste na peça. Por este motivo, optou-se também por adquirir chavetas e previamente instalá-las em todos os rotores adquiridos. 
Nas casas de ferragens podem ser encontradas barras de aço trifiladas, que são próprias para montagem de chavetas. Tais materiais são adequadamente usinados em barras com tamanhos padronizados para chavetas. A Figura A.7(a) ilustra a foto de algumas dessas barras de aço trifiladas.

A Figura A.7(b) mostra uma chaveta pronta para ser fixada no eixo do rotor. A barra foi adequadamente cortada e lixada por meio de um esmeril. O arredondamento também fora realizado manualmente pelo mesmo equipamento. Embora a espessura das chavetas necessitarem de uma dimensão justa e adequada, o seu acabamento não há necessidade de ser preciso. A Figura A.8 ilustra uma foto de uma chaveta fixada no eixo do rotor de um MIT.

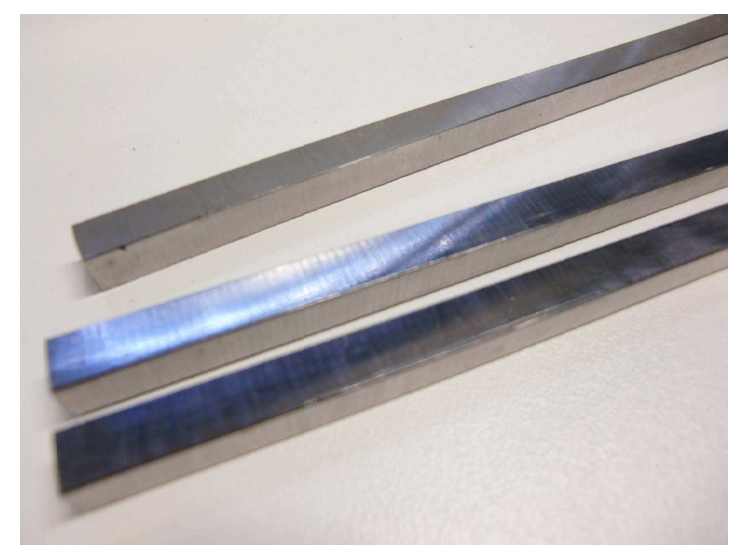

(a) Barras de aço trifiliado.

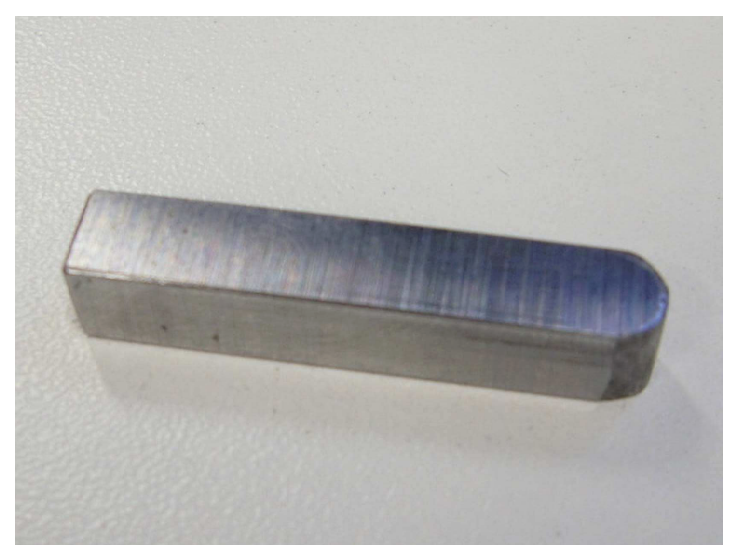

(b) Chaveta cortada e lixada.

Figura A.7: Chavetas usinadas para serem fixadas nos rotores.

Outra etapa relativamente simples da adaptação dos MIT que também deve ser mencionada consiste na perfuração da tampa defletora para a passagem do eixo prolongado. Conforme observado na Figura A.9, utilizou-se o torno mecânico para realizar esta tarefa. Embora este procedimento seja factível utilizando-se uma simples furadeira de bancada, nesta etapa, procurou-se prestar atenção na questão da centralização.

\section{A.2 Montagem da Placa de Conexão da Alimentação da Máquina}

A montagem da placa de conexão da alimentação do MIT por meio de bornes banana foi realizada utilizando-se um material resistente e altamente isolante denominado celeron. Este procedimento é de suma importância, uma vez que a alimentação oriunda do quandro de controle é fornecida por pinos banana, o que favorece a montagem e desmontagem da bancada com frequência.

A Figura A.10(a) ilustra a imagem de um MIT, cuja placa de alimentação fora removida. Observam-se que os terminais das bobinas trifásicas do estator estão à vista. Em 


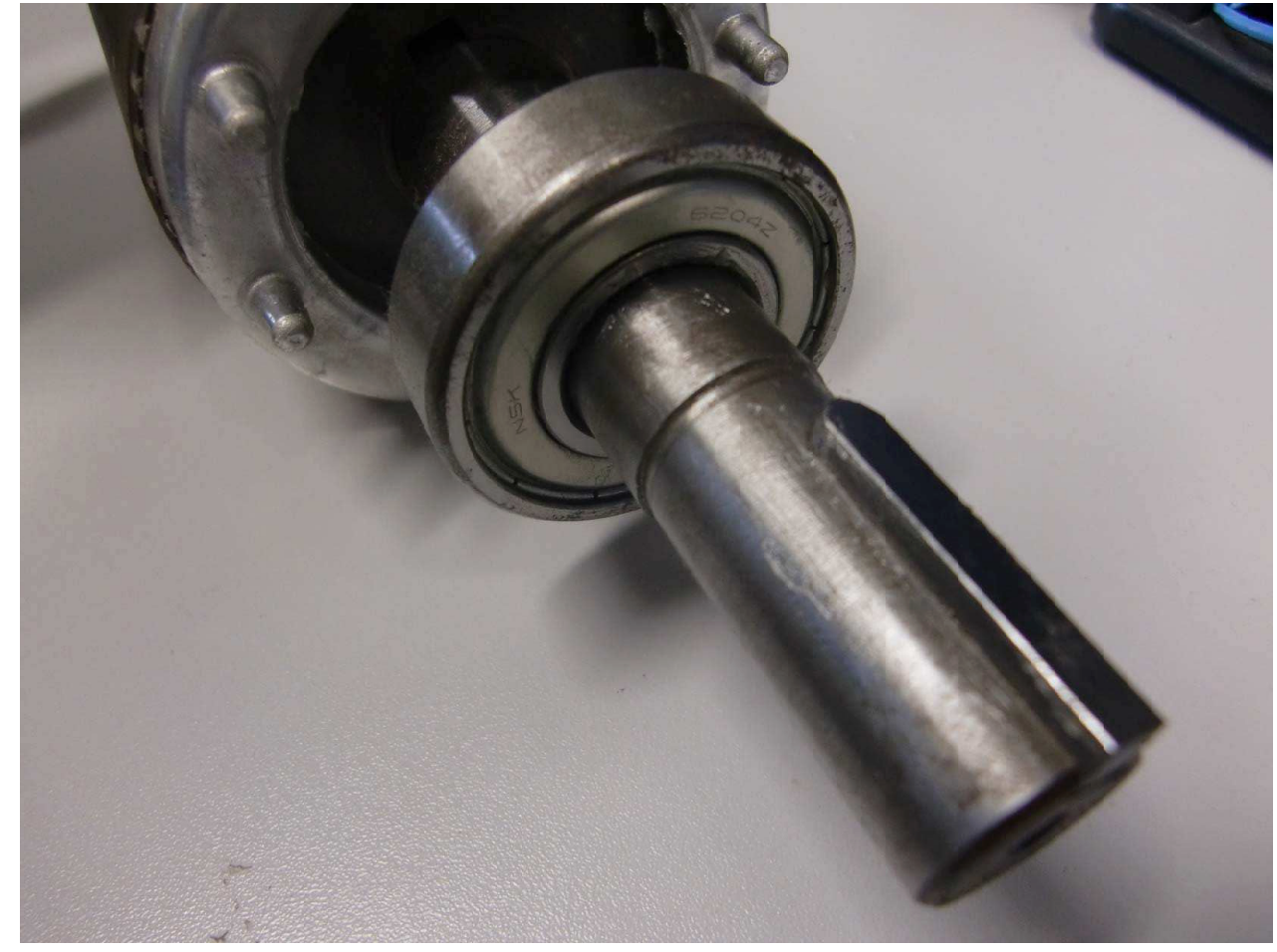

Figura A.8: Fixação das chavetas nos eixos dos rotores.

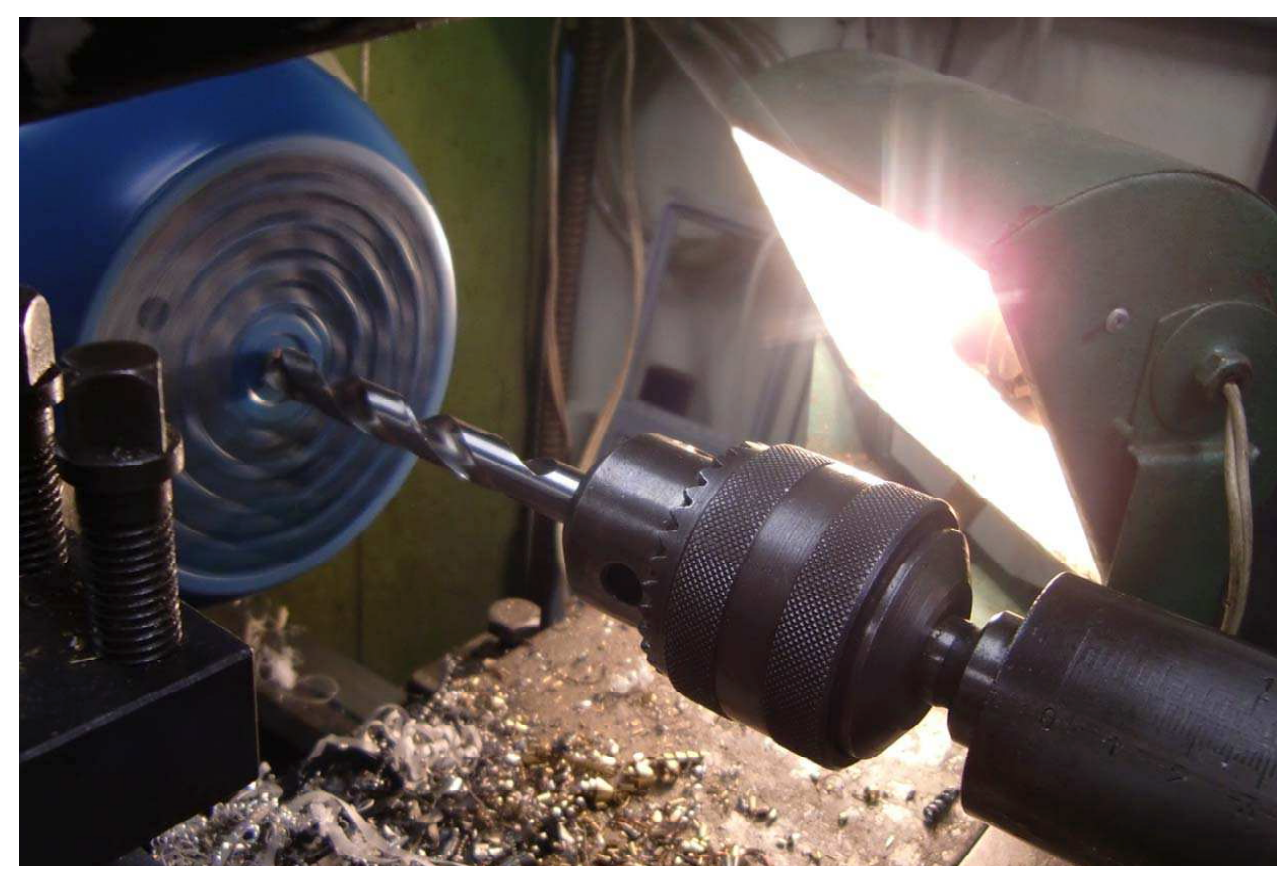

Figura A.9: Perfuração da tampa do MIT para a passagem do eixo prolongado.

primeira instância, soldaram-se terminais circulares que serão fixados aos bornes da placa customizada de alimentação. Além disso, marcações para cabos foram utilizadas para facilitar a manutenção futura.

Mediram-se as dimensões do motor e cortou-se em tamanho adequado à placa de celeron. Em seguida, efetuaram-se os furos por meio de uma furadeira de bancada para fixar a 
placa ao motor, bem como para posicionar os bornes bananas fêmeas. Este procedimento pode ser visualizado na Figura A.10(b).

A Figura A.10(c) ilustra a visão frontal da placa de alimentação com alguns bornes do tipo banana fêmea fixados. Com o intuito de se tornar a conexão mais legível e diminuir a probabilidade de erro de conexão do pesquisador, numerações foram coladas utilizando-se uma fita adesiva transparente. Por outro lado, a Figura A.10(d) ilustra a visão posterior da placa.

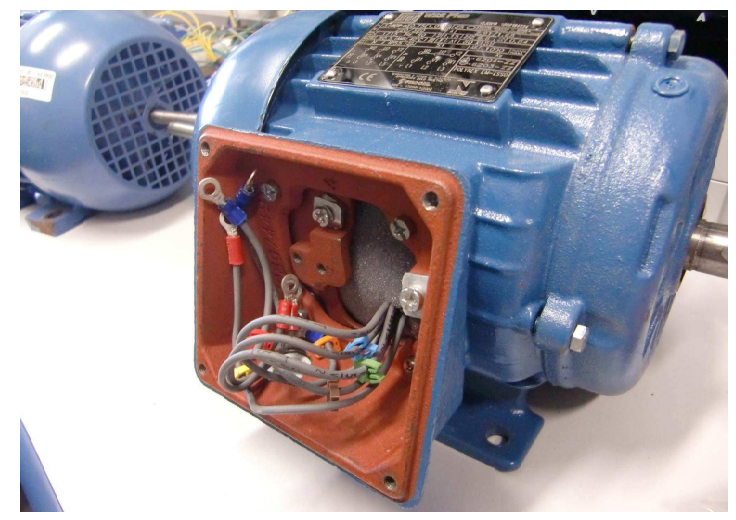

(a) MIT com a placa de alimentação removida.

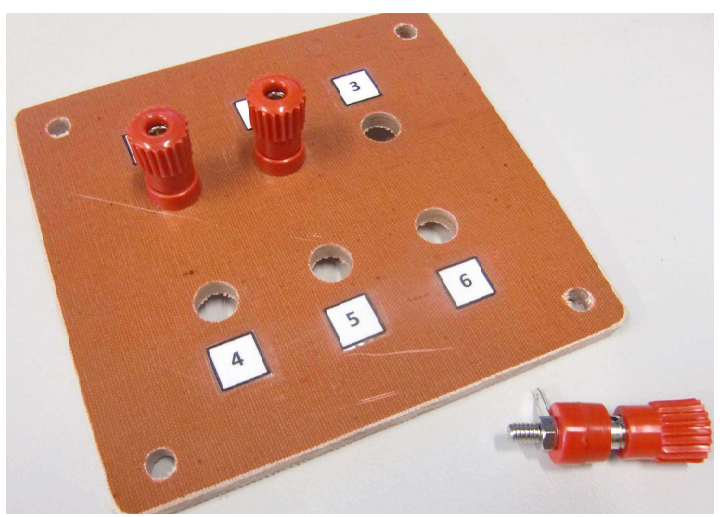

(c) Visão frontal da placa de alimentação.

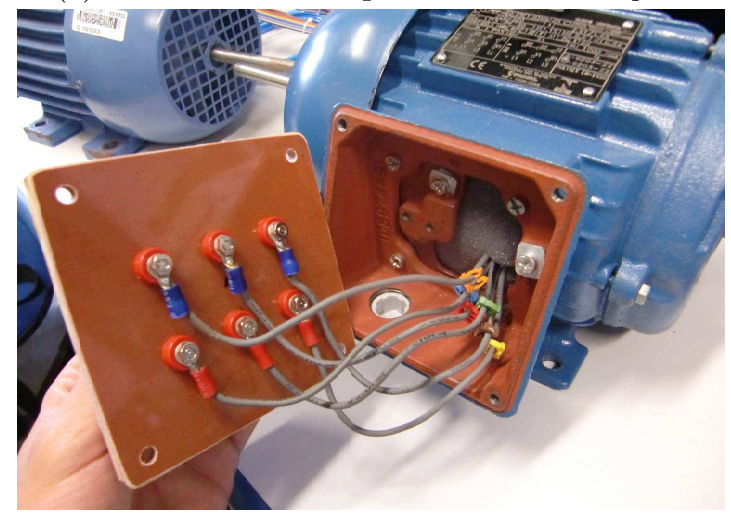

(e) Fixação dos terminais internos do MIT.

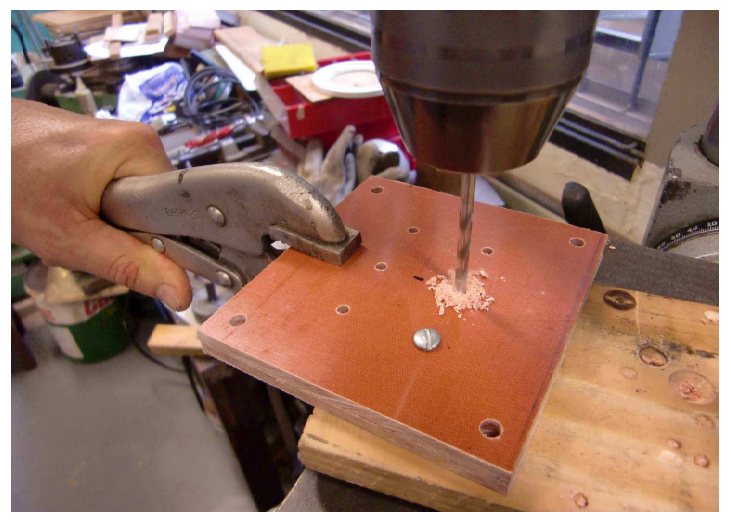

(b) Perfuração da placa de alimentação customizada.

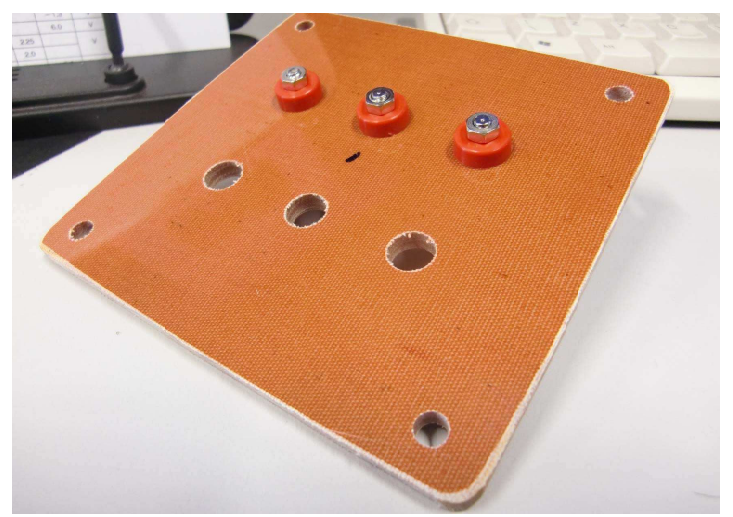

(d) Visão posterior da placa de alimentação.

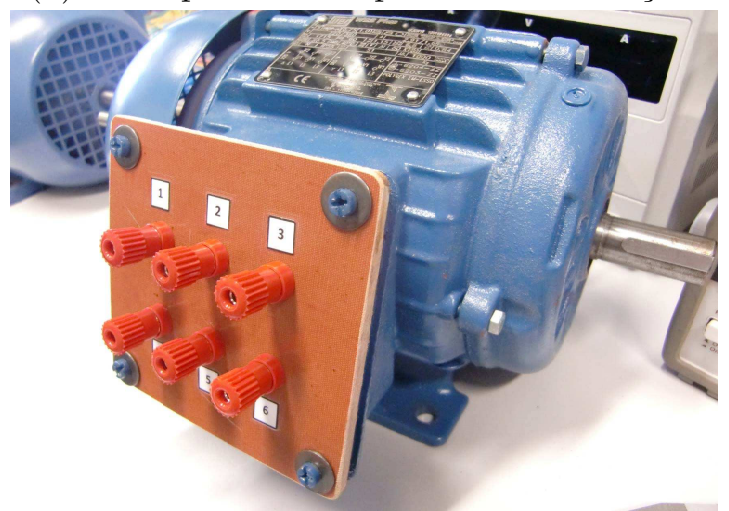

(f) Placa de alimentação fixa ao MIT.

Figura A.10: Montagem da placa de alimentação com bornes.

Após a fixação dos bornes, conectam-se os terminais circulares na parte posterior da placa, conforme ilustrado na Figura A.10(e). Nesta etapa, deve-se estar atento se todos 
os terminais estão devidamente isolados, a fim de reduzir o risco de um possível curtocircuito interno. A Figura A.10(f) ilustra a montagem final da placa de alimentação do MIT.

\section{A.3 Processo de Instalação/Remoção dos Rotores nas Máquinas}

O processo de Instalação/Remoção dos rotores dos MITs deve ser realizado cuidadosamente para evitar possíveis danos ou desalinhamento na estrutura mecânica. Tal precaução torna-se ainda mais relevante quando esse procedimento é realizado inúmeras vezes a fim de se realizar os devidos ensaios experimentais envolvidos na aquisição da base de dados. Neste contexto, nesta seção serão relatados os passos principais para realizar a instalação e a remoção dos rotores de um MIT.

A Figura A.11(a) ilustra um MIT com seu rotor totalmente removido. Cuidadosamente, insere-se o rotor que será o foco de análise encaixando o rolamento no mancal da parte posterior, conforme ilustrado na Figura A.11(b). Este procedimento é relativamente simples em virtude do rotor estar bem dimensionado e sob medida.

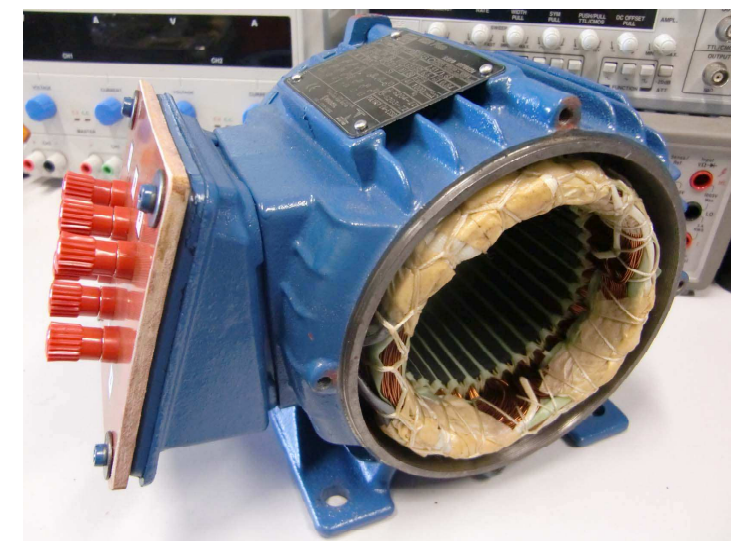

(a) MIT com rotor removido.

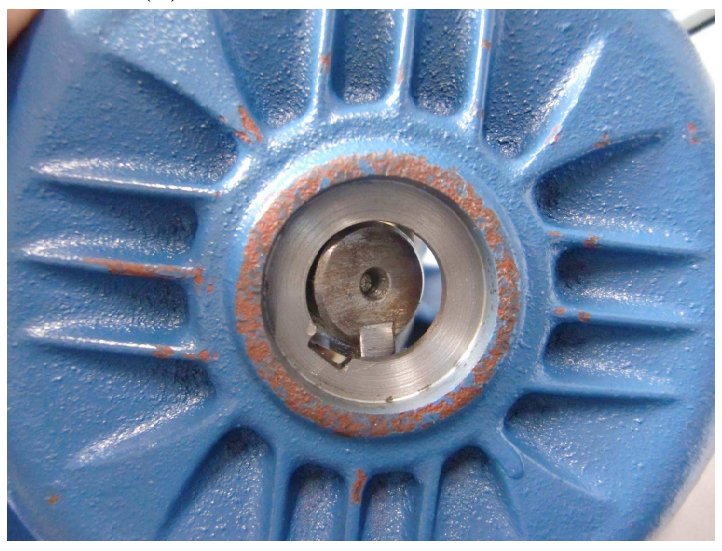

(c) Orifício para a chaveta.

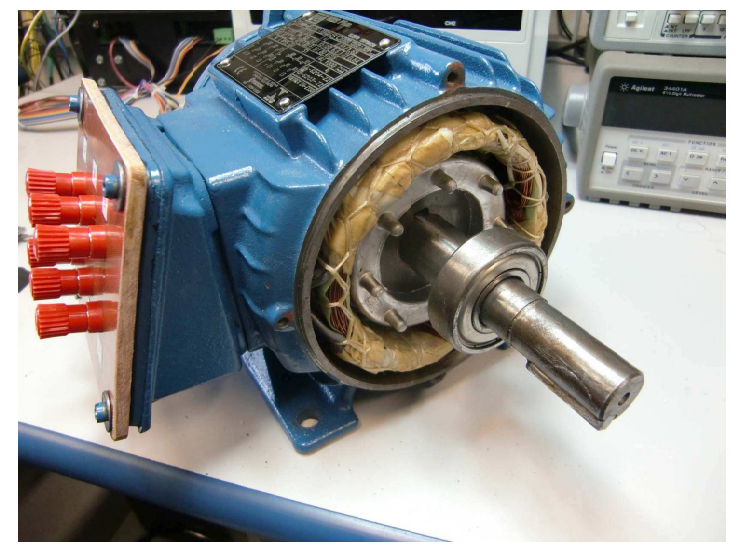

(b) Inserção do rotor.

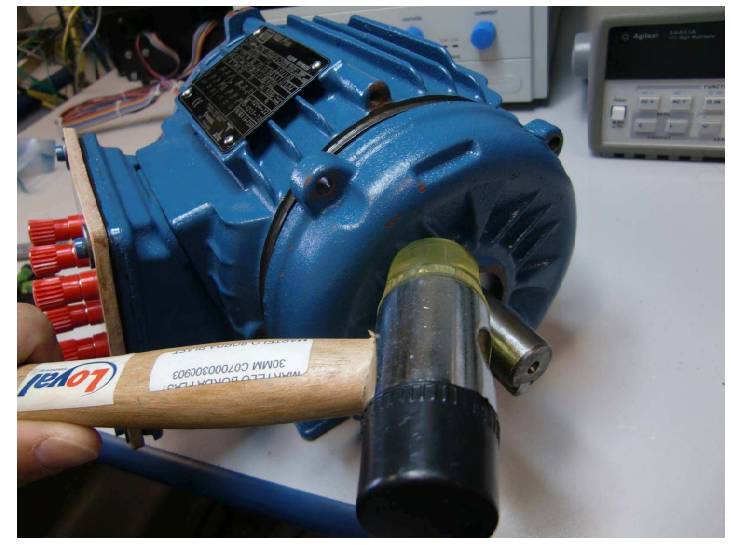

(d) Fixação da tampa.

Figura A.11: Procedimento de instalação dos rotores - Parte 1. 
Um aspecto bem relevante a ser mencionado neste passo consiste na adequada lubrificação com desengripante, ou vaselina em pasta, nas partes do rotor em que serão manuseadas a fim de evitar a sua oxidação e ferrugem. Outra alternativa plausível seria a utilização de luvas protetoras.

A Figura A.11(c) ilustra o processo de inserção da tampa lateral em que se situa a chaveta de acoplamento. Conforme descrito na Subseção A.1.3 da Página 119, inseriramse chavetas em todos os rotores com o intuito de evitar desgastes mecânicos tanto na peça como no rotor durante sua substituição. Conforme observada na Figura A.11(c), a tampa é impossibilitada de se passar pelo eixo devido à chaveta, visto que seu orifício fora dimensionado exatamente pelo diâmetro do eixo. Neste contexto, houve-se a necessidade de inserir uma pequena depressão com o tamanho da chaveta. Este procedimento foi realizado utilizando-se uma pequena lixa. Embora esta pequena abertura possibilite a entrada de poeiras, o laboratório de pesquisa é considerado um ambiente limpo.

Em seguida, a tampa é encaixada na carcaça do motor com o auxílio de um martelo de nylon, conforme ilustrado na Figura A.11(d). O martelo de nylon apresenta a vantagem de absorver parte do impacto, evitando que a tampa seja danificada. Um aspecto relevante a ser mencionado nesta etapa reside no fato de que o impacto deve ser cuidadoso e controlado com o intuito de evitar possíveis danos e desalinhamentos ao eixo e aos rolamentos.

A Figura A.12 apresenta os passos para a fixação dos componentes laterais do MIT, referente ao eixo prolongado para aferição de velocidade, bem como o processo de inserção do acoplador.

A Figura A.12(a) ilustra a visão lateral do MIT que teve o seu eixo prolongado. Nesta parte é inserida a ventoinha empregada para a ventilação. A sua fixação é relativamente bem simples e sem muitos problemas, conforme a Figura A.12(b). Entretanto, como o prolongamento do eixo fora colada com a cola anaeróbica, a sua fixação com o pino ficara comprometida. Entretanto, esta parcela não exige torque e como os ensaios do laboratório são de pequenas durações, este fato não acarretará em danos ao MIT. A Figura A.12(c) ilustra a foto do MIT com a tampa defletora conectada. A sua fixação é realizada por 3 parafusos nas partes laterais e superior.

A Figura A.12(d) ilustra a fixação do acoplador da carga junto ao eixo do rotor. Em virtude da medida desta peça ser bem justa e dimensionada, há então a necessidade de um pequeno auxílio do martelo de nylon. Em sua lateral e superior à chaveta, encontra-se um orifício para a inserção de um parafuso Allen utilizado para o reforço da fixação.

Finalmente, a Figura A.13 ilustra a imagem da montagem final e da inserção do MIT na bancada de experimentos. Os cuidados a serem tomados nesta etapa consistem principalmente no alinhamento dos eixos dos componentes envolvidos, tais como o encoder, o MIT, o torquímetro e o GCC.

A partir deste ponto, é possível então realizar os ensaios de acionamento de máquinas elétricas, considerando-se uma diversidade de análises, tais como o acionamento direto 


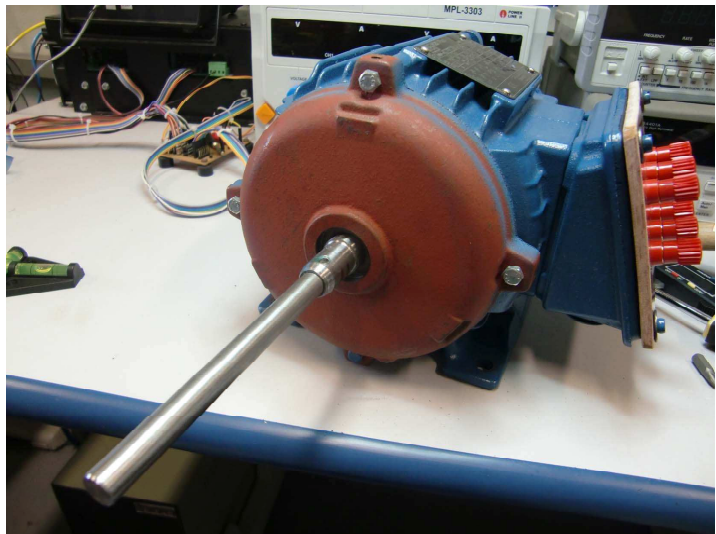

(a) Lado do eixo prolongado.

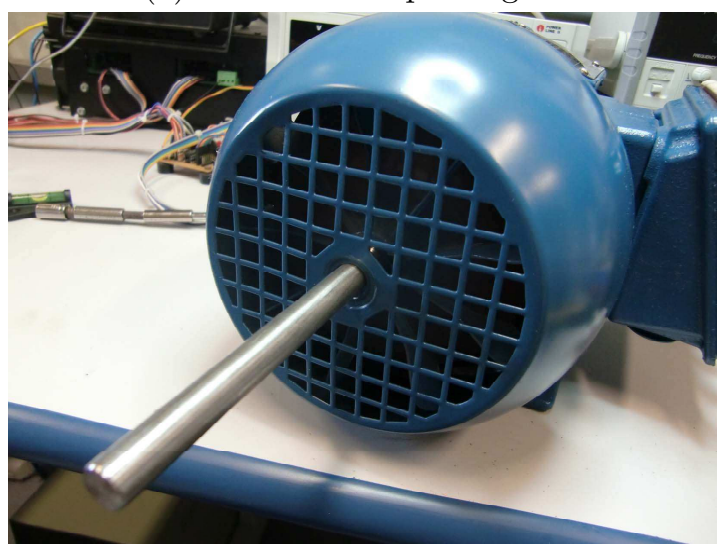

(c) Fixação da tampa defletora.

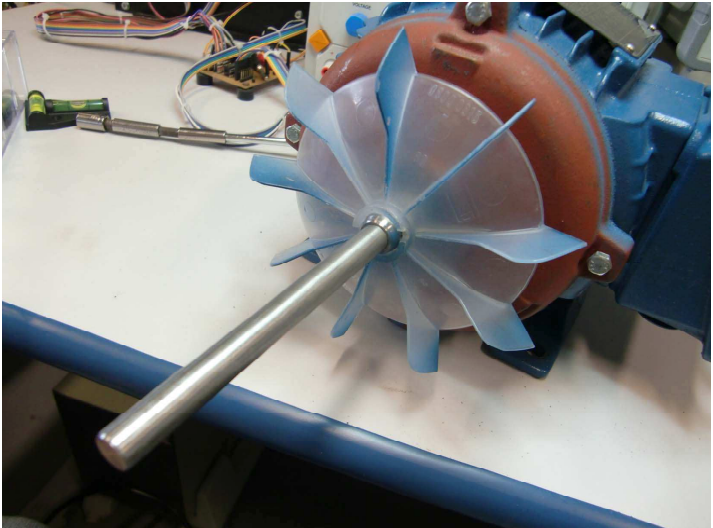

(b) Fixação da ventoinha.

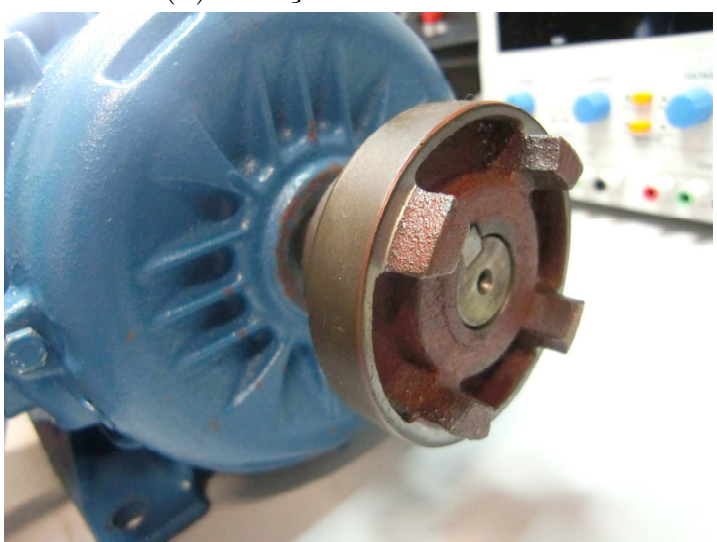

(d) Fixação do acoplador

Figura A.12: Procedimento de instalação dos rotores - Parte 2.

da rede, pelo inversor trifásico e comercial da WEG, pelo inversor da Semikron controlado pelo DSP da Texas Instruments; a inserção de cargas constantes, cargas variáveis, cargas dependentes da velocidade; a análise de regime permanente, a análise de regime transitório, entre outros.

O processo de remoção dos rotores do MIT é realizado de forma inversa ao de instalação. Entretanto, alguns cuidados diferentes da instalação devem ser levados em consideração para se realizar uma remoção segura e que evite danos à estrutura mecânica do motor. Este procedimento é descrito nos passos ilustrados pela Figura A.14.

A remoção do ventilador pode ser realizada utilizando-se uma chave de fenda relativamente grande como apoio. Como a fixação deste componente é realizada apenas por encaixe, a sua remoção é relativamente fácil, conforme pode ser observado na Figura A.14(a).

Por outro lado, o acoplador do eixo de carga é dimensionado sob medida justa e sua remoção é mais trabalhosa. Uma das alternativas seria a utilização de um martelo de nylon, entretanto, pela posição, dificilmente o impacto se dará de forma paralela ao eixo e possivelmente acarretará em danos no futuro. A maneira mais segura de se remover esta peça é mediante o auxílio de uma saca-polia, conforme pode ser observado na Figura A.14(b).

De maneira similar, a remoção da tampa frontal do MIT é realizada por meio do 


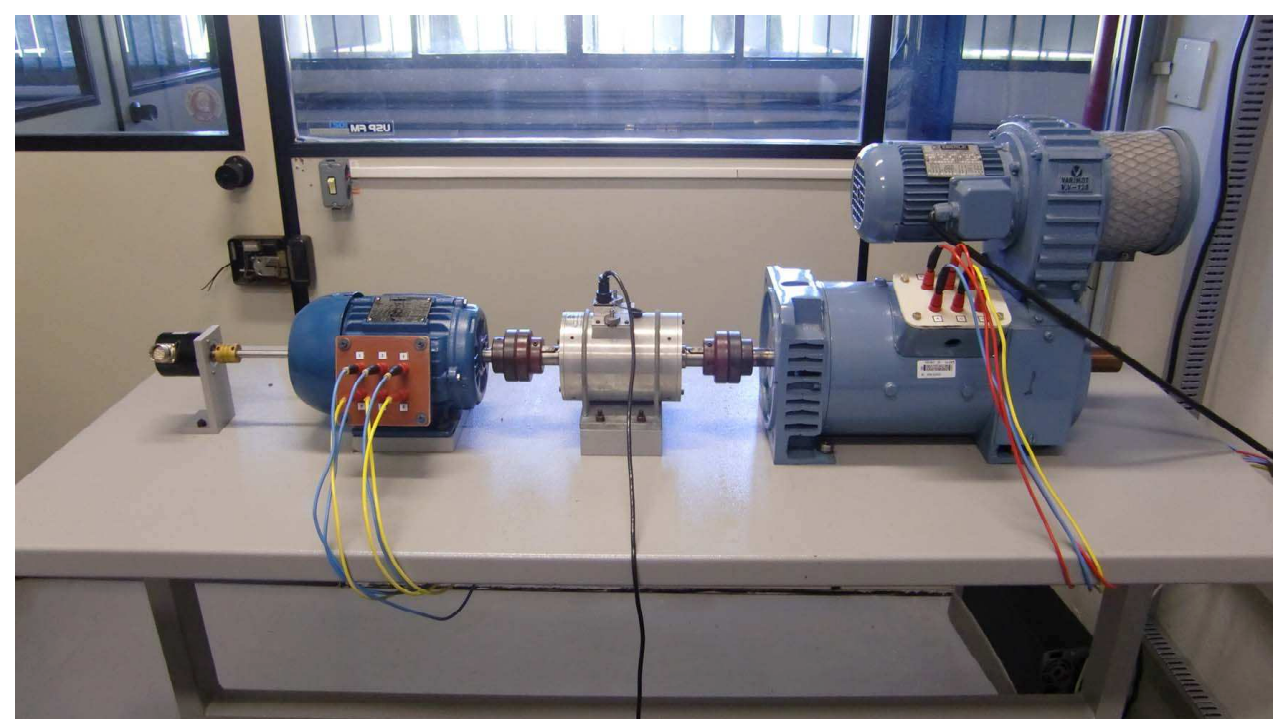

Figura A.13: Instalação do MIT na bancada de experimentos.

auxílio de uma saca-polia, de acordo com a ilustração da Figura A.14(c). O mancal que se situa na tampa apresenta uma dimensão justa para fixar os rolamentos e evitar vibrações. Neste caso, empregou-se uma ferramenta de maior porte, visto que o raio da tampa é muito maior que a do acoplamento.

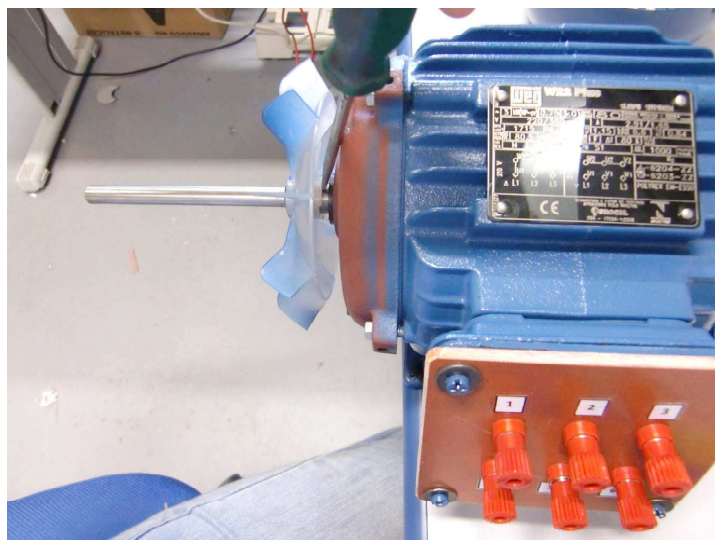

(a) Remoção da ventoinha.

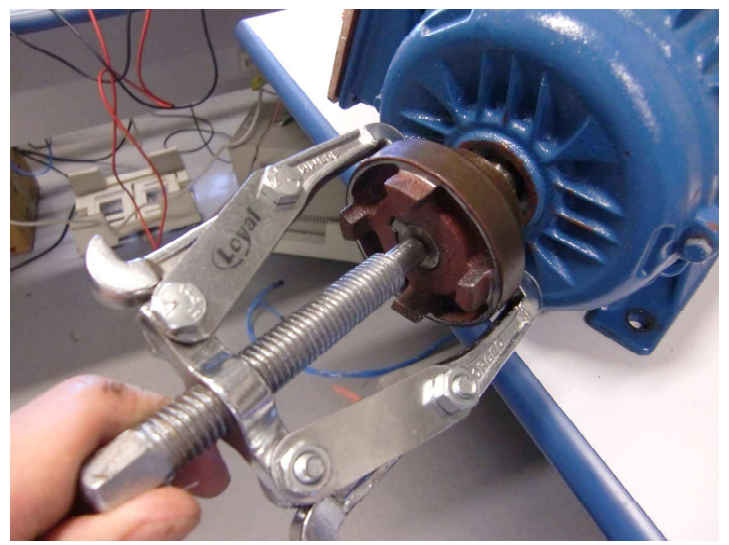

(b) Remoção do acoplador.

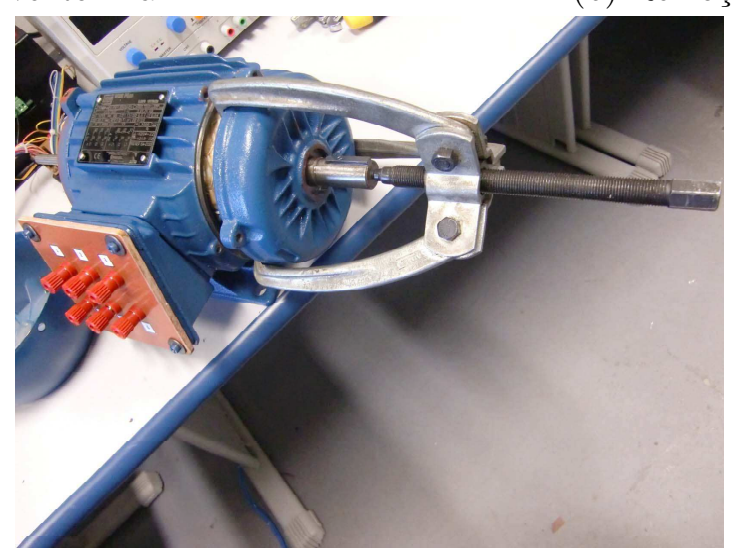

(c) Remoção da tampa frontal do MIT.

Figura A.14: Procedimento de remoção dos rotores. 